\title{
Preterm prelabor rupture of membranes: different gestational ages, different problems
}

Citation for published version (APA):

van der Heyden, J. L. (2014). Preterm prelabor rupture of membranes: different gestational ages, different problems. [Doctoral Thesis, Maastricht University]. Maastricht University.

https://doi.org/10.26481/dis.20140327jh

Document status and date:

Published: 01/01/2014

DOI:

10.26481/dis.20140327jh

Document Version:

Publisher's PDF, also known as Version of record

\section{Please check the document version of this publication:}

- A submitted manuscript is the version of the article upon submission and before peer-review. There can be important differences between the submitted version and the official published version of record.

People interested in the research are advised to contact the author for the final version of the publication, or visit the DOI to the publisher's website.

- The final author version and the galley proof are versions of the publication after peer review.

- The final published version features the final layout of the paper including the volume, issue and page numbers.

Link to publication

\footnotetext{
General rights rights.

- You may freely distribute the URL identifying the publication in the public portal. please follow below link for the End User Agreement:

www.umlib.nl/taverne-license

Take down policy

If you believe that this document breaches copyright please contact us at:

repository@maastrichtuniversity.nl

providing details and we will investigate your claim.
}

Copyright and moral rights for the publications made accessible in the public portal are retained by the authors and/or other copyright owners and it is a condition of accessing publications that users recognise and abide by the legal requirements associated with these

- Users may download and print one copy of any publication from the public portal for the purpose of private study or research.

- You may not further distribute the material or use it for any profit-making activity or commercial gain

If the publication is distributed under the terms of Article $25 \mathrm{fa}$ of the Dutch Copyright Act, indicated by the "Taverne" license above, 


\title{
Preterm prelabor rupture of membranes:
}

different gestational ages, different

\author{
problems
}


Studies in this thesis were supported by a grant by The Dutch Organisation for Health Research and Development, ZonMW (grant numbers 94507212 and 171002215).

ISBN: $\quad 978-94-6259-102-8$

Cover: Model: Joyce Koffeman

Belly paint by Marlies de Koning

Photo by Alex Koffeman

Layout: Tiny Wouters

Print: Ipskamp Drukkers, Enschede

(C) Copyright 2014 J.L. van der Heyden, the Netherlands

All rights reserved. No part of this thesis may be reproduced, stored in a retrieval system, or transmitted in any form or by any means, without permission of the author. 


\title{
Preterm prelabor rupture of membranes:
}

\section{different gestational ages, different}

\author{
problems
}

\author{
PROEFSCHRIFT \\ ter verkrijging van de graad van doctor aan de Universiteit Maastricht, \\ op gezag van de Rector Magnificus, \\ Prof. dr. L.L.G. Soete \\ volgens het besluit van het College van Decanen, \\ in het openbaar te verdedigen \\ op donderdag 27 maart 2014 om 14:00 uur
}

door

Jantien Leonie van der Heyden

Geboren 28 juni 1984

te Woerden 


\section{Promotores}

Prof. dr. J.G. Nijhuis

Prof. dr. B.W.J. Mol, AMC Amsterdam

\section{Copromotores}

Dr. C. Willekes

Dr. D.P. van der Ham, Martini ziekenhuis, Groningen

\section{Beoordelingscommissie}

Prof. dr. C.A.M.V.A. Bruggeman (voorzitter)

Prof. dr. B.W. Kramer

Prof. dr. S.G. Oei, MMC Veldhoven

dr. L.J.M. Smits 
"It always seems impossible until it's done"

Voor mijn familie 


\section{Contents}

Chapter 1 Introduction

Objectives of thesis

Chapter 2 Accuracy of imaging parameters in the prediction of letal

pulmonary hypoplasia secondary to midtrimester prelabor

rupture of fetal membranes: a meta-analysis

van Teeffelen ASP, vd Heyden J, Oei SG, Porath MM, Willekes C, Opmeer B, Mol BWJ.

Ultrasound Obstet Gynecol. 2012;39(5):495-9. Review.

Chapter 3 Outcome of pregnancies with preterm prelabor rupture of

membranes before 27 weeks' gestation: a retrospective cohort study

van der Heyden JL, van der Ham DP, van Kuijk S, Notten KJB, Janssen T, Nijhuis JG, Willekes $C$, Porath $M$, van der Post JA, Halbertsma F, Mol BWJ, Pajkrt E.

Eur J Obstet Gynecol Reprod Biol. 2013;170(1):125-30.

Chapter 4 Perinatal outcome in women with preterm prelabor rupture

of membranes between 26 and 34 weeks' gestation

van der Heyden IL, Ravelli ACJ, van Teeffelen ASP, van der Ham DP, Schaaf JM, Willekes C,

Pajkrt E, B.W.J. Mol, J.G. Nijhuis. Submitted

Chapter 5 Subsequent pregnancy after preterm prelabor rupture of membranes before 27 weeks' gestation

van der Heyden JL, van Kuijk S, van der Ham DP, Notten KJB, Janssen T, Nijhuis JG, Willekes $C$, Porath M, van der Post JA, Halbertsma F, Pajkrt E, Mol BWJ. AJP Rep. 2013;3(2):113-8.

Chapter 6 Is It useful to measure C-reactive protein and leukocytes in

patients with prelabor rupture of membranes?

van der Heyden JL, van Teeffelen ASP, Coolen JCG, Halbertsma FJ, Aardenburg R,

Mertens HJMM, Mol BWJ. Am J Perinatol. 2010;27(7):543-7.

Chapter 7 Management of late-preterm premature rupture of membranes: the PPROMEXIL-2 trial

van der Ham DP, van der Heyden JL, Opmeer BC, Mulder ALM, Moonen RMJ, van Beek JJ, Franssen MTM, Bloemenkamp KWM, Sikkema JM, de Groot CJM, Porath M, Kwee A, Woiski MD, Duvekot JJ, Akerboom BMC, van Loon AJ, de Leeuw JW, Willekes C, Mol BWJ, Nijhuis JG. Am J Obstet Gynecol. 2012;207(4):276.e1-276.e10. 
Chapter 8 Behavioral and developmental outcome of neonates at 2 years of age after preterm prelabor rupture of membranes:

Follow up of the PPROMEXIL trial

van der Heyden JL, Willekes C, van Baar AL, van Wassenaer-Leemhuis AG, Pajkrt E, Oudijk MA, Porath MM, Duvekot JJ, Bloemenkamp KWM, Franssen MTM, Woiski M, Nij Bijvank B, Bax CJ, van 't Hooft J, Sikkema JM, Mulder ALM, Nijhuis JG, Mol BWJ, van der Ham DP. Submitted.

Chapter 9 General discussion

Summary and main conclusions

Nederlandse samenvatting en conclusies

List of co-authors

List of publications

Dankwoord

Curriculum vitae 

Chapter 1

Introduction 
Chapter 1 


\section{Introduction}

Preterm Prelabor Rupture Of Membranes (PPROM) is an important problem for the gynecologist. The consequences can be serious, not only because of a relatively high risk of neonatal mortality and morbidity, but there is also an increased risk of maternal morbidity (infection or sepsis).

To make an assessment of the risk of perinatal complications, the gestational age at preterm PROM plays an important role. There are many differences between extreme preterm PROM (16 to 27 weeks), moderate preterm PROM (27 to 34 weeks) and late preterm PROM (34 to 37 weeks) in risks and chances of perinatal survival and/or morbidity. Some of the most important problems besides perinatal mortality are: serious respiratory complications (pulmonary hypoplasia), neonatal sepsis and prematurity.

There are still many unanswered and unknown issues on the subject of PPROM. Because extreme preterm PROM is a rare pregnancy complication with a very high risk of neonatal problems we aimed to find out whether the risk of pulmonary hypoplasia can be predicted by using imaging techniques. Another issue that we wanted to assess, was the perinatal outcome of such pregnancies and the risk of recurrence of this specific complication in pregnancy. Perinatal outcome was also a point of interest in moderate preterm PROM. Because neonatal sepsis (and its preceding infection) is a risk of (P)PROM as well, we hypothesized that measuring two laboratory parameters (C-reactive protein (CRP) and leukocytes) might be useful in the prediction of neonatal infection.

About late preterm PROM, we have wondered what the best management policy is (induction of labor or expectant management), while not only baring the short term results in mind but also the long-term childhood follow-up of infants born after a pregnancy with late preterm PROM.

\section{Definitions}

Prelabor Rupture of Membranes (PROM) means rupture of the fetal membranes (amniotic sac) before the onset of labor. Generally, labor starts with contractions, but in some cases rupture of the fetal membranes is the first symptom (at term in $8 \%$ of cases, before 37 weeks' gestation in up to $30-40 \%$ of cases). ${ }^{1,2}$

The duration of a normal pregnancy is between 37 and 42 weeks' gestation. In case of Preterm Prelabor Rupture Of Membranes (PPROM), the membranes rupture before 37 weeks' gestation.

Perinatal mortality is defined as intrauterine fetal death from a gestational age of 22 weeks onwards, or neonatal mortality up to 7 days after birth. 
The most common complication of preterm birth is respiratory distress. Sepsis, intraventricular hemorrhage and necrotizing enterocolitis are also associated with prematurity (but are less common near term). ${ }^{1}$

Pulmonary hypoplasia (PH) is an underdevelopment of the lungs and is more likely to develop in pregnancies with oligohydramnios. ${ }^{3}$ The lungs are particularly vulnerable for underdevelopment during the canalicular stage of the lung development, which takes place between 16 and 28 weeks' gestation.

The prevalence of $\mathrm{PH}$ varies widely, but in most studies the prevalence is around $10 \% .^{3,4,5,6}$ One of the reasons of this varying prevalence is the difference in definitions.

A prematurely born infant might be viable from a gestational age of 24 weeks. Between 24 and 26 weeks the risk of mortality and severe morbidity is high, with a high risk of handicaps later in life as well. After 26 weeks' gestation these risks slightly decrease, but still remain important.

In the Netherlands, we agree on active management (which means resuscitation of a newborn and taking measures to keep the newborn alive) from a gestational age of 26 weeks. At 24 weeks' gestation, this decision will depend on the desire of the parents. Between 25 and 26 weeks' gestation, the pediatrician will counsel on the possibility of active management, where the way of counseling will also depend on other factors that might play a role for the neonatal prognosis (e.g. estimated fetal weight).

Therefore, reliable counseling by a neonatologist and obstetrician is very important, so that the well-informed parents can take a decision on whether or not to aim for active management.

Until a gestational age of 32 weeks, the newborn should be taken care of on a neonatal intensive care unit (NICU). In the Netherlands there are 10 centers with a NICU (perinatal centers).

Ideally, a woman is already referred to a perinatal center during pregnancy when she is considered to be at risk for preterm birth. If this transfer was not possible antenatally, the newborn is transferred to a NICU as soon as possible after birth.

\section{Etiology}

The etiology of PPROM is multifactorial. Prior to rupture of the membranes, there is probably a disruption of collagen synthesis at molecular level, a change in collagen structure or increased collagen degradation.

Possible causes of PPROM, or associated factors, are history of preterm birth, short cervical length, cigarette smoking, low body mass index, black ethnicity, use of drugs, uterine over distention (e.g. as a result of polyhydramnios or multiple pregnancy), antepartum bleeding, bacterial vaginosis and invasive prenatal diagnosis (chorionic villus sampling or amniocentesis). ${ }^{1,2,7-9}$ 
Subclinical intrauterine infection has been implicated as a major etiological factor in the pathogenesis. ${ }^{9}$ The rate of positive culture of amniotic fluid (obtained by transabdominal amniocentesis) at the time of presentation with PPROM, in the absence of labor, is approximately $25-40 \%{ }^{9-11}$

However, the effectiveness of screening and treatment of the potential risk factors has not been proven effective for any of these factors and PPROM often occurs in the absence of any risk factors.

\section{Risks and complications of PPROM}

The main risks of PPROM are strongly dependent on the gestational age at ROM.

Therefore, the advised policy depends strongly on the gestational age at ROM. In the table below (Table 1.1), the incidence of PPROM, main risks and policy are rendered by gestational age at ROM. Hereby should be noted that these data are valid for the Dutch situation. In other countries different guidelines are followed (e.g. guidelines by The American Congress of Obstetricians and Gynecologists (ACOG) or the Royal College of Obstetricians and Gynaecologists (RCOG)).

Table 1.1 Characteristics of PPROM at different gestational age subcategories.

\begin{tabular}{|c|c|c|c|c|}
\hline Gestational age & $<27$ weeks & 27-34 weeks & 34-37 weeks & $>37$ weeks \\
\hline Incidence & $0.5 \%$ & $1 \%$ & $1.5 \%$ & $8 \%$ \\
\hline $\begin{array}{l}\text { Absolute numbers } \\
\text { in NL per year } \\
\text { (estimation based } \\
\text { on 190,000 } \\
\text { deliveries per } \\
\text { year) }\end{array}$ & 950 & 1900 & 2850 & 15200 \\
\hline $\begin{array}{l}\text { Main risks when } \\
\text { labor is induced }\end{array}$ & $\begin{array}{l}\text { - Perinatal mortality } \\
\text { - Serious neonatal } \\
\text { morbidity due to } \\
\text { prematurity }\end{array}$ & $\begin{array}{l}\text { - Perinatal mortality } \\
\text { - (Serious) neonatal } \\
\text { morbidity due to } \\
\text { prematurity }\end{array}$ & $\begin{array}{l}\text { - Neonatal morbidity } \\
\text { due to prematurity }\end{array}$ & $\begin{array}{l}\text { - Only possible } \\
\text { disadvantages } \\
\text { from induction of } \\
\text { labor }\end{array}$ \\
\hline $\begin{array}{l}\text { Main risks in case } \\
\text { of expectant } \\
\text { management }\end{array}$ & $\begin{array}{l}\text { - Intrauterine } \\
\text { infection/neonatal } \\
\text { sepsis } \\
\text { - Pulmonary } \\
\text { hypoplasia } \\
\text { - Contractures }\end{array}$ & $\begin{array}{l}\text { - Intrauterine } \\
\text { infection/neonatal } \\
\text { sepsis }\end{array}$ & $\begin{array}{l}\text { - Intrauterine } \\
\text { infection/neonatal } \\
\text { sepsis }\end{array}$ & $\begin{array}{l}\text { - Intrauterine } \\
\text { infection/ } \\
\text { neonatal sepsis }\end{array}$ \\
\hline Advised policy $^{2}$ & $\begin{array}{l}\text { Expectant } \\
\text { management* }\end{array}$ & $\begin{array}{l}\text { Expectant } \\
\text { management* }\end{array}$ & $\begin{array}{l}\text { Expectant } \\
\text { management* or } \\
\text { induction of labor** }\end{array}$ & Induction of labor \\
\hline
\end{tabular}

*Unless there is a contraindication for expectant management; ** Over 35 weeks gestational age, expectant management might be continued or induction of labor may be suggested, at the request of the pregnant woman. 
Early PPROM (that is PPROM before 26 or 27 weeks' gestation) is a rare complication of pregnancy with a major impact on the pregnant woman (and her partner) because of a great risk of serious problems in pregnancy outcome (perinatal mortality, $\mathrm{PH}$ and contractures). In the past, some studies are published on the perinatal outcomes of pregnancies with such a complication. Mostly, the study populations are small, due to the low incidence of this problem. Relatively little is known about the risk of recurrence of this pregnancy complication.

Pulmonary hypoplasia is a serious outcome because of the high risk of mortality. We try to predict the risk of pulmonary hypoplasia in patients with early PPROM using ultrasound parameters (such as thorax/abdomen ratio). However, we have insufficient information about the usefulness of these measurements in the prediction of pulmonary hypoplasia.

\section{Latency}

Latency is the duration between rupture of membranes (ROM) and delivery (this time frame can be hours, days or weeks). Latency is inversely correlated with the gestational age at ROM. ${ }^{12,13}$ The earlier the gestational age, the less likely labor will start at short notice after ROM. At term, the majority of women (90-95\%) have delivered within 72 hours without an intervention to induce labor. ${ }^{2}$

Because of the risk of a short latency period, many neonates are born prematurely after PPROM. Therefore the risk of morbidity and disabilities later in life because of prematurity is high. On the other hand, it is still quite unclear whether the effect of a longer latency period is positive or negative.

\section{Infection and sepsis}

The risk of neonatal sepsis depends on the gestational age at PPROM and is estimated between 4 and $36 \%$ in case of PPROM before 34 weeks' gestation and expectant management. ${ }^{14}$

Neonatal sepsis occurs twice as common in the setting of preterm PROM compared with preterm birth after preterm labor with intact membranes. ${ }^{15}$

A meta-analysis by Buchanan et al. (2010) on pregnancies with PPROM between 25 and 37 weeks' gestation found no significant difference in neonatal sepsis between those babies delivered early and those managed expectantly (risk ratio (RR) 1.33, 95\% Cl 0.72-2.47; $\mathrm{n}=692$ babies). ${ }^{16}$

The risk of chorioamnionitis depends on the gestational age at PPROM and is more common in case of expectant management compared to induction of labor. A previous 
study showed that at term induction of labor in 50 women is needed to prevent 1 case of chorioamnionitis. ${ }^{17}$

The most frequent pathogens in neonates with early onset (EO) sepsis are GBS (43\%) and

Escherichia coli (E.coli) (29\%). This was found in a study with 611 infants with positive cultures. The majority of infants with GBS were term (73\%), whereas the majority with E.coli were preterm (81\%).

Chorioamnionitis was more frequently documented in the maternal medical record of infants with E. coli than in GBS infections (56\% versus 33\%; adjusted $P=0.02$ ). ${ }^{18}$

Neonatal sepsis is associated with an increased risk of mortality and might have implications for the long-term childhood development as well. ${ }^{19}$

Klinger et al. studied 15,839 infants, of whom 383 (2.42\%) had early-onset sepsis (EOS). Infants with EOS and a very low birth weight (VLBW) had an increased risk of major neonatal morbidities (BPD, severe IVH and severe ROP). In VLBW infants with EOS, the odds for death or discharge with severe neurologic morbidity was approximately threefold that of infants without EOS. ${ }^{20}$

In 2004, Stoll et al. collected data from 7892 extremely low-birthweight (ELBW) infants and compared the long-term outcome of uninfected infants with children with infection or sepsis. $^{21}$

Overall, $41 \%$ of children assessed at 18 to 22 months of corrected gestational age had at least 1 adverse neurodevelopmental outcome. Children with infection had significant increases in most adverse outcomes. In general, infants without infection were least likely to have adverse outcomes, while those with sepsis/NEC were most likely.

Even though neonatal sepsis (and neonatal infection) is an important issue in pregnancies with PPROM, many pregnancies have an uncomplicated course or end without an infectious disease. In these cases neonates might benefit from a longer latency period, to reduce other problems associated with prematurity. Therefore it would be very useful to have a method to predict neonatal infection in patients with (P)PROM.

\section{Management}

There are different opinions on the management of PPROM, in particular on the management of late PPROM between 34 and 37 weeks' gestation. Internationally there are major differences on the opinions about the recommended policy.

If the gestational age is $<34$ weeks, induction of labor is only advised in case of risks for the mother (suspected intrauterine infection) or a serious risk of neonatal morbidity or mortality when the fetus remains intrauterine (nonreassuring fetal status at cardiotocography or obvious signs of placental abruption). 
The ACOG guideline (2013) states that the optimal gestational age for delivery is unclear and controversial. ${ }^{1}$

Based on a meta-analysis of seven randomized controlled trials ( $N=690$ women), it was concluded that there was insufficient evidence to guide clinical practice regarding the risks and benefits of expectant management versus induction of labor in cases with PPROM between 24 and 37 weeks' gestation. The trials were insufficiently powered, had methodological weaknesses, and were variable in the included gestational ages. ${ }^{16}$

According to the RCOG guideline (2006), delivery should be considered at 34 weeks of gestation. As quoted from this guideline: "Where expectant management is considered beyond this gestation, women should be informed of the increased risk of chorioamnionitis and the decreased risk of respiratory problems in the neonate". ${ }^{22}$

The Dutch Society of Obstetrics \& Gynecology (NVOG) advises expectant management below a gestational age of 35 weeks, unless there are maternal or fetal contraindications. Over 35 weeks gestational age, expectant management might be continued or labor might be induced in agreement with the pregnant woman. ${ }^{2}$

Van der Ham et al. recently performed the PPROMEXIL trial, where 266 women were allocated to induction of labor ( $\mathrm{loL}$ ) and 266 women to expectant management (EM). There was no significant difference in neonatal sepsis rate $(2.6 \%$ in the loL group and $4.1 \%$ in the EM group (relative risk [RR] $0.64 ; 95 \% \mathrm{Cl} 0.25$ to 1.6 )). The overall sepsis rate was lower than expected in this study. ${ }^{23}$ Currently, the PPROMT trial is an ongoing study, which randomizes between IoL and EM. ${ }^{24}$

Overall, there seems to be consensus that from a gestational age of 37 weeks onwards, induction of labor is the first choice treatment in case of PPROM. ${ }^{17}$

\section{Other management strategies}

If PPROM occurs between 24 and 34 weeks, antenatal administration of corticosteroids is advised to reduce the risk of neonatal mortality, RDS, IVH and NEC. Antenatal corticosteroids seem not to be associated with increased risks of maternal or neonatal infection. ${ }^{25}$ There are insufficient data to support or refute the use of prophylactic tocolysis (i.e. in the absence of regular contractions) in the setting of PPROM. ${ }^{1}$ A metaanalysis by Mackeen et al. (2011) including 408 women concluded that tocolysis therapy was associated with a prolongation of pregnancy and an increased risk of chorioamnionitis without significant maternal or neonatal benefit. ${ }^{26}$ Within the Dutch Obstetric Consortium, the APOSTEL-IV trial was recently started, which is a randomized double-blind placebo-controlled trial comparing administration of nifedipine (intervention) or placebo (control) in women with PPROM between $24^{+0}$ and $33^{+6}$ weeks' gestation (primary outcome measure is composite poor neonatal outcome). 
Women with PPROM before 32 weeks' gestation who are thought to be at risk of imminent delivery should be considered candidates for fetal neuroprotective treatment with magnesium sulfate. ${ }^{1,27}$

In case of suspicion of intrauterine infection, broadspectrum antibiotics should be administered. Prophylactic administration of broad-spectrum antibiotics prolongs pregnancy, reduces maternal and neonatal infections, and reduces gestational agedependent morbidity. The optimal antibiotic regimen is unclear because multiple regimens have demonstrated benefit. It may be reasonable to administer erythromycin alone. The use of amoxicillin-clavulanic acid is not recommended, because it has been associated with increased rates of NEC. ${ }^{1,28}$

\section{Objectives of thesis}

Obviously, many issues on PPROM are still unknown or unclear. Therefore, in this thesis we intended to answer some of these remaining questions:

$\checkmark$ Is there a useful diagnostic method available in the prediction of pulmonary hypoplasia in women with extreme preterm PROM? (Chapter 2)

$\checkmark$ How can we best counsel women with (early) PPROM about possible perinatal outcomes? (Chapters 3 and 4)

$\checkmark \quad$ What do we tell women about the risk of recurrence of early PPROM or preterm birth in a subsequent pregnancy after they have experienced early PPROM? (Chapter 5)

$\checkmark$ Can neonatal infection or clinical chorioamnionitis be predicted in women with (preterm) PROM by measuring laboratory parameters? (Chapter 6)

$\checkmark$ Is expectant management preferred over induction of labor in women with PPROM between 34 and 37 weeks' gestation? (Chapter 7)

$\checkmark$ Is there a difference in neurodevelopmental outcome and behavioral development at 2 years of age between induction of labor or expectant management in women with PPROM between 34 and 37 weeks' gestation? (Chapter 8) 


\section{References}

1. American College of Obstetricians and Gynecologists (ACOG). Practice Bulletin Number 139: Premature Rupture of Membranes. Obstet Gynecol 2013;122:918-30.

2. Nederlandse Vereniging voor Obstetrie en Gynaecologie (NVOG). [Breken van de vliezen voor het begin van de baring] (guideline). Version 1.0. 2002.

3. Shumway JB, Al-Malt A, Amon E, Cohlan B, Amini S, Abboud M, Winn HN. Impact of oligohydramnios on maternal and perinatal outcomes of spontaneous premature rupture of the membranes at 18-28 weeks. J Matern Fetal Med 1999;8:20-23.

4. Everest NJ, Jacobs SE, Davis PG, Begg L, Rogerson S. Outcomes following prolonged preterm premature rupture of the membranes. Arch Dis Child Fetal Neonatal Ed. 2008;93: F207-211.

5. Falk SJ, Campbell L, Lee-Parritz A, Cohen AP, Ecker J, Wilkins-Haug L, Lieberman E. Expectant management in spontaneous preterm premature rupture of membranes between 14 and 24 weeks' gestation. J Perinatal_2004;24: 611-616.

6. Kurkinen-Räty M, Koivisto M, Jouppila P. Perinatal and neonatal outcome and late pulmonary sequelae in infants born after preterm premature rupture of membranes. Obstet Gynecol 1998;92: 408.

7. Harger JH, Hsing AW, Tuomala RE, Gibbs RS, Mead PB, Eschenbach DA, Knox GE, Polk BF. Risk factors for preterm premature rupture of fetal membranes: a multicenter case-control study. Am J Obstet Gynecol 1990;163(1 Pt 1):130-137.

8. Savitz DA, Blackmore CA, Thorp JM. Epidemiologic characteristics of preterm delivery: etiologic heterogeneity. Am J Obstet Gynecol 1991;164:467-471.

9. Simhan HN, Canavan TP. Preterm premature rupture of membranes: diagnosis, evaluation and management strategies. BJOG 2005;112(Suppl 1):32-37.

10. Asrat T, Nageotte MP, Garite TJ, Gocke SE, Dorchester W. Gram stain results from amniocentesis in patients with preterm premature rupture of membranes-comparison of maternal and fetal characteristics. Am J Obstet Gynecol 1990;163:887-889.

11. Dudley J, Malcolm G, Ellwood D. Amniocentesis in the management of preterm premature rupture of the membranes. Aus N Z J Obstet Gynaeco. 1991;31:331-336.

12. Mercer BM. Preterm premature rupture of the membranes: current approaches to evaluation and management. Obstet Gynecol Clin North Am 2005;32:411-428.

13. Melamed N, Hadar E, Ben-Haroush A, Kaplan B, Yogev, Y. Factors affecting the duration of the latency period in preterm premature rupture of membranes. J Matern Fetal Neonatal Med 2009;22:1051-1056.

14. Newton ER. Preterm labor, preterm premature rupture of membranes, and chorioamnionitis. Clin Perinatol 2005;32:571-600.

15. Seo K, McGregor JA, French JI. Preterm birth is associated with increased risk of maternal and neonatal infection. Obstet Gynecol 1992;79:75-80.

16. Buchanan SL, Crowther CA, Levett KM, Middleton P, Morris J. Planned early birth versus expectant management for women with preterm prelabour rupture of membranes prior to 37 weeks' gestation for improving pregnancy outcome (Review). Cochrane Database Syst Rev 2010:CD004735.

17. Dare MR, Middleton P, Crowther CA, Flenady V, Varatharaju B. Planned early birth versus expectant management (waiting) for prelabour rupture of membranes at term (37 weeks or more) (Review). Cochrane Database Syst Rev_2006: CD005302.

18. Stoll BJ, Hansen NI, Sánchez PJ, Faix RG, Poindexter BB, Van Meurs KP, Bizzarro MJ, Goldberg RN Frantz ID $3^{\text {rd }}$, Hale EC, Shankaran S, Kennedy K, Carlo WA, Watterberg KL, Bell EF, Walsh MC, Schibler K, Laptook AR, Shane AL, Schrag SJ, Das A, Higgins RD. Early onset neonatal sepsis: the burden of group B Streptococcal and E. coli disease continues. Pediatrics 2011;127:817-826.

19. Bakhuizen SE, Teune MJ, Van Wassenaer AG, de Haan T, Van der Heyden JL, Van der Ham DP, Mol BWJ. Does neonatal sepsis result in severe morbidity in later life: a systematic review. Unpublished. 2013

20. Klinger G, Levy I, Sirota L, Boyko V, Lerner-Geva L, Reichman B. Outcome of early-onset sepsis in a national cohort of very low birth weight infants. Pediatrics 2010;125:e736-740.

21. Stoll BJ, Hansen NI, Adams-Chapman I, Fanaroff AA, Hintz SR, Vohr B, Higgins RD. Neurodevelopmental and growth impairment among extremely low-birth-weight infants with neonatal infection. JAMA 2004;292:2357-2365. 
22. Royal College of Obstetricians and Gynaecologists (RCOG). Guideline Number 44: Preterm prelabour rupture of membranes. 2006.

23. Van der Ham DP, Vijgen SM, Nijhuis JG, Van Beek JJ, Opmeer BC, Mulder AL, Moonen R, Groenewout M, Van Pampus MG, Mantel GD, Bloemenkamp KW, Van Wijngaarden WJ, Sikkema M, Haak MC, Pernet PJ, Porath M, Molkenboer JF, Kuppens S, Kwee A, Kars ME, Woiski M, Weinans MJ, Wildschut HI, Akerboom $\mathrm{BM}, \mathrm{Mol} \mathrm{BW}$, Willekes C. Induction of labor versus expectant management in women with preterm prelabor rupture of membranes between 34 and 37 weeks: a randomized controlled trial. PLoS Med 2012;9:e1001208.

24. Morris JM, Roberts CL, Crowther CA, Buchanan SL, Henderson-Smart DJ, Salkeld G. Protocol for the immediate delivery versus expectant care of women with preterm prelabour rupture of the membranes close to term (PPROMT) Trial [ISRCTN44485060]. BMC Pregnancy Childbirth 2006;6: 9.

25. Vidaeff $A C$, Ramin SM. Antenatal corticosteroids after preterm premature rupture of membranes. Clin Obstet Gynecol 2011;54:337-343.

26. Mackeen AD, Seibel-Seamon J, Grimes-Dennis J, Baxter JK, Berghella V. Tocolytics for preterm premature rupture of membranes. Cochrane Database Syst Rev_2011:CD007062.

27. Crowther CA, Hiller JE, Doyle LW, Haslam RR. Effect of magnesium sulfate given for neuroprotection before preterm birth: a randomized controlled trial. JAMA 2003;290:2669-2676.

28. Kenyon SL, Taylor DJ, Tarnow-Mordi W, ORACLE Collaborative Group. Broad-spectrum antibiotics for preterm, prelabour rupture of fetal membranes: the ORACLE I randomised trial. ORACLE Collaborative Group. Lancet 2001;357:979-988. 


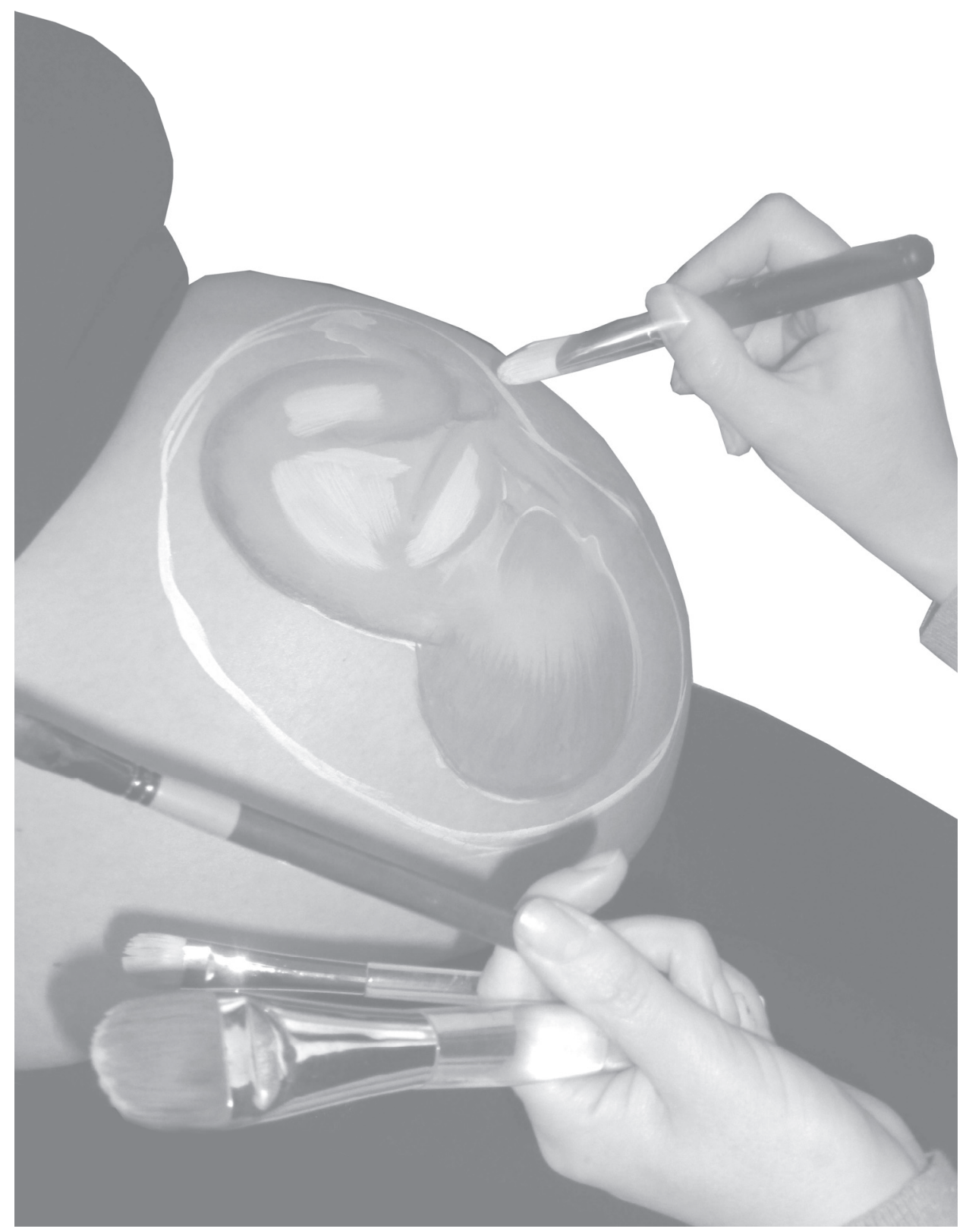




\section{Chapter}

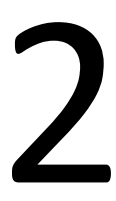

The accuracy of imaging parameters in the prediction of lethal pulmonary hypoplasia secondary to midtrimester prelabor rupture of fetal membranes: a meta-analysis MM Porath

C Willekes

B Opmeer BWJ Mol 


\section{Abstract}

In women who have suffered midtrimester prelabor rupture of membranes (PPROM) prediction of pulmonary hypoplasia is important for optimal management. We performed a systematic review to assess the capacity of imaging parameters to predict pulmonary hypoplasia. We searched articles that reported on biometrical parameters and allowed the construction of a two by two table comparing at least one of these parameters to the occurrence of pulmonary hypoplasia. The selected studies were scored on methodological quality, and we calculated sensitivity and specificity of the tests in the prediction of pulmonary hypoplasia and lethal pulmonary hypoplasia. Overall performance was assessed by summary Receiver Operating Characteristic (sROC) analyses that were performed with bivariate meta-analysis.

We detected 13 studies that reported on the prediction of lethal pulmonary hypoplasia. The quality of the included studies was poor to mediocre. The estimated SROC-curves for the chest circumference/abdominal circumference ratio and other parameters showed limited accuracy in the prediction of pulmonary hypoplasia.

In women with midtrimester PPROM, the available evidence indicates limited accuracy of biometric parameters in the prediction of pulmonary hypoplasia. 


\section{Introduction}

In fetal lung development there is a critical interval, the canalicular phase, between 16 and 28 weeks' gestation. Preterm prelabor rupture of membranes (PPROM) before 28 weeks can delay lung development thus causing pulmonary hypoplasia. ${ }^{1}$ Pulmonary hypoplasia poses a serious threat due to its high mortality and morbidity rate. It can occur as severe respiratory failure leading to early neonatal death, as respiratory insufficiency with pulmonary haemorrhage, bronchopulmonary dysplasia, or subacute lung disease, or as mild and even transient respiratory disease. ${ }^{2}$ Perinatal mortality approximates $70 \%$ in most series $(55-100 \%){ }^{3}$

Once midtrimester PPROM has occurred, assessment of the probability of pulmonary hypoplasia is important both for clinical decision making and counselling of patients. In a recent meta-analysis we assessed the predictive capacity of clinical parameters - gestational age at PPROM, latency period and degree of oligohydramnios for the presence of hypoplasia. ${ }^{4}$ The gestational age at which PPROM occurred was a significantly better predictor than the latency period and degree of oligohydramnios for the occurrence of pulmonary hypoplasia. The accuracy in the prediction of the lethal variant of pulmonary hypoplasia was similar.

Biometric parameters assessed by ultrasound (two- or threedimensional, Doppler) or MRI have also been proposed as instruments to predict pulmonary hypoplasia following PPROM. To our knowledge, the predictive capacity of these parameters for the presence of hypoplasia after midtrimester PPROM specifically has not been assessed systematically. We therefore performed this meta-analysis to assess the capacity of biometric parameters assessed with ultrasound or MRI to predict pulmonary hypoplasia following mid-trimester PPROM.

\section{Materials and methods}

We searched the literature for studies that reported on neonatal outcome after midtrimester PPROM, using combinations of the following search terms: pregnancy, oligohydramnios, fetal membranes - premature rupture, diagnostic imaging, fetal diseases, respiratory system,

fetal mortality, fetal death, infant mortality, pulmonary hypoplasia, lung hypoplasia, lung diseases and respiratory system. We performed an electronic search of MEDLINE (inception to 05-3-2011) and EMBASE (inception to 05-03-2011) and checked reference lists of known reviews and primary articles to identify cited articles not captured by electronic searches. Language restrictions were not applied.

The selection process was performed by one of the authors (A.S.P.v.T.). To be selected for inclusion, a study had to report on the outcome of pregnancies complicated by PPROM between 14 and 27 completed weeks of gestational age, in which any ultrasound or MRI parameter was used with the goal of predicting 
pulmonary hypoplasia. The diagnosis of pulmonary hypoplasia could be based either on clinical and radiological findings or on findings at autopsy. For the purposes of analysis we distinguished two types of hypoplasia: lethal hypoplasia and any form of hypoplasia. Lethal hypoplasia was defined as hypoplasia resulting in the death of the fetus or neonate due to hypoplasia. Fetuses with lung hypoplasia proven on autopsy after early pregnancy termination were also included in the lethal group. Any form of hypoplasia was defined as the sum of all cases of hypoplasia, both lethal and non-lethal. We chose not to include cases of oligohydramnios caused by conditions other than mid-trimester PPROM, since these are other entities, with their own specific pathophysiology which might have influenced the outcome of our review. Moreover, the biometric indices studied in this review might have been influenced by these conditions, for example measurements in foetuses with polycystic kidneys or obstructive uropathy might be influenced by subsequent abdominal enlargement. ${ }^{5}$

Studies had to report on any ultrasound or MRI parameter that was used with the goal of predicting pulmonary hypoplasia. The following characteristics of each study were noted: (1) sampling (consecutive or other), (2) data collection (prospective or retrospective) (3) study design (cohort study or case-control study), (4) blinding (present or absent), (5) verification bias (present or absent) and (6) selection bias (present or absent).

\section{Analysis}

\section{Data analysis}

For each published study, its characteristics were scored by two of the authors (A.S.P.v.T. and J.v.d.H.), who each constructed independently a $2 \times 2$ table crossclassifying one or more of the imaging parameters with the presence of pulmonary hypoplasia. In case of disagreement, the judgement of a third author (B.W.J.M.) was decisive. It appeared that all but two studies found were aimed at diagnosing lethal rather than any form of pulmonary hypoplasia. Therefore, we limited the outcome in this review to lethal hypoplasia.

To visualize the data, for each model we combined sensitivity and specificity in the form of a receiver-operating characteristics (ROC) curve. A bivariate meta-regression model was used to calculate summary estimates of sensitivity and specificity for predictive values and to fit summary ROC (sROC) curves. The bivariate method has been described extensively elsewhere. ${ }^{7-10}$ Briefly, rather than using a single outcome measure per study, such as the diagnostic odds ratio, the bivariate model preserves the two-dimensional nature of diagnostic data in a single model. This model incorporates the correlation that may exist between sensitivity and specificity within studies due to possible differences in threshold between studies. The bivariate model uses a random effects approach for both sensitivity and specificity, allowing for heterogeneity beyond 
chance due to clinical or methodological differences between studies. In addition, the model acknowledges the difference in precision by which sensitivity and specificity have been measured in each study. This means that studies with a larger number of pregnancies resulting in lethal pulmonary hypoplasia receive more weight in the calculation of the pooled estimate of sensitivity, while studies with more patients without hypoplasia are more influential in the pooling of specificity.

When individual study sensitivity-specificity points were grouped close to an imaginary underlying ROC curve (i.e. studies with high sensitivity had relatively low specificity and vice versa), an SROC-curve was drawn using parameter estimates from the bivariate model. ${ }^{11}$

Differences in the capacity of all parameters to predict lethal pulmonary hypoplasia were tested for statistical significance by entering the tests as covariates in the bivariate regression model. $P<0.05$ was taken to indicate a significant difference of one parameter as compared with the other.

\section{Results}

Figure 2.1 summarizes the identification and selection process of the thirteen published studies included in this meta-analysis. ${ }^{12-24}$ All studies reported on ultrasound parameters, and one also evaluated (two-dimensional) MRI parameters. Study characteristics of the 13 included studies are listed in Table 2.1. In two of the studies, sampling of data was consecutive. Data collection was prospective in all studies, and all studies were designed as cohort studies.

\begin{tabular}{|c|c|c|}
\hline \multicolumn{2}{|c|}{$\begin{array}{l}\text { Total citations identified from electronic searches to capture primary articles on diagnostic } \\
\text { imaging and neonatal outcome after midtrimester rupture of fetal membranes: }\end{array}$} & $n=497$ \\
\hline & $\begin{array}{l}\text { Citations excluded after screening titles and/or } \\
\text { abstracts: }\end{array}$ & $n=478$ \\
\hline \multicolumn{2}{|c|}{$\begin{array}{l}\text { Primary articles on diagnostic imaging and neonatal out } \\
\text { membranes: } \\
\text { Cross references articles retrieved: } \\
\text { Total: }\end{array}$} & $\begin{array}{l}n=17 \\
n=36\end{array}$ \\
\hline & $\begin{array}{l}\text { No data to construct } 2 \times 2 \text { table: } \\
\text { No original data (reviews, letters) } \\
\text { No report on pulmonary hypoplasia } \\
\text { Study population not right:: } \\
\text { Total excluded: }\end{array}$ & $\begin{array}{l}n=3 \\
n=3 \\
n=3 \\
n=14 \\
n=23\end{array}$ \\
\hline Eligible for review & & $\mathrm{n}=13$ \\
\hline
\end{tabular}

Figure 2.1 Process of literature identification and selection. 


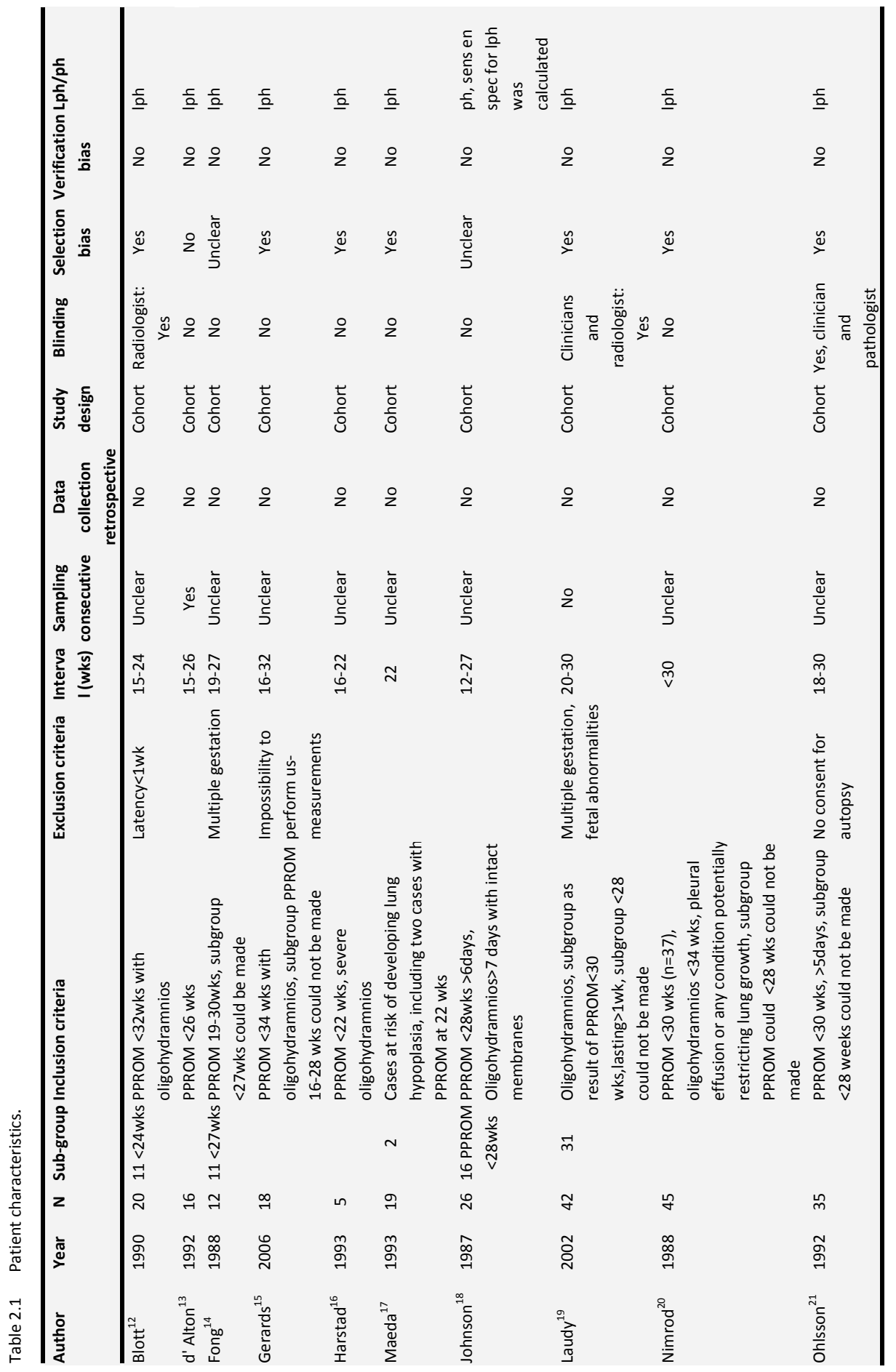




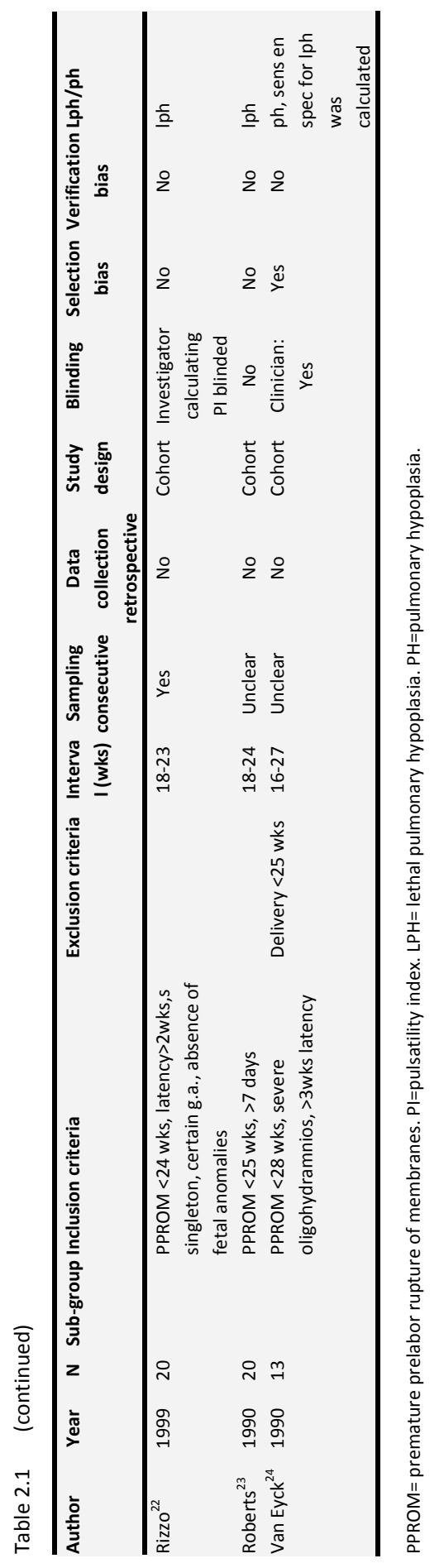


Five studies were adequately blinded. Selection bias was present in eight studies. Selection biases most frequently seen were limitation of studies to pregnancies with established oligohydramnios and inclusion of pregnancies in which PPROM occurred over 28 weeks. In one study of 45 pregnancies with oligohydramnios, in eight cases the oligohydramnios was not caused by PPROM. ${ }^{20}$ Since in the majority of cases in this study the cause was PPROM, we included it in our review. One study excluded pregnancies in which measurements were unsuccessful or in which the results of reference tests were not obtained. ${ }^{15}$ Verification bias was not present in any study. In six of the 13 studies, the diagnosis of lethal pulmonary hypoplasia was not always based on autopsy data; sometimes clinical and radiological data had to be used. ${ }^{14}$ Table 2.2 gives characteristics of the biometric parameters that were used. The most commonly used ultrasound parameters were chest circumference (seven studies), chest circumference/abdominal circumference ratio (six studies) and chest circumference/femur length ratio (three studies). The MRI parameters used in the only study incorporating MRI were chest circumference and ratio of chest area minus cardiac area divided by cardiac area; volumes were not measured. The sensitivities and specificities for chest circumference, chest circumference/abdominal circumference ratio and chest circumference/femur length ratio, as well as some other parameters that were used less frequently in the diagnosis of lethal hypoplasia, are summarized in Tables 2.3 and 2.4, the former giving parameters derived from 2D ultrasound measurements, and the latter parameters derived from 3D ultrasound, 2D MRI or Doppler measurements.

A plot of sensitivity-specificity points for chest circumference, chest circumference/abdominal circumference ratio and chest circumference/femur length ratio for lethal pulmonary hypoplasia is shown in Figure 6.2. The study of Laudy et al. ${ }^{19}$ was the only one to report an optimal sensitivity for chest circumference, but this was at the expense of low specificity; the other six studies combined a high specificity with a sensitivity varying between $50 \%$ and $80 \%$. The study of d'Alton et al. ${ }^{13}$ was the only one to demonstrate perfect sensitivity and specificity for chest circumference/abdominal circumference ratio; all other studies had either suboptimal sensitivity or suboptimal specificity. Figure 6.3 shows the performance of chest circumference/abdominal circumference ratio, as in Figure 6.2, as compared with the sROC of our previous metaanalysis ${ }^{4}$ which assessed the predictive capacity of gestational age at PPROM, latency time between PPROM and delivery and amount of amniotic fluid. The study of van Eyck et al. ${ }^{24}$ used Doppler measurements during (induced) periods of fetal breathing. All these studies were relatively small, and none indicated that any of the evaluated tests had a good accuracy. The study of Ohlsson et al. ${ }^{21}$ reported almost perfect accuracy for the chest circumference/femur length ratio, with a sensitivity of $100 \%$ and a specificity of $97 \%$, but again the sample size in this study was rather low, as there were only 35 pregnancies in the cohort. Neither the amount nor the timing of measurements performed throughout the latency period was uniform, as can be seen from Table 6.2. 


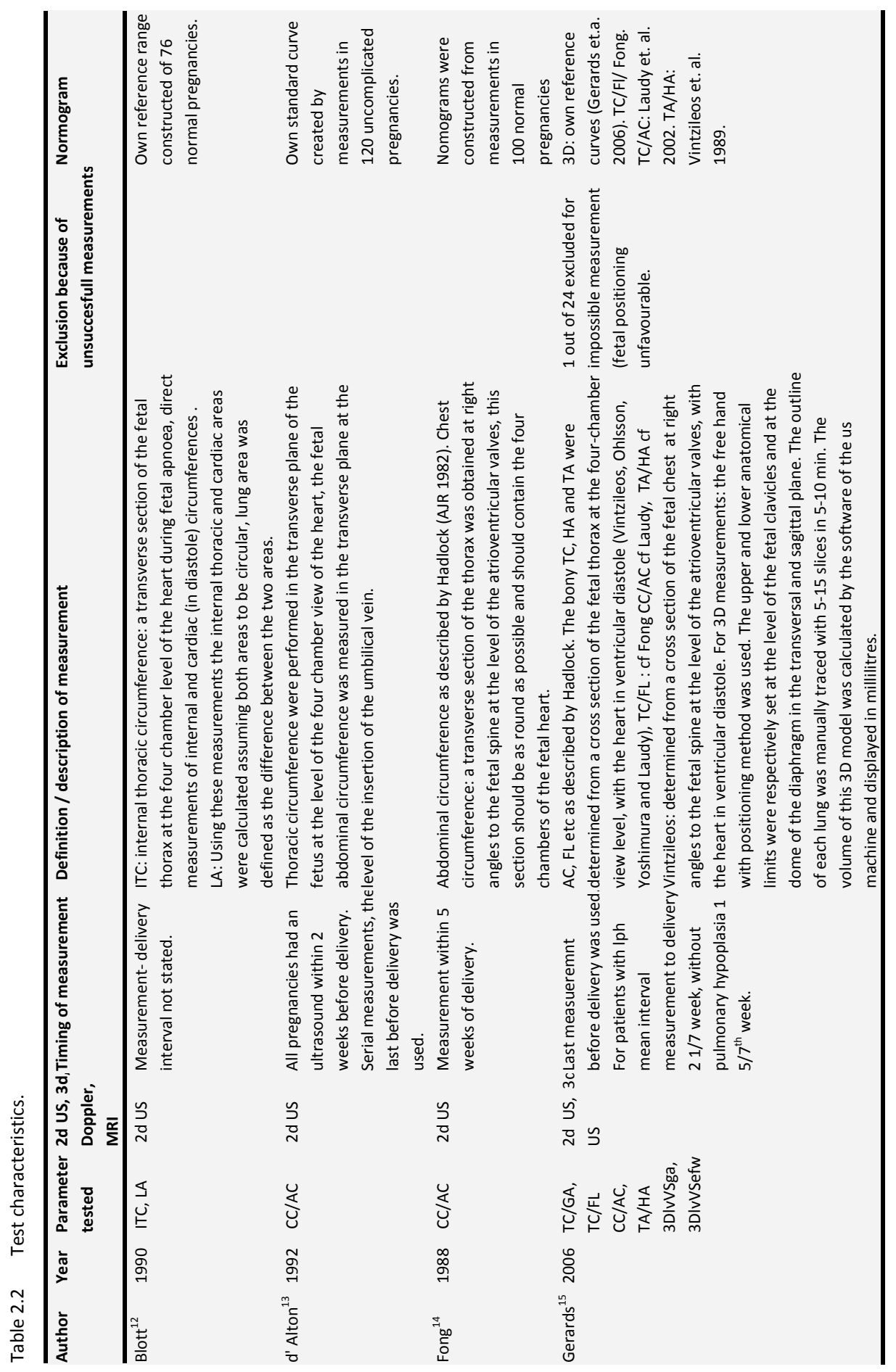




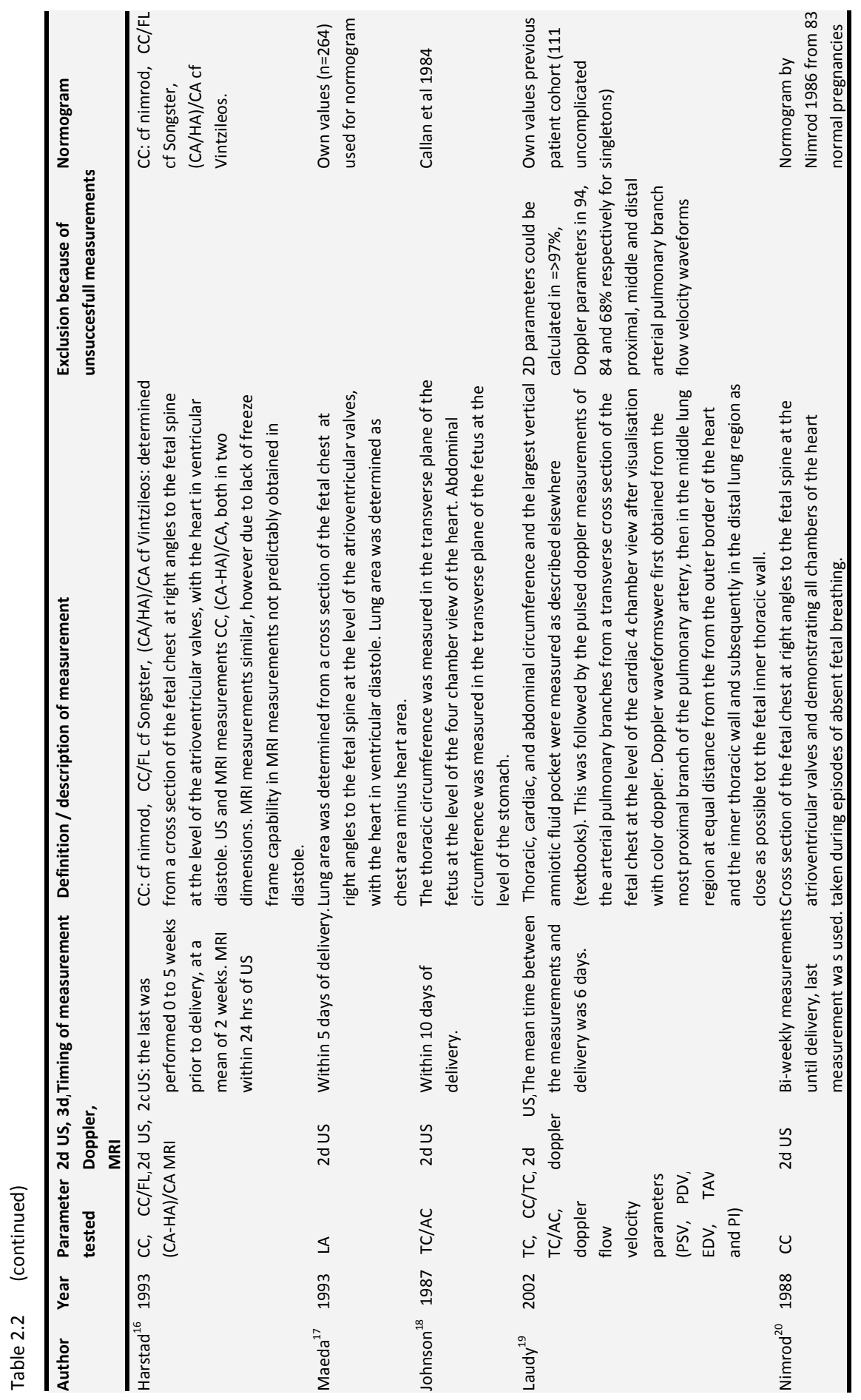


Introduction 31

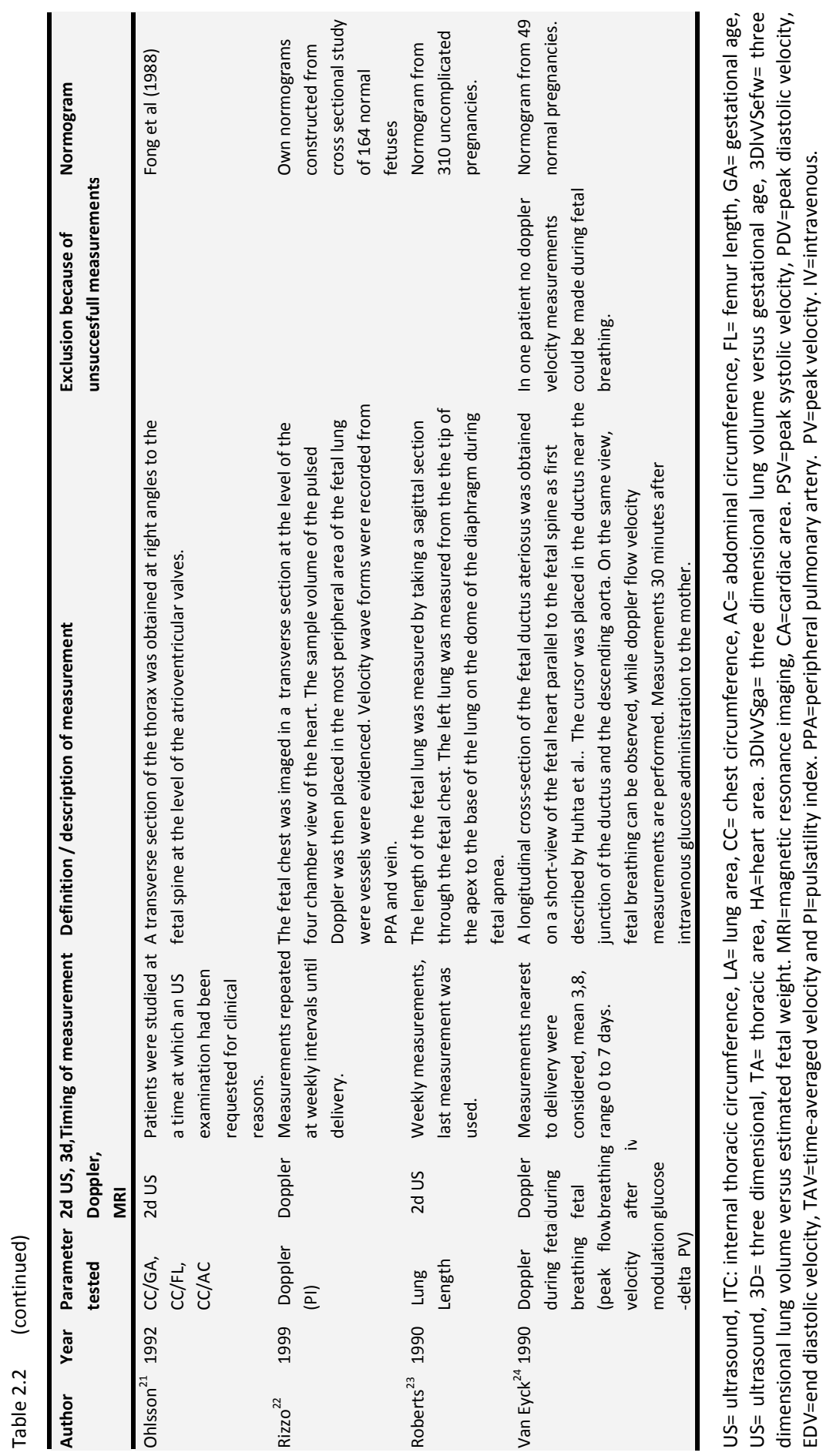




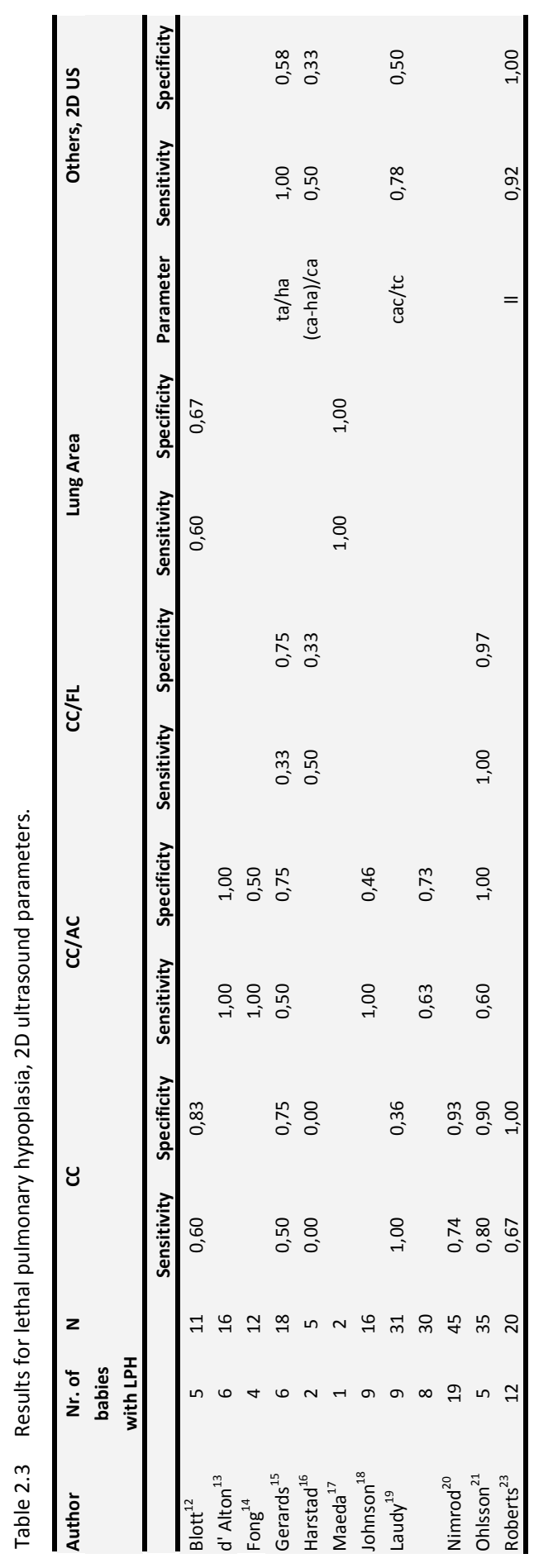




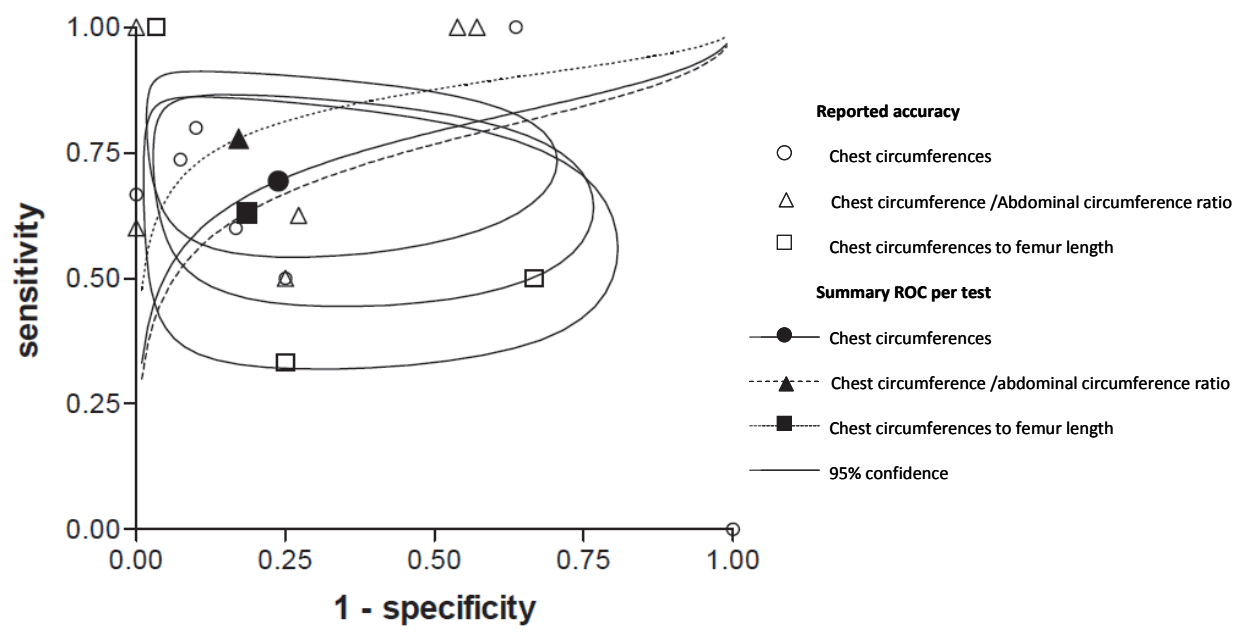

Figure 2.2 Sensitivity-specificity points and their reported accuracy for chest circumferences, the ratio of chest circumferences to abdominal circumferences, and for the ratio of chest circumferences to femur length for lethal pulmonary hypoplasia.

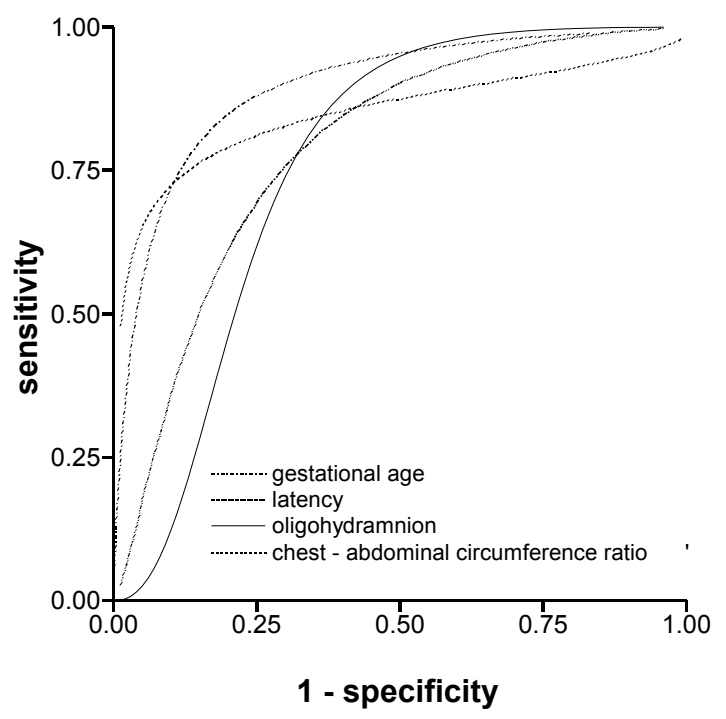

Figure 2.3 Performance of the ratio of chest circumferences to abdominal circumferences, as compared to the estimated summary ROC-curves for gestational age at PPROM, latency time and oligohydramnios for the prediction of lethal pulmonary hypoplasia. 
Table 2.4 Results for lethal pulmonary hypoplasia, 3D ultrasound, 2D MRI, Doppler parameters.

\begin{tabular}{|c|c|c|c|c|c|}
\hline \multirow[t]{2}{*}{ Author } & \multirow[t]{2}{*}{ Nr. of babies with LPH } & \multirow[t]{2}{*}{$\mathbf{N}$} & \multirow[t]{2}{*}{ Parameter } & \multicolumn{2}{|c|}{ Others } \\
\hline & & & & Sensitivity & Specificity \\
\hline \multirow[t]{2}{*}{ Gerards $^{15}$} & 6 & 18 & 3D US Iv/ga & 0,83 & 1,00 \\
\hline & & & 3D US Iv/efw & 0,67 & 1,00 \\
\hline \multirow[t]{2}{*}{ Harstad $^{16}$} & 2 & 3 & 2D MRI ca-ha/ca & 0,00 & 1,00 \\
\hline & & & 2D MRI cc & 0,00 & 0,00 \\
\hline \multirow[t]{10}{*}{ Laudy $^{19}$} & 6 & 29 & Doppler PPB tav & 0,63 & 0,76 \\
\hline & & & Doppler PPB psv & 0,63 & 0,9 \\
\hline & & & Doppler PPB pdv & 0,25 & 0,9 \\
\hline & & & Doppler PPB edv & 0,38 & 0,86 \\
\hline & & & Doppler PPB pi & 0,38 & 0,76 \\
\hline & 6 & 26 & Doppler MPB tav & 0,71 & 0,84 \\
\hline & & & Doppler MPB psv & 0,43 & 0,84 \\
\hline & & & Doppler MPB pdv & 0,14 & 0,68 \\
\hline & & & Doppler MPB edv & 0,57 & 0,95 \\
\hline & & & Doppler MPB pi & 0,29 & 0,79 \\
\hline $\operatorname{Rizzo}^{22}$ & 6 & 20 & Doppler pi/ppa & 0,63 & 0,95 \\
\hline Van Eyck ${ }^{24}$ & 4 & 12 & $\begin{array}{c}\text { Doppler during fetal breathing } \\
\text { (peak flow velocity modulation- } \\
\text { delta PV) }\end{array}$ & 1,00 & 0,88 \\
\hline
\end{tabular}

US=ultrasound, $3 \mathrm{D}=$ three dimensional, $2 \mathrm{D}=$ two dimensional, $\mathrm{LA}=$ lung area, $\mathrm{CC}=$ chest circumference, $\mathrm{AC}=$ abdominal circumference, $\mathrm{FL}=$ femur length, $\mathrm{GA}=$ gestational age, $3 \mathrm{D}=$ three dimensional, $\mathrm{TA}=$ thoracic area, $\mathrm{HA}=$ heart area. $\mathrm{LL}=$ lung length, $\mathrm{CAC}=$ cardiac circumference, $\mathrm{TC}=$ thoracic circumference lv=lung volume, efw=estimated fetal weight. $M R I=$ magnetic resonance imaging, $C A=$ cardiac area. PSV=peak systolic velocity, $P D V=$ peak diastolic velocity, $E D V=e n d$ diastolic velocity, $T A V=$ time-averaged velocity and $\mathrm{PI}=$ pulsatility index. PPA=peripheral pulmonary artery. $\mathrm{PV}=$ peak velocity.

\section{Discussion}

In this meta-analysis, we included 13 studies that reported on the prediction of lethal pulmonary hypoplasia. The estimates for sensitivity and specificity showed the capacity of imaging techniques to predict hypoplasia to be very limited. Our review identified several weaknesses in the literature. First, the methodological quality of the studies was limited. Many suffered from verification bias, as a result of the test being used in the management of the patients or because the observers were not blinded. All studies were single-center, which is worrisome, since second-trimester PPROM is a rare condition ( $0.7 \%$ of pregnancies), making it unlikely that a single-center study would reach sufficient power. Indeed, the sample size of each of the studies was rather small, especially with respect to the number of cases of hypoplasia. Most of the studies that we identified focussed on lethal pulmonary hypoplasia. This is important, as accurate prediction of lethal pulmonary hypoplasia before 24 weeks gives parents the chance to opt for termination of pregnancy. Moreover, this information could be of clinical relevance in women for whom discussions on intervention have to be made at 
gestational ages around that of viability of the child. In women relatively early on in pregnancy who are at high risk of fetal lethal pulmonary hypoplasia, the decision for an unnecessary cesarean section could be delayed. As we included studies performed between 1988 and 2006, there will have been differences between them in terms of treatments. Differences in antenatal management (tocolysis, corticosteroids, antibiotics) and advances in neonatal intensive care could have resulted in lower mortality figures in the more recent studies, with a subsequent lower incidence of lethal pulmonary hypoplasia. The reference test used in the various articles showed strong variation, which is also a source of heterogeneity. In seven of the 13 studies, all cases with lethal pulmonary hypoplasia were proven by autopsy, albeit with different pathological standards. The technique to diagnose pulmonary hypoplasia in autopsy varies widely. The three criteria used to define pulmonary hypoplasia are lung weight/body weight ratio, radial alveolar count and amount of DNA detected in lung tissue (lung DNA (in $\mathrm{mg}$ )/body weight (in g) ratio). Each of these three criteria has its own disadvantage. (Wet) lung weight/body weight ratio is decreased in pulmonary hypoplasia; however, tissue edema could increase the ratio, confusing the diagnosis. Radial alveolar counts are difficult to interpret in the preterm lung before the development of alveoli. The numbers in a fixed expanded lung differ from those in a fixed collapsed lung. The lung DNA/body weight ratio is confounded by the presence of increased pulmonary interstitial inflammatory cells. ${ }^{25}$ In six studies, some of the affected cases were identified by (predefined) clinical and radiological characteristics. However, a clinical diagnosis of pulmonary hypoplasia is difficult to establish since congenital pneumonia or infant respiratory distress syndrome sometimes occur simultaneously and have overlapping symptoms. The diagnostic meta-analysis we performed allows for control for heterogeneity in sensitivity and specificity, since both report on the same underlying test. When the cut-off for abnormality increases, sensitivity increases and specificity decreases, while a decrease in the cut-off for abnormality has the opposite effect. The summary ROC curves we estimated are a means of addressing this heterogeneity. We previously assessed the predictive capacity of gestational age at PPROM, latency time between PPROM and delivery and the amount of amniotic fluid. ${ }^{4}$ Gestational age at PPROM performed significantly better than did the two other parameters in the prediction of pulmonary hypoplasia. Future studies should focus on whether ultrasound parameters or other imaging techniques can further improve on the prediction of pulmonary hypoplasia that is possible using age at PPROM. In view of the current evidence, we feel that there is no indication to perform such tests in a clinical setting. 


\section{References}

1. Kilbride HW, Thibeault DW. Neonatal complications of preterm rupture of membranes. Clin Perinatol 2001;28:761-85.

2. Sherer DM, Davis JM, Woods JR Jr. Pulmonary hypoplasia: a review. Obstet Gynecol Surv 1990; 45: 792-803.

3. Laudy JA, Wladimiroff JW. The fetal lung. 2: Pulmonary hypoplasia. Ultrasound Obstet Gynecol 2000;16: 482-94.

4. van Teeffelen AS, van der Ham DP, Oei SG, Porath MM, Willekes C, Mol BW. The accuracy of clinical parameters in the prediction of perinatal pulmonary hypoplasia secondary to midtrimester prelabour rupture of fetal membranes: a meta-analysis. Eur J Obstet Gynecol Reprod Biol 2010;148:3-12.

5. Vintzileos AM, Campbell WA, Rodis JF, Nochimson DJ, Pinette MG, Petrikovsky BM. Comparison of six different ultrasonographic methods for predicting lethal fetal pulmonary hypoplasia. Am J Obstet Gynecol 1989;161:606-12.

6. Lijmer JG, Mol BW, Heisterkamp S, Bonsel GJ, Prins MH, van der Meulen JH, Bossuyt PM. Empirical evidence of design-related bias in studies of diagnostic tests. JAMA 1999;282:1061-6.

7. Van Houwelingen HC, Zwinderman KH, Stijnen T. A bivariate approach to meta-analysis. Stat Med 1993; 12:2273-84.

8. Van Houwelingen HC, Arends LR, Stijnen T. Advanced methods in meta-analysis: multivariate approach and meta-regression. Stat Med 2002 28;21:589-624.

9. Reitsma JB, Glas AS, Rutjes AW, Scholten RJ, Bossuyt PM, Zwinderman AH. Bivariate analysis of sensitivity and specificity produces informative summary measures in diagnostic reviews. $J$ Clin Epidemiol 2005;58:982-90.

10. Arends LR, Hamza TH, Van Houwelingen HC, Heijenbrok KMH, Hunink MGM, Stijnen T. Multivariate random-effects meta-analysis of ROC-curves. Med Decis Making 2006.

11. Harbord RM, Deeks JJ, Egger M, Whiting P, Sterne JAC. A unification of models for meta-analysis of diagnostic accuracy studies. Biostatistics 2007;8:239-51.

12. Blott M, Greenough A, Nicolaides KH, Campbell S. The ultrasonographic assessment of the fetal thorax and fetal breathing movements in the prediction of pulmonary hypoplasia. Early Hum Dev 1990; 21:143-51.

13. D'Alton M, Mercer B, Riddick E, Dudley D. Serial thoracic versus abdominal circumference ratios for the prediction of pulmonary hypoplasia in premature rupture of the membranes remote from term. Am J Obstet Gynecol 1992;166:658-63.

14. Fong $\mathrm{K}$, Ohlsson A, Zalev A. Fetal thoracic circumference: a prospective cross-sectional study with realtime ultrasound. Am J Obstet Gynecol. 1988; 158(5):1154-60. Erratum in: Am J Obstet Gynecol 1990; 163:1363.

15. Gerards FA, Twisk JW, Fetter WP, Wijnaendts LC, Van Vugt JM. Two- or three-dimensional ultrasonography to predict pulmonary hypoplasia in pregnancies complicated by preterm premature rupture of the membranes. Prenat Diagn 2007;27:216-21.

16. Harstad TW, Twickler DM, Leveno KJ, Brown CE. Antepartum prediction of pulmonary hypoplasia: an elusive goal? Am J Perinatol 1993;10:8-11.

17. Maeda H, Nagata H, Tsukimori K, Satoh S, Koyanagi T, Nakano H. Prenatal evaluation and obstetrical management of fetuses at risk of developing lung hypoplasia. J Perinat Med 1993;21:355-61.

18. Johnson A, Callan NA, Bhutani VK, Colmorgen GH, Weiner S, Bolognese RJ. Ultrasonic ratio of fetal thoracic to abdominal circumference: an association with fetal pulmonary hypoplasia. Am J Obstet Gynecol 1987;157:764-9.

19. Laudy JA, Tibboel D, Robben SG, de Krijger RR, de Ridder MA, Wladimiroff JW. Prenatal prediction of pulmonary hypoplasia: clinical, biometric, and Doppler velocity correlates. Pediatrics 2002;109:250-8.

20. Nimrod C, Nicholson S, Davies D, Harder J, Dodd G, Sauve R. Pulmonary hypoplasia testing in clinical obstetrics. Am J Obstet Gynecol 1988;158:277-80.

21. Ohlsson A, Fong K, Rose T, Hannah M, Black D, Heyman Z, Gonen R. Prenatal ultrasonic prediction of autopsy-proven pulmonary hypoplasia. Am J Perinatol 1992;9:334-7. 
22. Rizzo G, Capponi A, Angelini E, Mazzoleni A, Romanini C. Blood flow velocity waveforms from fetal peripheral pulmonary arteries in pregnancies with preterm premature rupture of the membranes: relationship with pulmonary hypoplasia. Ultrasound Obstet Gynecol 2000;15:98-103.

23. Roberts $A B$, Mitchell JM. Direct ultrasonographic measurement of fetal lung length in normal pregnancies and pregnancies complicated by prolonged rupture of membranes. Am J Obstet Gynecol 1990;163:1560-6.

24. van Eyck J, van der Mooren K, Wladimiroff JW. Ductus arteriosus flow velocity modulation by fetal breathing movements as a measure of fetal lung development. Am J Obstet Gynecol 1990;163:558-66.

25. Kilbride HW, Yeast J, Thibeault DW. Defining limits of survival: lethal pulmonary hypoplasia after midtrimester premature rupture of membranes. Am J Obstet Gynecol 1996;175:675-81. 


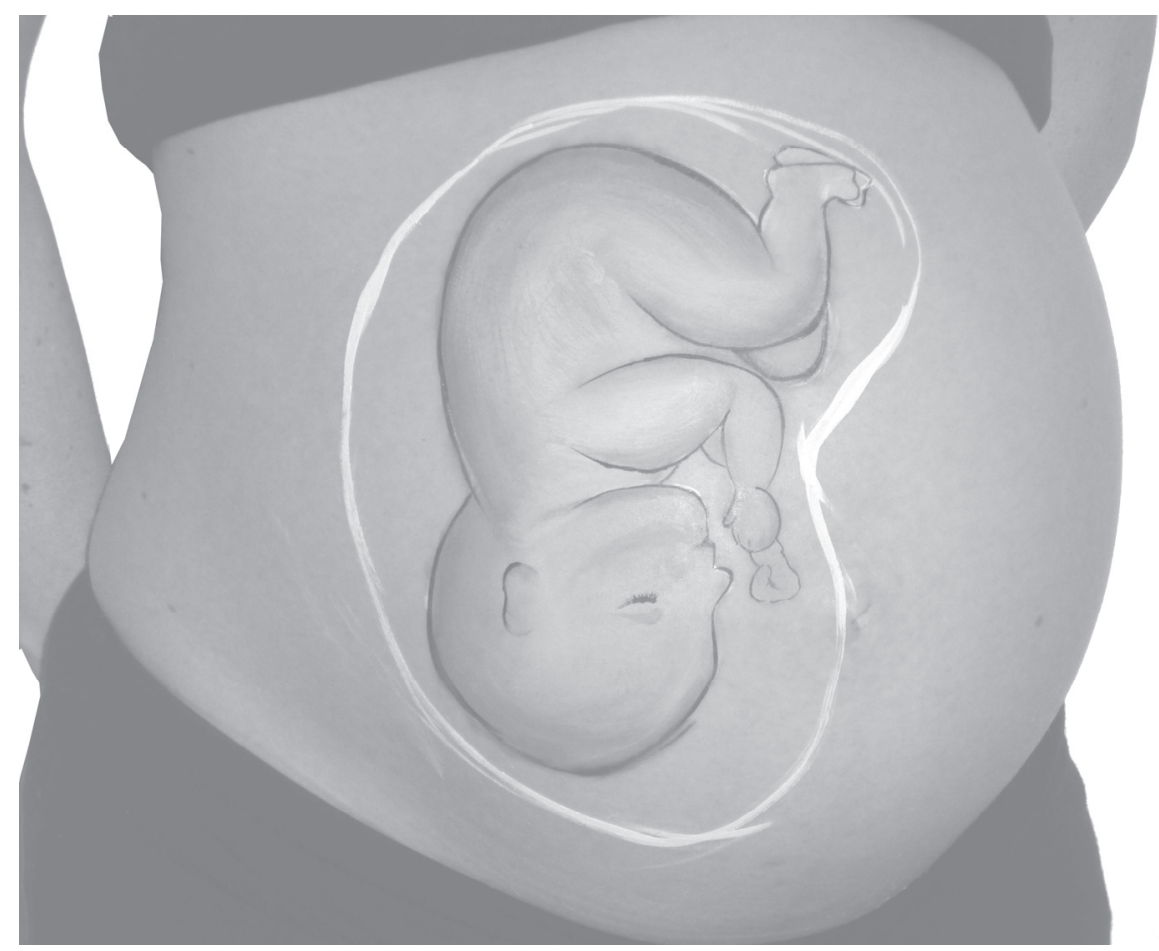




\section{Chapter}

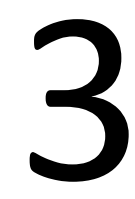

Outcome of pregnancies with preterm prelabor rupture of membranes before 27 weeks' gestation: a retrospective cohort study

JL van der Heyden DP van der Ham $S$ van Kuijk KJB Notten

T Janssen JG Nijhuis

C Willekes M Porath JA van der Post

F Halbrtsma BWJ Mol E Pajkrt 
40 Chapter 3 


\section{Introduction}

Preterm prelabor rupture of membranes (PPROM) before 27 weeks' gestation occurs in approximately $0.5 \%$ of all pregnancies. ${ }^{1}$ It is associated with severe complications, such as premature birth, pulmonary hypoplasia and fetal death. ${ }^{2}$

latrogenic PPROM may be triggered by invasive procedures such as amniocentesis, chorionic villus sampling, cervical surgery or mechanical trauma. Midtrimester PPROM after amniocentesis occurs in up to $1 \%$ of all procedures. ${ }^{3}$ The pathogenesis of spontaneous PPROM is not well understood: possible risk factors are history of preterm labor or PPROM, cervical insufficiency, smoking, multiple gestation and antepartum bleeding. $^{4-6}$

Complications of second trimester PPROM have been studied previously, but the results are inconsistent. ${ }^{7-15}$ Overall, the prognosis for perinatal survival and morbidity after early PPROM seems poor, with survival rates between 14\% and 70\% (Table 3.1). Prediction of neonatal outcome in pregnancies with early PPROM is virtually impossible, due to heterogeneity of previous studies, small sample sizes and increased health care compared to the era in which previous studies were reported (1970s to 1980s)

It is, however, crucial to counsel the woman accurately on the risks in a case of early PPROM, in order to decide whether or not to terminate pregnancy. The primary aim of the current study was to report our findings on perinatal outcome in pregnancies complicated by early PPROM and to provide tools for counseling. Furthermore, we investigated if the risk of perinatal death could be predicted from antepartum variables.

\section{Materials and methods}

We performed a retrospective cohort study in the obstetric departments of the Máxima Medical Center in Veldhoven (MMC) in the period 1994-2005, Academic Medical Center in Amsterdam (AMC) in the period 1996-2009, and Maastricht University Medical Center (MUMC) in the period 1997-2001. The difference in time periods between the three centers can be explained by logistic reasons.

\section{Patients}

Women with PPROM before 27 weeks' gestation were eligible for this study. Exclusion criteria were contractions at presentation (subsequently resulting in PPROM), cervical insufficiency necessitating cervical cerclage, or pregnancies with known lethal fetal anomalies. Women were identified from local electronic databases in which the moment of rupture of the membranes (ROM) and moment of birth were registered. 


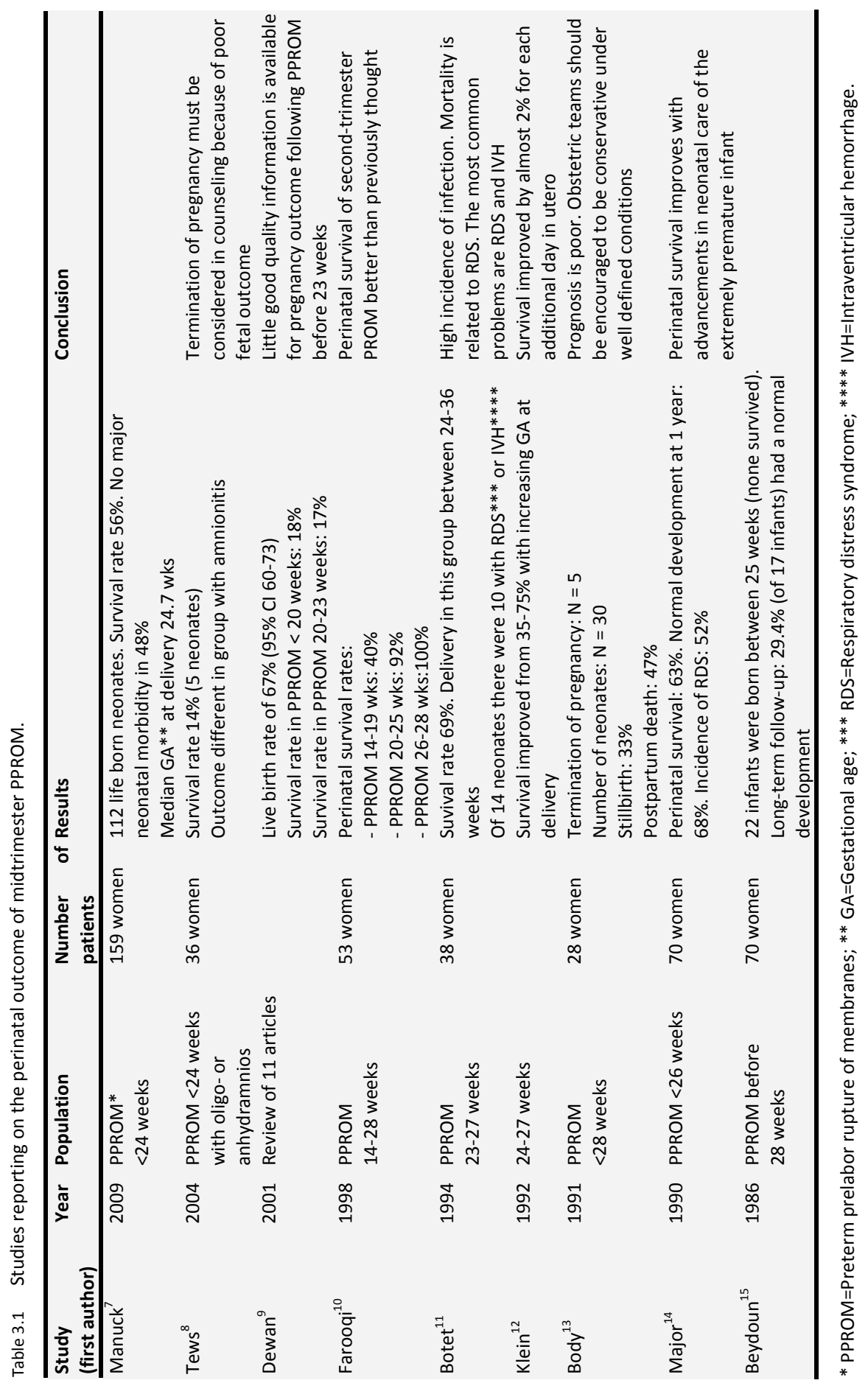


Women were managed expectantly as inpatients. Routinely daily temperature measurements and cardiotocography were performed and blood samples were taken at least once weekly. Corticosteroids were administered for fetal lung maturation from 25 weeks onwards, and preterm labor was arrested with tocolytics. Prophylactic antibiotics, erythromycin $250 \mathrm{mg} 4$ times daily for 10 days, were administered in two centers (MUMC and MMC). In one center (AMC) antibiotics were given only when clinical signs of infection were present (maternal temperature $>37.8^{\circ} \mathrm{C}\left(100^{\circ} \mathrm{F}\right)$ or fetal tachycardia). This policy differed between the centers, because the national guideline does not provide a clear recommendation on the use of antibiotics in cases of PPROM. ${ }^{1}$

\section{Outcome}

We recorded the following outcome measurements: perinatal mortality, premature delivery, and neonatal morbidity, i.e. pulmonary hypoplasia, respiratory distress syndrome (RDS), intraventricular hemorrhage (IVH), necrotizing enterocolitis (NEC), chronic lung disease (CLD) and sepsis.

Pulmonary hypoplasia was defined as neonatal death within $24 \mathrm{~h}$ after birth, due to respiratory failure not attributable to other causes and impossibility of postpartum ventilation, if possible confirmed by histological examination of the lungs. RDS was defined as clinical signs of respiratory distress in prematurely born infants, with impaired oxygenation and characteristic radiologic signs (air bronchograms, ground glass appearance). ${ }^{16,17}$ CLD, (formerly named bronchopulmonary dysplasia (BPD), was defined as infants with oxygen dependency at either 28 days of life or 36 weeks' gestation. ${ }^{18}$

IVH was defined as hemorrhage in the germinal matrix, ventricles, or cerebral parenchyma, observed by ultrasound examination or MRI. Ultrasound examination is routinely performed in all neonates born prior to 32 weeks' gestation, or in neonates with neurologic symptoms. ${ }^{19}$

A diagnosis of NEC was made on the presence of the characteristic clinical features of abdominal distention, with or without rectal bleeding, and abdominal radiographic findings associated with pneumatosis intestinalis (this last finding is an abnormal gas pattern with dilated loops consistent with ileus). ${ }^{20}$

Neonatal sepsis was classified as suspected or proven (caused by any pathogen) and defined as a neonatal infection with cardiorespiratory instability or a positive blood culture caused by any pathogen. Clinical infection includes symptoms like positive findings on clinical exam, imaging, or laboratory tests. Laboratory signs of infection were increased C-reactive protein (CRP), leukocytosis or leukocytopenia. ${ }^{21}$

For pregnancy outcome and neonatal outcome measurements, a subdivision was made for different categories: PPROM between 13 and 20 weeks, 20 to 24 weeks and 24 to 27 weeks. 


\section{Statistical analysis}

We calculated the rates of each outcome measure, expressed as percentage, mean with standard deviation or median with interquartile ranges. Kaplan-Meier curves were constructed, indicating time to delivery in relation to gestational age at PPROM.

\section{Prediction model development}

\section{Potential predictors}

For the estimation of the individual risk of perinatal death, we assumed the following variables as potential predictors: maternal age, gestational age at PPROM, interval between PPROM and birth, anhydramnios, positive vaginal culture (any bacteria) and positive vaginal culture for GBS (group B streptococcus).

\section{Model building}

To account for missing values, we used multiple imputation techniques. We introduced all potential predictors in a multivariable logistic regression model and used backward stepwise elimination to reduce the amount of predictors per dataset, using a liberal $P$ value of 0.20 .

\section{Internal validation}

We adjusted the model using bootstrapping techniques to reduce the probability of overfitting (i.e. the model performs particularly well on the data that we used to develop the model, but is often very disappointing in future patients). ${ }^{22}$

\section{Model performance}

To quantify the performance of the final model, we assessed the discriminative ability, the calibration, and the overall performance. The discriminative ability is the models' ability to distinguish cases from non-cases. It ranges from 0.5 (no discrimination) to 1.0 (perfect discrimination). A Hosmer and Lemeshow ( $\mathrm{H}-\mathrm{L}$ ) goodness-of-fit statistic was computed. A high $\mathrm{H}$-L statistic will yield a low $\mathrm{p}$-value and provides evidence of lack of fit. The overall performance, or the accuracy of the model, was quantified by computing the Brier score. ${ }^{22}$

Analyses were done using Microsoft Excel, SPSS version 18.0 for Windows (SPSS inc, IL, Chicago, USA) and R version 2.12.2. 


\section{Results}

PPROM before 27 weeks was identified in 314 women (158 cases from AMC, 36 from MUMC and 120 from MMC), of whom three were excluded as their outcome was unknown. Six $(1.9 \%)$ women requested termination of pregnancy before 24 weeks' gestation (all singleton pregnancies with PPROM between $15^{+0}$ and $20^{+5}$ weeks). Of the remaining 305 women, 25 were twin pregnancies and three triplet pregnancies, leaving 336 fetuses eligible for analysis (Table 3.2).

Gestational age (GA) at PPROM varied from $13^{+0}$ weeks to $26^{+6}$ weeks. The median GA at PPROM was $23^{+1}$ weeks (interquartile range (IQR) $19^{+5} ; 25^{+0}$ weeks). Maternal baseline characteristics are shown in Table 3.2. PPROM following amniocentesis and chorionic villus sampling occurred in 24 (7.9\%) and 9 women $(2.9 \%)$, respectively. The median GA at delivery was $25^{+6}$ weeks (IQR $23^{+5} ; 27^{+2}$ weeks). Subdivided for iatrogenic and spontaneous PPROM, the mean GA at delivery was $28^{+5}$ weeks [ \pm 7.7 ] and $25^{+3}$ $[ \pm 3.8]$ respectively.

Table 3.2 Maternal baseline characteristics.

\begin{tabular}{|c|c|c|c|c|c|}
\hline Characteristic* & $\begin{array}{c}\text { Total } \\
n=305\end{array}$ & $\begin{array}{c}\text { PPROM } \\
\begin{array}{c}\geq 13 \text { and } \\
<20 \text { weeks } \\
n=89\end{array}\end{array}$ & $\begin{array}{c}\text { PPROM } \\
\begin{array}{c}\geq 20 \text { and } \\
<24 \text { weeks } \\
n=96\end{array}\end{array}$ & $\begin{array}{c}\text { PPROM } \\
\geq 24 \text { and } \\
<27 \text { weeks } \\
n=120\end{array}$ & $p$-value*** \\
\hline $\begin{array}{l}\text { Maternal age (years) } \\
\text { (mean [ } \pm \text { standard deviation]) }\end{array}$ & $31.7[5.3]$ & $32.9[5.4]$ & $30.9[5.2]$ & $31.4[5.4]$ & 0.03 \\
\hline \multicolumn{6}{|l|}{ Parity** } \\
\hline Nulliparity & $124(40 \%)$ & $34(38 \%)$ & $32(33 \%)$ & $57(48 \%)$ & \multirow{2}{*}{0.10} \\
\hline Multiparity & $186(60 \%)$ & $54(61 \%)$ & $64(67 \%)$ & $63(53 \%)$ & \\
\hline \multicolumn{6}{|l|}{ Singleton/multiple pregnancy } \\
\hline Singletons & $283(91 \%)$ & $80(10 \%)$ & 91 (95\%) & $105(88 \%)$ & \multirow{3}{*}{0.21} \\
\hline Twins & $25(8.0 \%)$ & $9(10 \%)$ & $5(5.2 \%)$ & $12(10 \%)$ & \\
\hline Triplets & $3(1.0 \%)$ & $0(0 \%)$ & $0(0 \%)$ & $3(2.5 \%)$ & \\
\hline
\end{tabular}

* Values are expressed as absolute numbers with percentage, median with range or mean with standard deviation where appropriate; ** Parity: unknown in 1 case; $* * * P$-value: calculated for subcategories: PPROM 13-20 weeks, 20-24 weeks and 24-27 weeks (total $n=311$ not included in this analysis).

Table 3.3 shows pregnancy outcomes in different subcategories.

In the total group, 70 (21\%) neonates were born within $48 \mathrm{~h}$ after PPROM, whereas $56(17 \%)$ neonates were still unborn 50 days after PPROM. The median interval between PPROM and delivery was 10 days (IQR 3 days; 33 days). Of all neonates, 238 (71\%) were born before 27 weeks and only 8 (2.4\%) after 37 weeks.

In the early gestational age group (PPROM 13-20 weeks), significantly more women were still pregnant 50 days after PPROM, compared to the subcategory PPROM 24-27 weeks (35\% versus 1.4\%; RR 0.31 ( $95 \% \mathrm{Cl} 0.23-0.40)$; $p<0.0001)$, with an absolute risk reduction (ARR) of $66 \%$. 
The Kaplan Meier curve expressing time to delivery (Figure 3.1) shows that the earlier the GA at PPROM, the more likely the chance of continuation of pregnancy for several days or weeks.

The overall perinatal mortality rate was 166/336 (49\%), of which 93 (28\%) were stillbirths. Table 3.3 shows the mortality rates in the different subgroups. The relation between gestational age at PPROM and perinatal mortality is shown in a Kaplan Meier curve (Figure 3.2).

Table 3.3 Pregnancy Outcome measures.

\begin{tabular}{|c|c|c|c|c|c|}
\hline Outcome* & $\begin{array}{c}\text { Total } \\
n=336\end{array}$ & $\begin{array}{c}\text { PPROM } \\
\geq 13 \text { and }<20 \\
\text { weeks } \\
n=97\end{array}$ & $\begin{array}{c}\text { PPROM } \\
\begin{array}{c}\geq 20 \text { and }<24 \\
\text { weeks } \\
n=101\end{array}\end{array}$ & $\begin{array}{c}\text { PPROM } \\
\begin{array}{c}\geq 24 \text { and }<27 \\
\text { weeks } \\
n=138\end{array}\end{array}$ & $\begin{array}{l}p \text {-value for } \\
\text { difference } * *\end{array}$ \\
\hline \multicolumn{6}{|l|}{ Mode of delivery } \\
\hline Spontaneous delivery & $255(76 \%)$ & $73(78 \%)$ & $79(78 \%)$ & $103(75 \%)$ & \\
\hline Vaginal instrumental delivery & $10(3.0 \%)$ & $2(2.1 \%)$ & $2(2.0 \%)$ & $6(4.3 \%)$ & 0.034 \\
\hline Caesarean section & $57(17 \%)$ & $13(14 \%)$ & $20(20 \%)$ & $24(17 \%)$ & \\
\hline Unknown & $11(3.3 \%)$ & $9(9.3 \%)$ & $0(0 \%)$ & $5(3.6 \%)$ & \\
\hline \multicolumn{6}{|l|}{ Gestational age at delivery } \\
\hline$<27$ weeks & $238(71 \%)$ & $69(71 \%)$ & $69(68 \%)$ & $100(72 \%)$ & \\
\hline $27-30$ weeks & $54(16 \%)$ & $11(11 \%)$ & $18(18 \%)$ & $25(18 \%)$ & \\
\hline $30-34$ weeks & $27(8.0 \%)$ & $6(6.2 \%)$ & $9(8.9 \%)$ & $12(8.7 \%)$ & 0.002 \\
\hline $34-37$ weeks & $9(2.7 \%)$ & $3(3.1 \%)$ & $5(5.0 \%)$ & $1(0.7 \%)$ & \\
\hline$>37$ weeks & $8(2.4 \%)$ & $8(8.2 \%)$ & $0(0 \%)$ & $0(0 \%)$ & \\
\hline $\begin{array}{l}\text { GA*** at delivery (wks) } \\
\text { (mean [ } \pm \text { standard deviation]) }\end{array}$ & $25.7[4.4]$ & $24.1[6.8]$ & $26.1[3.4]$ & $26.7[2.0]$ & $<0.001$ \\
\hline Delivery $\leq 48$ hours after PPROM & $70(21 \%)$ & $17(18 \%)$ & $16(16 \%)$ & $37(27 \%)$ & \\
\hline $\begin{array}{l}\text { Delivery } 2 \text { days to } 7 \text { days after } \\
\text { PPROM }\end{array}$ & $77(23 \%)$ & $19(20 \%)$ & $14(14 \%)$ & $44(32 \%)$ & \\
\hline $\begin{array}{l}\text { Delivery } 1 \text { week to } 2 \text { weeks } \\
\text { after PPROM }\end{array}$ & $46(14 \%)$ & $7(7.2 \%)$ & $14(14 \%)$ & $25(18 \%)$ & \\
\hline $\begin{array}{l}\text { Still pregnant } 50 \text { days after } \\
\text { PPROM }\end{array}$ & $56(17 \%)$ & $34(35 \%)$ & $20(20 \%)$ & $2(1.4 \%)$ & \\
\hline $\begin{array}{l}\text { Antepartum and peripartum } \\
\text { death }\end{array}$ & $93(28 \%)$ & 47 (48\%) & $30(30 \%)$ & $16(12 \%)$ & $<0.001$ \\
\hline Neonatal death & & & & & 0.003 \\
\hline $\begin{array}{l}\text { Death within } 24 \text { hours after } \\
\text { birth }\end{array}$ & $54(16 \%)$ & $19(20 \%)$ & $23(23 \%)$ & $12(8.7 \%)$ & \\
\hline Death 1-7 days after birth & 19 (5.7\%) & $3(3.1 \%)$ & $7(7.0 \%)$ & $9(6.5 \%)$ & \\
\hline Death $>7$ days after birth & $11(3.3 \%)$ & $0(0 \%)$ & $2(2.0 \%)$ & $9(6.5 \%)$ & \\
\hline
\end{tabular}

* Values are expressed as absolute numbers with percentage, median with range or mean with standard deviation where appropriate; ** P-value: calculated for subcategories: PPROM 13-20 weeks, 20-24 weeks and 24-27 weeks (total $n=336$ not included in this analysis); cells counting less than 5 not included in calculation; ${ }^{* *} \mathrm{GA}=$ gestational age. 


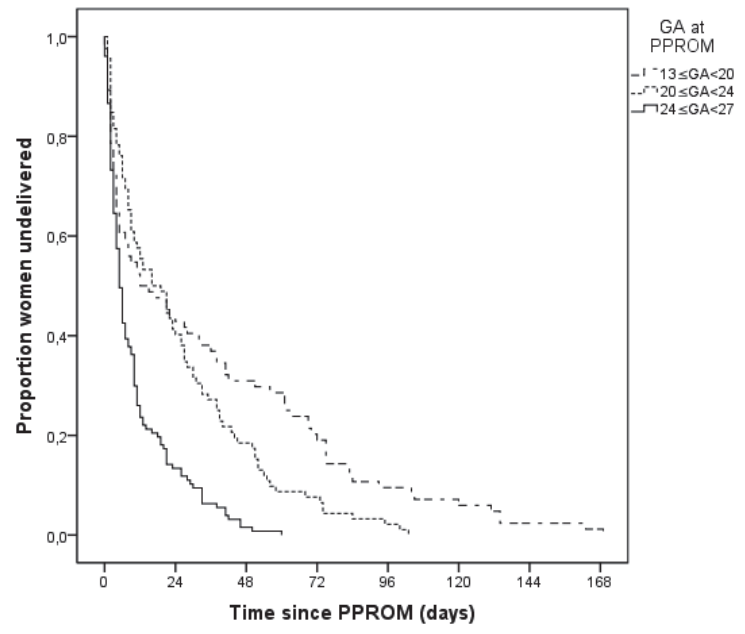

Figure 3.1 Kaplan Meier curve.

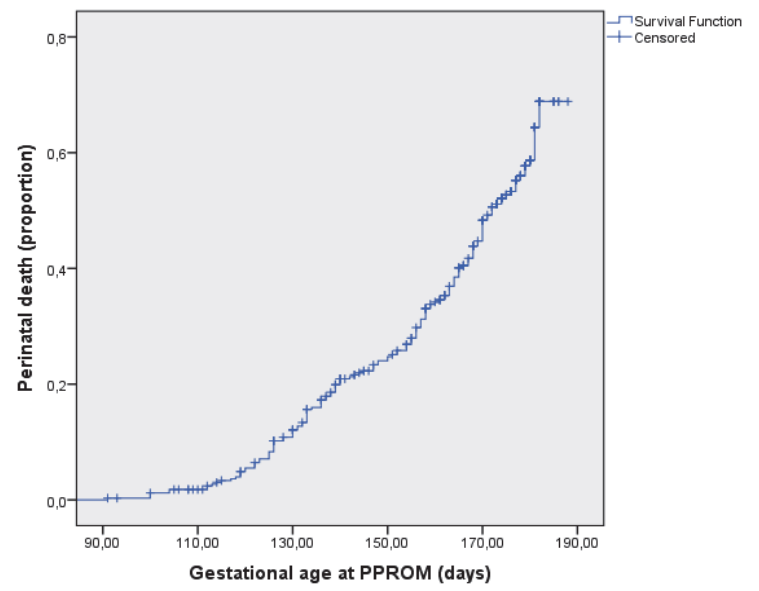

Figure 3.2 Kaplan Meier curve perinatal mortality.

Pulmonary hypoplasia was diagnosed in 11 of the neonates who died within $24 \mathrm{~h}$ post-delivery (3.3\%).

Of the 170 surviving neonates (alive at seven days after birth), 70 (41\%) suffered serious morbidity (RDS grade 3 or 4, IVH, NEC, CLD or (suspicion of) sepsis). Some neonates had multiple morbidities.

One hundred neonates (59\% of the surviving neonates) survived without any of these endpoints, which is $30 \%$ of the total group of 336 neonates. Table 3.4 
summarizes the outcome measurement per subgroup. Survival rates without major morbidity ranged from $20 \%$ to $37 \%$ amongst the subgroups.

Table $3.4 \quad$ Outcome in neonates alive 7 days after birth.

\begin{tabular}{|c|c|c|c|c|c|}
\hline & $\begin{array}{c}\text { Total } \\
n=170\end{array}$ & $\begin{array}{c}\text { PPROM } \\
\geq 13 \text { and }<20 \\
\text { weeks } \\
n=28\end{array}$ & $\begin{array}{c}\text { PPROM } \\
\geq 20 \text { and }<24 \\
\text { weeks } \\
n=41\end{array}$ & $\begin{array}{c}\text { PPROM } \\
\begin{array}{c}\geq 24 \text { and }<27 \\
\text { weeks } \\
n=101\end{array}\end{array}$ & $p$-value** \\
\hline \multicolumn{6}{|l|}{$\begin{array}{l}\text { Respiratory distress } \\
\text { syndrome }\end{array}$} \\
\hline Grade 1-2 & $50(29 \%)$ & $3(11 \%)$ & $10(24 \%)$ & 37 (37\%) & \multirow{2}{*}{0.003} \\
\hline Grade 3-4 & $13(7.6 \%)$ & $0(0 \%)$ & $7(17 \%)$ & $6(6.0 \%)$ & \\
\hline \multicolumn{6}{|l|}{$\begin{array}{l}\text { Intraventricular } \\
\text { hemorrhage }\end{array}$} \\
\hline Grade 1-2 & $19(11 \%)$ & $0(0 \%)$ & $6(15 \%)$ & $13(13 \%)$ & \multirow{2}{*}{0.11} \\
\hline Grade 3-4 & $4(2.4 \%)$ & $0(0 \%)$ & $2(4.9 \%)$ & $2(2.0 \%)$ & \\
\hline $\begin{array}{l}\text { Necrotizing } \\
\text { enterocolitis }\end{array}$ & $7(4.1 \%)$ & $1(3.6 \%)$ & $1(2.4 \%)$ & $5(5.0 \%)$ & 0.87 \\
\hline $\begin{array}{l}\text { Proven or suspected } \\
\text { sepsis }\end{array}$ & $22(13 \%)$ & $1(3.6 \%)$ & $4(9.8 \%)$ & $17(17 \%)$ & 0.05 \\
\hline Chronic lung disease & $29(17 \%)$ & 3 (11\%) & $7(17 \%)$ & 19 (19\%) & 0.71 \\
\hline $\begin{array}{l}\text { Survival without } \\
\text { major morbidity* }\end{array}$ & $100 / 336(30 \%)$ & $24 / 97(25 \%)$ & $20 / 101(20 \%)$ & $51 / 138(37 \%)$ & \\
\hline
\end{tabular}

* Percentage shown for total group; ** P-value: calculated for subcategories: PPROM 13-20 weeks, 20-24 weeks and 24-27 weeks (total $n=170$ not included in this analysis); cells counting less than 5 not included in calculation.

\section{Prediction model}

From the preselected candidate predictor variables, GA at PPROM, interval between PPROM and birth and positive vaginal culture (any bacteria) were selected in the multivariable logistic regression analysis (Table 3.5). Ten different bacteria were identified in positive vaginal cultures (e.g. E.Coli, Enterobacter cloacae, Gardnerella vaginalis, Klebsiella and Proteus mirabilis). The model performance was good. The area under the original ROC curve (Figure 3.3) was $91.0 \%$ (95\% Cl: 87.9-94.1), after correction for optimisms it was $88.8 \%$ (95\% Cl: 85.7-91.9), which indicates a good expected discriminative ability. The calibration of the model was good: the calibration plot indicates that predicted probabilities equal observed frequencies. The H-L goodness-of-fit test $(P=0.69)$, confirms this. 
Table 3.5 Prediction model for the estimation of the individual risk of perinatal mortality.

\begin{tabular}{|c|c|c|}
\hline Variable & $\begin{array}{c}\text { Regression } \\
\text { coefficient* }\end{array}$ & $\begin{array}{c}\text { Odds ratio } \\
(95 \% \mathrm{Cl})\end{array}$ \\
\hline Intercept** & 24.52 & - \\
\hline AD PPROM (days) & -0.14 & $0.87(0.83-0.91)$ \\
\hline Interval (days) & -0.11 & $0.90(0.87-0.93)$ \\
\hline Vaginal culture (pos/neg) & 0.60 & $1.82(0.92-3.60)$ \\
\hline \multicolumn{3}{|c|}{$\begin{array}{l}\text { To calculate the absolute risk of perinatal death: } \\
\mathrm{P}(\text { perinatal death })=\end{array}$} \\
\hline \multicolumn{3}{|c|}{$\begin{array}{c}1 \\
\times 100 \%\end{array}$} \\
\hline
\end{tabular}

* Mean regression coefficients over 10 imputed datasets, after adjustment for overfitting by shrinkage (shrinkage factor $=0.89$ ), the intercept was re-estimated; ${ }^{* *}$ The intercept is added so that the average predicted value equals the proportion of cases.

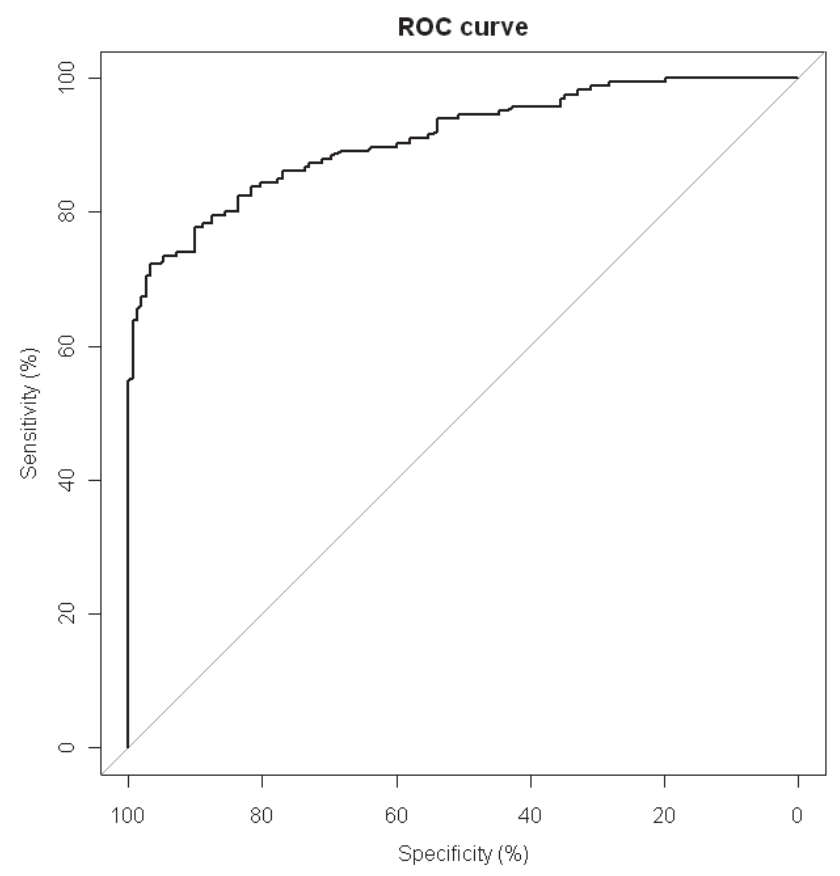

Figure 3.3 ROC curve. 


\section{Comments}

We reported a perinatal mortality rate of $49 \%$ in this retrospective cohort study. Of the survivors, $41 \%$ suffered serious morbidity, but $59 \%$ of surviving neonates had no serious morbidity. In other words, after PPROM prior to 27 weeks' gestational age, the overall chance of survival without severe morbidity is $30 \%$. Our perinatal mortality rate is comparable with previous studies ${ }^{7-15}$, but perinatal mortality rates varying from $25 \%{ }^{12}$ to $86 \%^{8}$ have been reported. An important remark should be made. The perinatal mortality rate decreases with increasing gestational age at PPROM. The perinatal mortality rate is $71 \%$ in the subgroup PPROM between 13 and 20 weeks, 59\% in the subgroup PPROM between 20 and 24 weeks and only $27 \%$ in the group PPROM between 24 and 27 weeks. The morbidity rate, however, does not improve with increasing gestational age at PPROM.

Approximately $20 \%$ of women delivered within $48 \mathrm{~h}$ after ROM. Latency seems related to gestational age at ROM, with early GA at ROM being related to a longer latency.

A previous study from Farooqi et al. reports a mean latency period varying from 12 to 72 days. ${ }^{10}$ We found a latency period of 25 days. The effect of latency on perinatal outcome is not entirely clear and the effects of a prolonged latency period do not seem to be consistent across gestational ages. ${ }^{23}$ In our study, latency did not lead to an improvement in perinatal survival. This may be explained by the fact that although the latency period in the group with the earliest PPROM appeared to be the longest, many of these fetuses could not benefit from this latency as 70\% were born before 27 weeks and 59\% even before 24 weeks. The earlier the GA at PPROM, the higher the perinatal mortality rate (71\% in subgroup PPROM $13-20$ weeks versus $27 \%$ in subgroup $24-27$ weeks).

A recently published study from France by Azria et al. ${ }^{24}$, on PPROM between 15 and 25 weeks, focused on pregnancies which are terminated after early PPROM, instead of only pregnancies that have been continued. The authors hypothezised that perinatal outcomes are better in settings where a low risk group is selected and TOP is frequently performed. The incidence of TOP is much higher in the French study (50\%), compared to the incidence of $2 \%$ in our study. In the Netherlands we seem to be more conservative in many pregnancy-related problems. The result of this French study is that the neonatal major morbidity and mortality were not lower in the center with higher rates of TOP, which is the opposite of what the authors expected. In our data, however, perinatal survival and major neonatal morbidity was much better in the conservatively managed group than in the French study. Nevertheless, the authors of the French study do find the perinatal risks after PPROM very high.

In our large retrospective study on women with PPROM before 27 weeks, we were able to study over 300 women. Since this was a retrospective study, it has its limitations. Because of the low incidence of early PPROM we decided to collect data 
over the period 1994-2009, which in itself may have influenced the outcome due to the improvement in neonatal care. We were unable, however, to demonstrate an improvement in perinatal mortality or morbidity over these years.

Referral bias probably explains the rather unfavorable outcome of iatrogenic PPROM in $45 \%$ of pregnancies in our study. This in contrast to a study by Borgida et al., who reported a perinatal survival rate of $91 \%$ after iatrogenic PPROM and $9 \%$ after spontaneous PPROM. ${ }^{25}$ We expect that this difference can, at least partly, be explained by the difference between the definition of PPROM between Borgida's study and our study. Borgida et al. considered both women with persistent leak of fluid, and women with a normal amount of amniotic fluid on ultrasonic examination as having ruptured membranes. In our study, women with transient loss of amniotic fluid after an invasive procedure were probably not referred to these high care centers and could thus not be included. The mean latency period between iatrogenic PPROM and delivery was 65 days in our study and 124 days in Borgida's study.

Due to the retrospective character of our study, some data were missing. Still, we were able to collect data on perinatal death in over $99 \%$ of women. Pulmonary hypoplasia was a difficult item to report. Since the majority of parents declined autopsy postpartum, we decided to define this item as respiratory failure not attributable to other causes and impossibility of postpartum ventilation.

We were able to construct a prediction model based on four antepartum parameters; early GA at PPROM, short interval between PPROM and delivery, positive vaginal culture (any bacteria) and no use of antibiotics during admission. The AUC and the H-L goodness-to-fit statistics suggest that the model seems reliable, but this prediction model is based on retrospective data collection and has to be externally validated.

The results of this study can be helpful in future counseling of women with early PPROM and help parents in their decision on whether or not to terminate pregnancy after early PPROM. However, the factor 'interval between PPROM and delivery' cannot possibly be predicted when PPROM occurs.

Based on the results from the prediction model, we advise giving prophylactic antibiotics to all women with early PPROM and treating any bacteria in the vaginal culture, since both might contribute to better perinatal outcome. In our study, the use of prophylactic antibiotics in case of PPROM differed between the three perinatal care centers. Previous literature has shown that the use of antibiotics (erythromycin or a combination of ampicillin and erythromycin followed by amoxicillin and erythromycin) in women with PPROM might lead to a reduction in neonatal morbidity. ${ }^{26,27}$

In conclusion, in cases of PPROM before 27 weeks' gestation, the risk of perinatal death in the total group is $49 \%$. Looking at the outcome per age category, there seems to be a logical improvement in perinatal survival with increasing gestational age. There seems to be a high risk of serious morbidity in the neonate and only $30 \%$ survive without major complications. 
Antepartum variables seem to be useful in the prediction of the individualized risk of neonatal mortality and morbidity, which in itself are important for objective counseling of women with early PPROM. 


\section{References}

1. Nederlandse Vereniging van Obstetrie en Gynaecologie [Rupture of the membranes before onset of labour]. [Online link: http://nvog-documenten.nl/index.php?pagina=/richtlijn/pagina.php\&fSelectTG_ 62 =75\&fSelectedSub=62\&fSelectedParent $=75$, accessed March 9th 2011.

2. Ernest JM. Neonatal consequences of preterm PPROM. Clin Obstet Gynecol 1998;41:827-31.

3. Tabor A, Philip J, Madsen M, Bang J, Obel EB, Nørgaard-Pedersen B. Randomised controlled trial of genetic amniocentesis in 4606 low-risk women. Lancet 1986;1:1287-93.

4. Harger JH, Hsing AW, Tuomala RE, Gibbs RS, Mead PB, Eschenbach DA, Knox GE, Polk BF. Risk factors for preterm premature rupture of fetal membranes: a multicenter case-control study. Am J Obstet Gynecol 1990;163:130-7.

5. lams JD, Goldenberg RL, Meis PJ, Mercer BM, Moawad A, Das A, Thom E, McNellis D, Copper RL, Johnson F, Roberts JM. The length of the cervix and the risk of spontaneous premature delivery. National Institute of Child Health and Human Development Maternal Fetal Medicine Unit Network. $N$ Engl J Med 1996;334:567-72.

6. American College of Obstetricians and Gynecologists Committee on Practice Bulletins-Obstetrics, Society for Maternal-Fetal Medicine, ACOG Joint Editorial Committee. ACOG Practice Bulletin \#56: Multiple gestation: complicated twin, triplet, and high-order multifetal pregnancy. Obstet Gynecol 2004;104:869.

7. Manuck TA, Eller AG, Esplin MS, Stoddard GJ, Varner MW, Silver RM. Outcomes of expectantly managed preterm premature rupture of membranes occurring before 24 weeks of gestation. Obstet Gynecol 2009;114:29-37.

8. Tews G, Shebl O, Ebner T, Sommergruber M, Jesacher K. Premature rupture of membranes with oligoor anhydramnios before 24 weeks of gestation and the chances of fetal survival. Wien Klin Wochenschr 2004;116:692-4.

9. Dewan $\mathrm{H}$, Morris JM. A systematic review of pregnancy outcome following preterm premature rupture of membranes at a previable gestational age. Aust N Z J Obstet Gynaecol 2001;41:389-94.

10. Farooqi A, Holmgren PA, Engberg S, Serenius F. Survival and 2-year outcome with expectant management of second-trimester rupture of membranes. Obstet Gynecol 1998;92:895-901.

11. Botet F, Cararach V, Sentis J. Premature rupture of membranes in early pregnancy. Neonatal prognosis. J Perinat Med 1994;22:45-52.

12. Klein JM. Neonatal morbidity and mortality secondary to premature rupture of membranes. Obstet Gynecol Clin North Am 1992;19:265-80.

13. Body G, Forveille F, Lemseffer J, Kone M, Pierre F, Lansac J, Soutoul JH, Berger C. Spontaneous rupture of the membranes before 28 weeks of amenorrhea. Obstetrical and perinatal outcome. Apropos of 28 cases. J Gynecol Obstet Biol Reprod (Paris) 1991;20:93-100. [Article in French]

14. Major CA, Kitzmiller JL. Perinatal survival with expectant management of midtrimester rupture of membranes. Am J Obstet Gynecol 1990;163:838-44.

15. Beydoun SN, Yasin SY. Premature rupture of the membranes before 28 weeks: conservative management. Am J Obstet Gynecol 1986;155:471-9.

16. Rudolph AJ, Smith CA. Idiopathic respiratory distress syndrome of the newborn. J Pediatr 1960;57: 905-21.

17. Rennie JM Roberton NRC. Textbook of Neonatology. 3rd ed. Edinburgh: Churchill Livingstone; 1999: 481.

18. Halliday HL, Ehrenkranz RA, Doyle LW. Early (< 8 days) postnatal corticosteroids for preventing chronic lung disease in preterm infant. Cochrane Library 2010;1:CD001146.

19. Volpe, JJ. Intracranial hemorrhage: Germinal matrix-intraventricular hemorrhage. In: Neurology of the Newborn, 4th ed. Philadelphia: WB Saunders 2001:428.

20. Bell MJ, Ternberg JL, Feigin RD, Keating JP, Marshall R, Barton L, Brotherton T. Neonatal necrotizing enterocolitis. Therapeutic decisions based upon clinical staging. Ann Surg 1978;187:1.

21. Goldstein B, Giroir B, Randolph A; International Consensus Conference on Pediatric Sepsis. International pediatric sepsis consensus conference: definitions for sepsis and organ dysfunction in pediatrics. Pediatr Crit Care Med 2005;6:2-8. 
22. Steyerberg EW, Vickers AJ, Cook NR, Gerds T, Gonen M, Obuchowski N, Pencina MJ, Kattan MW. Assessing the performance of prediction models: a framework for traditional and novel measures. Epidemiology 2010;21:128-38.

23. Blumenfeld YJ, Lee HC, Gould JB, Langen ES, Jafari A, El-Sayed YY. The effect of preterm premature rupture of membranes on neonatal mortality rates. Obstet Gynecol 2010;116:1381-6.

24. Azria E, Anselem O, Schmitz T, Tsatsaris V, Senat MV, Geoffinet F. Comparison of perinatal outcome after pre-viable preterm prelabour rupture of the membranes in two centres with different rates of termination of pregnancy. BJOG 2012;119:449-57.

25. Borgida AF, Mills AA, Feldman DM, Rodis JF, Egan JF. Outcome of pregnancies complicated by ruptured membranes after genetic amniocentesis. Am J Obstet Gynecol 2000;183:937-9.

26. Mercer BM, Miodovnik M, Thurnau GR et al. Antibiotic therapy for reduction of infant morbidity after preterm premature rupture of the membranes. A randomized controlled trial. National Institute of Child Health and Human Development Maternal-Fetal Medicine Units Network. JAMA 1997;278:989-95.

27. Kenyon S, Boulvain M, Neilson J. Antibiotics for preterm premature rupture of membranes. Cochrane Database Syst Rev 2001:CD001058. 


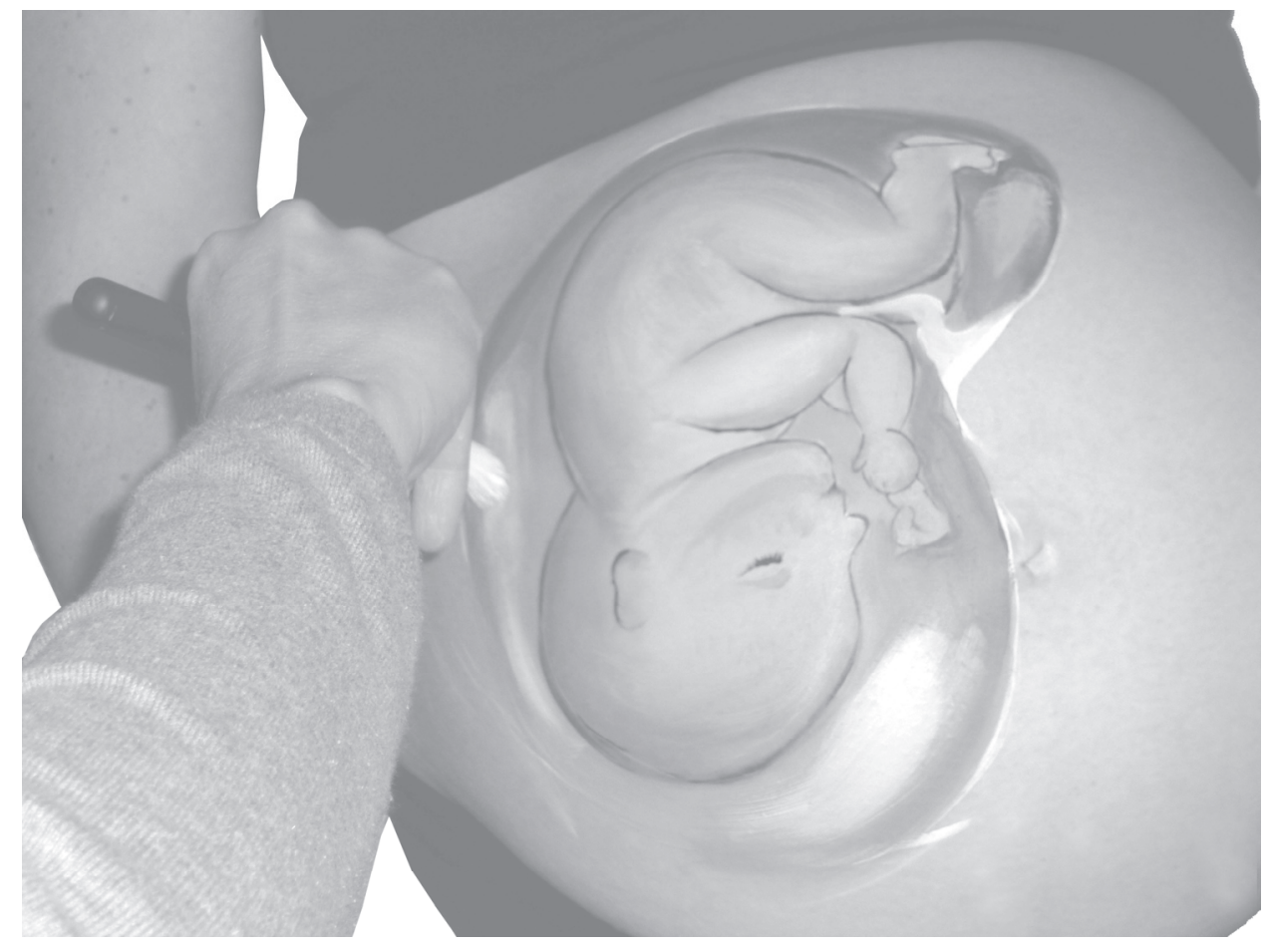




\section{Chapter 4}

Perinatal outcome in women with preterm prelabor rupture of membranes between 26 and 34 weeks' gestation

JL van der Heyden ACJ Ravelli ASP van Teeffelen DP van der Ham JM Schaaf C Willekes E Pajkrt BWJ Mol JG Nijhuis Submitted 


\section{Abstract}

\section{Objective}

To assess the impact of gestational age at rupture of membranes (ROM) and interval between ROM and delivery (latency) on one end and perinatal outcome on the other hand, in women with preterm prelabor rupture of membranes (PPROM) between 26 and 34 weeks' gestation.

\section{Study design}

We obtained data on women with PPROM in a singleton pregnancy who delivered $>24$ hours after PPROM from the Netherlands Perinatal Registry from 1999 to 2007. Severe poor neonatal outcome was defined as a composite of perinatal mortality, intraventricular hemorrhage, bronchopulmonary dysplasia, necrotizing enterocolitis, respiratory distress syndrome, neonatal sepsis and 5 minute Apgar score $<7$. We associated gestational age at ROM, interval between ROM and delivery and gestational age at delivery.

\section{Results}

From a population of 1,445,305 pregnancies delivering after 22 weeks, 5,723 $(0.4 \%)$ had suffered PPROM over 24 hours between 26 and 34 weeks. The mortality rate was $2.5 \%$, whereas $24 \%$ suffered composite neonatal morbidity. When PPROM occurred between 26 and 27 weeks, 30 and 31 weeks and between 33 and 34 weeks, perinatal mortality rates were $9.1 \%, 3.3 \%$ and $0.7 \%$, respectively. Composite neonatal morbidity rates at these gestational ages at PPROM were $54 \%$, $31 \%$ and $13 \%$, respectively. The earlier the GA at PPROM and the earlier the GA at delivery, the higher the perinatal mortality rate.

\section{Conclusions}

In pregnancies complicated by PPROM between 26 and 34 weeks' gestation, early gestational age at PPROM was related to adverse perinatal outcome and increased latency was associated with a decrease in composite neonatal morbidity and neonatal sepsis. 


\section{Introduction}

Preterm prelabor rupture of membranes (PPROM) before 37 weeks' gestation occurs in approximately $3 \%$ of all pregnancies. ${ }^{1}$ The perinatal mortality rate is $3 \%$ for PPROM between 28 and 31 weeks and $0.41 \%$ for PPROM between 32 and 33 weeks. ${ }^{2}$ Apart from the risk of perinatal mortality, a substantial proportion of neonates suffer serious morbidity, such as sepsis, respiratory distress syndrome (RDS), necrotizing enterocolitis (NEC), intraventricular hemorrhage (IVH) and bronchopulmonary dysplasia (BPD).

The risk of neonatal mortality and serious neonatal morbidity decreases with increasing gestational age at PPROM. The effect of latency, namely a longer time interval between rupture of membranes (ROM) and delivery, on perinatal outcome is still unclear. ${ }^{3-6}$ Manuck et al. studied 306 pregnancies with PPROM between 22 and 34 weeks and found that latency did not appear to affect perinatal outcome. In this study, the median gestational age (GA) at PPROM was 29.4 weeks and the median GA at delivery was 31.4 weeks. ${ }^{3}$ However, Melamed et al. found that latency more than 7 days was associated with increased adverse neonatal outcome in a population with PPROM between 28 and 34 weeks' gestation. The risk of neonatal infectious morbidity (after exclusion of clinical chorioamnionitis) was not related to the duration of the latency period. ${ }^{4}$

In contrast to these results, Nayot et al. found that PPROM before 32 weeks' gestation with a latency of less than 72 hours was associated with a two-fold higher incidence of severe neonatal morbidity compared to latency $>72$ hours. Up to a GA of 34 weeks, a beneficial effect on moderate morbidity was shown if latency was longer than 72 hours. After 34 weeks, no clear benefit of longer latency time could be demonstrated, whereas a significant increase in the incidence of NEC, a trend in increased severe morbidity and longer NICU length of stay were observed after longer latency. ${ }^{5}$

Aziz et al. stated that earlier GA at time of PPROM was associated with longer latency, which was not associated with increased risk of neonatal sepsis or chorioamnionitis. $^{6}$

Pasquier et al. reported that a short latency period was associated with higher infant mortality in cases with PPROM before 30 weeks' gestation, whereas after 30 weeks a short latency period was associated with a lower mortality rate. ${ }^{7}$

Theoretically, a longer latency after ROM might decrease the risk of problems associated with prematurity. On the other hand, the risk of intra-uterine infection or chorioamnionitis and neonatal sepsis may increase with longer duration of ROM. Ramsey et al. showed a higher neonatal morbidity rate in pregnancies complicated by chorioamnionitis. $^{8}$

Consequently, counseling of patients with PPROM is difficult because of varying results of studies on this subject. Therefore, and because of the fact that we have access to a large database (the Netherlands Perinatal Registry (PRN)) containing valuable information, we decided to study perinatal outcome after PPROM between 26 
and 34 weeks' gestation. We specifically tried to assess the effect of latency after ROM on neonatal sepsis, composite morbidity and perinatal mortality rate.

A great advantage of the PRN database, is the linkage between the obstetric database (with information on pregnancies and deliveries) and the pediatric database (with information on neonatal problems and (re) admissions until 28 days after delivery).

\section{Methods}

Data for this study were obtained from the PRN from 1999 until 2007. The PRN database contains information on pregnancies, deliveries, newborns and (re)admissions of the mothers or the babies until 28 days after delivery (population-based). These data are collected by caregivers. Data are available from three independent registries: the midwifery registry (LVR1), the obstetric registry (LVR2) and the neonatology/pediatric registry (LNR). The midwifery and obstetric registries start at the booking visit and contain complete perinatal data from 22 weeks onwards. The neonatology registry contains data on hospital admissions of newborns. These databases are combined into one nationwide perinatal database via a validated linkage method. ${ }^{9}$ The PRN registry covers $96 \%$ of all births in the Netherlands. ${ }^{10}$ Outcome is registered in the LNR registry by $53 \%$ of the neonatologists $(100 \%$ in tertiary hospitals and $47 \%$ in non- tertiary hospitals). ${ }^{11}$ The PRN does not record long-term neonatal outcome.

Singleton pregnancies from $26^{+0}$ weeks until $33^{+6}$ weeks' gestation, with a duration of ROM for $>24$ hours were included. Multiple pregnancies and pregnancies with congenital abnormalities were excluded.

Because the PRN does not register rupture of membranes without contractions as first sign of (threatened) labor we decided to select women with at least 24 hours of ROM in order to minimize the inclusion of women with other reasons than preterm prelabor rupture of membranes as pregnancy complication. Furthermore, in order to be able to formulate an opinion or advice about the management in case of PPROM between 26 and 34 weeks' gestation, we were less interested in women who delivered soon after spontaneous ROM.

\section{Outcome measures}

Both perinatal mortality (antepartum and during the first 28 days after birth), as well as severe neonatal morbidity were studied. Severe morbidity was defined as a composite of perinatal mortality, RDS, IVH, BPD, NEC, neonatal sepsis and Apgar score < 7 after 5 minutes. These composite morbidity outcome measures were selected because prematurity is an important risk factor for these conditions with a risk of adverse long- 
term consequences in children. The composite morbidity outcome measures were defined by the attending pediatrician during admission and should have occurred in the same admission after birth or during a re-admission within the first 28 days of life. Perinatal mortality was defined as the number of fetal deaths (stillbirths) and neonatal deaths in the first twenty-eight days of life per 1,000 births.

\section{Multivariable regression analysis}

Multivariable regression analysis was performed to assess possible factors with predictive values for adverse perinatal outcome. The factors which were included in this model are: GA at PPROM, interval between ROM and delivery (latency) and GA at delivery. We have corrected for parity, ethnicity and maternal age ( $\geq 35$ years) and for the overall values we have corrected for parity, ethnicity, maternal age $\geq 35$ years, GA at delivery, interval between ROM and delivery and GA at PPROM.

Categories that were selected as reference values were: GA at delivery 40 to 42 weeks, interval between ROM and delivery $\geq 5$ weeks, GA at PPROM 33 to 34 weeks.

\section{Analysis}

Data were analyzed according to gestational age at PPROM and gestational age at delivery, as well as interval between PPROM and delivery. To analyze the outcome in respect of latency, gestational age at PPROM was shown per week and gestational age at delivery was assessed per 2 weeks. Data were analyzed using the SAS statistical software package version 9.2 (SAS Institute Inc., Cary, NC, USA) and presented as absolute numbers with percentage, mean with standard deviation, or odds ratio (OR) with $95 \%$ confidence interval $(\mathrm{Cl})$.

\section{Results}

Between 1999 and 2007, a total of 1,445,305 deliveries were registered. PPROM between 26 and 34 weeks' gestation occurred in 20,324 (1.4\%) patients with a singleton pregnancy. From this group, 5,723 patients $(28 \% ; 0.4 \%$ of total) had a duration of ROM of more than 24 hours (Figure 4.1).

Maternal baseline characteristics and neonatal outcomes are shown in Table 4.1. 


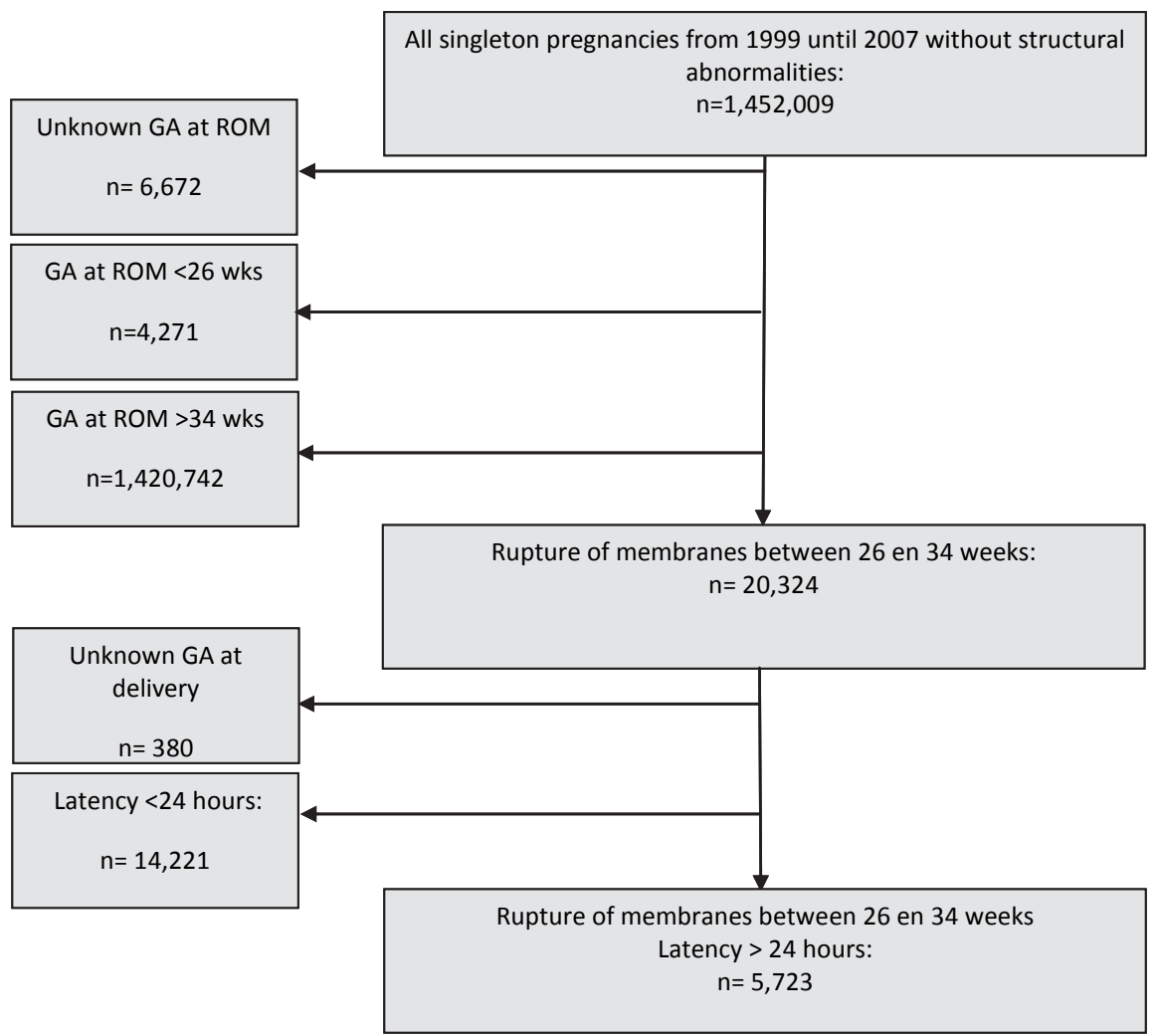

Figure 4.1 Flow chart.

Table 4.1 Baseline characteristics and neonatal outcomes.

\begin{tabular}{lc}
\hline Maternal characteristics & $\mathbf{N}=\mathbf{5 7 2 3}$ \\
\hline Maternal age (years) (mean [SD]) & $30.4[5.1]$ \\
Maternal age $\geq 35$ years & $1161(20 \%)$ \\
Nulliparous ( $(\%))$ & $3270(57 \%)$ \\
Ethnicity: European white (n (\%)) & $4761(83 \%)$ \\
Gestational age at PPROM (weeks) (mean [SD]) & $31.5[2.0]$ \\
Gestational age at delivery (weeks) (mean [SD]) & $33.2[2.9]$ \\
\hline Neonatal outcomes & $2153[666]$ \\
\hline Birthweight (grams) (mean [SD]) & $3299(58 \%)$ \\
Fetal gender: Male ( $\mathrm{n})(\%)$ & $144(2.5 \%)$ \\
Perinatal mortality & $1388(24 \%)$ \\
Perinatal mortality and composite neonatal morbidity & $792(14 \%)$ \\
Neonatal sepsis & \\
\hline
\end{tabular}


Overall perinatal mortality occurred in 144 out of 5,723 cases (2.5\%) (Table 4.2A). There were 68 cases of stillbirth (1.2\%), 55 babies died intrapartum or in the first seven days after birth (1.0\%) and 21 neonates $(0.4 \%)$ died between the $7^{\text {th }}$ and $28^{\text {th }}$ day after birth.

Table 4.2A Perinatal mortality by gestational age of ROM and delivery.

\begin{tabular}{|c|c|c|c|c|c|c|c|c|c|}
\hline \multirow{2}{*}{$\begin{array}{l}\text { GA at ROM in } \\
\text { weeks }\end{array}$} & \multicolumn{9}{|c|}{ GA at delivery in weeks } \\
\hline & $26-27^{+6}$ & $28-29^{+6}$ & $30-31^{+6}$ & $32-33^{+6}$ & $34-35^{+6}$ & $36-37^{+6}$ & $38-39^{+6}$ & $>40$ & Total \\
\hline \multirow[t]{2}{*}{$26-26^{+6}$} & $16 \%$ & $7.9 \%$ & $6.9 \%$ & $8.3 \%$ & $11 \%$ & $0 \%$ & $0 \%$ & $0 \%$ & $9.1 \%$ \\
\hline & $16 / 98$ & $3 / 38$ & $2 / 29$ & $1 / 12$ & $1 / 9$ & $0 / 4$ & $0 / 55$ & $0 / 9$ & $23 / 254$ \\
\hline \multirow[t]{2}{*}{$27-27^{+6}$} & $17 \%$ & $8.8 \%$ & $0 \%$ & $8.3 \%$ & $0 \%$ & $0 \%$ & $0 \%$ & $2.0 \%$ & $7.6 \%$ \\
\hline & $10 / 58$ & 9/102 & $0 / 23$ & $1 / 12$ & $0 / 7$ & $0 / 19$ & $0 / 6$ & $1 / 51$ & $21 / 278$ \\
\hline \multirow[t]{2}{*}{$28-28^{+6}$} & & $8.0 \%$ & $7.7 \%$ & $0 \%$ & $6.7 \%$ & $3.2 \%$ & $0 \%$ & $0 \%$ & $5.6 \%$ \\
\hline & & $11 / 137$ & $4 / 52$ & $0 / 20$ & $1 / 15$ & $1 / 31$ & $0 / 5$ & $0 / 45$ & $17 / 305$ \\
\hline \multirow[t]{2}{*}{$29-29^{+6}$} & & $5.2 \%$ & $3.9 \%$ & $2.9 \%$ & $4.4 \%$ & $0 \%$ & $4.0 \%$ & $0 \%$ & $3.7 \%$ \\
\hline & & $4 / 77$ & $7 / 179$ & $2 / 70$ & $1 / 23$ & $0 / 25$ & $1 / 25$ & $0 / 7$ & $15 / 406$ \\
\hline \multirow[t]{2}{*}{$30-30^{+6}$} & & & $4.8 \%$ & $3.0 \%$ & $1.9 \%$ & $0 \%$ & $0 \%$ & $0 \%$ & $3.3 \%$ \\
\hline & & & $15 / 312$ & $4 / 132$ & $1 / 53$ & $0 / 31$ & $0 / 71$ & $0 / 5$ & $20 / 604$ \\
\hline \multirow[t]{2}{*}{$31-31^{+6}$} & & & $3.2 \%$ & $1.8 \%$ & $1.1 \%$ & $2.3 \%$ & $0 \%$ & $1.6 \%$ & $2.0 \%$ \\
\hline & & & $6 / 189$ & $7 / 387$ & $1 / 95$ & $1 / 44$ & $0 / 31$ & $1 / 62$ & $16 / 808$ \\
\hline \multirow[t]{2}{*}{$32-32^{+6}$} & & & & $1.8 \%$ & $0.9 \%$ & $0 \%$ & $0 \%$ & $1.6 \%$ & $1.5 \%$ \\
\hline & & & & $16 / 916$ & $2 / 216$ & 0/97 & $0 / 12$ & $1 / 62$ & $19 / 1303$ \\
\hline \multirow[t]{2}{*}{$33-33^{+6}$} & & & & $1.3 \%$ & $0.4 \%$ & $0 \%$ & $1.6 \%$ & $0 \%$ & $0.7 \%$ \\
\hline & & & & $9 / 682$ & $3 / 847$ & $0 / 148$ & $1 / 63$ & $0 / 25$ & $13 / 1765$ \\
\hline \multirow[t]{2}{*}{ Total } & $17 \%$ & $7.6 \%$ & $4.3 \%$ & $1.8 \%$ & $0.8 \%$ & $0.5 \%$ & $0.7 \%$ & $1.1 \%$ & $2.5 \%$ \\
\hline & $26 / 156$ & $27 / 354$ & $34 / 784$ & $40 / 2231$ & $10 / 1265$ & 2/399 & $2 / 268$ & $3 / 266$ & $144 / 5723$ \\
\hline
\end{tabular}

$\mathrm{GA}=$ gestational age; ROM=rupture of membranes. Perinatal mortality: antepartum death, durante partu death and mortality up to 28 days after birth.

One or more items of composite morbidity were present in 1,388 neonates (24\%). In multiple cases neonates suffered from more than 1 morbidity. From the total group of 5,723 singleton pregnancies, there were 792 neonates (14\%) who suffered from sepsis. 4,335 Neonates (76\%) survived without severe morbidity.

Advanced gestational age at delivery increased the survival rate until a gestational age of 38 weeks (Table 4.2A). For babies born between 26 and 28 weeks, the survival rate was $83 \%$, whereas it was $99 \%$ for babies born between 34 and 36 weeks. Above 36 weeks, the survival rate was $99 \%$ as well. This improvement was significant for a GA at delivery between 26 and 34 weeks, whereas after 34 weeks' gestation these rates are not statistically significant.

Composite morbidity was present in 54\% of cases with PPROM between 26 and 27 weeks and in 13\% of neonates who were born after PPROM between 33 and 34 weeks' gestation (Table 4.3A). The decrease in neonatal morbidity rate was statistically significant.

Sepsis occurred in 683 of 3,525 (19\%) of neonates born between 26 and 34 weeks and in 109 of 2,198 (5.0\%) neonates born after 34 weeks (Table 4.4A). 
Overall, earlier gestational age at PPROM seems to be related to adverse perinatal outcome.

Table 4.3A Severe composite morbidity* by gestational age of ROM and delivery.

\begin{tabular}{|c|c|c|c|c|c|c|c|c|c|}
\hline \multirow{2}{*}{$\begin{array}{l}\text { GA at } R O M \\
\text { in weeks }\end{array}$} & \multicolumn{9}{|c|}{ GA at delivery in weeks } \\
\hline & $26-27^{+6}$ & $28-29^{+6}$ & $30-31^{+6}$ & $32-33^{+6}$ & $34-35^{+6}$ & $36-37^{+6}$ & $38-39^{+6}$ & $>40$ & Total \\
\hline \multirow[t]{2}{*}{$26-26^{+6}$} & $86 \%$ & $76 \%$ & $65 \%$ & $25 \%$ & $22 \%$ & $25 \%$ & $0 \%$ & $0 \%$ & $54 \%$ \\
\hline & $84 / 98$ & $29 / 38$ & $19 / 29$ & $3 / 12$ & $2 / 9$ & $1 / 4$ & $0 / 55$ & $0 / 9$ & $138 / 254$ \\
\hline \multirow[t]{2}{*}{$27-27^{+6}$} & $86 \%$ & $76 \%$ & $61 \%$ & $25 \%$ & $0 \%$ & $5.3 \%$ & $0 \%$ & $2.0 \%$ & $53 \%$ \\
\hline & $50 / 58$ & $78 / 102$ & $14 / 23$ & $3 / 12$ & $0 / 7$ & $1 / 19$ & $0 / 6$ & $1 / 51$ & $147 / 278$ \\
\hline \multirow[t]{2}{*}{$28-28^{+6}$} & & $68 \%$ & $52 \%$ & $40 \%$ & $6.7 \%$ & $6.5 \%$ & $20 \%$ & $2.2 \%$ & $44 \%$ \\
\hline & & $93 / 137$ & $27 / 52$ & $8 / 20$ & $1 / 15$ & $2 / 31$ & $1 / 5$ & $1 / 45$ & $133 / 305$ \\
\hline \multirow[t]{2}{*}{$29-29^{+6}$} & & $55 \%$ & $48 \%$ & $26 \%$ & $8.7 \%$ & $4 \%$ & $8.0 \%$ & $0 \%$ & $37 \%$ \\
\hline & & $42 / 77$ & $86 / 179$ & $18 / 70$ & $2 / 23$ & $1 / 25$ & $2 / 25$ & $0 / 7$ & $151 / 406$ \\
\hline \multirow[t]{2}{*}{$30-30^{+6}$} & & & $45 \%$ & $30 \%$ & $15 \%$ & $0 \%$ & $0 \%$ & $0 \%$ & $31 \%$ \\
\hline & & & $141 / 312$ & $39 / 132$ & $8 / 53$ & $0 / 31$ & $0 / 71$ & $0 / 5$ & $188 / 604$ \\
\hline \multirow[t]{2}{*}{$31-31^{+6}$} & & & $37 \%$ & $23 \%$ & $14 \%$ & $18 \%$ & $0 \%$ & $1.6 \%$ & $22 \%$ \\
\hline & & & $70 / 189$ & $89 / 387$ & $13 / 95$ & $8 / 44$ & $0 / 31$ & $1 / 62$ & $181 / 808$ \\
\hline \multirow[t]{2}{*}{$32-32^{+6}$} & & & & $19 \%$ & $15 \%$ & $4.1 \%$ & $8.3 \%$ & $1.6 \%$ & $17 \%$ \\
\hline & & & & $177 / 916$ & $32 / 216$ & $4 / 97$ & $1 / 12$ & $1 / 62$ & $215 / 1303$ \\
\hline \multirow[t]{2}{*}{$33-33^{+6}$} & & & & $18 \%$ & $13 \%$ & $4.1 \%$ & $1.6 \%$ & $4 \%$ & $13 \%$ \\
\hline & & & & $120 / 682$ & $107 / 847$ & $6 / 148$ & $1 / 63$ & $1 / 25$ & $235 / 1765$ \\
\hline \multirow[t]{2}{*}{ Total } & $86 \%$ & $68 \%$ & $45 \%$ & $20 \%$ & $13 \%$ & $5.8 \%$ & $1.9 \%$ & $1.9 \%$ & $24 \%$ \\
\hline & $134 / 156$ & $242 / 354$ & $357 / 784$ & $457 / 2231$ & $165 / 1265$ & 23/399 & $5 / 268$ & $5 / 266$ & $1388 / 5723$ \\
\hline
\end{tabular}

* Severe composite morbidity =Perinatal mortality and composite of RDS, IVH, BPD, NEC, neonatal sepsis and Apgar score 5 minutes $<7$; GA=Gestational age; ROM: rupture of membranes.

Table 4.4A Neonatal sepsis by gestational age of delivery and gestational age at PPROM.

\begin{tabular}{|c|c|c|c|c|c|c|c|c|c|}
\hline \multirow{2}{*}{$\begin{array}{l}\text { GA at ROM } \\
\text { in weeks }\end{array}$} & \multicolumn{9}{|c|}{ GA at delivery in weeks } \\
\hline & $26-27^{+6}$ & $28-29^{+6}$ & $30-31^{+6}$ & $32-33^{+6}$ & $34-35^{+6}$ & $36-37^{+6}$ & $38-39^{+6}$ & $>40$ & Total \\
\hline \multirow[t]{2}{*}{$26-26^{+6}$} & $49 \%$ & $45 \%$ & $31 \%$ & $8.3 \%$ & $11 \%$ & $0 \%$ & $0 \%$ & $0 \%$ & $30 \%$ \\
\hline & $48 / 98$ & $17 / 38$ & $9 / 29$ & $1 / 12$ & $1 / 9$ & $0 / 4$ & $0 / 55$ & $0 / 9$ & $76 / 254$ \\
\hline \multirow[t]{2}{*}{$27-27^{+6}$} & $47 \%$ & $45 \%$ & $35 \%$ & $8.3 \%$ & $0 \%$ & $5.3 \%$ & $0 \%$ & $0 \%$ & $30 \%$ \\
\hline & $27 / 58$ & $46 / 102$ & $8 / 23$ & $1 / 12$ & $0 / 7$ & $1 / 19$ & $0 / 6$ & $0 / 51$ & $83 / 278$ \\
\hline \multirow[t]{2}{*}{$28-28^{+6}$} & & $40 \%$ & $29 \%$ & $15 \%$ & $0 \%$ & $0 \%$ & $0 \%$ & $2.2 \%$ & $24 \%$ \\
\hline & & $55 / 137$ & $15 / 52$ & $3 / 20$ & $0 / 15$ & $0 / 31$ & $0 / 5$ & $1 / 45$ & $74 / 305$ \\
\hline \multirow{2}{*}{$29-29^{+6}$} & & $27 \%$ & $32 \%$ & $14 \%$ & $0 \%$ & $0 \%$ & $0 \%$ & $0 \%$ & $22 \%$ \\
\hline & & $21 / 77$ & $58 / 179$ & $10 / 70$ & $0 / 23$ & $0 / 25$ & $0 / 25$ & $0 / 7$ & $89 / 406$ \\
\hline \multirow[t]{2}{*}{$30-30^{+6}$} & & & $29 \%$ & $13 \%$ & $7.6 \%$ & $0 \%$ & $0 \%$ & $0 \%$ & $18 \%$ \\
\hline & & & $89 / 312$ & $17 / 132$ & $4 / 53$ & $0 / 31$ & $0 / 71$ & $0 / 5$ & $110 / 604$ \\
\hline \multirow[t]{2}{*}{$31-31^{+6}$} & & & $16 \%$ & $15 \%$ & $6.3 \%$ & $6.8 \%$ & $0 \%$ & $0 \%$ & $12 \%$ \\
\hline & & & $30 / 189$ & $57 / 387$ & $6 / 95$ & $3 / 44$ & $0 / 31$ & $0 / 62$ & $96 / 808$ \\
\hline \multirow[t]{2}{*}{$32-32^{+6}$} & & & & $11 \%$ & $9.3 \%$ & $1.0 \%$ & $8.3 \%$ & $0 \%$ & $9.4 \%$ \\
\hline & & & & $101 / 916$ & $20 / 216$ & $1 / 97$ & $1 / 12$ & $0 / 62$ & $123 / 1303$ \\
\hline \multirow[t]{2}{*}{$33-33^{+6}$} & & & & $10 \%$ & $7.8 \%$ & $2.7 \%$ & $0 \%$ & $4.0 \%$ & $8.0 \%$ \\
\hline & & & & $70 / 682$ & $66 / 847$ & $4 / 148$ & $0 / 63$ & $1 / 25$ & $141 / 1765$ \\
\hline \multirow[t]{2}{*}{ Total } & $48 \%$ & $39 \%$ & $27 \%$ & $12 \%$ & $7.7 \%$ & $3.4 \%$ & $0.4 \%$ & $0.8 \%$ & $14 \%$ \\
\hline & $75 / 156$ & $139 / 354$ & $209 / 784$ & $260 / 2231$ & $97 / 1265$ & $9 / 399$ & $1 / 268$ & $2 / 266$ & $792 / 5723$ \\
\hline
\end{tabular}

$\mathrm{GA}=$ gestational age; $\mathrm{ROM}=$ rupture of membranes 
From all 5,723 pregnancies with PPROM between 26 and 34 weeks, 933 women delivered after 36 weeks (16\%). From 254 women who suffered PPROM between 26 and 27 weeks, 68 patients delivered after 36 weeks (27\%). For women suffering PPROM at $27-28,28-29,29-30,30-31,31-32,32-33,33-34$ weeks, this was $27 \%, 27 \%, 14 \%, 18 \%$, $17 \%, 13 \%$ and $13 \%$, respectively.

Composite neonatal morbidity improved with longer latency (Figure 4.2).

For PPROM between 26 and 27 weeks, the incidence of composite morbidity decreased from $87 \%$ for a latency duration $<1$ week to $13 \%$ for a latency duration $\geq 5$ weeks. For PPROM between 30 and 31 weeks, the incidence of composite morbidity decreased from $49 \%$ for a latency duration $<1$ week to $1 \%$ for a latency duration $\geq 5$ weeks. (Figure 4.2). In the subcategory GA at PPROM 33 to 34 weeks, the effect of latency was the least obvious, since the composite morbidity rate decreased from $16 \%$ for a latency duration $<1$ week to $3 \%$ for a latency duration of $\geq 5$ weeks.

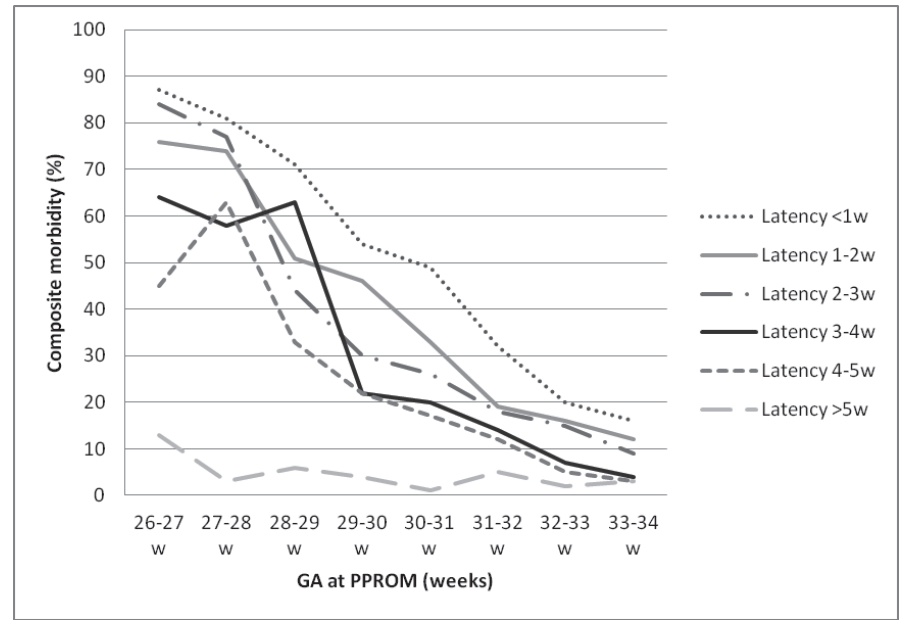

Figure 4.2 Effect of GA at PPROM and latency on composite morbidity.

Subsequently, multivariable regression analysis was performed. From the preselected candidate predictor variables, GA at PPROM, interval between ROM and delivery and GA at delivery were selected in the multivariable logistic regression analysis.

GA at delivery between 26 and 32 weeks' gestation significantly increased the perinatal mortality rate, compared to GA at delivery between 40 and 42 weeks' gestation.

Interval between ROM and delivery of less than one week significantly increased the perinatal mortality compared to a latency period $\geq 5$ weeks (OR $2.1 ; 95 \% \mathrm{Cl} 1.1-4.0$ ) and 
early GA at PPROM (26 to 33 weeks) significantly increased the perinatal mortality rate compared to GA at PPROM 33 to 34 weeks (Table 4.2B).

Table 4.2B Multivariable regression analysis, outcome: Perinatal mortality.

\begin{tabular}{|c|c|c|c|c|c|c|}
\hline & \multicolumn{2}{|c|}{ Crude } & \multicolumn{2}{|c|}{ Adjusted*1 } & \multicolumn{2}{|c|}{ Overall*2 } \\
\hline & OR & $95 \% \mathrm{Cl}$ & OR & $95 \% \mathrm{Cl}$ & OR & $95 \% \mathrm{Cl}$ \\
\hline \multicolumn{7}{|c|}{ GA at delivery } \\
\hline $26-28$ wks & 17.5 & $5.2-59.0$ & 16.9 & $5.0-57.0$ & 14.2 & $1.4-142$ \\
\hline $28-30$ wks & 7.2 & $2.2-24.1$ & 7.0 & $2.1-23.5$ & 8.0 & $1.0-62.9$ \\
\hline $30-32$ wks & 4.0 & $1.2-13.0$ & 3.8 & $1.2-12.6$ & 5.9 & $1.0-35.2$ \\
\hline $32-34$ wks & 1.6 & $0.5-5.2$ & 1.6 & $0.5-5.2$ & 4.6 & $1.0-22.1$ \\
\hline $34-36$ wks & 0.7 & $0.2-2.6$ & 0.7 & $0.2-2.5$ & 2.6 & $0.6-11.8$ \\
\hline $36-38$ wks & 0.4 & $0.1-2.7$ & 0.4 & $0.1-2.7$ & 0.7 & $0.1-4.6$ \\
\hline $38-40$ wks & 0.7 & $0.1-4.0$ & 0.7 & $0.1-4.0$ & 0.6 & $0.1-4.0$ \\
\hline $40-42$ wks & Ref & & Ref & & Ref & \\
\hline \multicolumn{7}{|c|}{ Interval between ROM and delivery } \\
\hline$<1 \mathrm{wk}$ & 2.1 & $1.1-4.0$ & 2.1 & 1.1-3.9 & 0.7 & $0.2-3.3$ \\
\hline $1-<2$ wks & 1.1 & $0.5-2.4$ & 1.1 & $0.5-2.3$ & 0.4 & $0.1-1.6$ \\
\hline $2-<3$ wks & 0.9 & $0.3-2.5$ & 0.9 & $0.3-2.3$ & 0.3 & $0.1-1.3$ \\
\hline $3-<4$ wks & 0.7 & $0.2-2.6$ & 0.7 & $0.2-2.6$ & 0.3 & $0.1-1.5$ \\
\hline $4-<5$ wks & 1.2 & $0.4-3.4$ & 1.2 & $0.4-3.4$ & 0.9 & $0.2-3.1$ \\
\hline$\geq 5$ wks & Ref & & Ref & & Ref & \\
\hline \multicolumn{7}{|l|}{ GA at PPROM } \\
\hline $26-27$ wks & 13.4 & $6.7-26.9$ & 13.3 & $6.6-26.7$ & 5.8 & $1.2-26.9$ \\
\hline $27-28$ wks & 11.0 & $5.4-22.3$ & 10.8 & $5.3-21.9$ & 5.2 & $1.3-21.3$ \\
\hline $28-29$ wks & 8.0 & $3.8-16.6$ & 7.8 & $3.7-16.3$ & 4.9 & $1.4-17.9$ \\
\hline $29-30$ wks & 5.2 & $2.4-11.0$ & 5.1 & $2.4-10.8$ & 3.5 & $1.1-10.7$ \\
\hline $30-31$ wks & 4.6 & 2.3-9.3 & 4.5 & $2.2-9.2$ & 3.6 & $1.4-9.8$ \\
\hline $31-32$ wks & 2.7 & $1.3-5.7$ & 2.7 & 1.3-5.6 & 2.3 & $1.0-5.4$ \\
\hline $32-33$ wks & 2.0 & $1.0-4.1$ & 2.0 & $1.0-4.0$ & 1.7 & $0.8-3.7$ \\
\hline 33-34 wks & Ref & & Ref & & Ref & \\
\hline Adjusted *1: & \multicolumn{6}{|c|}{ Adjusted for maternal age, parity and ethnicity } \\
\hline Overall*2: & \multicolumn{6}{|c|}{$\begin{array}{l}\text { Adjusted for maternal age, parity and ethnicity and for GA at delivery, interval between } \\
\text { ROM and delivery and GA at PPROM }\end{array}$} \\
\hline
\end{tabular}

In the overall model (adjusted for parity, maternal age, ethnicity, GA at delivery, interval between PPROM and delivery and GA at PPROM), GA at delivery between 26 and 34 weeks significantly increased the risk of perinatal mortality compared to GA at delivery 40-42 weeks.

Latency did not significantly affect the risk of perinatal mortality. GA at PPROM increased the perinatal mortality rate until a gestational age of 32 weeks (compared to GA at PPROM 33 to 34 weeks).

The risk of composite morbidity was significantly increased at a GA at delivery between 26 and 38 weeks (compared to GA at delivery 40 to 42 weeks). The overall model showed the same result. Composite morbidity was increased at every interval between ROM and delivery, with the odds ratio increasing as latency duration decreased (latency duration <1 week: OR 7.9 (95\% Cl 5.6-11.2) and latency duration 4-5 weeks: OR 2.6 (95\% Cl 1.6-4.3). Again, this finding was the same as in the overall 
model. Also GA at PPROM significantly increased the risk of composite morbidity for all subcategories ( 26 to 27 weeks, 27 to 28 weeks, 28 to 29 weeks, 29 to 30 weeks, 31 to 32 weeks and 32 to 33 weeks), compared to GA at PPROM 33 to 34 weeks, both in the crude as the adjusted model as in the overall model (Table 4.3B).

Neonatal sepsis occurred significantly more often in pregnancies with a GA at delivery between 26 and 36 weeks (compared to GA at delivery 40 to 42 weeks). Also a latency duration of $<1$ week up to 4 weeks increased the risk of neonatal sepsis and GA at PPROM between 26 and 32 weeks led to an increased risk of neonatal sepsis compared to GA at PPROM 33 to 34 weeks. The overall model came to the same conclusions for these three variables (Table 4.4B).

Table 4.3B Multivariable regression analysis, outcome: Composite morbidity.

\begin{tabular}{|c|c|c|c|c|c|c|}
\hline & \multicolumn{2}{|c|}{ Crude } & \multicolumn{2}{|c|}{ Adjusted*1 } & \multicolumn{2}{|c|}{ Overall*2 } \\
\hline & OR & $95 \% \mathrm{Cl}$ & OR & $95 \% \mathrm{Cl}$ & OR & $95 \% \mathrm{Cl}$ \\
\hline \multicolumn{7}{|l|}{ GA at delivery } \\
\hline $26-28$ wks & 318 & $118-858$ & 302 & $112-815$ & 43.5 & 11.1-171 \\
\hline $28-30$ wks & 113 & $45.3-281$ & 109 & $43.9-273$ & 25.4 & $7.7-84.4$ \\
\hline $30-32$ wks & 43.6 & $17.8-107$ & 42.1 & $17.2-103$ & 16.9 & $5.6-50.8$ \\
\hline $32-34$ wks & 13.4 & $5.5-32.8$ & 13.1 & $5.4-32.0$ & 8.8 & $3.1-24.9$ \\
\hline 34-36 wks & 7.8 & $3.2-19.3$ & 7.6 & $3.1-18.7$ & 6.4 & $2.2-17.7$ \\
\hline $36-38$ wks & 3.2 & $2.0-8.5$ & 3.2 & $1.2-8.5$ & 3.3 & $1.2-9.3$ \\
\hline $38-40$ wks & 1.0 & $0.3-3.5$ & 1.0 & $0.3-3.4$ & 0.9 & $0.2-3.1$ \\
\hline $40-42$ wks & Ref & & Ref & & Ref & \\
\hline \multicolumn{7}{|c|}{ Interval between ROM and delivery } \\
\hline$<1$ wk & 8.1 & $5.7-11.4$ & 7.9 & $5.6-11.2$ & 3.2 & $1.5-6.7$ \\
\hline $1-<2$ wks & 6.5 & 4.4-9.3 & 6.3 & 4.3-9.1 & 2.5 & $1.3-5.1$ \\
\hline $2-<3$ wks & 6.6 & $4.4-9.9$ & 6.4 & 4.3-9.6 & 2.5 & $1.3-4.9$ \\
\hline $3-<4$ wks & 4.6 & 2.9-7.2 & 4.6 & 2.9-7.2 & 2.2 & $1.1-4.1$ \\
\hline $4-<5$ wks & 2.6 & $1.6-4.4$ & 2.6 & $1.6-4.3$ & 2.0 & $1.1-3.7$ \\
\hline$\geq 5$ wks & Ref & & Ref & & Ref & \\
\hline \multicolumn{7}{|l|}{ GA at PPROM } \\
\hline $26-27$ wks & 7.7 & $5.8-10.3$ & 7.8 & $5.9-10.4$ & 6.1 & $3.0-12.6$ \\
\hline 27-28 wks & 7.3 & $5.6-9.6$ & 7.4 & $5.6-9.7$ & 5.1 & $2.7-9.5$ \\
\hline 28-29 wks & 5.0 & $3.9-6.6$ & 5.1 & $3.9-6.6$ & 3.5 & $2.0-6.1$ \\
\hline $29-30$ wks & 3.9 & $3.0-4.9$ & 3.8 & $3.0-4.9$ & 2.3 & $1.5-3.5$ \\
\hline 30-31 wks & 2.9 & $2.4-3.7$ & 2.9 & $2.3-3.6$ & 2.1 & $1.5-3.0$ \\
\hline $31-32$ wks & 1.9 & $1.5-2.3$ & 1.9 & $1.5-2.3$ & 1.6 & $1.2-2.1$ \\
\hline $32-33$ wks & 1.3 & $1.1-1.6$ & 1.3 & $1.0-1.6$ & 1.2 & $1.0-1.5$ \\
\hline 33-34 wks & Ref & & Ref & & Ref & \\
\hline Adjusted *1: & \multirow{2}{*}{\multicolumn{6}{|c|}{$\begin{array}{l}\text { Adjusted for maternal age, parity and ethnicity } \\
\text { Adjusted for maternal age, parity and ethnicity and for GA at delivery, interval between } \\
\text { ROM and delivery and GA at PPROM }\end{array}$}} \\
\hline Overall*2: & & & & & & \\
\hline
\end{tabular}


Table 4.4B Multivariable regression analysis, outcome: Neonatal sepsis

\begin{tabular}{|c|c|c|c|c|c|c|}
\hline & \multicolumn{2}{|c|}{ Crude } & \multicolumn{2}{|c|}{ Adjusted*1 } & \multicolumn{2}{|c|}{ Overall*2 } \\
\hline & OR & $95 \% \mathrm{Cl}$ & OR & $95 \% \mathrm{Cl}$ & OR & $95 \% \mathrm{Cl}$ \\
\hline \multicolumn{7}{|c|}{ GA at delivery } \\
\hline $26-28$ wks & 122 & 29.4-509 & 116 & $27.8-482$ & 9.6 & $1.5-61.7$ \\
\hline $28-30$ wks & 85.3 & 20.9-349 & 82.6 & $20.2-338$ & 10.5 & $1.8-59.7$ \\
\hline 30-32 wks & 48.0 & $11.8-195$ & 47.0 & 11.6-191 & 11.1 & $2.1-57.4$ \\
\hline $32-34$ wks & 17.4 & $4.3-70.4$ & 17.2 & 4.3-69.5 & 7.0 & $1.4-34.3$ \\
\hline $34-36$ wks & 11.0 & $2.7-44.7$ & 10.9 & $2.7-44.3$ & 5.6 & $1.2-27.0$ \\
\hline $36-38$ wks & 3.0 & $0.7-14.2$ & 3.0 & $0.6-14.2$ & 3.1 & $0.6-15.3$ \\
\hline $38-40$ wks & 0.5 & $0.05-5.5$ & 0.5 & $0.04-5.4$ & 0.5 & $0.04-5.1$ \\
\hline 40-42 wks & Ref & & Ref & & Ref & \\
\hline \multicolumn{7}{|c|}{ Interval between ROM and delivery } \\
\hline$<1 \mathrm{wk}$ & 11.0 & $6.3-19.2$ & 10.8 & $6.2-18.9$ & 5.5 & 2.1-14.7 \\
\hline $1-<2$ wks & 9.6 & $5.4-17.2$ & 9.5 & $5.3-16.9$ & 4.6 & $1.8-11.7$ \\
\hline $2-<3$ wks & 10.1 & $5.5-18.5$ & 9.9 & $5.4-18.2$ & 4.4 & $1.8-10.7$ \\
\hline $3-<4$ wks & 5.4 & $2.7-10.8$ & 5.5 & $2.8-10.9$ & 2.7 & $1.1-6.3$ \\
\hline $4-<5$ wks & 2.0 & $0.9-4.7$ & 2.0 & $0.9-4.7$ & 1.4 & $0.5-3.7$ \\
\hline$\geq 5$ wks & Ref & & Ref & & Ref & \\
\hline \multicolumn{7}{|c|}{ GA at PPROM } \\
\hline $26-27$ wks & 4.9 & $3.6-6.8$ & 4.9 & $3.5-6.7$ & 6.1 & $2.6-14.2$ \\
\hline $27-28$ wks & 4.9 & $3.6-6.8$ & 4.9 & $3.6-6.7$ & 5.1 & $2.4-10.7$ \\
\hline $28-29$ wks & 3.7 & $2.7-5.0$ & 3.7 & $2.7-5.0$ & 3.6 & $1.9-7.0$ \\
\hline $29-30$ wks & 3.2 & $2.4-4.3$ & 3.2 & $2.4-4.3$ & 2.5 & $1.5-4.2$ \\
\hline 30-31 wks & 2.6 & $2.0-3.4$ & 2.5 & $1.9-3.3$ & 2.1 & $1.4-3.3$ \\
\hline $31-32$ wks & 1.6 & $1.2-2.0$ & 1.5 & $1.2-2.0$ & 1.4 & $1.0-2.0$ \\
\hline $32-33$ wks & 1.2 & $0.9-1.5$ & 1.2 & $0.9-1.5$ & 1.1 & $0.9-1.5$ \\
\hline 33-34 wks & Ref & & Ref & & & Ref \\
\hline Adjusted $* 1$ : & $\begin{array}{l}\text { Adjusted } \\
\text { Adjusted } \\
\text { and deliv }\end{array}$ & GA at PPR & $\begin{array}{l}\text { ad eth } \\
\text { hd eth }\end{array}$ & nd for $\mathrm{G}$ & ery, & between \\
\hline
\end{tabular}

\section{Discussion}

In this cohortstudy, we found that $0.4 \%$ of all pregnancies suffered PPROM over 24 hours between 26 and 34 weeks in the period between 1999 and 2007. The perinatal mortality rate was $2.5 \%$, whereas $24 \%$ suffered severe neonatal morbidity. Early gestational age at PPROM was related to adverse perinatal outcome and increased latency duration seems to be related to a decrease in perinatal mortality and neonatal sepsis.

The PRN is a nationwide database, in which all deliveries in the Netherlands are registered. Therefore, the PRN database is an important source to obtain information on obstetric issues. This database enabled us to select 5,723 cases with PPROM between 26 and 34 weeks from 1,445,305 pregnancies that were registered between 1999 and 2007. 
The use of the PRN data has several limitations. Only 53\% of the neonatologists register in the LNR registry and long term outcome is not recorded in the PRN registry.

When the analysis of neonatal outcomes was limited to the hospitals who registered during 2 or more years during the study period, the results were similar.

The registration rate is higher for deliveries before 32 weeks' gestation, since these deliveries take place in tertiary care hospitals, where more neonatologists participate in the LNR registry. This is, however, also a limitation. We study a group which delivered before 32 weeks' gestation, most certainly in a tertiary care center with a high LNR registration rate. However, we also study a group that delivered after 32 weeks' gestation, probably in a secondary care hospital with a lower registration rate. Therefore, data on neonatal outcome in case of deliveries $>32$ weeks should be interpreted with caution.

We faced the problem that the data collection in the PRN registry might not be 100 percent perfect, which is another limitation of the study design.

Also, the definition of severe morbidity which we used might be debated. In our opinion, perinatal mortality and sepsis are the main outcomes in case of PPROM. Secondly, outcomes such as RDS, IVH, NEC, BPD and Apgar score $<7$ after 5 minutes are considered to be the most important morbidities associated with prematurity.

The incidence of PPROM (>24 hours) between 26 and 34 weeks' gestation was $0.4 \%$. This is lower compared to incidences that are reported by other studies and in international guidelines. They estimate an incidence of approximately $1 \%{ }^{12,13}$ In other studies, the interval between PPROM and delivery is often unknown (not described) or $<24$ hours. We defined the interval between ROM and delivery as at least 24 hours. This was decided because in the PRN registry data were selected on the item 'onset of labor'. If the item 'spontaneous rupture of membranes and spontaneous contractions' was chosen as onset of labor, we were unsure if labor started with contractions or with PPROM. Therefore we decided to add the interval of 24 hours.

Chances of survival without severe morbidity are important in the decision to induce labor or to remain expectant. However, counseling remains difficult due to limitations in quality and quantity of available data.

The most important risks after PPROM, with the highest chance of adverse neonatal outcome, are preterm birth and neonatal sepsis or infection. ${ }^{14}$

In our study, longer latency decreased the rate of adverse perinatal outcome, including neonatal sepsis. Only for a latency period of 5-6 weeks, a slight increase was found.

Our findings are partly in line with a study of Aziz et al (2008). These authors state that in case of duration of ROM $\geq 48$ hours, duration of latency was inversely associated with intracerebral hemorrhage, 5-minute Apgar score $<7$, neonatal death, and the composite neonatal outcomes. However, latency duration was not associated with 
neonatal sepsis, RDS, or umbilical artery $\mathrm{pH}<7.0$. In pregnancies with latency $\geq 1$ week, duration of latency was not associated with poor perinatal outcomes. ${ }^{6}$

Nayot et al. demonstrated a benefit for infant outcome with latency $>72$ hours up to a gestational age of 34 weeks for moderate morbidity and up to 32 weeks for severe morbidity. ${ }^{5}$

Manuck et al. (2009) showed that duration of latency did not predict perinatal morbidity. ${ }^{3}$

Melamed et al. drew a different conclusion. They found that a latency period $>7$ days was associated with a higher rate of composite neonatal morbidity. Latency was not associated with the risk of neonatal infectious morbidity. In the first 7 days after ROM, overall composite neonatal morbidity improved in the group of women who were undelivered. ${ }^{4}$

We were unable to study the effect of chorioamnionitis on perinatal outcome in this study, because data on chorioamnionitis were not available from the PRN database.

Previous studies have studied the relation between chorioamnionitis and neonatal morbidity.

Park et al. studied the effect of prolonged latency in cases with PPROM $<34$ weeks. They found that the risk of histological chorioamnionitis increased with increasing latency, but no relationship was found between latency interval after PPROM and neonatal brain damage. ${ }^{15}$

Ramsey et al. concluded that chorioamnionitis increases the risk of neonatal morbidities. ${ }^{8}$

In our study, we found an overall incidence of neonatal sepsis of $16 \%$. This rate is comparable to incidences previously reported. ${ }^{16,17}$ The sepsis rates vary widely depending on gestational age at delivery (from $36 \%$ at 27 weeks to $4 \%$ at 34 weeks 18 and in another study from $71 \%<26$ weeks to $1.7 \%$ at 34 weeks). 19 These numbers are more or less comparable to the rates that were found in our study (61\% sepsis for delivery at 26 to 28 weeks and $6.9 \%$ for delivery between 34 and 36 weeks).

Antenatal administration of corticosteroids to increase fetal lung maturation is common practice in the Netherlands in case of threatened preterm birth and/or PPROM before 34 weeks' gestation.

With this large retrospective study, we are able to add data to the existing literature on the perinatal outcome of many pregnancies with PPROM between 26 and 34 weeks' gestation.

Our results point towards expectant management being preferred over induction of labor in case of PPROM between 26 and 34 weeks' gestation. Our results are in line with a meta-analysis by Al-Mandeel et al., who concluded that intentional delivery 
carries some maternal and neonatal risks with no added benefits in pregnancies complicated with PPROM between 28 and 34 weeks. $^{20}$

\section{Conclusion}

PPROM between 26 and 34 weeks' gestation (with a duration of ROM >24 hours) occurred in $0.4 \%$ of pregnancies and resulted in a perinatal mortality rate of $2.5 \%$. The incidence of neonatal sepsis decreased with increasing gestational age at PPROM and at delivery. Earlier gestational age at PPROM was related to adverse perinatal outcome while longer latency decreased the risk of composite neonatal morbidity and neonatal sepsis. Therefore, expectant management in case of PPROM between 26 and 34 weeks is advised. 


\section{References}

1. Mercer BM. Preterm premature rupture of the membranes. Obstetr Gynecol 2003;101:178-93.

2. Pasquier JC, Rabilloud M, Picaud JC, Ecochard R, Claris O, Gaucherand P, Collet F, Chabert P, Mellier G. A prospective population-based study of 598 cases of PPROM between 24 and 34 weeks' gestation: description, management, and mortality (DOMINOS cohort). Eur J Obstet Gynecol Reprod Biol 2005; 121:164-70.

3. Manuck TA, Maclean CC, Silver RM, Varner MW. Preterm premature rupture of membranes: does the duration of latency influence perinatal outcomes? Am J Obstet Gynecol 2009;201:414 e1-6.

4. Melamed N, Ben-Haroush A, Pardo J, Chen R, Hadar E, Hod M, Yogev Y. Expectant management of preterm premature rupture of membranes: is it all about gestational age? Am J Obstet Gynecol 2011;204:48.e4-8.

5. Nayot D, Penaval D, Da Silva O, Richardson BS, de Vrijer B. Neonatal outcomes are associated with latency after preterm premature rupture of membranes. J Perinatol 2012;32:970-7.

6. Aziz N, Cheng YW, Caughey AB. Factors and outcomes associated with longer latency in preterm premature rupture of membranes. J Matern Fetal Neonatal Med 2008;21: 821-5.

7. Pasquier JC, Bujold E, Rabilloud M, Picaud JC, Ecochard R, Claris O, Moret S, Mellier G. "Effect of latency period after premature rupture of membranes on 2 years infant mortality (DOMINOS study)." European J Obstet Gynecol Reprod Biol 2007;135:21-7.

8. Ramsey PS, Lieman JM, Brumfield CG, Carlo W. Chorioamnionitis increases neonatal morbidity in pregnancies complicated by preterm premature rupture of membranes. Am J Obstet Gynecol 2005; 192:1162-6.

9. Meray N, Reitsma JB, Ravelli AC, Bonsel GJ. Probabilistic record linkage is a valid and transparent tool to combine databases without a patient identification number. J Clin Epidemiol 2007;60:883-91.

10. Ravelli AC, Tromp M, Van Huis M, Steegers EA, Tamminga P, Eskes M, Bonsel GJ. Decreasing perinatal mortality in The Netherlands, 2000-2006: a record linkage study. J Epidemiol Community Health 2009;63:761-5.

11. Stichting Perinatale Registratie Nederland. Perinatal care in The Netherlands. 2011.

12. Nederlandse Vereniging voor Obstetrie en Gynaecologie (NVOG). [Breken van de vliezen voor het begin van de baring] (guideline). Version 1.0. 2002.

13. Parry S, Strauss JF 3rd. Premature rupture of the fetal membranes. N Engl J Med 1998;338:663-70.

14. Cornette L. Fetal and neonatal inflammatory response and adverse outcome. Semin Fetal Neonatal Med 2004;9:459-70.

15. Park SH, Kim HJ, Yang JH, Choi JS, Lim JE, Oh MJ, Na JY. Neonatal brain damage following prolonged latency after preterm premature rupture of membranes. J Korean Med Sci 2006;21: 485-9.

16. Ye G, Jiang $Z$, Lu S, Le Y. Premature infants born after preterm premature rupture of membranes with 24-34 weeks of gestation: a study of factors influencing length of neonatal intensive care unit stay. $J$ Matern Fetal Neonatal Med 2011;24:960-5.

17. Gezer A, Parafit-Yalciner E, Guralp O, Yedigoz V, Altinok T, Madazli R. Neonatal morbidity mortality outcomes in pre-term premature rupture of membranes. J Obstet Gynaecol 2013;33:38-42.

18. Newton ER. Preterm labor, preterm premature rupture of membranes, and chorioamnionitis. Clin Perinatol 2005;32:571-600.

19. Lieman JM, Brumfield CG, Carlo W, Ramsey PS. Preterm premature rupture of membranes: is there an optimal gestational age for delivery? Obstet Gynecol 2005;105:12-7.

20. Al-Mandeel H, Alhindi MY, Sauve R. Effects of intentional delivery on maternal and neonatal outcomes in pregnancies with preterm prelabour rupture of membranes between 28 and 34 weeks of gestation: a systematic review and meta-analysis. J Matern Fetal Neonatal Med 2013;26: 83-9. 


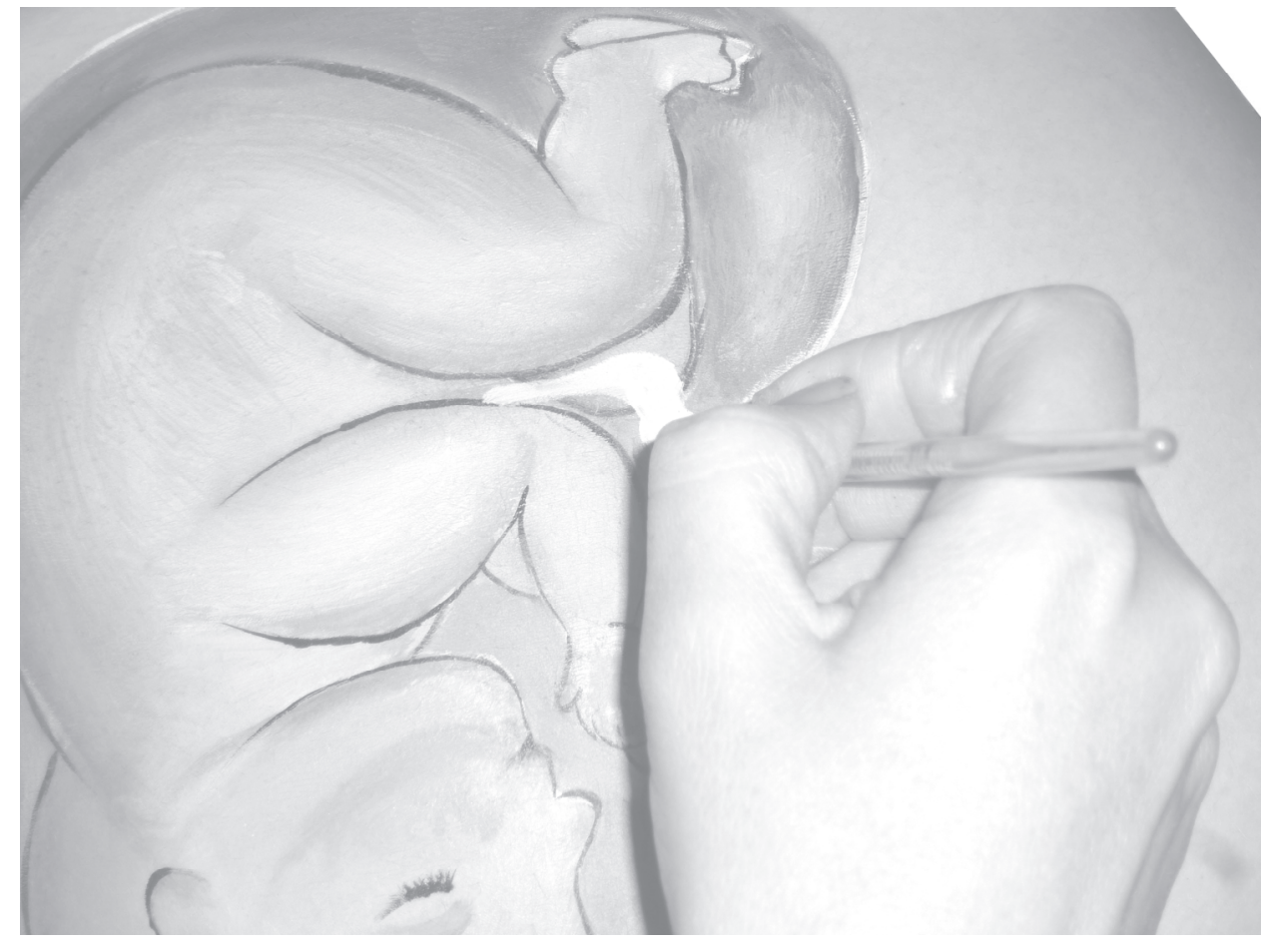




\title{
Chapter
}

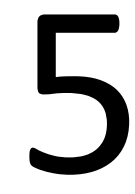

Subsequent pregnancy after preterm prelabor rupture of membranes before 27 weeks' gestation

\author{
JL van der Heyden \\ $S$ van Kuijk \\ DP van der Ham \\ KJB Notten \\ T Janssen \\ JG Nijhuis \\ C Willekes \\ M Porath \\ $J$ van der Post \\ F Halbertsma \\ E Pajkrt \\ BWJ Mol
}

AJP Rep 2013;3:113-118 


\section{Abstract}

\section{Objective}

Midtrimester preterm prelabor rupture of membranes (PPROM) has a high rate of neonatal mortality and morbidity. The aim of this study was to study outcomes of subsequent pregnancies after a pregnancy with PPROM before 27 weeks' gestation.

\section{Study design}

Retrospective study of subsequent pregnancies of women who suffered PPROM before 27 weeks' gestation from 1994 to 2009. The main outcome measure was the risk of recurrence of PPROM before 27 weeks' gestation. We also studied preterm birth and pregnancy outcome in the subsequent pregnancy. Finally, we assessed associative factors for subsequent premature delivery.

\section{Results}

We identified 307 patients, of whom 118 women had a subsequent pregnancy. Of 99 women with complete outcome data, 9 women (9\%) had PPROM before 27 weeks' gestation in a subsequent pregnancy and 35 women (35\%) had a preterm delivery. In $58(59 \%)$ of pregnancies no major complications occurred. We found three associative factors for premature delivery in a subsequent pregnancy: negative vaginal culture for Group B streptococcus, increasing maternal age and early gestational age at PPROM in the index pregnancy.

\section{Conclusions}

Women with PPROM before 27 weeks have a 9\% recurrence risk of early PPROM and a risk of $35 \%$ of having a preterm delivery in a subsequent pregnancy. 


\section{Introduction}

Preterm birth is a leading cause of neonatal morbidity and mortality. Preterm prelabor rupture of membranes (PPROM) before 37 weeks' gestation complicates $3 \%$ of all pregnancies ${ }^{1}$ and accounts for approximately $30 \%$ of the preterm births. ${ }^{2}$ It is well known that one of the largest risk factors for preterm delivery is a history of preterm delivery. ${ }^{3,4}$

Previous studies on the risk of PPROM recurrence focus on the recurrence of PPROM in general and not specifically on midtrimester PPROM. Table 5.1 summarizes the studies that report on the recurrence risk of PPROM. ${ }^{5-7}$

Getahun et al. ${ }^{5}$ studied over 180,000 women; the two other studies ${ }^{6-7}$ had a much smaller population. All these studies concluded that the risk of PPROM recurrence was increased compared with the incidence of PPROM in a general population.

Early PPROM, that is, PPROM before 27 weeks' gestation, occurs in about $0.6 \%$ of pregnancies. $^{8}$ Early PPROM is associated with severe complications, such as intrauterine infection, pulmonary hypoplasia, premature birth, contractures and ultimately neonatal death. ${ }^{2}$ Considering the consequences of early PPROM, women that have had a pregnancy complicated by early PPROM are usually concerned about the recurrence of such a complication.

As most of the data on the recurrence of preterm delivery are not derived from studies addressing early (midtrimester) PPROM we aimed to determine the risk of recurrence of early PPROM before 27 weeks' gestation in a subsequent pregnancy. Adequate counseling regarding the risk in a subsequent pregnancy is important to help couples in their consideration of a future pregnancy.

The aim of this study was to assess the risk of PPROM before 27 and between 27 and 34 weeks in patients with a previous pregnancy with PPROM before 27 weeks. The secondary aim was to identify the recurrence risk of preterm birth in a subsequent pregnancy.

\section{Methods}

We performed a retrospective cohort study between 1994 and 2009 in three perinatal centers with a regional function in the Netherlands. These centers were the Máxima Medical Center (MMC) in Veldhoven, the Academic Medical Center (AMC) in Amsterdam and the Maastricht University Medical Center (MUMC) in Maastricht. Patients were identified from electronic databases. All patients who were diagnosed with preterm prelabor rupture of membranes before 27 weeks' gestation in the index pregnancy were included in the study. Demographic, medical and obstetric data were obtained from medical files. Information on subsequent pregnancies was gained from medical files and patients were contacted personally if information in the medical files was not adequate. If patients were lost to follow-up, we tried to obtain contact 
information from other sources (mostly through the general practitioner). A subsequent pregnancy was defined as a singleton or multiple pregnancy, both ongoing pregnancies as miscarriages. Only data on the first subsequent pregnancy after the index pregnancy were used for analysis.

Table 5.1 Studies reporting on the risk of recurrence of PPROM or preterm birth.

\begin{tabular}{|c|c|c|c|c|}
\hline Study & Year & Number of patients & Results & Conclusion \\
\hline${\text { Getahun et } \mathrm{al}^{5}}^{5}$ & 2010 & 180,940 women & $\begin{array}{l}\text { Recurrence risk of PPROM } \\
\text { among white women } 5.7 \% \\
\text { and } 10.3 \% \text { among African } \\
\text { American women }\end{array}$ & $\begin{array}{l}\text { Short interval between index and } \\
\text { subsequent pregnancy is } \\
\text { associated with increased risk for } \\
\text { PPROM recurrence }\end{array}$ \\
\hline Asrat et al ${ }^{6}$ & 1991 & 121 women & $\begin{array}{l}\text { Risk of recurrence of PPROM: } \\
32.2 \% \\
\text { No association between } \\
\text { estimated GA at time of } \\
\text { rupture in index pregnancy, } \\
\text { latency period and interval } \\
\text { between pregnancies }\end{array}$ & $\begin{array}{l}\text { There is a significant risk of } \\
\text { recurrence and need to have } \\
\text { close follow-up in their } \\
\text { subsequent pregnancies }\end{array}$ \\
\hline Lee et $\mathrm{al}^{7}$ & 2003 & 114 women & $\begin{array}{l}\text { Recurrence rate of PPROM: } \\
16.7 \% \\
\text { Recurrence rate of preterm } \\
\text { delivery: } 34.2 \%\end{array}$ & $\begin{array}{l}\text { The risk for recurrent preterm } \\
\text { premature rupture of } \\
\text { membranes is increased by } 20 \text { - } \\
\text { fold and for recurrent preterm } \\
\text { delivery by almost } 4 \text {-fold }\end{array}$ \\
\hline
\end{tabular}

$\mathrm{GA}=$ gestational age; PPROM=preterm prelabor rupture of membranes.

\section{Statistics}

The primary outcome among women with a subsequent pregnancy was recurrence of PPROM before 27 weeks' gestation. Results were expressed as absolute numbers with a percentage, mean with standard deviation, median with interquartile ranges and odds ratio with $95 \%$ confidence intervals $(\mathrm{Cl})$.

We used univariable and multivariable logistic regression to identify potential prediction variables. We considered maternal age, gestational age at PPROM (index pregnancy), gestational age at delivery, vaginal culture positive for Group B streptococcus (GBS), live birth in index pregnancy or postpartum death as potential prediction variables. Live birth was defined as a neonate born with Apgar score after 1 minute $\geq 1$ at any gestational age. Postpartum death was defined as death of a live born neonate at any time after birth. We assessed multiple variables from the index pregnancy in a logistic regression analysis to determine which variables can be used as associative factors for preterm birth in a subsequent pregnancy. Factors with a $P$ value $<0.10$ were considered as factors with associative value. 
A Kaplan-Meier curve was constructed to assess time to delivery. All data were analyzed using Excel version 2007 (Microsoft Office) and SPSS version 20.0 for Windows (SPSS inc, Chicago, IL).

\section{Results}

A flow chart of women included is shown in Figure 5.1. We identified 307 patients with a singleton or multiple pregnancies. Of these patients, 26 (8.5\%) were lost to follow-up, $118(38 \%)$ had at least one subsequent pregnancy and 163 (53\%) did not conceive again.

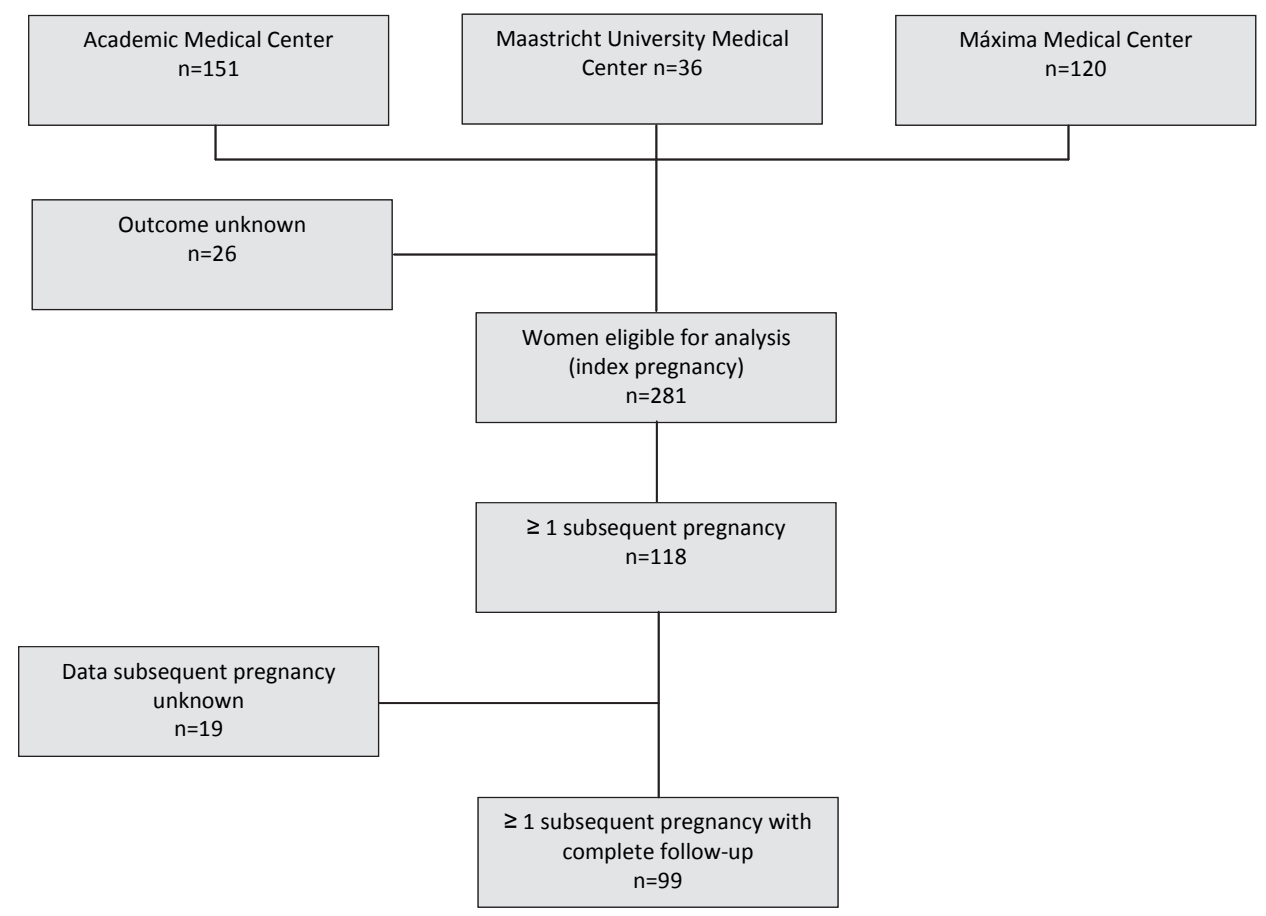

Figure 5.1 Flowchart of women included in the study.

Table 5.2 shows the baseline demographic and clinical characteristics and perinatal outcomes of the 118 index pregnancies. In 19 pregnancies data on the subsequent pregnancy were unknown, leaving 99 pregnancies eligible for analysis. In Table 5.3, perinatal outcome in the subsequent pregnancy is shown. 
Table 5.2 Demographic factors index pregnancy.

\begin{tabular}{lccc}
\hline Factors & Number $(\mathbf{n}=\mathbf{1 1 8})$ & Percentage (\%) & Mean (range) [SD] \\
\hline Maternal age & & & $30.2(17.8-44.6)[5.1]$ \\
\hline Parity & & & \\
\hline Nulliparity & 63 & 53 & \\
$\quad$ Multiparity & 55 & 47 & \\
Singleton pregnancy & 105 & 10 & $21.9(14.9-26.9)[2.9]$ \\
\hline Multiple pregnancies & 12 & 0.8 & \\
\hline Twins & 1 & & \\
Triplets & & 17 & \\
Gestational age at PPROM & 20 & & \\
Vaginal culture positive for GBS &
\end{tabular}

GBS=group B streptococcus; PPROM=preterm prelabor rupture of membranes.

Table 5.3 Perinatal outcome index and subsequent pregnancy.

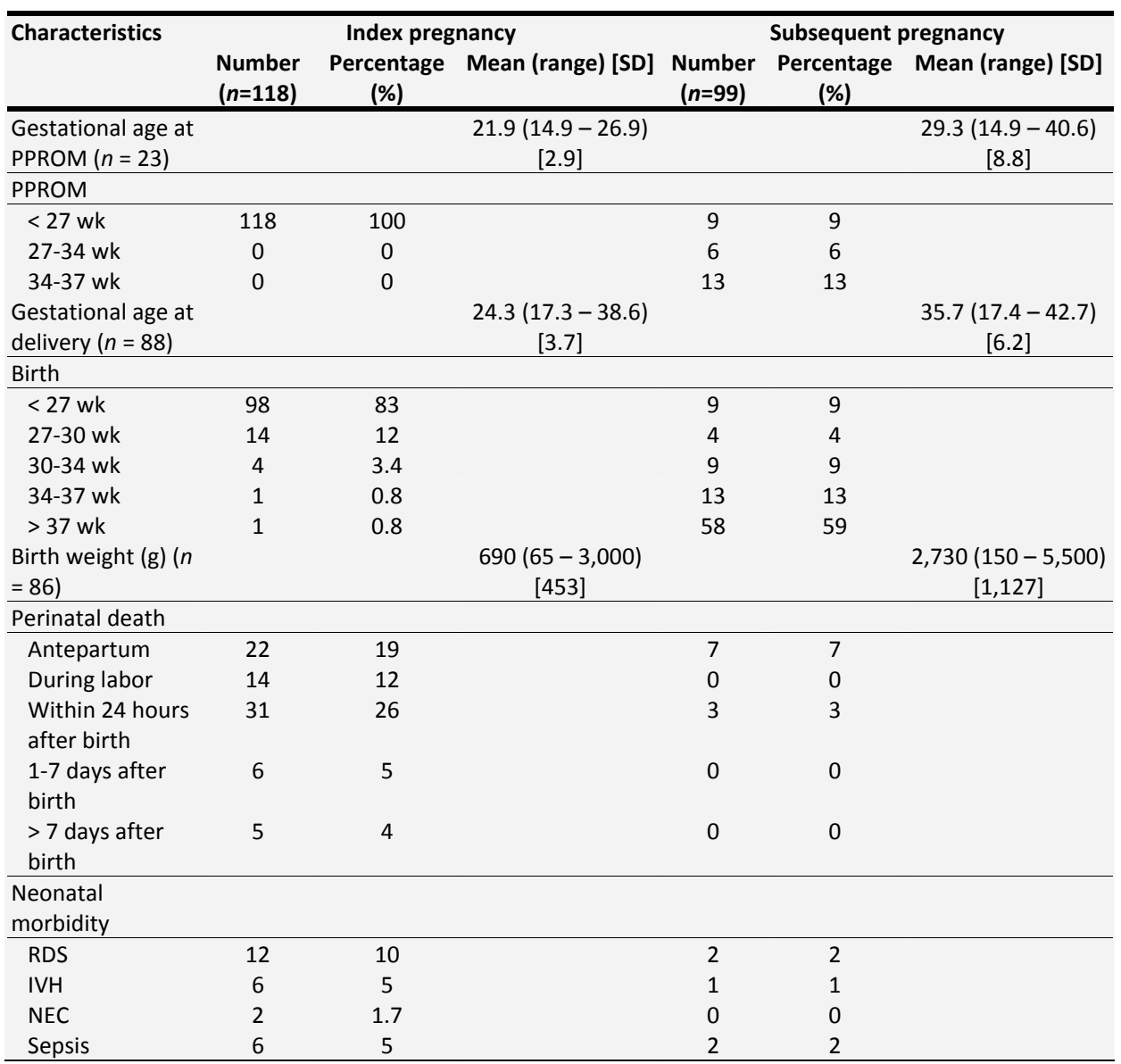

IVH=intraventricular hemorrhage; $N E C=$ necrotizing enterocolitis; PPROM=preterm prelabor rupture of membranes; RDS=respiratory distress syndrome; sepsis: proven or suspected sepsis; wk=weeks. 
The mean gestational age at delivery in the subsequent pregnancy was 35 weeks and 6 days ( \pm 6.0 days). Overall 9 women (9\%) delivered before 27 weeks, 13 (13\%) between 27 and 34 weeks, 13 (13\%) between 34 and 37 weeks and 58 women (59\%) delivered at term.

The Kaplan-Meier curve (Figure 5.2) shows that in the subsequent pregnancy, 50\% of women delivered before a gestational age of 37.9 weeks.

Recurrence of PPROM before 27 weeks occurred in nine women (9\%), while six women (6\%) suffered PPROM between 27 and 34 weeks' gestation. In the subsequent pregnancy, there were 71 deliveries after 34 weeks' gestation without major complications (72\%).

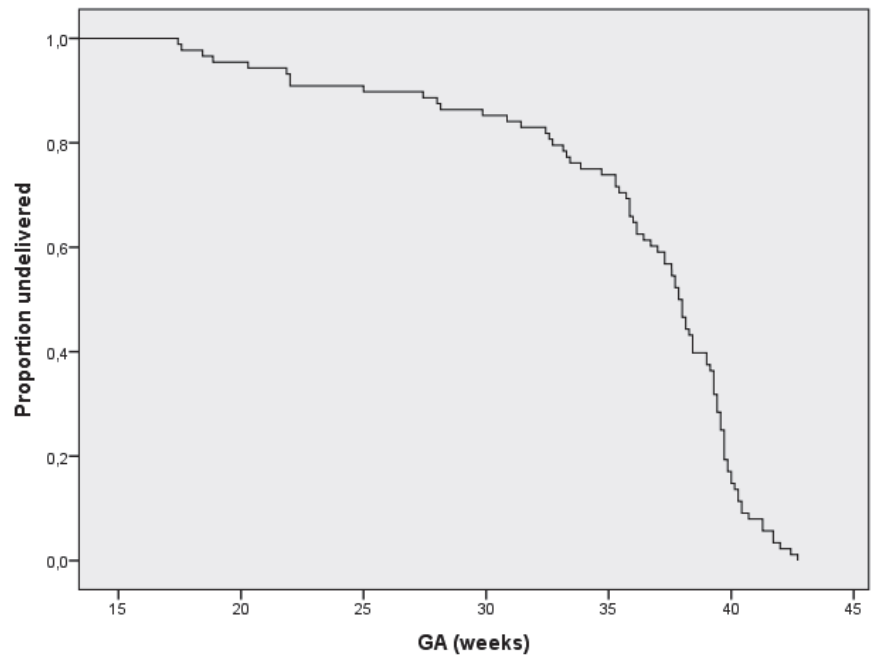

Figure 5.2 Kaplan-Meier curve. GA, gestational age.

Table 5.4 shows potential associative factors for preterm delivery in a subsequent pregnancy. In the multivariable analysis, positive vaginal culture for GBS reduced the risk of preterm delivery (OR .19, $95 \% \mathrm{Cl} 0.04$ to 0.91 ) and (increasing) maternal age (OR $1.12,95 \% \mathrm{Cl} 1.0$ to 1.26$)$ was an associative factor for preterm delivery. Moreover, (early) gestational age at PPROM in the index pregnancy, but not gestational age at delivery was also slightly associative for renewed preterm birth (OR $0.97,95 \% \mathrm{Cl} 0.94$ to 1.0). 
Table 5.4 Risk factors for preterm delivery before 37 weeks in subsequent pregnancy.

\begin{tabular}{lcccccc}
\hline \multirow{2}{*}{ Clinical characteristic } & \multicolumn{3}{c}{ Univariable analysis $^{{ }^{a}}$} & \multicolumn{3}{c}{ Multivariable analysis $^{\text {b }}$} \\
\hline Maternal age (y) & OR & $\mathbf{9 5 \%} \mathbf{~ C l}$ & $\boldsymbol{P}$ value & OR & $\mathbf{9 5 \% ~ C l}$ & $\boldsymbol{P}$ value \\
GA at PPROM index pregnancy (d) & 1.07 & $0.98-1.18$ & 0.14 & 1.12 & $1.00-1.26$ & 0.05 \\
GA at birth index pregnancy (d) & 0.98 & $0.96-1.00$ & 0.11 & 0.97 & $0.94-1.00$ & 0.09 \\
Positive vaginal culture (GBS) & 0.99 & $0.97-1.00$ & 0.15 & 1.00 & $0.97-1.03$ & 1.00 \\
Life birth & 0.31 & $0.08-1.22$ & 0.09 & 0.19 & $0.04-0.91$ & 0.04 \\
Postpartum death & 0.42 & $0.17-1.02$ & 0.06 & 0.51 & $0.10-2.5$ & 0.41 \\
\hline
\end{tabular}

$\mathrm{Cl}=$ confidence interval; $\mathrm{d}=$ =days; $\mathrm{GA}=$ gestational age; $\mathrm{GBS}=\mathrm{Group} \mathrm{B}$ streptococcus; OR=odds ratio;

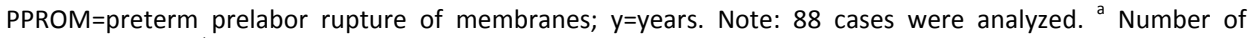
missing data: $30 ;^{\text {b }}$ Number of missing data: 42.

\section{Discussion}

In this retrospective study, we studied the risk of recurrence in midtrimester PPROM, since perinatal morbidity and mortality is much higher in this group compared with the group with advanced gestational ages. In this study, the recurrence risk of PPROM before 27 weeks was $9 \%$. A total of $22 \%$ of patients delivered before 34 weeks. Neonatal morbidity is mainly related to the early gestational age at delivery. From that perspective, a recurrence rate of PPROM before 34 weeks of $15 \%$ is relatively high. The results are pretty comparable to data from previous reported studies, with an increased risk of recurrent PPROM of $6 \%$ to $32 \% .^{5-7}$

These studies however, reported on PPROM in general and not on midtrimester PPROM. The recurrence risk of premature delivery of $34 \%$ reported by Lee et al. is also comparable to the recurrence risk after midtrimester PPROM in our study.

\section{Strengths}

This study included consecutive patients who matched the inclusion criteria. From 307 index pregnancies, only 118 women had a subsequent pregnancy. From this group, we could obtain the most important information from 99 pregnancies.

We specifically studied the recurrence risk of PPROM before 27 weeks' gestation, because of the high neonatal mortality and morbidity in this group. This might result in high impact on parents, followed by fear of a renewed pregnancy.

\section{Weaknesses}

Potential drawbacks of the present study are the retrospective nature and the lost to follow-up rate. As we could not gain information on $9 \%$ of the pregnancies, and we missed follow-up on another $16 \%$ of the women. The retrospective character hampered complete data collection. Despite these limitations, we believe that our wide time 
period and the multicenter data collection increased the sample size for this relatively rare disease of PPROM before 27 weeks.

\section{Possible predictive factors}

We found that positive vaginal culture for GBS in the index pregnancy decreased the risk of premature delivery in a subsequent pregnancy. This is the opposite of what we expected. We hypothesized that, women with a known positive culture for GBS might be more intensively examined or treated in a subsequent pregnancy. We tried to check this hypothesis using our data. Unfortunately, we have very limited information on the use of antibiotics in the subsequent pregnancy (only known in $36 \%$ of cases). With these limited data, we were not able to confirm this hypothesis. In both groups (use of antibiotics vs. no use of antibiotics), 15\% of women were known GBS positive in the index pregnancy.

A second factor that increased the risk of premature delivery in the subsequent pregnancy was increasing maternal age. The third factor with predictive value is gestational age at PPROM in the index pregnancy. The OR for positive culture for GBS was 0.19 , for maternal age 1.12 and for gestational age at PPROM 0.97, respectively. Therefore, these factors can be considered as potential associative factors and seem to be clinically relevant predictors.

The importance of this study is that obstetrician gynecologists may use the results to counsel more objectively. Patients should be aware of the higher risk of recurrence in order to make a proper decision about the continuation of the pregnancy. However, we were surprised to see that less than $50 \%$ of the women decided to conceive again, while the outcome of the subsequent pregnancy was relatively good. With data from our study, patients are able to make better decisions for future pregnancies.

\section{Conclusion}

Women with PPROM before 27 weeks' gestation in a pregnancy have an increased risk of recurrence of early PPROM. Furthermore, the risk of a premature delivery in future pregnancies is $35 \%$, which is about 3 to 4 times higher compared with the risk in a general population, but still allows a new conception after previous early PPROM. The risk of recurrence of PPROM or preterm birth is increased after a previous pregnancy with midtrimester PPROM. 


\section{References}

1. Guideline of the Dutch Society for Obstetrics and Gynecology: Rupture of the membranes before the start of labor; Version 1.0 [in Dutch]. Online link: http://nvog-documenten.nl/index.php?pagina=/ richtlijn/pagina.php\&fSelectTG_62=75\&fSelectedSub=62\&fSelectedParent=75, accessed March 9, 2011.

2. Ernest JM. Neonatal consequences of preterm PROM. Clin Obstet Gynecol 1998;41:827-31.

3. Ekwo EE, Gosselink CA, Moawad A. Unfavorable outcome in penultimate pregnancy and premature rupture of membranes in successive pregnancy. Obstet Gynecol 1992;80:166-72.

4. Heffner LJ, Sherman CB, Speizer FE, Weiss ST. Clinical and environmental predictors of preterm labor. Obstet Gynecol 1993;81(5 ( Pt 1)):750-7.

5. Getahun D, Strickland D, Ananth CV, Fassett MJ, Sacks DA, Kirby RS, Jacobsen SJ. Recurrence of preterm premature rupture of membranes in relation to interval between pregnancies. Am J Obstet Gynecol 2010; 202:e1-e6.

6. Asrat T, Lewis DF, Garite TJ, Major CA, Nageotte MP, Towers CV, Montgomery DM, Dorchester WA. Rate of recurrence of preterm premature rupture membranes in consecutive pregnancies. Am J Obstet Gynecol 1991;165:1111-5.

7. Lee T, Carpenter MW, Heber WW, Silver HM. Preterm premature rupture of membranes: risks of recurrent complications in the next pregnancy among a population-based sample of gravid women. $A m$ J Obstet Gynecol 2003;188(1):209-213.

8. Schucker JL, Mercer BM. Midtrimester premature rupture of the membranes. Semin Perinatol 1996;20:389-400. 


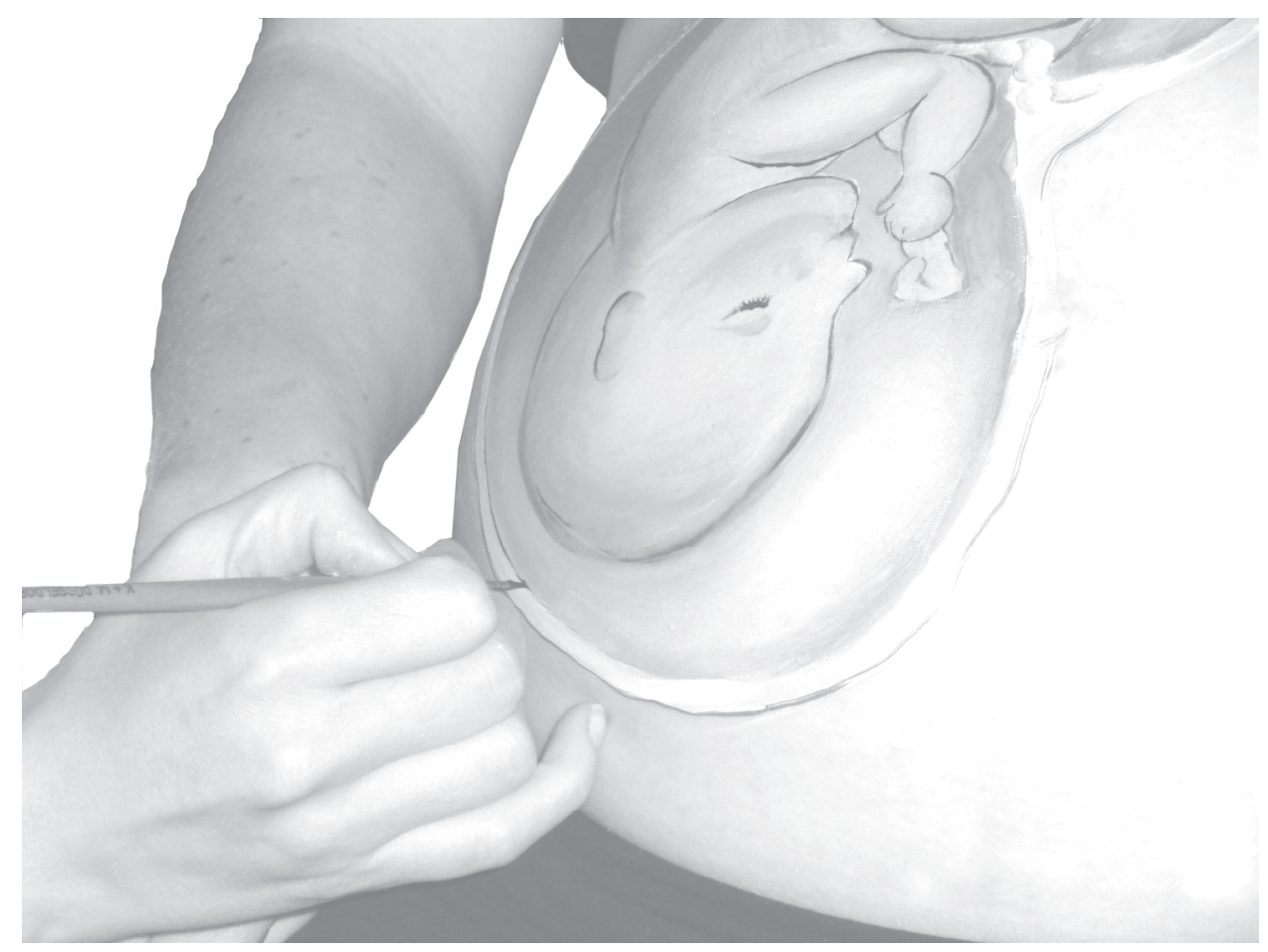




\title{
Chapter

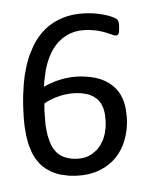

Is it useful to measure C-reactive protein and leukocytes in patients with prelabor rupture of membranes?

\author{
JL van der Heyden \\ ASP van Teeffelen \\ JCG Coolen \\ FJ Halbertsma \\ R Aardenburg \\ HJMM Mertens \\ BWJ Mol
}




\section{Abstract}

Neonatal infection is the main complication of prelabor rupture of membranes (PROM). We studied the accuracy of measuring C-reactive protein (CRP) and leukocytes in maternal serum to predict neonatal infection.

We performed a retrospective cohort study in two hospitals in the Netherlands between 2003 and 2006. We included consecutive women hospitalized for PROM. In both hospitals, CRP and leukocytes were measured routinely in maternal serum every 2 days until delivery. End points considered were clinical neonatal infection and proven neonatal sepsis. The accuracy of CRP and leukocytes was assessed using receiver operating characteristics (ROC) analysis.

We included 299 women with PROM, 12 of whom had a twin pregnancy. Gestational age at inclusion varied between 26 weeks and 0 days and 41 weeks and 5 days with a median of 37 weeks and 3 days. In 47 women (16\%), the neonate developed a clinical infection. The areas under the ROC curve of CRP and leukocytes in the prediction of clinical neonatal infection were 0.61 and 0.62 , respectively. Of the 47 infected neonates, six neonates (2\%) had a proven neonatal sepsis. In the mothers of these septic neonates, maternal CRP did not rise above 50 $\mathrm{mg} / \mathrm{L}$ and leukocyte values varied between 9.8 and $25.8 \times 10^{9} / \mathrm{I}$.

In women with PROM, CRP and leukocytes should not be measured routinely. 


\section{Introduction}

Prelabor rupture of membranes (PROM) is defined as rupture of the membranes without the start of labor for at least 24 hours. The estimated incidence of PROM after 26 weeks of gestation is $10 \% .{ }^{1}$ The main complication of PROM is intrauterine infection. If the neonate is born immediately after PROM, the risk of sepsis is $2.5 \%$, whereas it is thought to increase to $7.5 \%$ in cases of expectant management. ${ }^{2-4}$

To determine the risk of neonatal infection before birth, several risk factors can be considered. Maternal fever, fetal tachycardia and green or fetid amniotic fluid are all associated with the presence of infection. Apart from these risk factors, it is thought that measuring C-reactive protein (CRP) and/or white blood cells (leukocytes) might be of value for early detection of neonatal infection in these patients. ${ }^{5,6}$

In the literature, conflicting results on the use of CRP in the prediction of infection in women with PROM have been reported. ${ }^{5-7}$ In 2007, Trochez-Martinez et al. performed a systematic review and found no clear evidence that supported the use of CRP for the early diagnosis of chorioamnionitis ${ }^{8}$. However, the association between CRP and neonatal infection was not assessed due to a lack of studies on the subject.

In view of this lack of knowledge, the objective of the present study was to determine the accuracy of CRP and leukocytes measured in maternal serum in the prediction of neonatal infection.

\section{Methods}

We performed a retrospective cohort study between 2003 and 2006 in the Orbis Medical Center Sittard and Máxima Medical Center Veldhoven. Both hospitals are large, nonacademic teaching hospitals in the south of the Netherlands. We included consecutive women with PROM, with a gestational age between 26 and 42 weeks. These women were identified from local electronic databases with data on all deliveries. In both hospitals, in women with PROM before 37 weeks' gestation, CRP and leukocytes were measured routinely in maternal serum twice a week until delivery. In women with PROM at term, CRP and leukocytes were measured 24 hours after rupture of the membranes and labor was induced after 48 hours. The measurements of CRP and leukocytes were used in combination with other data. The decision to induce labor or to continue expectant management (the probability of the presence of an intrauterine infection) was based on maternal fever, fetid or green amniotic fluid, tachycardia of the fetus, as well as on the results of CRP and leukocytes. In one of the hospitals (only in the Máxima Medical Center Veldhoven), antibiotics (erythromycin $250 \mathrm{mg} 4$ times daily for 10 days) were given to patients with PROM before 37 weeks' gestation. ${ }^{9}$ The difference in this policy is a result of the guideline of the Dutch Society for Obstetrics and Gynecology, which does not give a clear recommendation on the use of antibiotics in patients with PROM before 37 weeks' gestation. In both hospitals, 
patients with PROM before 34 weeks' gestation received intramuscular corticosteroid injections. Maternal CRP was measured with a turbidimetric immuno-assay (Roche Modular ${ }^{\circledR}$, Basel, Switzerland). Leukocytes were measured with a flow cytometric test (impedance measurement from Beckman Coulter ${ }^{\circledR}$, Brea, CA). Patients in whom CRP and leukocytes had not been measured were not included. For every patient with PROM, we collected data about the pregnancy, vaginal culture, maternal temperature, clinical infection in the neonate, admission to hospital and use of antibiotics in the neonate in a case record form.

End points were clinical neonatal infection and proven neonatal sepsis. According to the International Pediatric Sepsis Consensus Conference $2005^{10}$, infection is suspected or proven (by positive culture, tissue stain, or polymerase chain reaction test) caused by any pathogen. Evidence of clinical infection includes symptoms with a high probability of infection, like positive findings on clinical exam, imaging, or laboratory tests. For signs of infection at clinical examination we used respiratory distress, tachypnea, lethargy (silent or hypotonic neonate), feeding problems, hyperthermia or hypothermia. Laboratory signs of infection were increased CRP, leukocytosis, or leukocytopenia. ${ }^{10}$

Neonatal sepsis is defined as neonatal infection with cardiorespiratory instability or a positive blood culture caused by any pathogen.

\section{Statistical analysis}

The distribution of each of the variables was compared between the neonates with and neonates without infection. For continuous variables, we calculated means or medians in both groups. For statistical comparison, we used the appropriate statistical test depending on normality of the distributions.

Subsequently, for both CRP and leucocytes we performed receiver operating characteristic (ROC) analysis, in which infection was considered the disease. For comparison, the accuracy of maternal temperature for neonatal infection or sepsis was considered. The article was reported using the STARD-guidelines for the report of diagnostic research. ${ }^{11}$

\section{Results}

We included 386 women with PROM, of whom 65 women were excluded, because CRP and leukocytes were not determined in these women. In 22 women, PROM had occurred before 26 weeks of gestation, leaving 299 women eligible for analysis (see Figure 6.1). Gestational age at inclusion varied from 26 weeks and 0 days to 41 weeks and 5 days with a median of 37 weeks and 3 days. Baseline characteristics are shown in Table 6.1. In 47 women (16\%), the neonate developed a clinical infection, of which six 
children (2\%) had an early onset neonatal sepsis. The babies from the other 252 women did not develop an infection.

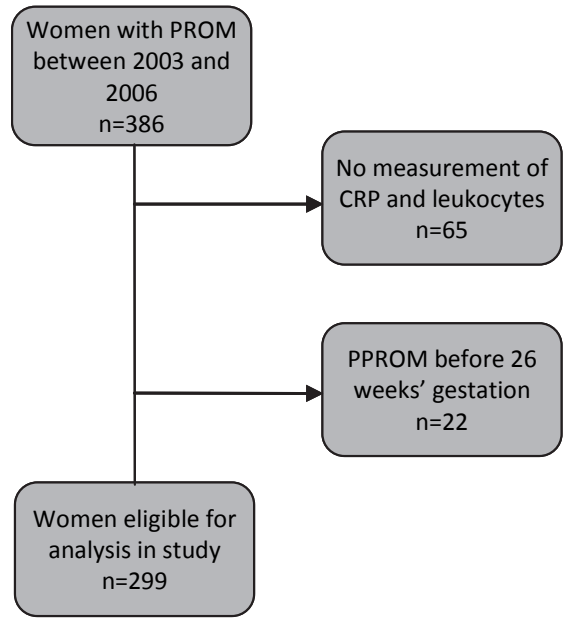

Figure 6.1 Inclusion of patients. CRP, C-reactive protein; PPROM, preterm prelabor rupture of membrane; PROM, prelabor rupture of membranes.

Table 6.1 Baseline characteristics.

\begin{tabular}{lcc}
\hline Characteristic & Number & $\begin{array}{c}\text { Number in women whose } \\
\text { neonate had sepsis }\end{array}$ \\
\hline Maternal age, y (mean and standard deviation) & 30.4 years $( \pm 4.6)$ & 28.3 years \\
Nulliparous women & $196(65.6 \%)$ & $5(83.3 \%)$ \\
Multiparous women & $103(34.4 \%)$ & $1(16.7 \%)$ \\
Gestational age (median and range) & $37 \mathrm{wk}, 3 \mathrm{~d}$ & $36 \mathrm{wk}, 2 \mathrm{~d}$ \\
& $(26 \mathrm{wk}-41 \mathrm{wk}, 5 \mathrm{~d})$ & $(31 \mathrm{wk}, 1 \mathrm{~d}-40 \mathrm{wk}, 4 \mathrm{~d})$ \\
Singletons & $287(96.0 \%)$ & $6(100 \%)$ \\
Twins & $12(4.0 \%)$ & $0(0 \%)$ \\
Positive vaginal culture & $123(41.1 \%)$ & $5(83.3 \%)$ \\
Women who smoked & $27(9.0 \%)$ & $1(16.7 \%)$ \\
\hline
\end{tabular}

Values are expressed as absolute numbers with percentage, median with range or mean with standard deviation where appropriate.

In the 252 women with babies who did not develop infection, the last measured CRP in maternal serum before birth was minimum $1 \mathrm{mg} / \mathrm{l}$ and maximum $70 \mathrm{mg} / \mathrm{l}$ (median $8 \mathrm{mg} / \mathrm{l}$ ) and the median leukocyte value was 13.0 (range 5.7 to $31.2 \times 10^{9} / \mathrm{l}$ ).

Of six children with early onset sepsis, one neonate suffered from Listeria meningitis and sepsis. Two children showed a hemolytic Streptococcus group B in the blood culture. One neonate had Staphylococcus epidermidis and one had Staphylococcus capitis in the blood culture. One neonate had a neonatal infection and was 
hypothermic. The S. epidermidis in the blood culture might have been caused by contamination. However, this neonate also showed clinically signs of sepsis. In these six neonates with early onset sepsis, last measured CRP in maternal serum before birth did not rise above $50 \mathrm{mg} / \mathrm{l}$ and leukocyte values varied between 9.8 and $25.8 \times 10^{9} / \mathrm{l}$. We did not observe an effect of the use of antibiotics on the occurrence of sepsis.

In 47 women (16\%), the neonate developed a clinical infection. The mean values of $\mathrm{CRP}$, leukocytes and temperature in mothers of a child with clinical infection are shown in Table 6.2. Figures 6.2A and 6.2B show the ROC curves for CRP and leukocytes.

The area under the ROC curve for CRP and leukocytes in the diagnosis of clinical infection was 0.61 and 0.62 , respectively.

Table 6.2 Clinical neonatal infection.

\begin{tabular}{lcc}
\hline & Positive $(\boldsymbol{n}=\mathbf{4 7})$ & Negative $(\boldsymbol{n}=\mathbf{2 5 2})$ \\
\hline C-reactive protein $(\mathrm{mg} / \mathrm{l})$ & 21.7 & 11.7 \\
Leukocytes $\left(\times 10^{9}\right)$ & 16.0 & 14.0 \\
Maximal maternal temperature $\left({ }^{\circ} \mathrm{C}\right)$ & 37.2 & 36.8 \\
\hline
\end{tabular}

Results are mean values.
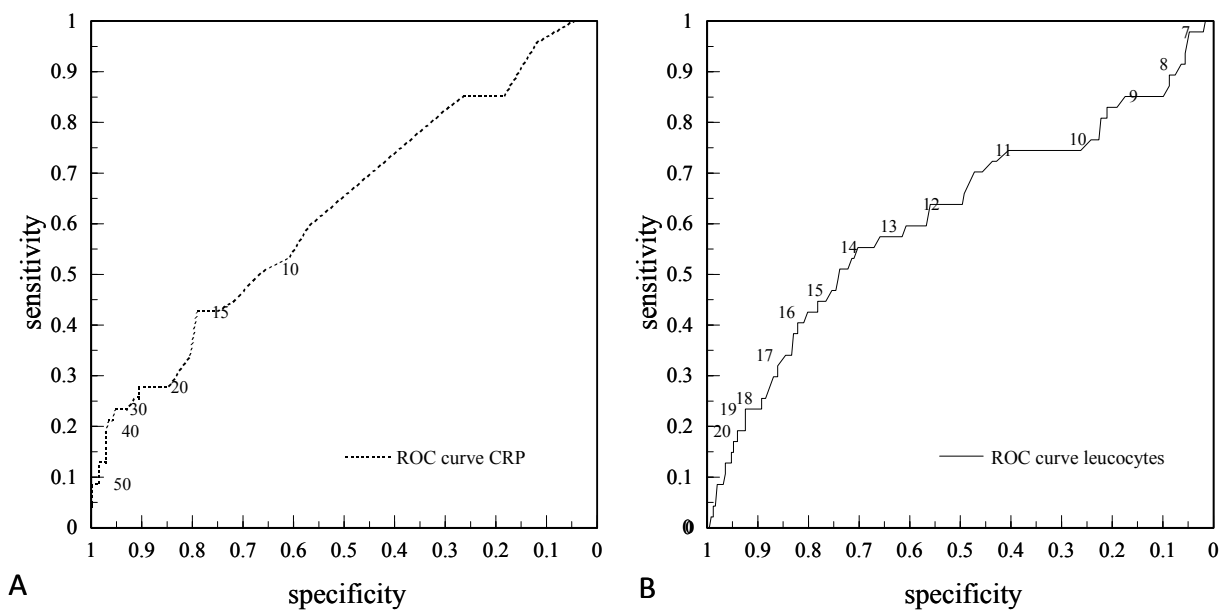

Figure 6.2 (A) Receiver operating characteristics (ROC) curve of C-reactive protein (CRP). Along the ROC curves, we have pointed the cut-off values. (B) ROC curve of leukocytes.

Figure 6.3 shows the ROC curve for the last maternal temperature measured before delivery in a similar plot as the curves for CRP and leukocytes. The area under the ROC curve was 0.61 , and there was no clear clinical useful cut-off point for maternal temperature to diagnose neonatal sepsis.

Of the 299 included patients, 15 had a birth weight below the 10th percentile, of which three neonates had signs of infection. In these three neonates, maternal CRP 
values were $16 \mathrm{mg} / \mathrm{l}, 17 \mathrm{mg} / \mathrm{l}$ and $9 \mathrm{mg} / \mathrm{l}$, respectively, whereas in the 12 low-birthweight neonates without signs of infection, maternal CRP values varied from $3 \mathrm{mg} / \mathrm{l}$ to $27 \mathrm{mg} / \mathrm{l}$. Thus, we did not find an indication that measuring CRP was useful in small-forgestational-age infants.

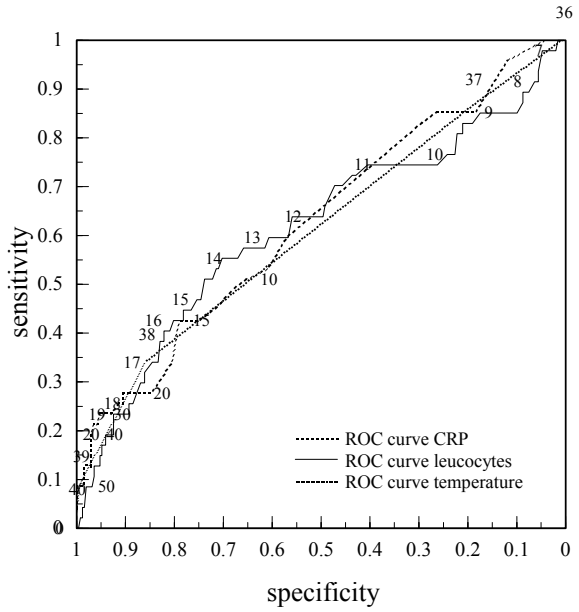

Figure 6.3 Combined receiver operating characteristic (ROC) curves of C-reactive protein (CRP), leukocytes and maternal temperature.

\section{Discussion}

We studied almost 300 women with PROM between 26 and 42 weeks' gestation. In the six children with early onset sepsis, maternal CRP last measured before birth did not rise above $50 \mathrm{mg} / \mathrm{l}$ and leukocyte values varied between 9.8 and $25.8 \times 10^{9} / \mathrm{l}$. CRP and leukocytes had an area under the ROC curve of only 0.61 and 0.62 in the prediction of clinical infection.

A possible limitation of this study is its retrospective character. In the study period, CRP and leukocytes might have been used in the decision to induce labor or to stop tocolysis. Although exact data on the number of patients in whom this occurred are not known, we do not think that this has a major impact on our results. Another limitation might be the subjectivity of the term "clinical infection". What some physicians might call a clinical infection might be interpreted as symptom(s) due to another cause by other physicians.

We tried to overcome this by making a list of possible symptoms of infection (e.g. tachypnea, feeding problems or hypothermia). If we could not find another explanation for these symptoms, we considered the symptom(s) as a clinical infection. Moreover, the diagnosis of clinical infection was made independently from the results of CRP and leukocytes. 
Among the 386 included patients, 56 did not have CRP and leukocytes measured. As this was a retrospective study, it is inevitable that some data are missing. It is possible that some patients had contractions and delivered before these parameters could be measured. These missing values occurred at random rather than systematically.

The fact that the results of CRP and leukocytes were known to the clinician might have caused bias. However, the complete absence of an association between CRP and leukocytes on one hand and the occurrence of sepsis on the other hand can not be explained completely by this bias.

As this was a retrospective study with limited resources, we did not perform a power calculation prior to our study, but rather decided to collect data over the period 2003 to 2006 as this was within our possibilities. Few studies on diagnostic accuracy report considerations of sample size. ${ }^{12} \mathrm{~A}$ post hoc power calculation showed that the sample size of 47 cases with suspected infection was large enough to rule out with $95 \%$ certainty that the sensitivity of either CRP or leukocytes was higher than $64 \%$. This is sufficient to conclude that the test is not useful in clinical practice. Similarly, the specificity was at maximum $56 \%$.

Previous studies have reported the predictive capacity of CRP and leukocyte measurement in patients with PROM in respect to chorioamnionitis. Conflicting results were found, but overall CRP was shown not to be predictive for the early diagnosis of chorioamnionitis. Only Hirsch et al studied the association between CRP and neonatal infection and hypothesized that CRP might help determine the risk of infection, especially in infants with low birth weight. ${ }^{7}$

At present, the effectiveness of induction of labor and expectant management in women with PPROM near term are evaluated in several multicenter trials. ${ }^{4,13}$ In the PPROMEXIL trial, CRP and leukocytes in maternal serum are also measured. These data might provide new insight in the potential value of measuring CRP and leukocytes in maternal serum.

Because we found no evidence that measuring CRP and leukocytes in women with PROM is useful in the prediction of neonatal infection, we recommend that these parameters not be measured routinely these parameters in women with PROM. Particularly, these parameters should not be used to in the decision to induce labor or to maintain expectant management. Other factors, such as fetal tachycardia, fetid and/or green amniotic fluid, and maternal fever might be better indicators of intrauterine infection. Based on our study, we conclude that in women with PROM, CRP and white blood cells measured in maternal serum are poor predictors of neonatal infection. These parameters should therefore not be measured routinely in women with PROM. 


\section{References}

1. Modena $A B$, Kaihura $C$, Fieni S. Prelabour rupture of the membranes: recent evidence. Acta Biomed 2004;75:5-10.

2. Neerhof MG, Cravello C, Haney El, Siver RK: Timing of labour induction after premature rupture of membranes between 32 and 36 weeks gestation. Am J Obstet Gynecol 1999;180:349-52.

3. Lieman JM, Brumfield CG, Carlo W: Preterm premature rupture of membranes: Is there an optimal gestational age for delivery? Obstet Gynecol 2005;105:12-7.

4. van der Ham DP, Nijhuis JG, Mol BW, van Beek JJ, Opmeer BC, Bijlenga D, Groenewout M, Arabin B, Bloemenkamp KW, van Wijngaarden WJ, Wouters MG, Pernet PJ, Porath MM, Molkenboer JF, Derks JB, Kars MM, Scheepers HC, Weinans MJ, Woiski MD, Wildschut HI, Willekes C. Induction of labour versus expectant management in women with preterm prelabour rupture of membranes between 34 and 37 weeks (the PPROMEXIL-trial). BMC Pregnancy Childbirth 2007;7:11.

5. Hirsch W, Koppitz D, Morack G, Gerhardt C. C-reactive protein in the maternal serum and risk of fetal infection in premature rupture of the fetal membranes and threatened premature labor. Zentralbl Gynakol 1989;111: 1411-6.

6. Salzer HR, Genger H, Muhar U. C-reactive protein: an early marker for neonatal bacterial infection due to prolonged rupture of amniotic membranes and/of amnionitis. Acta Obstet Gynaecol Scand 1987;66: 365-7.

7. Farb HF, Arnesen M, Geistler P, Knox GE. C-reactive protein with premature rupture of membranes and premature labor. Obstet Gynecol 1983;62:49-51.

8. Trochez-Martinez RD, Smith P, Lamont RF. Use of C-reactive protein as a predictor of chorioamnionitis in preterm prelabour rupture of membranes: a systematic review. BJOG 2007;114:796-801.

9. Kenyon S, Boulvain M, Neilson J. Antibiotics for preterm rupture of membranes. Cochrane Database Syst Rev 2003:CD001058.

10. Goldstein B, Giroir B, Randolph A. International pediatric sepsis consensus conference: Definitions for sepsis and organ dysfunction in pediatrics. Pediatr Crit Care Med 2005;6:2-8.

11. Bossuyt PM, Reitsma JB. Standards for Reporting of Diagnostic Accuracy; The STARD initiative. Lancet 2003;361:71.

12. Bachmann LM, Puhan MA, ter Riet G, Bossuyt PM. Sample sizes of studies on diagnostic accuracy: literature survey. BMJ 2006;332:1127-9.

13. Morris JM, Roberts CL, Crowther CA, Buchanan SL, Henderson-Smart DJ, Salkeld G. Protocol for the immediate delivery versus expectant care of women with preterm prelabour rupture of the membranes close to term (PPROMT) Trial (ISRCTN44485060). BMC Pregnancy Childbirth 2006;6:9 


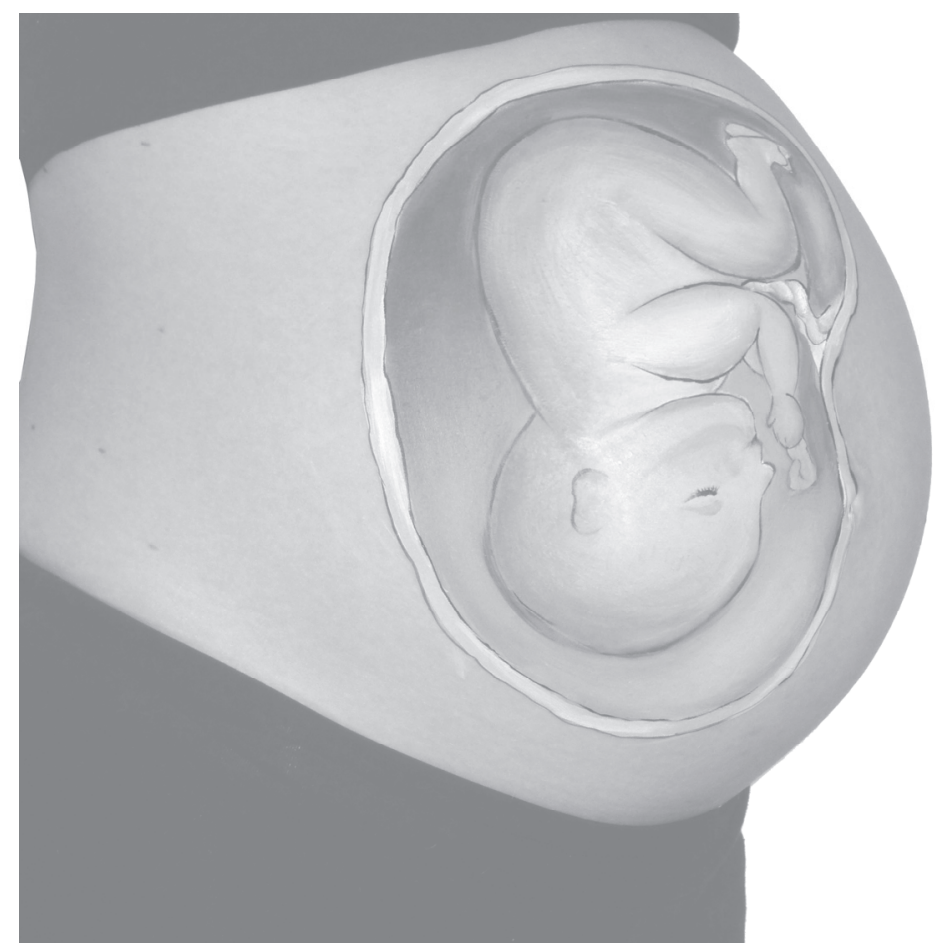




\title{
Chapter 7
}

\section{Management of late-preterm premature rupture of}

membranes: the PPROMEXIL-2 trial

\author{
DP van der Ham \\ JL van der Heyden \\ BC Opmeer \\ ALM Mulder \\ RMJ Moonen \\ J van Beek \\ MTM Franssen \\ KWM Bloemenkamp \\ M Sikkema \\ CJM de Groot \\ $M$ Porath \\ A Kwee \\ MD Woiski \\ J Duvekot \\ BMC Akerboom \\ AJ van Loon \\ JW de Leeuw \\ BWJ Mol \\ JG Nijhuis
}

Am J Obstet Gynecol 2012;207:276.e1-276.e10 


\section{Abstract}

\section{Objective}

The evidence for the management of near term prelabor rupture of membranes is poor. From January 2007 until September 2009, we performed the PPROM Expectant Management versus Induction of Labor (PPROMEXIL) trial. In this trial, we showed that in women with preterm prelabor rupture of membranes (PPROM), the incidence of neonatal sepsis was low, and the induction of labor (loL) did not reduce this risk. Because the PPROMEXIL trial was underpowered and because of a lower-than-expected incidence of neonatal sepsis, we performed a second trial (PPROMEXIL-2), aiming to randomize 200 patients to improve the evidence in near-term PPROM.

\section{Study design}

In a nationwide multicenter study, nonlaboring women with PPROM between 34 and 37 weeks' gestational age were eligible for inclusion. Patients were randomized to loL or expectant management (EM). The primary outcome measure was neonatal sepsis.

\section{Results}

From December 2009 until January 2011, we randomized 100 women to loL and 95 to EM. Neonatal sepsis was seen in 3 neonates (3.0\%) in the loL-group versus 4 neonates (4.1\%) in the EM group (relative risk, 0.74; $95 \%$ confidence interval, $0.17-3.2$ ). One of the sepsis cases in the loL group resulted in neonatal death because of asphyxia. There were no significant differences in secondary outcomes.

\section{Conclusion}

The risk of neonatal sepsis after PPROM near term is low. Induction of labor does not reduce this risk. 


\section{Background}

Preterm prelabor rupture of membranes (PPROM) is associated with neonatal morbidity and mortality as well as maternal morbidity. ${ }^{1-4}$ In international guidelines, no clear recommendation is given on the management of PPROM between 34 and 37 weeks. $^{5-7}$

A recent Cochrane review on the management of PPROM prior to 37 weeks demonstrated insufficient evidence for the management of PPROM in clinical practice. ${ }^{3}$ Given this lack of evidence to justify the induction of labor or expectant management, a randomized controlled trial was performed as the PPROMEXIL (PPROM Expectant Management versus Induction of Labor) trial. ${ }^{8}$ In this trial, we tested the hypothesis that induction of labor ( $\mathrm{loL}$ ) would reduce the incidence of neonatal sepsis.

In the PPROMEXIL trial, the incidence of neonatal sepsis in the expectant group was $4.1 \%$, which is lower than the expected $7.5 \%$, and the risk of neonatal sepsis was not decreased by induction of labor (2.6\% vs $4.1 \%$; relative risk [RR], 0.64 ; $95 \%$ confidence interval $[\mathrm{Cl}], 0.25-1.6)$. In contrast, in the loL group, the risk of neonatal hypoglycemia and hyperbilirubinemia was increased $(\mathrm{RR}, 2.2 ; 95 \% \mathrm{Cl}, 1.4-3.4$, and $\mathrm{RR}, 1.5 ; 95 \% \mathrm{Cl}$, 1.1-1.9, respectively). Because of this lack of power, there remained equipoise on the subject after the completion of our PPROMEXIL trial.

In view of this equipoise and in view of uncertainty of the continuation of the other large ongoing trial on the subject at that time, Preterm Prelabour Rupture of Membranes Close to Term Trial(PPROMT), ${ }^{9}$ which was dependent on funding, we decided to set up a new trial called PPROMEXIL-2, with a similar design as our PPROMEXIL study, aiming to randomize an additional 200 women. We planned to combine the results of the PPROMEXIL trials with the results of the possible prematurely terminated PPROMT trial into an individual patient data meta-analysis, which would then reach the planned power calculation of the PPROMT trial. The decision to start PPROMEXIL-2 was made after the completion and analysis of the results of PPROMEXIL, and it should therefore be considered as an independent trial.

\section{Materials and methods}

We performed a nationwide randomized controlled trial in The Netherlands between December 2009 until January 2011. The methods of this trial have been described earlier extensively by van der Ham et al. ${ }^{8,10}$ The PPROMEXIL-2 trial was a randomized controlled trial that ran in 60 academic and nonacademic hospitals in The Netherlands. For the PPROMEXIL-2 trial, no changes were made in this trial protocol or in the outcome measures. This trial was registered in the ISRCTN register: ISRCTN05689407 (http://www.controlledtrials.com/ISRCTN05689407/ppromexil). 
The PPROMEXIL-2 study was approved by the Medical Ethics Committee of the Maastricht University Medical Center as an amendment of the PPROMEXIL trial (MEC 05-240).

Women with a singleton or twin pregnancy were eligible for the PPROMEXIL trial when they were not in labor 24 hours after PPROM between 34 and 37 weeks of gestational age. PPROM had to be diagnosed after $26+0$ weeks. Women with a monochorionic multiple pregnancy, nonreassuring cardiotocogram, meconium stained amniotic fluid, major fetal anomalies, HELLP (hemolysis, elevated liver enzymes, andlow platelets) syndrome, or severe preeclampsia and signs of intrauterine infections were not eligible.

Randomization was performed in a password-protected, web-based database in a 1:1 for immediate delivery ( $\mathrm{OL}$ ) versus expectant management (EM). If women were allocated to loL, labor was induced within 24 hours after randomization. IoL was performed according to the Dutch national guidelines. ${ }^{11}$ If a cesarean section was indicated (for example, in the case of a child in breech position), this was done as soon as feasible after randomization. Women allocated to EM were monitored according to a standard local protocol, until delivery started spontaneously. If a participant reached $37+0$ weeks' gestational age (GA), labor was induced. Labor was induced prior to $37+0$ weeks of gestation when there were clinical signs of infection or on another neonatal or maternal indication that justified induction of labor. Data were collected by research staff in a web-based, password-protected database. The Dutch guidelines on PPROM give no clear recommendation on the use of antibiotics prior to labor. Therefore, antibiotics were administered according to local protocol. In pregnancies with PPROM prior to 34 weeks' gestation, corticosteroids were given for fetal pulmonary maturation. Administration of tocolytics was dependent on the local protocol.

\section{Outcome measures}

The primary outcome was neonatal sepsis, defined as a positive blood culture taken at birth (not Staphylococcus epidermidis) or within 72 hours 2 or more symptoms of infection (apnea, temperature instability, lethargy, feeding, intolerance, respiratory distress, hemodynamic instability) plus 1 of the following 3 items: (1) positive blood culture (culture-proven sepsis); (b) C-reactive protein greater than 20 (suspicion sepsis); or (3) positive surface cultures of a known virulent pathogen (suspicion of sepsis). When the local investigator classified a case as sepsis or when criteria for sepsis were registered in the database, the case was judged by an independent panel of pediatricians (A.L.M.M., R.M.J.M.) who were not aware of the allocation of randomization. After the relevant data were presented to the panel, they adjudicated between neonatal sepsis (proven or suspected sepsis) or no sepsis. Secondary neonatal outcome measures were respiratory distress syndrome, asphyxia, hypoglycemia, hyperbilirubinemia, total length of hospital stay and admission, and length of stay on 
the neonatal intensive care unit (NICU) and perinatal death. Maternal outcome measures were antepartum hemorrhage, signs of (histological or clinical) chorioamnionitis, total length of hospital stay, and admission to the intensive care unit. Finally, we recorded mode of delivery and need for anesthesia.

No changes to trial outcomes were made after the trial commenced.

\section{Statistical analysis and meta-analysis}

Within a well-organized nationwide Dutch research consortium, it seemed feasible to recruit 200 patients within approximately 1 year. These 200 patients combined with the 536 patients of the PPROMEXIL trial ${ }^{8}$ and the estimated number of included patients at the end of 2010 for the PPROMT trial ${ }^{9}$ would provide the power calculation as calculated by the investigators of the PPROMT trial (1812 women). Therefore, no separate power calculation was done for this trial.

Data were analyzed on an intention-to-treat basis. The RRs, absolute risk reduction, mean difference (MD), and $95 \% \mathrm{Cls}$ were calculated for the relevant outcome measures. $P<0.05$ was considered to indicate statistical significance. Statistical analyses were performed using SPSS Statistics (version 17.0; SPSS Inc, Chicago, IL).

We further updated a recent Cochrane review ${ }^{3}$ on the subject for sepsis (overall), culture proven neonatal sepsis, respiratory distress syndrome (RDS), and the cesarean section rate as we did after the PPROMEXIL trial ${ }^{8}$ with the data from the PPROMEXIL trial and the current PPROMEXIL-2 trial, using Review Manager Software version 5.1. ${ }^{12}$

\section{Results}

From December 2009 until January 2011, a total of 241 women were asked to participate in the trial, of which 198 women (82\%) gave informed consent. Of these women, 3 had to be excluded because they had been randomized at a gestational age longer than $36+6$ weeks. The remaining 195 women were eligible for analysis. A total of 100 women were randomized to induction of labor (loL group) and 95 to expectant management (EM group). Figure 7.1 outlines the study profile.

Baseline characteristics are shown in Table 7.1. The median gestational age at randomization was 251 days. Thirty three women (17\%) had PPROM prior to 34 weeks' GA. 


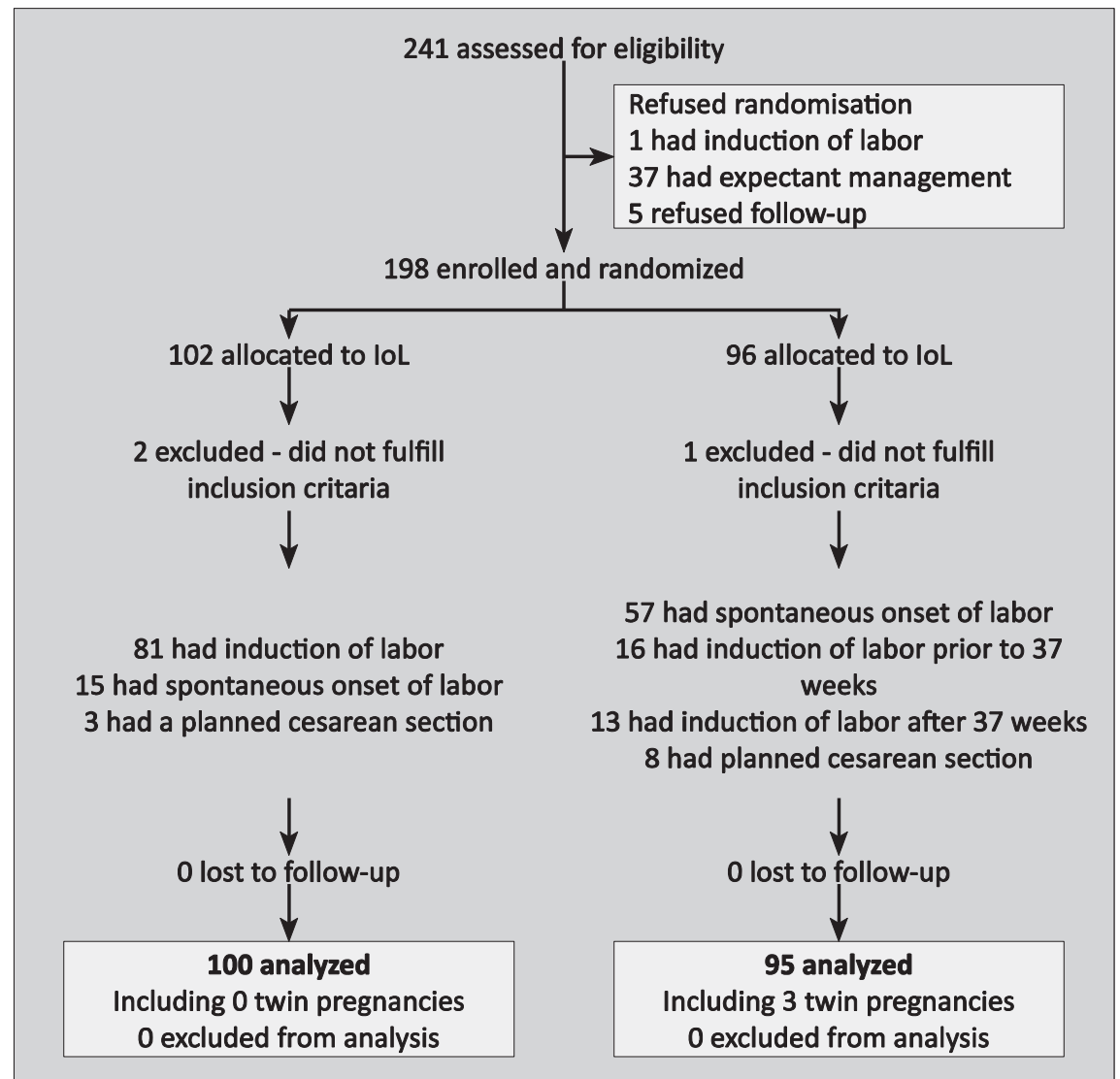

Figure 7.1 Trial profile.

Table 7.2 shows data on pregnancy outcome and mode of delivery. Women in the loL group delivered on average 3.5 days earlier ( $95 \% \mathrm{Cl}, 1.8-5.2$ days) than women in the EM group. Women in the EM group stayed on average 4.4 days longer in the hospital (95\% $\mathrm{Cl}, 2.2-6.7$ days).

The mode of delivery was not statistically significant different. There were fewer cesarean sections in the loL group (13 [13\%] vs. 22 [22\%]; RR, 0.58; 95\% Cl, 0.31-1.08; $P=0.081$ ). This difference was partly because of the higher number of planned cesarean sections in the EM-group(3 vs. 8), which was known at baseline and could not be due to randomization.

Antibiotics during admission and during labor were administered equally.

There were no differences in the rates of epidural and/or spinal analgesia. 
Table 7.1 Baseline characteristics.

\begin{tabular}{|c|c|c|}
\hline Characteristic $^{\mathrm{a}}$ & IoL $(n=100)$ & $\operatorname{EM}(n=95)$ \\
\hline Maternal age (range) [ $\pm S D], y$ & $30.5(19.4-43.6)[ \pm 5.3]$ & $29.4(19.2-41.8)[ \pm 5.0]$ \\
\hline Number nulliparous, n (range) (\%) & $48(0-6)(48 \%)$ & $49(0-4)(52 \%)$ \\
\hline Twin pregnancy, n (\%) & $0(0 \%)$ & \\
\hline \multicolumn{3}{|l|}{ Ethnic origin } \\
\hline White, n (\%) & $78(78 \%)$ & $67(71 \%)$ \\
\hline Other etnic origin, $\mathrm{n}(\%)$ & $15(15 \%)$ & $18(19 \%)$ \\
\hline Unknown, n (\%) & $7(7.0 \%)$ & $10(11 \%)$ \\
\hline \multicolumn{3}{|l|}{ Education } \\
\hline Primary school (4 to $12 \mathrm{y}), \mathrm{n}(\%)^{\mathrm{b}}$ & $0(0 \%)$ & $2(4.0 \%)$ \\
\hline Secondary school (12-18 y), n(\%) & $9(17 \%)$ & $3(6.0 \%)$ \\
\hline Lower professional school, $\mathrm{n}(\%)^{\mathrm{b}}$ & $5(9.3 \%)$ & $6(12 \%)$ \\
\hline Medium professional school, $\mathrm{n}(\%)^{\mathrm{b}}$ & $20(37 \%)$ & $23(46 \%)$ \\
\hline Higher professional school, $\mathrm{n}(\%)^{\mathrm{b}}$ & $19(35 \%)$ & $11(22 \%)$ \\
\hline University, $\mathrm{n}(\%)^{\mathrm{b}}$ & $1(1.9 \%)$ & $5(10 \%)$ \\
\hline Maternal smoking, n (\%) & $25(27 \%)$ & $25(27 \%)$ \\
\hline Antenatal administration of corticosteroids, $\mathrm{n}(\%)$ & $20(22 \%)$ & $13(16 \%)$ \\
\hline \multicolumn{3}{|l|}{ Body mass index } \\
\hline At booking (range) $[ \pm \mathrm{SD}], \mathrm{kg} / \mathrm{m}^{2 \mathrm{c}}$ & $26.2(16.5-53.3)[ \pm 6.6]$ & $25.0(15.8-46.3)[ \pm 6.4]$ \\
\hline At study entry (range) $[ \pm \mathrm{SD}], \mathrm{kg} / \mathrm{m}^{2 \mathrm{c}}$ & $30.1(17.8-56.2)[ \pm 8.1]$ & $29.6(20.8-46.3)[ \pm 5.6]$ \\
\hline \multicolumn{3}{|l|}{ Diagnostic test for rupture of membranes ${ }^{d}$} \\
\hline Positive history, n (\%) & $67(70 \%)$ & $71(76 \%)$ \\
\hline Positive ferning, n (\%) & $48(79 \%)$ & $34(67 \%)$ \\
\hline Positive $\mathrm{pH}$ test, $\mathrm{n}(\%)$ & $2(7.7 \%)$ & $2(7.7 \%)$ \\
\hline Positive PAMG-1 test, $\mathrm{n}(\%)$ & $11(32 \%)$ & $19(50 \%)$ \\
\hline Decrease amniotic fluid on ultrasound, $\mathrm{n}(\%)$ & $53(76 \%)$ & $52(70 \%)$ \\
\hline \multicolumn{3}{|l|}{ Gestational age at PPROM } \\
\hline$<34$ wks, n (\%) & $20(20 \%)$ & $13(14 \%)$ \\
\hline $34+0$ to $34+6$ wks, $n(\%)$ & $11(11 \%)$ & $16(17 \%)$ \\
\hline $35+0$ to $35+6$ wks, $n(\%)$ & $29(29 \%)$ & $28(30 \%)$ \\
\hline $36+0$ to $36+6$ wks, $n(\%)$ & $40(40 \%)$ & 37 (39\%) \\
\hline Gestational age at PPROM, median [IQR], d & $249[240-254]$ & 249 [241-253] \\
\hline Gestational age at randomization, median [IQR], d & $251[242-255]$ & $251[243-255]$ \\
\hline \multicolumn{3}{|l|}{ Fetal position at data entry } \\
\hline Cephalic, n (\%) & 96 (96\%) & $87(92 \%)$ \\
\hline Breech, n (\%) & $4(4.0 \%)$ & $8(8.4 \%)$ \\
\hline Maternal temperature at inclusion, mean $[ \pm S D]$ oC & $36.8[ \pm 0.44]$ & $36.8[ \pm 0.44]$ \\
\hline
\end{tabular}

IQR, interquartile range; PAMG-1, placental alpha macroglobulin-1; PPROM, preterm prelabor rupture of membranes. ${ }^{a}$ Percentages given are related to available data per characteristic and may differ from total number of patients; ${ }^{b}$ Percentages are given as part of known educational level; ${ }^{c}$ Outcome characteristic with more than $5 \%$ missing data; ethnic origin: data available from 178 cases (91\%); education: data available from 104 cases (53\%); maternal smoking: data available from 184 cases (94\%); body mass index at booking: data available from 161 cases (84\%); body mass index at start study available from 84 cases (44\%); antenatal administration of corticosteroids: data available from 173 cases (89\%); maternal temperature at inclusion: data available from 172 cases (90\%); ${ }^{d}$ Sum of tests exceeds $100 \%$ because more than 1 test could be applied on the same patient; percentages are given as part of applied tests. Data on positive history were available from 190 of 195 cases (97\%). Ferning was done in 112 cases, pH test was done in 52 cases, PAMG-1 test was done in 72 cases, and ultrasound was done in 146 cases; $^{e}$ In one woman, the term at rupture of membranes was unknown. 


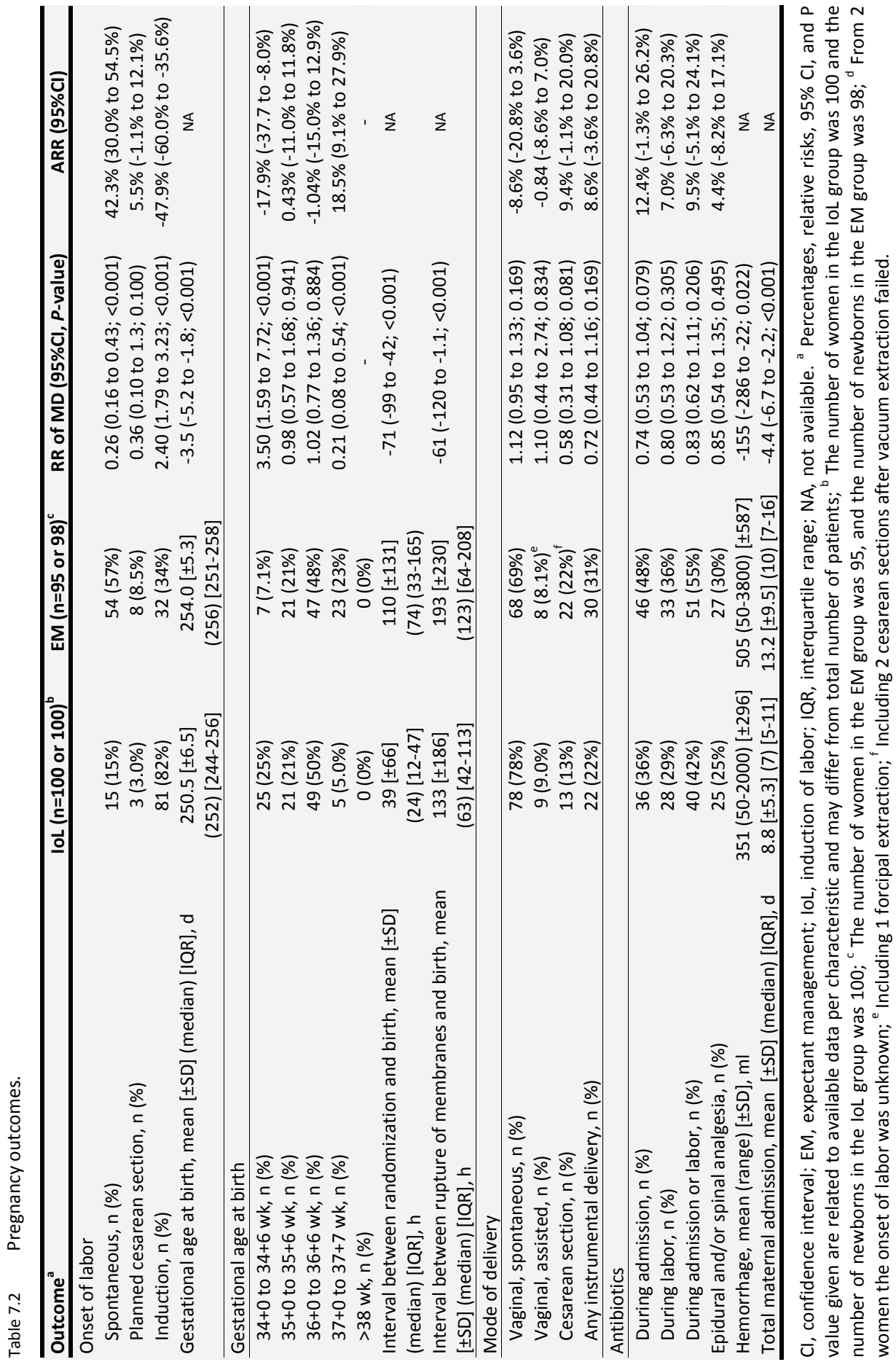




\section{Neonatal sepsis}

Neonatal sepsis was seen in 3 neonates (3.0\%) in the loL group versus four (4.1\%) in the EM group (RR, $0.74 ; 95 \% \mathrm{Cl}, 0.17-3.2$ ) (Table 7.3). One neonate in he loL group who had a proven sepsis died 48 hours postpartum because of the complications of a severe asphyxia and anemia. During labor, fetal blood sampling was performed because of a suboptimal cardiotocography. This procedure resulted in heavy blood loss, after which an emergency cesarean section was performed. An asphyctic male neonate (arterial pH $6.98 \mathrm{mmol} / \mathrm{I}$ and Apgar score 0/0) was born and was transferred to an NICU-center in which multi-organ failure occurred with a Sarnat stage 3 asphyxia and positive blood cultures for group B-Streptococcus. The child died 48 hours postpartum. This case was reported to the Medical Ethical Committee of the Maastricht University Medical Center, and it was extensively discussed by our panel of neonatologists (A.L.M.M, R.M.J.M.) as well as by an independent gynecologist. Neonatal death was considered to be related to the severe asphyxia and anemia and not to neonatal sepsis. Induction of labor was not considered to be the cause of this severe adverse event.

\section{Other neonatal outcomes}

Table 7.3 shows all neonatal outcomes. Neonates born in the loL group stayed 7.4 days in the hospital compared with 6.9 days (MD, $0.52 ; 95 \% \mathrm{Cl},-0.5$ to 2.3 days) after EM. Neonates in the loL group were equally admitted to the NICU (7 [7.0\%] cases vs. 8 [8.2\%] in the EM group; RR, 0.86; $95 \% \mathrm{Cl}, 0.32-2.3$ ). Newborns admitted to the NICU in the loL group stayed a shorter time than those in the EM group (mean 2.0 vs. 7.0 days; $\mathrm{MD},-5.0 ; 95 \% \mathrm{Cl},-9.0$ to -1.0$)$. Respiratory distress syndrome was seen in 6 newborns in the loL group (6.0\%) versus 5 in the $\mathrm{EM}$ group (5.1\%) (RR, 1.2; $95 \% \mathrm{Cl}, 0.37-3.7)$. Hypoglycemia (8 [8.1\%] vs. 8 [8.2\%]; RR, $0.99 ; 95 \% \quad \mathrm{Cl}, 0.39-2.5)$ and hyperbilirubinemia (20 [20\%] vs. 21 [21\%]; RR, $0.95 ; 95 \% \mathrm{Cl}, 0.55-1.6)$ were seen equally in both groups. For other neonatal outcome measures, there were also no significant differences between both groups.

\section{Maternal outcomes}

Table 7.4 shows all maternal outcomes. Clinical chorioamnionitis was not seen in the loL group and in 4 women in the EM group $(4.3 \%)(P=0.038)$. The incidence of histological chorioamnionitis was $12(18 \%)$ versus 18 (31\%), respectively (RR, 0.64; 95\% $\mathrm{Cl}, 0.33-1.2)$. 


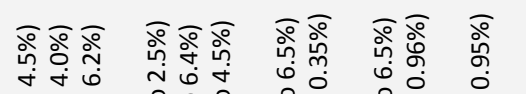

용

용

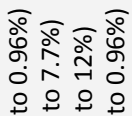

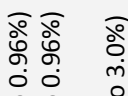

西

$\circ$ 요

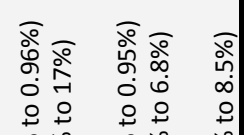

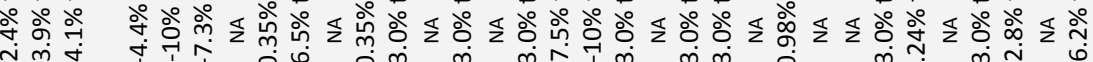

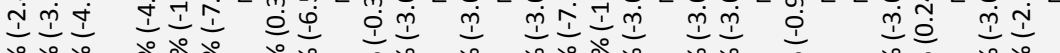

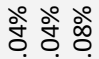

iं

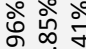

ठे ఫे

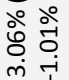

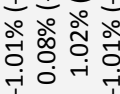

ㅇํㅇ ㅇํㅇ

วัे

oे ठे ळे

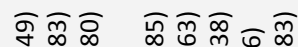

นิำ

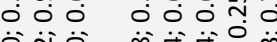

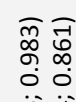

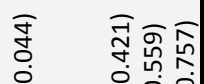

官萑灾

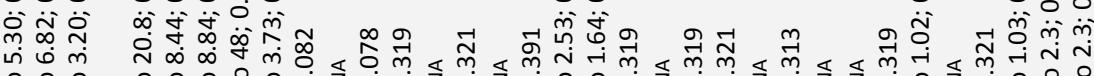

0 ○.

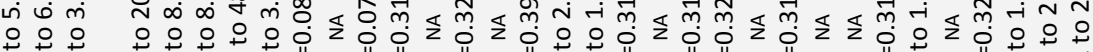

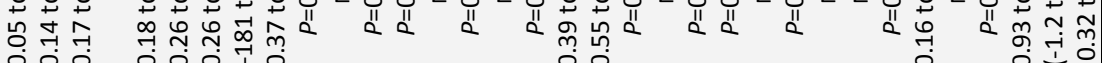

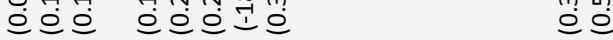

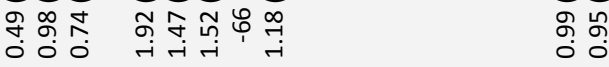

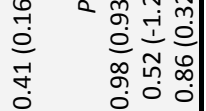

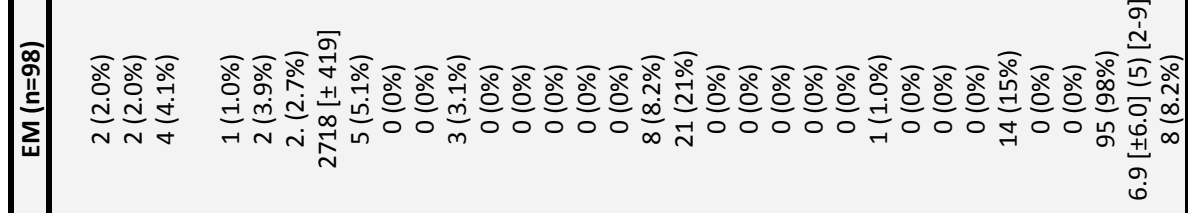

흘

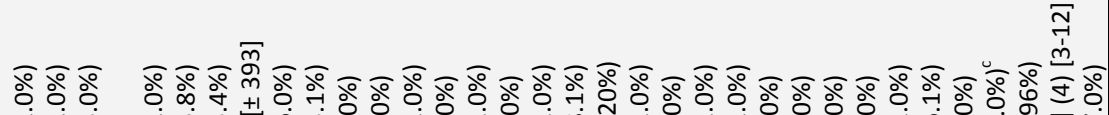

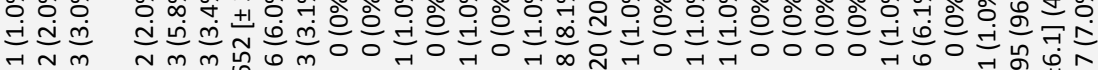


$\mathrm{Cl}$, confidence interval; HIE, hypoxic ischemic encephalopathy; IVH, interventriculair hemorrhage; IQR, interquartile range; NA, not available; NICU, neonatal intensive care unit; PVL, periventriculair leucomalacia; RDS, respiratory distress syndrome. ${ }^{a}$ Percentages, relative risks, $95 \% \mathrm{Cl}$, and $\mathrm{P}$ value given according to available data; ${ }^{b}$ Outcome characteristic with more than $5 \%$ missing data; neonatal temperature data available from 103 cases (52\%); pH umbilical artery $7.1 \mathrm{mmol} / /$ data available from 147 (74\%); ${ }^{\mathrm{C}}$ One neonate died because of a severe anemia after ruptured vasa previa and a proven neonatal sepsis.

\section{Meta-analysis}

In total 1428 neonates could be analyzed from 9 studies for neonatal sepsis, 1090 neonates ( 6 studies) for culture-proven sepsis, 1428 neonates ( 9 studies) for RDS, and 1417 women (9 studies) for cesarean section rate. As shown in Figure 7.2, the risk ratio of all outcomes were not statistically different.

Table 7.4 Maternal outcome.

\begin{tabular}{|c|c|c|c|c|}
\hline Outcome $^{a}$ & IoL $(n=100)$ & $\operatorname{EM}(n=95)$ & RR of $\mathrm{MD}(95 \% \mathrm{Cl}, P$-value $)$ & ARR $(95 \% \mathrm{Cl})$ \\
\hline \multicolumn{5}{|l|}{ Maternal complications } \\
\hline Antepartum hemorrhage, $n(\%)$ & $1(1.0 \%)$ & $1(1.1 \%)$ & 0.95 (0.06 to $15.0 ; 0.971)$ & $0.05 \%(-2.8$ to $2.9 \%)$ \\
\hline Cord prolapse, $\mathrm{n}(\%)$ & $0(0 \%)$ & $0(0 \%)$ & NA & NA \\
\hline Uterine rupture, $\mathrm{n}(\%)$ & $0(0 \%)$ & $0(0 \%)$ & NA & NA \\
\hline Clinical chorioamnionitis, $\mathrm{n}(\%)$ & $0(0 \%)$ & $4(4.3 \%)$ & $p=0.038$ & $4.28 \%(0.18 \%$ to $8.3 \%)$ \\
\hline Infection, $\mathrm{n}(\%)$ & $1(1.0 \%)$ & $2(2.1 \%)$ & $0.47(0.04$ to $5.1 ; 0.530)$ & $1.11 \%(-2.4 \%$ to $4.6 \%)$ \\
\hline Sepsis, $n(\%)$ & $0(0 \%)$ & $0(0 \%)$ & NA & NA \\
\hline $\begin{array}{l}\text { Thromboembolic complications, } n \\
\text { (\%) }\end{array}$ & $0(0 \%)$ & $0(0 \%)$ & NA & NA \\
\hline $\begin{array}{l}\text { Urinary tract infections treated } \\
\text { with antibiotics, } n(\%)\end{array}$ & $1(1.0 \%)$ & $1(1.1 \%)$ & 0.96 (0.06 to $15.1 ; 0.977)$ & $0.04 \%(-2.8 \%$ to $2.9 \%)$ \\
\hline Endometritis, $\mathrm{n}(\%)$ & $0(0 \%)$ & $0(0 \%)$ & NA & NA \\
\hline Pneumonia, n (\%) & $0(0 \%)$ & $0(0 \%)$ & NA & NA \\
\hline Anaphylactic shock, n (\%) & $0(0 \%)$ & $0(0 \%)$ & NA & NA \\
\hline HELLP syndrome, $n(\%)$ & $0(0 \%)$ & $0(0 \%)$ & NA & NA \\
\hline Death, $\mathrm{n}(\%)$ & $0(0 \%)$ & $0(0 \%)$ & NA & NA \\
\hline Other complications, $\mathrm{n}(\%)$ & $1(1.0 \%)$ & $3(3.2 \%)$ & 0.32 (0.03 to $2.99 ; 0.289$ ) & $2.18 \%(-1.9 \%$ to $6.2 \%)$ \\
\hline \multicolumn{5}{|l|}{ Perineum } \\
\hline No laceration, $\mathrm{n}(\%)$ & $46(47 \%)$ & $46(49 \%)$ & 0.95 (0.71 to $1.28 ; 0.731)$ & $2.47 \%(-12 \%$ to $17 \%)$ \\
\hline First degree laceration, $\mathrm{n}(\%)$ & $14(14 \%)$ & $18(19 \%)$ & 0.74 (0.39 to $1.40 ; 0.350)$ & $5.01 \%(-5.5 \%$ to $16 \%)$ \\
\hline Second degree laceration, $\mathrm{n}(\%)$ & 9 (9.1\%) & $8(8.5 \%)$ & 1.07 (0.43 to $2.65 ; 0.887)$ & $-0.58 \%(-8.6 \%$ to $7.4 \%)$ \\
\hline Third degree laceration, $n(\%)$ & $1(1.0 \%)$ & $1(1.1 \%)$ & 0.95 (0.06 to $15.0 ; 0.971)$ & $0.05 \%(-2.8 \%$ to $2.9 \%)$ \\
\hline Fourth degree laceration, $n(\%)$ & $2(2.0 \%)$ & $1(1.1 \%)$ & 1.90 (0.18 to $20.6 ; 0.591)$ & $-0.96 \%(-4.4 \%$ to $2.5 \%)$ \\
\hline Episiotomy, $\mathrm{n}(\%)$ & $27(27 \%)$ & $21(22 \%)$ & 1.22 (0.74 to $2.00 ; 0.428)$ & $-4.93 \%(-17 \%$ to $7.2 \%)$ \\
\hline \multicolumn{5}{|l|}{ Delivery placenta } \\
\hline Spontaneous, n (\%) & $78(78 \%)$ & $64(67 \%)$ & $1.16(0.97$ to $1.38 ; 0.095)$ & $-10.6 \%$ (-23 to $1.8 \%)$ \\
\hline Manual placental removal, $\mathrm{n}(\%)$ & $9(9 \%)$ & $9(9.5 \%)$ & 0.94 (0.39 to $2.27 ; 0.890)$ & $0.57 \%(-7.6 \%$ to $8.8 \%)$ \\
\hline During cesarean section, $\mathrm{n}(\%)$ & $13(13 \%)$ & $22(23 \%)$ & $0.56(0.30$ to $1.04 ; 0.059)$ & $10.4 \%(-0.40 \%$ to $21 \%)$ \\
\hline $\begin{array}{l}\text { Histological chorioamnionitis, } n \\
(\%)^{b}\end{array}$ & $12(18 \%)$ & $18(31 \%)$ & 0.64 (0.33 to $1.23 ; 0.174)$ & $10.4 \%(-4.7 \%$ to $25 \%)$ \\
\hline Histological funisitis, $\mathrm{n}(\%)^{\mathrm{b}}$ & $6(9.2 \%)$ & $8(14 \%)$ & $0.66(0.24$ to $1.78 ; 0.406)$ & $4.8 \%(-6.6 \%$ to $16 \%)$ \\
\hline
\end{tabular}

$\mathrm{Cl}$, confidence interval; HELLP, hemolysis, elevated liver enzymes, and low platelets; NA, not available.

${ }^{a}$ Percentages, relative risks, $95 \% \mathrm{Cls}$, and $\mathrm{P}$ value given are related to available data per characteristic and may differ from total number of patients; ${ }^{b}$ Outcome characteristic with more than $5 \%$ missing data; histological chorioamnionitis data available from 124 cases (64\%); histological funisitis data available from 122 cases (63\%). 
Induction of labor Expectant management

Risk Ratio

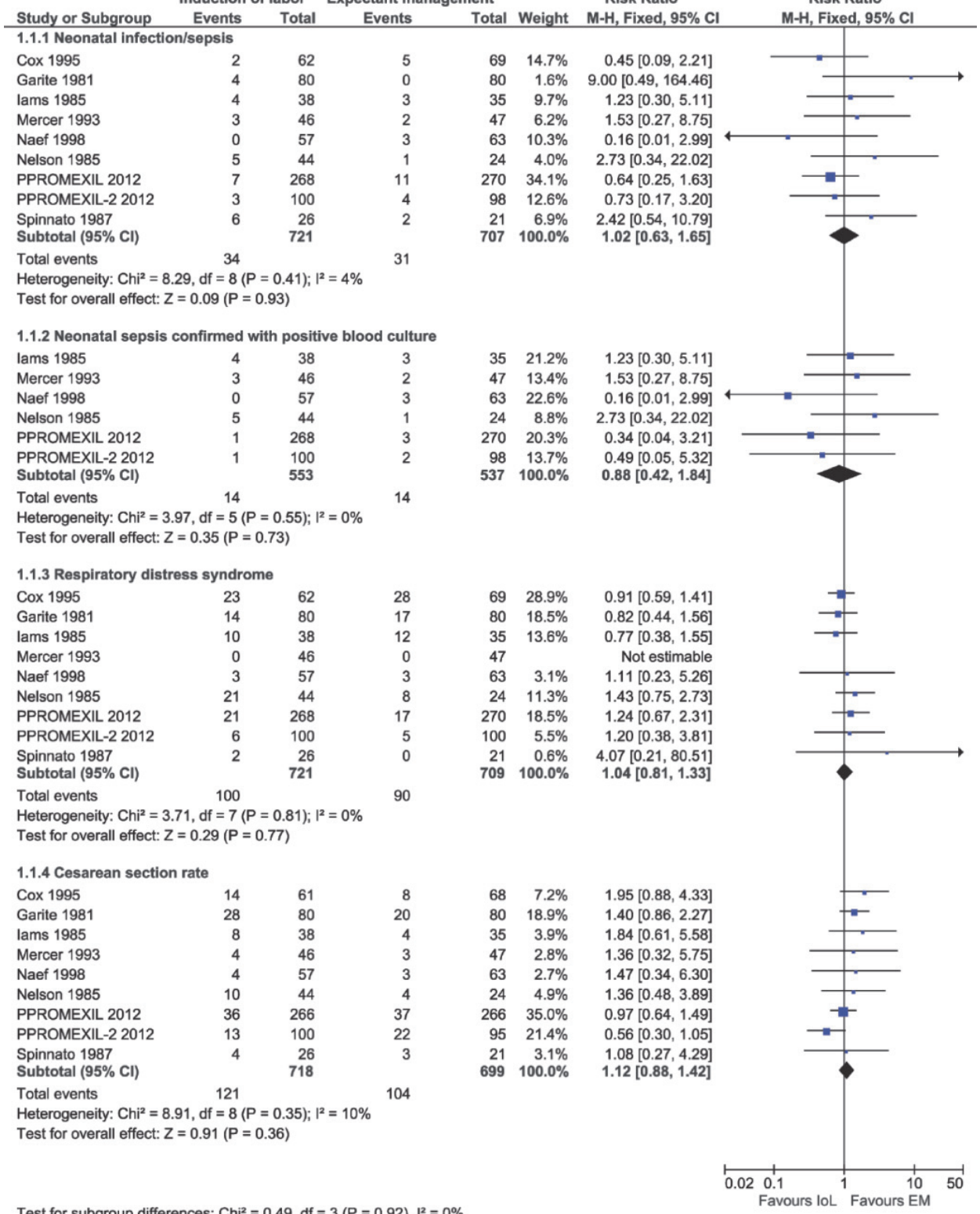

Figure 7.2 Meta analysis. 


\section{Comment}

In this PPROMEXIL-2 trial, 195 women with PPROM between 34 and 37 weeks were included and analyzed. We found that induction of labor did not reduce the incidence of neonatal sepsis, nor did it influence the rates of cesarean section and RDS. Because all cases with possible signs for neonatal sepsis were adjudicated by a panel of neonatologists, we believe that we did not miss any case of neonatal sepsis, nor did we overestimate the incidence of neonatal sepsis. Induction of labor did reduce the risk of clinical chorioamnionitis, but we did not find a significant difference in histological chorioamnionitis. Nevertheless, incidences of chorioamnionitis were in the same magnitude as in the PPROMEXIL trial. It has been suggested in the previous studies that chorioamnionitis is related to cerebral palsy. ${ }^{13-16}$ However, we believe that this association cannot be extrapolated to our population because these studies were reporting on very preterm infants. Because the incidence of cerebral palsy in the near term population is very low, we do not believe that this association justifies induction of labor in women with late preterm PROM.

In contrast to the PPROMEXIL trial, ${ }^{8}$ we found no difference in the incidence of hypoglycemia and hyperbilirubinemia between both groups.

As shown in the meta-analysis based on more than 1400 neonates, expectant management seems to be a safe strategy with respect to neonatal sepsis, RDS, and cesarean section rates.

This trial has its limitations. As mentioned in the introductory text, the design of the study was approved and registered after we finished the PPROMEXIL trial and should therefore be considered as a separate trial. Because of the remaining equipoise at that moment and major funding problems of the ongoing PPROMT trial, ${ }^{9}$ this smaller additional trial was executed to improve the number of inclusion to perform and individual patient data meta-analysis (IPD-MA) with data of PPROMT and both PPROMEXIL trials. Recruitment of an additional 200 women within a 12 month period seemed feasible. However, near the closing of the recruitment of the patients for the PPROMEXIL-2 trial, the investigators of the PPROMT trial gained extra funding to complete their estimated inclusions (1812 women). The results as presented in the current trial should be interpreted with some caution because of the fact that no proper power calculation was done.

As in the PPROMEXIL trial ${ }^{8}$ during which we observed lower-than-expected sepsis rates (2.6\% in the IoL group vs $4.1 \%$ in the EM group), the incidences of sepsis in the PPROMEXIL-2trial were low (3.0\% vs $4.1 \%$, respectively). The liberal use of antibiotic therapy before or during labor (overall $47 \%$ received antibiotics) might have contributed to a lower incidence compared with the other trials in which antibiotics were not administered prophylactically. ${ }^{17-23}$ Improvements in the health care system over the last decades may have contributed to a reduction of the incidence of neonatal sepsis. Expectant management prolonged gestation with 4 days, and this rather small difference, which was in line with the PPROMEXIL trial, might partly be due to the fact 
that the median gestational age at rupture of membranes was $35+4$ weeks and the median gestational age at randomization was $35+6$ weeks. The overrepresentation of women with gestational age longer than 35 weeks can be caused by the fact that women between 34 and 35 weeks of gestation more often refused to participate (mean gestational age at PPROM in the nonrandomized group was $34+6$ weeks). Furthermore, the hesitation of clinicians to induce labor before 35 weeks of gestation, which was not recommended in the Dutch guideline prior to the start of the PPROMEXIL trial, ${ }^{11}$ may also have influenced this outcome. If we combine the results of both PPROMEXIL trials for neonatal sepsis, we find a relative risk of 0.66 (95\% $\mathrm{Cl}, 0.30-1.5)$, and the absolute risk reduction is $1.4 \%(95 \% \mathrm{Cl},-4.0 \%$ to $1.3 \%)$. The number needed to treat with the current combined result of the PPROMEXIL trials is 71 for 1 case of neonatal sepsis. Even if a larger trial like the current ongoing PPROMT trial ${ }^{9}$ or a meta-analysis with independent patient data (IPD-MA) of the current PPROMEXIL trials with the PPROMT trial will find a significant difference, its clinical relevance might be debated.

In view of our recently completed PPROMEXIL and PPROMEXIL-2 studies and in view of the ongoing Australian initiated PPROMT study, one could question whether we could plan the generation of evidence more efficiently from a global perspective. Although we are in close contact with the PPROMT investigators, prospective trial registration at the moment that trials are planned would have been helpful. One could have collaborative execution of the trials under the umbrella of a prospective individual patient data meta-analysis, leaving the decision when to stop studies in such a collaborative to a Data Safety Monitoring Board overseeing all the trials. Until such scenarios have become reality, we believe that planning similar trials in different countries with a post-hoc meta-analysis of data is the best alternative.

In conclusion, this current trial expanded the amount of evidence on the management of near-term PPROM with an additional 195 women. Still, the incidence of neonatal sepsis is low after these pregnancies, and this rate is not reduced by induction of labor. Induction of labor does not increase the risk of any other adverse neonatal or maternal outcome. To this date, the PPROMEXIL trials and updated meta-analysis provide in our opinion enough evidence to prefer expectant management in women with near-term PPROM. 


\section{References}

1. Goldenberg RL, Nelson KG, Davis RO, Koski J. Delay in delivery: influence of gestational age and the duration of delay on perinatal outcome. Obstet Gynecol 1984;64:480-4.

2. Furman B, Shoham-Vardi I, Bashiri A, Erez O, Mazor M. Clinical significance and outcome of preterm prelabor rupture of membranes: population-based study. Eur J Obstet Gynecol Reprod Biol 2000;92:209-16.

3. Buchanan SL, Crowther CA, Levett KM, Middleton P, Morris J. Planned early birth versus expectant management for women with preterm prelabour rupture of membranes prior to 37 weeks' gestation for improving pregnancy outcome. Cochrane Database Syst Rev 2010:CD004735.

4. Mateus J, Fox K, Jain S, Latta R, Cohen J. Preterm premature rupture of membranes: clinical outcomes of late-preterm infants. Clin Pediatr (Phila) 2010;49:60-5.

5. NVOGNet. [Breken van de vliezen voor het begin van de baring]: NVOG, 2002.

6. Gynaecologists RCoOa. Preterm prelabour rupture of membranes, 2006 (vol 2010).

7. ACOG. ACOG Practice Bulletin No. 80: premature rupture of membranes. Clinical management guidelines for obstetrician-gynecologists. Obstet Gynecol 2007;109:1007-19.

8. van der Ham DP, Vijgen SM, Nijhuis JG, et al. Induction of labor versus expectant management in women with preterm prelabor rupture of membranes between 34 and 37 weeks: a randomized controlled trial. PLoS Medicine 2012;9:e1001208.

9. Morris JM, Roberts CL, Crowther CA, Buchanan SL, Henderson-Smart DJ, Salkeld G. Protocol for the immediate delivery versus expectant care of women with preterm prelabour rupture of the membranes close to term (PPROMT) Trial [ISRCTN44485060]. BMC Pregnancy Childbirth 2006;6:9.

10. van der Ham DP, Nijhuis JG, Mol BW, et al. Induction of labour versus expectant management in women with preterm prelabour rupture of membranes between 34 and 37 weeks (the PPROMEXILtrial). BMC Pregnancy Childbirth 2007;7:11.

11. NVOGNet. [Induction of labor]NVOGnet voorlichting \& richtlijnen (vol 2010).

12. Review Manager (RevMan) Copenhagen: The Nordic Cochrane Centre, The Cochrane Collaboration, 2011.

13. Alexander JM, McIntire DM, Leveno KJ. Chorioamnionitis and the prognosis for term infants. Obstet Gynecol 1999;94:274-8.

14. Lau J, Magee F, Qiu Z, Hoube J, Von Dadelszen P, Lee SK. Chorioamnionitis with a fetal inflammatory response is associated with higher neonatal mortality, morbidity, and resource use than chorioamnionitis displaying a maternal inflammatory response only. Am J Obstet Gynecol 2005;193: 708-13.

15. Leviton A, Allred EN, Kuban KC, et al. Microbiologic and histologic characteristics of the extremely preterm infant's placenta predict white matter damage and later cerebral palsy. the ELGAN study. Pediatr Res 2010;67:95-101.

16. O'Shea TM, Allred EN, Dammann O, et al. The ELGAN study of the brain and related disorders in extremely low gestational age newborns. Early Hum Dev 2009;85:719-25.

17. Garite TJ, Freeman RK, Linzey EM, Braly PS, Dorchester WL. Prospective randomized study of corticosteroids in the management of premature rupture of the membranes and the premature gestation. Am J Obstet Gynecol 1981;141:508-15.

18. lams JD, Talbert ML, Barrows H, Sachs L. Management of preterm prematurely ruptured membranes: a prospective randomized comparison of observation versus use of steroids and timed delivery. Am J Obstet Gynecol 1985;151:32-8.

19. Nelson LH, Meis PJ, Hatjis CG, Ernest JM, Dillard R, Schey HM. Premature rupture of membranes: a prospective, randomized evaluation of steroids, latent phase, and expectant management. Obstet Gynecol 1985;66:55-8.

20. Spinnato JA, Shaver DC, Bray EM, Lipshitz J. Preterm premature rupture of the membranes with fetal pulmonary maturity present: a prospective study. Obstet Gynecol 1987;69:196-201.

21. Mercer BM, Crocker LG, Boe NM, Sibai BM. Induction versus expectant management in premature rupture of the membranes with mature amniotic fluid at 32 to 36 weeks: a randomized trial. Am J Obstet Gynecol 1993;169:775-82. 
22. Cox SM, Leveno KJ. Intentional delivery versus expectant management with preterm ruptured membranes at 30-34 weeks' gestation. Obstet Gynecol 1995;86:875-9.

23. Naef RW, 3rd, Allbert JR, Ross EL, Weber BM, Martin RW, Morrison JC. Premature rupture of membranes at 34 to 37 weeks' gestation: aggressive versus conservative management. Am J Obstet Gynecol 1998;178:126-30. 


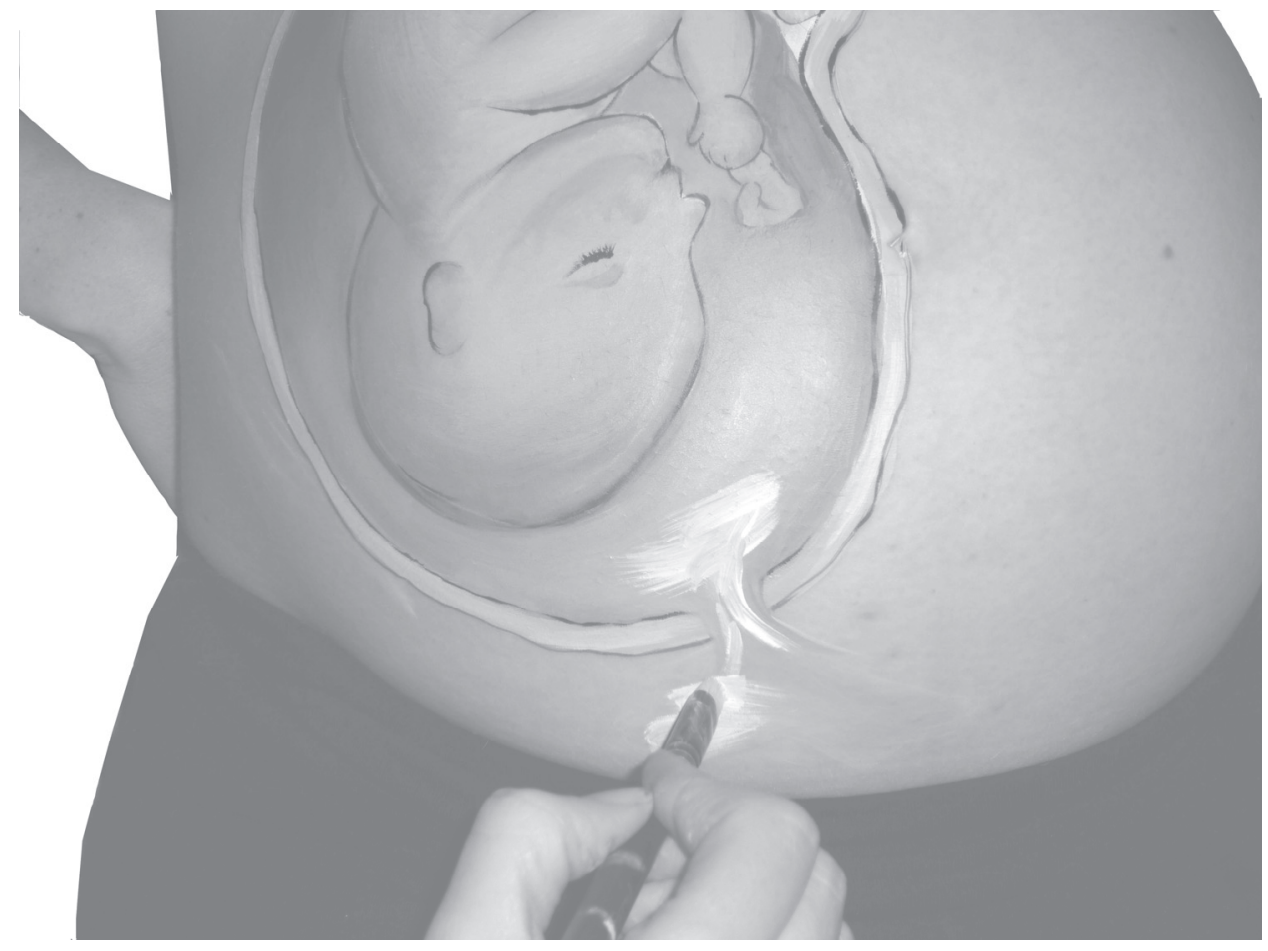




\section{Chapter}

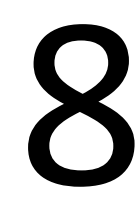

Behavioral and developmental outcome of neonates at 2 years of age after preterm premature rupture of membranes: Follow up of the PPROMEXIL trial

JL van der Heyden

C Willekes

AL van Baar

$A G$ van Wassenaer-Leemhuis

E Pajkrt

MA Oudijk

MM Porath

JJ Duvekot

KWM Bloemenkamp

MTM Franssen

M Woiski

B Nij Bijvank

CJ Bax

$J$ van 't Hooft

JM Sikkema

ALM Mulder

JG Nijhuis

BWJ Mol

DP van der Ham

Submitted 


\section{Abstract}

Introduction

We recently showed in women with late preterm premature rupture of membranes (PPROM) that induction of labor does not improve short term neonatal outcome (PPROMEXIL trial). We here analyze the neuro- and behavorial development at 2 years of age.

\section{Methods and materials}

We studied women with PPROM between 34 and 37 weeks who were not in labor within 24 hours after PPROM. Women had been randomized to induction of labor or expectant management. Women who refused randomization were studied in an observational study. When the children were two years of age, their parents were send the ages and stages questionnaire (ASQ), the child behavioral checklist (CBCL) and a general questionnaire.

\section{Results}

We approached 551 of the 739 eligible women (75\%). Complete follow-up data were obtained from 320 children (response rate $58 \%$ ). In the loL group $14 \%(n=16)$ of children had an abnormal score in $\geq 1$ areas of the ASQ, versus $26 \%(n=27)$ in the EM group ( $R R 0.55,95 \% \mathrm{Cl} 0.32$ to 0.96 ). For the CBCL, an abnormal scores in $\geq 1$ areas was found in $13 \%(n=15)$ in the loL group and in $15 \%(n=16)$ in the EM group) (RR $0.96,95 \% \mathrm{Cl} 0.45$ to 1.65 ).

\section{Conclusion}

Although a policy of induction of labor in women with late PPROM does not improve short term neonatal outcome, it is possibly associated with a decrease in neurodevelopmental difficulties at the age of two compared to expectant management. 


\section{Introduction}

Management of preterm premature rupture of membranes (PPROM) between 34 and 37 weeks' gestation is widely debated. No clear recommendation is given in international guidelines. ${ }^{1,2,3}$ The American (ACOG) guideline advises "proceed to delivery" and "GBS prophylaxis as indicated" for PPROM between 34 and 37 weeks' gestation. ${ }^{1}$ The British (RCOG) guideline states that the decision to induce labor of to manage expectantly requires an assessment of the risks of development of intrauterine infection compared with the gestational-age related risks of prematurity. At 34 weeks' gestation "delivery should be considered and where expectant management is considered beyond this gestation, women should be informed of the increased risk of chorioamnionitis and the decreased risk of respiratory problems in the neonate". ${ }^{2}$ The Dutch (NVOG) guideline advises expectant management until a gestational age of 35 weeks, unless there are maternal or fetal contra-indications for expectant management. Above 35 weeks' gestation, "the decision to induce labor or to maintain expectant management can be taken in agreement with the pregnant woman". ${ }^{3}$

A Cochrane review on the management of PPROM prior to 37 weeks demonstrated insufficient evidence for the management of PPROM in clinical practice. ${ }^{4}$

In view of this lack of knowledge, we performed a randomized controlled trial under the acronym PPROMEXIL trial (PPROM Expectant Management versus Induction of Labor). ${ }^{5}$ In this trial the hypothesis was tested that induction of labor (loL) would reduce the incidence of neonatal sepsis. In total, 532 women were randomized between loL or expectant management (EM). Neonatal sepsis occurred in seven $(2.6 \%)$ newborns of women in the loL group and in 11 (4.1\%) neonates in the EM group, with a relative risk (RR) of 0.64 and a $95 \%$ confidence interval $(\mathrm{Cl})$ of 0.25 to 1.6. The risk of histological chorioamnionitis was reduced in the loL group (RR $0.69 ; 95 \% \mathrm{Cl} 0.49$ to 0.96). The PPROMEXIL trial thus showed that IoL not substantially improved neonatal outcomes compared to EM. Neonatal secondary outcomes in the PPROMEXIL trial were amongst others respiratory distress syndrome (RDS), hypoglycemia, hyperbilirubinemia, admission on a neonatal intensive care unit (NICU). Hypoglycemia and hyperbilirubinemia occurred significantly more often in the loL group compared to the EM group (RR 2.2; 95\% $\mathrm{Cl} 1.4$ to 3.4 and $\mathrm{RR} 1.5 ; 95 \% \mathrm{Cl} 1.1$ to 1.9 , respectively).

However, the (neuro)development of these neonates in early and later childhood is important as well.

Prematurity is associated with long-term neurodevelopmental consequences, with risks increasing as gestation decreases. ${ }^{6}$

A review by Teune et al. showed that late preterm infants have a 4 times increased risk of death in the first year after birth, and an increased risk of adverse neurologic development in later life as well. The risk of cerebral palsy was 3 times increased 
compared with infants born at term and the relative risk to develop mental retardation was 1.5 (95\% Cl 1.2-1.9).

Also, late preterm infants suffer more often from developmental delay and schoolrelated problems during the first 5 years of life. ${ }^{7}$

Chorioamnionitis is associated with adverse neonatal outcome and effect on longterm development. Wu et al. (2003) performed a case-control study and concluded that the risk of cerebral palsy in term infants is fourfold increased in patients with clinical chorioamnionitis. In previous published studies they found that chorioamnionitis, or inflammation of the placental membranes, may increase the risk of cerebral palsy in term infants by 2 - to 12 -fold. ${ }^{8}$

Although neurodevelopmental and behavioral outcome seem to be negatively influenced in late preterm neonates, we have not been able to find literature on the outcome of these pregnancies when they are complicated by PPROM. Moreover, there are no data on whether induction of labor will improve or deteriorate these outcomes in late preterm PROM.

The PPROMEXIL trial is a large prospective and randomized study and therefore particularly suitable for follow-up of childhood development.

The aim of the present study was to assess the neurological and behavioral development of neonates at the age of two years who are born after a pregnancy with PPROM between 34 and 37 weeks' gestation, and whether induction of labor would enhance these outcomes compared with expectant management.

\section{Methods and materials}

We used data from the PPROMEXIL trial, a study that recruited participants between January 2007 and September 2009. For the present follow-up study, both randomized as well as non-randomized women could participate.

The follow-up study started in April 2009 and ended approaching participants in September 2011.

Women who had participated in the PPROMEXIL study were approached by phone to announce the follow-up at the age of the child of 23 months. This was done by research staff after they received a reminder email from a central database. Thereafter, three questionnaires were sent to the participant, together with a cover letter. The first questionnaire was a short list with general questions. The second questionnaire was the Ages and Stages Questionnaire (ASQ; version 2) and the third questionnaire was the Child Behavioral Check List (CBCL; version 2-3 years). ${ }^{9,10}$ 
Participants were asked to fill out the questionnaires and to send them back in a pre-stamped reply envelope in a time frame of 2 months (age of the child 23 to 25 months). The questionnaires were then entered in an electronic database. If the questionnaires were not returned during this period, the participant received a reminder by telephone.

\section{Developmental assessment: Ages and Stages Questionnaire}

The Ages and Stages Questionnaire (ASQ) is a comprehensive first-level screening questionnaire to detect developmental delay in children. It contains questions about 5 areas of development of the child: communication, gross motor function, fine motor function, problem solving, and personal-social. The questions are answered and filled out by the parents. For each area, a mean score is calculated. An abnormal score is a score of $\geq 2$ SD below the expected mean of a reference population, adjusted for age. This finding indicates a delay in development and a need for further assessment.

\section{Child Behavior Checklist}

The Child Behavior Checklist (CBCL) consists of 100 items concerning behavioral problems, on the basis of which a total problem score can be computed. It also informs on 6 narrow syndrome scales (anxious/depressed, withdrawn, sleep problems, somatic problems, aggressive behavior, destructive behavior) and 2 broader scales (internalizing and externalizing behavior).

For each scale, a standardized $T$-score is calculated and a score $>97$ th percentile falls

into the clinical range that indicates serious behavioral problems. The higher the $T$-score, the more serious the behavioral problems.

\section{Statistical analysis}

Comparison of the induction of labor group with the expectant management group was done by calculating medians with interquartile ranges, means with standard deviations and absolute numbers with difference in percentage. Students T-test, Mann-Whitney U test and Chi-square tests were used if appropriate. Univariate regression analysis was performed to test the predictive value of multiple antepartum variables on the neurodevelopmental outcome. All data were analyzed using SPSS software (SPSS, version 20.0; SPSS Inc, Chicago, IL).

Both the original PPROMEXIL study as well as follow-up had been approved by the institutional review board of the Academic Medical Center. The original PPROMEXIL study was funded by ZonMW (Grant number 94507212). Funding for the follow-up study was provided by ZonMW as well (Grant number 171002215). The funder had no influence on the study design, analysis or report. 


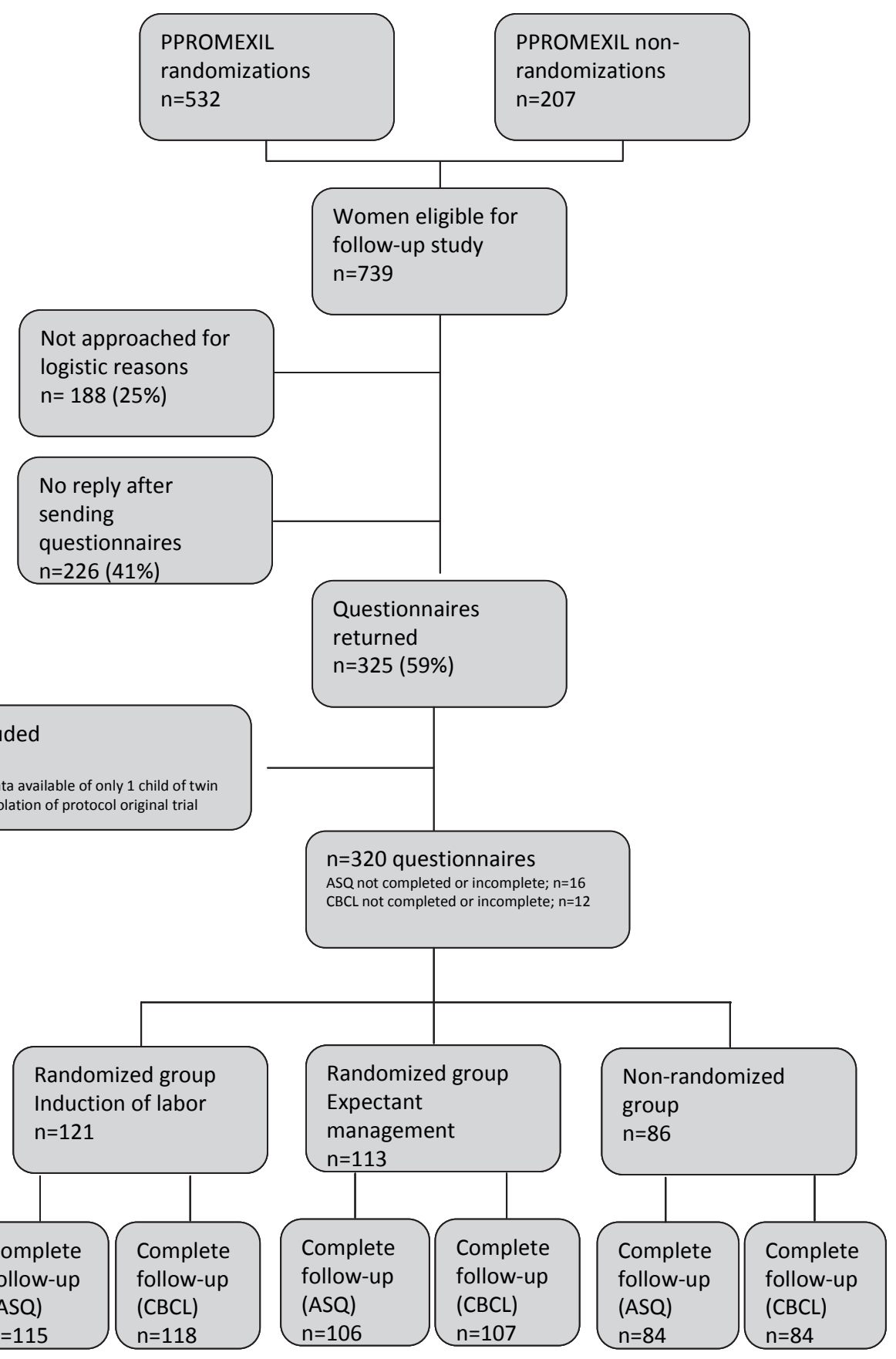

Figure 8.1 Inclusion flow chart. 


\section{Results}

\section{Participants}

From potential participants of the original PPROMEXIL trial, 739 women were eligible for participation in the follow-up study (532 randomized and 207 non-randomized women). Due to relocation or other reasons (such as difficulty to obtain contact information due to participation in original PPROMEXIL trial in a center without permanent research staff), not all participants were approached for participation in the follow-up study. Overall, 551 women (75\%) were approached to fill out the questionnaires.

The response rate with follow-up data was $58 \%(n=320)$ (43\% from the original group of 739 women). In the randomized group ( $n=532$ ) follow-up data were obtained from 234 infants (44\%) ( $n=121$ in the loL group and $n-113$ in the EM group), whereas this was $42 \%$ ( $n=86$ infants) in the non-randomized group. Sixteen ASQs (5.0\%) and 12 $\mathrm{CBCL}$ questionnaires (3.8\%) were not fully completed, most of these incomplete questionnaires were excluded and not analyzed.

We included all questionnaires, even though some questionnaires ( $n=50$ for ASQ and $n=52$ for $C B C L$ ) were filled out outside the indicated age range of 23 to 26 months. We decided to repeat the analysis on the questionnaires that were filled out outside the indicated age period.

\section{Baseline characteristics}

Similar to the findings of the primary trial, there were no differences in the baseline characteristics between the IoL and the EM group.

When comparing the responders with the non-responders, the responders were less frequent smokers ( $19 \%$ vs. $35 \%)$, were more often Caucasian $(90 \%$ vs. $79 \%)$ and were more often higher educated (38\% vs. $25 \%$ ). The incidence of neonatal sepsis and RDS was lower among responders than among non-responders (for neonatal sepsis $2.1 \%$ vs. $6.0 \%$ and for RDS $4.3 \%$ vs. $8.6 \%$ ) (Table 8.1 ). Table 8.2 shows the neonatal outcomes, comparing the loL group with the EM group.

In the randomized group, 43 infants had an abnormal score in $\geq 1$ areas of the ASQ (18\%) and 31 infants (13\%) had $\geq 1$ abnormal scores on the CBCL. In the total group (randomized and non-randomized women), 56 infants (17\%) had an abnormal score in $\geq 1$ areas of the ASQ and 45 infants (14\%) had one or more abnormal scores on the $\mathrm{CBCL}$. 


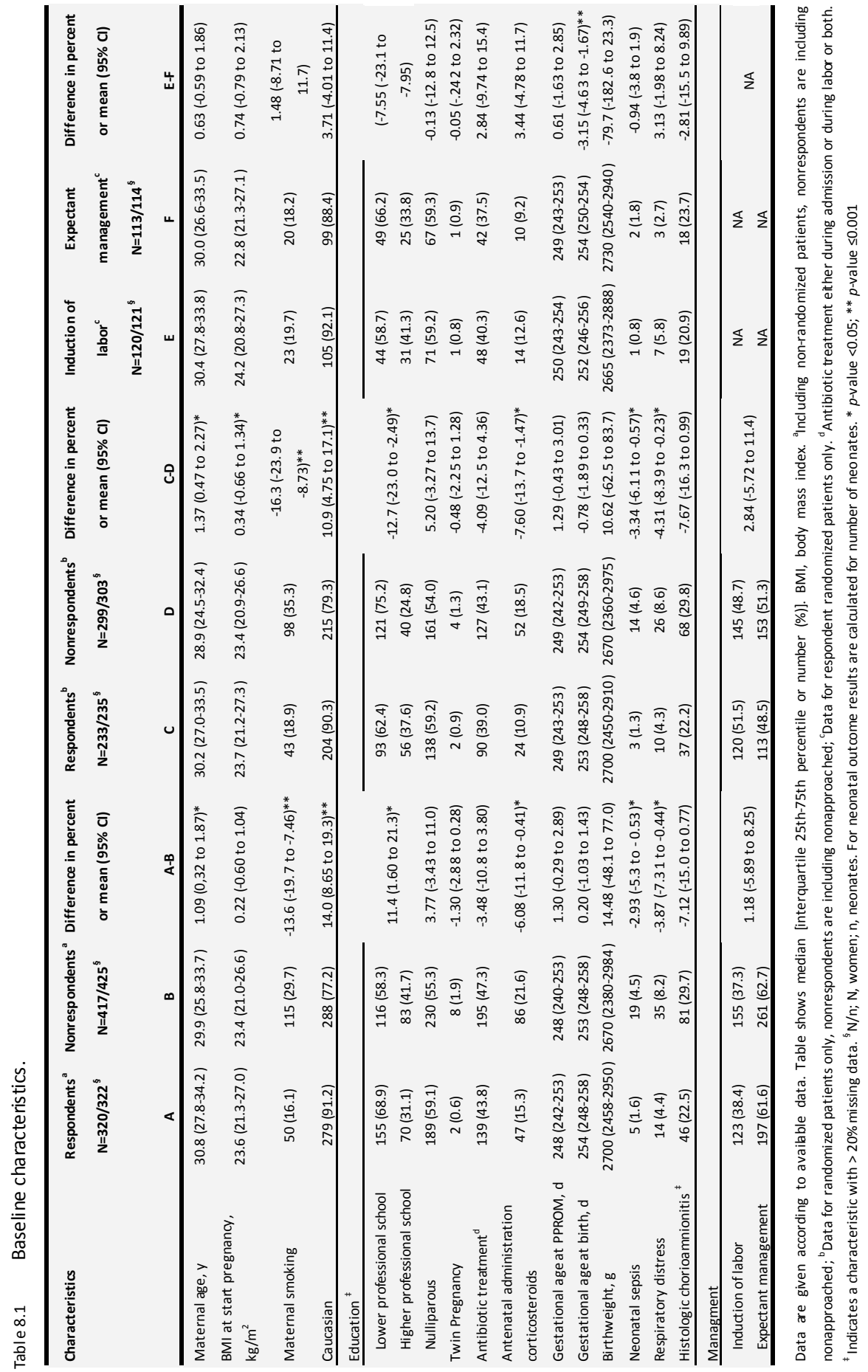


Table $8.2 \quad$ Neonatal outcome.

\begin{tabular}{lccc}
\hline Characteristic & Induction of labor & $\begin{array}{c}\text { Expectant } \\
\text { management } \\
\mathbf{n = 1 1 3}\end{array}$ & $\begin{array}{c}\text { Difference in percent or mean } \\
\text { (95\% Cl; } \mathbf{p} \text {-value) }\end{array}$ \\
\hline Gestational age at birth, d & $252(246-256)$ & $254(250-254)$ & $-3.15(-4.63$ to $-1.67 ;<0.001)$ \\
Birthweight, g & $2665(2373-2888)$ & $2730(2540-2940)$ & $-79.7(-182.6$ to $23.3 ; 0.129)$ \\
Neonatal sepsis & $1(0.8)$ & $2(1.8)$ & $-0.94(-3.8$ to $1.9 ; 0.52)$ \\
Hospital admission & $119(98.3)$ & $109(96.5)$ & $1.89(-2.21$ to $5.98 ; 0.363)$ \\
Admission NICU & $9(7.4)$ & $4(3.5)$ & $3.90(-1.89$ to $9.68 ; 0.195)$ \\
5-min Apgar score $<7$ & $0(0.0)$ & $0(0.0)$ & NA \\
Asphyxia ${ }^{\ddagger}$ & $4(4.4)$ & $4(4.7)$ & $-0.26(-6.46$ to $5.93 ; 0.934)$ \\
Hyperbilirubinaemia & $43(37.7)$ & $35(31.5)$ & $6.19(-6.22$ to $18.6 ; 0.331)$ \\
Hypoglycemia & $20(17.5)$ & $10(9.2)$ & $8.37(-0.47$ to $17.2 ; 0.068)$ \\
\hline
\end{tabular}

Data are given according to available data. Table shows median [interquartile 25th-75th percentile or number (\%)]. ${ }^{\ddagger}$ Indicates a characteristic with $>20 \%$ missing data.

\section{Ages and Stages Questionnaire}

\section{Randomized group}

Of the children in the loL group, $14 \%(n=16)$ had an abnormal score in $\geq 1$ areas of the ASQ, whereas $26 \%(n=27)$ of the children in the EM group had an abnormal score in $\geq 1$ areas $(p=0.033$ ) (Figure 8.2).

There were no statistically significant differences in the mean scores per area between the loL and the EM group (Table 8.3).

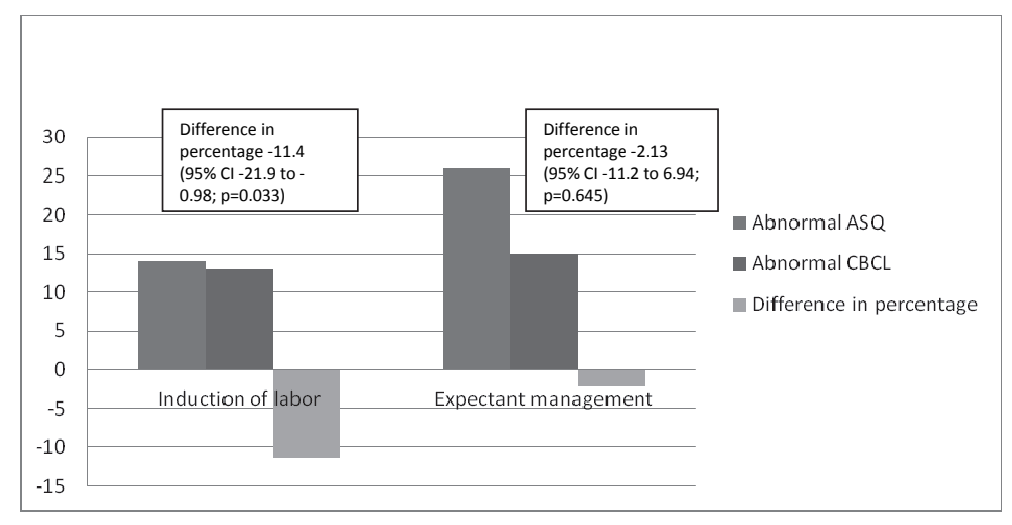

Figure 8.2 Abnormal ASQ and CBCL scores in $\geq 1$ areas. Randomized women only.

$\mathrm{ASQ}$, Ages and Stages Questionnaire; $\mathrm{CBCL}$, Child Behavior Checklist; $\mathrm{Cl}$, Confidence Interval; ASQ, $n=114$ for Induction of labor and $n=106$ for Expectant management; $C B C L, n=117$ for Induction of labor and $\mathrm{n}=107$ for Expectant management. 


\section{Ages and Stages Questionnaire}

\section{Total group of randomized plus non-randomized women}

When comparing the total group of randomized plus non-randomized women, the gross motor score was significantly higher in women where labor was induced (53.84) compared to women who were managed expectantly (51.43) (mean difference (MD) 2.4 (95\% Cl 0.13 to $4.81 ; p$-value 0.047 ).

\section{Child Behavior Checklist}

For the $\mathrm{CBCL}, 13 \%$ in the loL group and $15 \%$ in the $\mathrm{EM}$ had an abnormal score in $\geq 1$ areas of the $\mathrm{CBCL}(p=0.645)$ (Figure 8.2). There were no differences between the mean $t$ scores for a policy of induction of labor compared with expectant management (Table 8.3).

Table 8.3 Mean scores for Ages and Stages Questionnaire and Child Behavior Checklist compared between randomization allocation.

\begin{tabular}{lccc}
\hline Variable & Induction of labor & Expectant management & $\boldsymbol{p}$-value \\
\hline Problem area ASQ & ASQ $(\mathrm{n}=119)$ & $\mathrm{ASQ}(\mathrm{n}=110)$ & \\
\hline Communication & $51.9(11.9)$ & $50.9(12.1)$ & 0.711 \\
Gross Motor & $45.9(10.5)$ & $48.8(10.9)$ & 0.102 \\
Fine motor & $50.4(9.3)$ & $48.8(10.9)$ & 0.354 \\
Problem solve & $45.9(10.5)$ & $44.9(10.5)$ & 0.480 \\
Personal social & $48.3(9.8)$ & $46.6(12.0)$ & 0.392 \\
\hline Problem scale CBCL & $\mathrm{CBCL}(\mathrm{n}=118)$ & $\mathrm{CBCL}(\mathrm{n}=107)$ & 0.640 \\
\hline Anxious/depressed & $50.6(2.3)$ & $50.8(2.6)$ & 0.440 \\
Withdrawn & $51.0(3.1)$ & $51.4(3.4)$ & 0.165 \\
Sleep problems & $51.8(5.1)$ & $51.6(5.1)$ & 0.478 \\
Somatic problems & $52.9(5.2)$ & $53.7(6.1)$ & 0.359 \\
Aggressive behavior & $51.4(3.3)$ & $51.9(4.1)$ & 0.655 \\
Destructive behavior & $51.5(3.6)$ & $51.9(3.9)$ & 0.870 \\
Internalizing & $41.2(8.1)$ & $41.3(8.3)$ & 0.421 \\
Externalizing & $45.4(7.4)$ & $45.1(8.5)$ & 0.594 \\
Total problem score & $43.5(7.9)$ & $43.4(9.1)$ & \\
\hline
\end{tabular}

Table show mean score per area (ASQ) or mean t score (CBCL) and standard deviation (SD). Groups were compared using Mann-Whitney U test. ASQ, Ages and Stages Questionnaire; CBCL, Child Behavior Checklist

The repeated analysis on the questionnaires that had been filled out between 23 and 26 months ( $\mathrm{n}=184$ for $\mathrm{ASQ}$ and $\mathrm{n}=182$ for $\mathrm{CBCL}$ ), showed similar results compared with the analysis on all questionnaires (more often abnormal score in $\geq 1$ areas of the ASQ in the EM group compared with the loL group $(p=0.035)$ and no significant difference between the groups in $C B C L$ result $(p=0.783))$. 


\section{Univariate regression analysis}

Univariate regression analysis was performed to identify factors that were correlated to an abnormal outcome of the ASQ or CBCL.

Table 8.4 shows that an abnormal outcome of the ASQ or CBCL was not statistically significant affected by neonatal morbidity (neonatal sepsis, composite morbidity, admission to neonatal intensive care unit, hyperbilirubinemia and hypoglycemia), by the presence of histological chorioamnionitis or by gestational age at birth.

Antenatal administration of corticosteroids and a lower maternal education level were significantly correlated to an abnormal outcome of the $\mathrm{CBCL}$, while expectant management was associated with an abnormal ASQ outcome (Table 8.4). In the total group (randomized plus non-randomized women, data not shown), antenatal administration of corticosteroids and lower maternal educational level were still associated with an abnormal $\mathrm{CBCL}$ outcome, whereas none of the investigated factors was related to the ASQ.

\section{Discussion}

Late preterm birth can have long-term consequences on development. A systematic review including 10 studies, assessed different aspects of late preterm infants. The follow-up period varied from one to eleven years of age. This review showed poorer outcomes on neurodevelopmental disabilities, educational ability, early-intervention requirements, medical disabilities, and physical growth among late preterm infants compared with term-born children. ${ }^{11}$

In the PPROMEXIL trial, the difference in median gestational age at delivery was 4 days ( 252 days in the loL group versus 256 days in the EM group). ${ }^{5}$

Nevertheless, comparing the two groups seems important. Not only to assess a possible developmental difference of prematurity (to a greater or lesser extent), but also to assess other factors with potential influence on neonatal (neuro)developmental outcome, e.g. chorioamnionitis.

\section{Chorioamnionitis}

The role of chorioamnionitis on long-term development is still relatively unknown, but chorioamnionitis might be associated with adverse neonatal outcome and an effect on long-term development. $8,12,13$

In the present follow-up study, chorioamnionitis was not related to adverse neurodevelopmental outcome at two years of age.

A difficulty of previous published studies is the difference in definition of chorioamnionitis and the criteria that are being used, while the relation between clinical and histological chorioamnionitis is very controversial, there may even be no relationship. ${ }^{8}$ 
Our study on the other hand might be too small to demonstrate a difference in neurodevelopmental outcome in patients with and without histological chorioamnionitis.

Table 8.4 Univariate analysis of possible factors of influence on ASQ or CBCL, randomized women only.

\begin{tabular}{|c|c|c|c|c|}
\hline Variable & Any abnormal ASQ domain & $p$-value & Any abnormal CBCL domain & $p$-value \\
\hline \multicolumn{5}{|l|}{ Gestational age a birth (wks) } \\
\hline $34-34+6$ & $6(26.1)$ & \multirow[t]{5}{*}{0.635} & $7(26.9)$ & \multirow[t]{5}{*}{0.346} \\
\hline $35-35+6$ & $8(13.6)$ & & 7 (11.7) & \\
\hline $36-36+6$ & $22(21.8)$ & & $13(12.7)$ & \\
\hline $37-37+6$ & 7 (18.9) & & $4(11.1)$ & \\
\hline$>38$ & $0(0.0)$ & & $0(0.0)$ & \\
\hline \multicolumn{5}{|l|}{ Aspyxia $(\text { ph }<7.1)^{\ddagger}$} \\
\hline Yes & $0(0.0)$ & \multirow[t]{2}{*}{0.152} & $1(12.5)$ & \multirow[t]{2}{*}{0.888} \\
\hline No & $33(20.6)$ & & $23(14.3)$ & \\
\hline \multicolumn{5}{|l|}{ Antenatal steroids } \\
\hline Yes & $7(30.4)$ & \multirow[t]{2}{*}{0.170} & $6(25.0)$ & \multirow[t]{2}{*}{0.070} \\
\hline No & $34(18.4)$ & & $22(11.7)$ & \\
\hline \multicolumn{5}{|l|}{ Antibiotic treatment } \\
\hline Yes & $19(21.3)$ & \multirow[t]{2}{*}{0.597} & $14(16.1)$ & \multirow[t]{2}{*}{0.449} \\
\hline No & $24(18.5)$ & & $17(12.5)$ & \\
\hline \multicolumn{5}{|l|}{ Chorioamnionitis $^{\ddagger}$} \\
\hline Yes & $7(18.9)$ & \multirow[t]{2}{*}{0.851} & $5(13.5)$ & \multirow[t]{2}{*}{0.713} \\
\hline No & $25(20.3)$ & & $14(11.3)$ & \\
\hline \multicolumn{5}{|l|}{ Positive GBS culture } \\
\hline Yes & $9(19.6)$ & \multirow[t]{2}{*}{0.983} & $5(10.6)$ & \multirow[t]{2}{*}{0.483} \\
\hline No & $34(19.4)$ & & $26(14.6)$ & \\
\hline \multicolumn{5}{|l|}{ Neonatal sepsis } \\
\hline Yes & $2(40.0)$ & \multirow[t]{2}{*}{0.241} & $0(0.0)$ & \multirow[t]{2}{*}{0.366} \\
\hline No & $41(19.0)$ & & $31(14.1)$ & \\
\hline \multicolumn{5}{|l|}{ RDS } \\
\hline Yes & $0(0.0)$ & \multirow[t]{2}{*}{0.112} & $0(0.0)$ & \multirow[t]{2}{*}{0.221} \\
\hline No & $43(20.4)$ & & $31(14.4)$ & \\
\hline \multicolumn{5}{|l|}{ Hypoglycemia } \\
\hline Yes & $8(28.6)$ & 0.189 & $4(14.3)$ & 0.957 \\
\hline No & $33(18.0)$ & & $26(13.9)$ & \\
\hline Hyperbilirubinemia & & & & \\
\hline Yes & $18(23.7)$ & 0.231 & $13(17.8)$ & 0.226 \\
\hline No & $23(16.9)$ & & $17(11.8)$ & \\
\hline Admission NICU & & & & \\
\hline Yes & $1(9.2)$ & 0.373 & $0(0.0)$ & 0.138 \\
\hline No & $42(20.0)$ & & $31(14.6)$ & \\
\hline Management policy & & & & \\
\hline Induction of labor & $16(13.9)$ & 0.030 & $15(12.7)$ & 0.626 \\
\hline Expectant management & $27(25.5)$ & & $16(15.0)$ & \\
\hline Maternal educational level & & & & \\
\hline Lower professional school & $22(26.2)$ & 0.158 & $18(20.0)$ & 0.016 \\
\hline Higher professional school & $9(16.1)$ & & $3(5.5)$ & \\
\hline
\end{tabular}

Percentage are given between abnormal and normal scores. Percentages are give according to available data. ${ }^{\ddagger}$ Indicates a characteristic with $>20 \%$ missing data. 


\section{Current study results}

The long-term follow-up of the PPROMEXIL is a prospective study, comparing different management strategies (induction of labor versus expectant management).

This study shows a significant difference in developmental outcome (ASQ result) at 2 years of age in infants born near or at term after preterm prelabor rupture of membranes between 34 and 37 weeks' gestation. There are no significant differences in behavioral outcome (CBCL result).

\section{Strengths}

This follow-up study is an important and even essential part of the original PPROMEXIL trial, since the intervention in pregnancy possibly affects the developmental outcome in childhood and should therefore be accurately assessed.

The prospective character of this study may have an advantageous effect compared to a retrospective study. Furthermore, we obtained a large study population by including all randomized and non-randomized women from the PPROMEXIL trial. ${ }^{5}$

With a limited budget we were able to perform this follow-up study, as an important part of the randomized PPROMEXIL trial. Only because of the existing infrastructure of the Dutch Consortium for Women's Health and Reproductivity Studies (www.studies-obsgyn.nl) we were able to make use of research staff to approach eligible women and to send them the questionnaires.

We used two validated and valuable questionnaires ( $A S Q$ and $\mathrm{CBCL}$ ) in order to assess the neurodevelopmental outcome as well as behavioral development.

\section{Weaknesses}

The main problem that we encountered, was the large amount of centers that participated in this study. Since 60 hospitals included patients, eligible patients live across the Netherlands. Therefore, it was sometimes difficult for research staff, which we deployed over several hospitals, to contact the participants and to send the questionnaires. This has caused some loss-to-follow-up. Furthermore, a substantial number of parents had moved. It is well known that transmigration is common during the first years after childbirth. We would have wanted to approach more (all eligible) participants for follow-up.

The response rate was comparable between the loL group and the EM group.

A possible problem from this study design might be that parents are more likely to participate when their child is healthy and experiences no problems. This does also seem evident from the fact that neonatal sepsis and RDS less frequently occurred among the responders. Therefore our findings might be a little too optimistic. 


\section{Response rate}

We have used postal questionnaires to assess psychomotor and behavioral development of these children.

In this study, we aimed to screen the children for developmental problems and to compare the long-term outcome of the children between the two management strategies. The questionnaires that are used are validated for this aim. Because of limited budget, we decided not to invite the parents with their child for consultation, but only asked them to fill out the questionnaires.

We are quite satisfied with the response rate of $58 \%$ ( $43 \%$ of the total group of eligible participants). Ideally, the response rate would have been higher, due to logistic reasons however that was not feasible.

From previous studies we known that the best predictor of response in surveys of a general public is the number of follow-up mailings. ${ }^{14,15}$ In our study we have tried to optimize the response rate by sending a reminder email to the research employee after a non-response, who contacted the parents by telephone as a reminder.

\section{Responders}

In the baseline characteristics (Table 8.1) was shown that mothers who responded to the questionnaires were less frequently smokers, higher educated and were more frequently Causasian compared with non-responders.

It is already known, that such characteristics (non-smoking, higher education and Caucasian ethnicity) are more often seen in groups or patients who are more likely to participate in studies. ${ }^{16,17}$

Women with a healthy infant seem more likely to respond to the questionnaires ${ }^{18}$, something we found because the incidence of neonatal sepsis and RDS were lower in the group of responders.

\section{Influencing factors}

Two factors were found to be correlated to an abnormal score in $\geq 1$ areas of the $\mathrm{CBCL}$, these were antenatal administration of corticosteroids and lower maternal education level. Antenatal administration of corticosteroids has proven to be effective in preterm birth before 32 weeks' gestation to reduce the risk of RDS, neonatal mortality, necrotizing enterocolitis (NEC) and intraventricular hemorrhage (IVH). ${ }^{19}$ Therefore it would be unwise to abolish the use of corticosteroids in all women with threatened preterm birth (in combination with ruptured membranes as well) before 32 weeks' gestation. However, based on our findings and results from some other studies $^{20,21}$, we would advise to be reluctant with the use of this medication and administer it only on good indication.

Maternal education level, which is to some extent a derivate of social economic status, can hardly be altered or influenced. 


\section{Future perspectives}

We decided to perform this follow-up study at the age of two years. Possibly, this age is a rather young to assess behavioral problems, as (neuro)developmental problems may not yet have become evident at this age. On the other hand, we expected to achieve a higher response rate at the age of two compared to waiting until the children are older (relocation might be even a bigger issue). Furthermore, we expected that major problems would become evident, even at a younger age.

Ideally, long-term follow-up would have been continued at later ages (e.g. at 5 and 8 years of age). Unfortunately, we had to decide not to perform follow-up at 5 years of age due to limited budget resulting in the impossibility to use the infrastructure of the research staff in the Dutch Obstetric Consortium. Fortunately, funding for follow-up was provided by ZonMW, resulting in the possibility to perform follow-up studies in the Dutch Obstetric Consortium. Long-term follow-up however, is important in all randomized obstetric studies.

\section{Conclusion}

Neurodevelopmental problems at two years of age seem to occur slightly more often after expectant management compared to induction of labor in the ASQ outcome of women with late preterm PROM. There are, however, no significant differences between induction of labor and expectant management in mean scores on the separate ASQ problem areas. Induction of labor nor expectant management did lead to a difference in CBCL outcome.

The most important predictive factors for developmental problems at 2 years of age (abnormal score on $\geq 1$ areas of the $\mathrm{CBCL}$ ) are antenatal administration of corticosteroids and a lower maternal education level. This study however, has its limitations. For example, there were several differences in baseline characteristics between responders and non-responders.

The negative effects of late prematurity (higher risk of hypoglycemia and hyperbilirubinemia) must be weighed against the negative effects of expectant management (possibly a slightly higher risk of an abnormal ASQ outcome at two years of age).

Further studies are desirable to perform follow-up at later ages (e.g. at 5 and 8 years of age), ideally with assessment of schoolperformances, intelligence quotient and motor function. 


\section{References}

1. The American College of Obstetricians and Gynecologists (ACOG) (2013). Practice Bulletin Number 139: Premature Rupture of Membranes. Obstetrics \& Gynecology.

2. Royal College of Obstetricians and Gynaecologists (RCOG) (2006). Green-top Guideline Number 44: Preterm Prelabour Rupture of Membranes.

3. Nederlandse Vereniging voor Obstetrie en Gynaecologie (NVOG) (2002). [Breken van de vliezen voor het begin van de baring] (guideline). Version 1.0.

4. Buchanan SL, Crowther CA, Levett KM, Middleton P, Morris J. Planned early birth versus expectant management for women with preterm prelabour rupture of membranes prior to 37 weeks' gestation for improving pregnancy outcome (Review). Cochrane Database of Systematic Reviews 2010;(3): CD004735.

5. Van der Ham DP, Vijgen SM, Nijhuis JG, Van Beek JJ, Opmeer BC, Mulder AL, Moonen R, Groenewout M, Van Pampus MG, Mantel GD, Bloemenkamp KW, Van Wijngaarden WJ, Sikkema M, Haak MC, Pernet PJ, Porath M, Molkenboer JF, Kuppens S, Kwee A, Kars ME, Woiski M, Weinans MJ, Wildschut HI, Akerboom $\mathrm{BM}, \mathrm{Mol} \mathrm{BW}$, Willekes $\mathrm{C}$. Induction of labor versus expectant management in women with preterm prelabor rupture of membranes between 34 and 37 weeks: a randomized controlled trial. PLoS Medicine 2012;9: e1001208.

6. Petrini JR, Dias T, McCormick MC, Massolo ML, Green NS, Escobar GJ. Increased risk of adverse neurological development for late preterm infants. J Pediatrs 2009;154: 169-76.

7. Teune, M. J., et al. A systematic review of severe morbidity in infants born late preterm. Am J Obstet Gynecoly 2011;205: 374.e371-9.

8. Wu YW, Escobar GJ, Grether JK, Croen LA, Greene JD, Newman TB. Chorioamnionitis and cerebral palsy in term and near-term infants. JAMA 2003;290: 2677-84

9. BrookesPublishing. http://www.brookespublishing.com/resource-center/screening-and-assessment/asq/. Retrieved 17 December 2013.

10. Achenbach T, Verhulst F. Achenbach System of Empirically Based Assessment (ASEBA). http://www.aseba.nl/. Retrieved 17 December 2013.

11. McGowan JE, Alderdice FA, Holmes VA, Johnston L. Early childhood development of late-preterm infants: a systematic review. Pediatrics 2011;127: 1111-24.

12. Alexander JM, McIntire DM, Leveno KJ. Chorioamnionitis and the prognosis for term infants. Obstet Gynecol 1999;94: 274-8.

13. Leviton A, Allred EN, Kuban KC, Hecht JL, Onderdonk AB, O'shea TM, Paneth N. Microbiologic and histologic characteristics of the extremely preterm infant's placenta predict white matter damage and later cerebral palsy. the ELGAN study. Pediatr Res 2010;67: 95-101.

14. Heberlein T, Baumgarnter R. Factors affecting response rates to mailed questionnaires: a quantitative analysis of the published literature. American Sociological Review 1978;43: 447-62.

15. Barclay S, Todd C, Finlay I, Grande G, Wyatt P. Not another questionnaire! Maximizing the response rate, predicting non-response and assessing non-response bias in postal questionnaire studies of GPs. Fam Pract 2002;19: 105-11.

16. Van Wyk L, Boers KE, Van der Post JA, Van Pampus MG, Van Wassenaer AG, Van Baar AL, Spaanderman ME, Becker JH, Kwee A, Duvekot JJ, Bremer HA, Delemarre FM, Bloemenkamp KW, de Groot CJ, Willekes C, Roumen FJ, Van Lith JM, Mol BW, le Cessie S, Scherjon SA. Effects on (neuro)developmental and behavioral outcome at 2 years of age of induced labor compared with expectant management in intrauterine growth-restricted infants: long-term outcomes of the DIGITAT trial. Am J Obstet Gynecol 2012;206: 406.e401-7.

17. Nilsen RM, Vollset SE, Gjessing HK, Skjaerven R, Melve KK, Schreuder P, Alsaker ER, Haug K, Daltveit AK, Magnus P. Self-selection and bias in a large prospective pregnancy cohort in Norway. Paediatr Perinatal Epidemiol 2009;23: 597-608.

18. Tin W, Fritz S, Wariyar U, Hey E. Outcome of very preterm birth: children reviewed with ease at 2 years differ from those followed up with difficulty. Archives of Disease in Childhood. Fetal and Neonatal Edition 1998;79: F83-7. 
19. Roberts D, Dalziel S. Antenatal corticosteroids for accelerating fetal lung maturation for women at risk of preterm birth. Cochrane Database of Systematic Reviews 2006;(3): CD004454.

20. Shinwell ES, Eventov-Friedman S. Impact of perinatal corticosteroids on neuromotor development and outcome: review of the literature and new meta-analysis. Semin Fetal Neonatal Med 2009;14: 164-70.

21. Stålnacke J, Diaz Heijtz R, Norberg H, Norman M, Smedler AC, Forssberg H. Cognitive outcome in adolescents and young adults after repeat courses of antenatal corticosteroids. J Pediatr 2013;163: 441-6. 


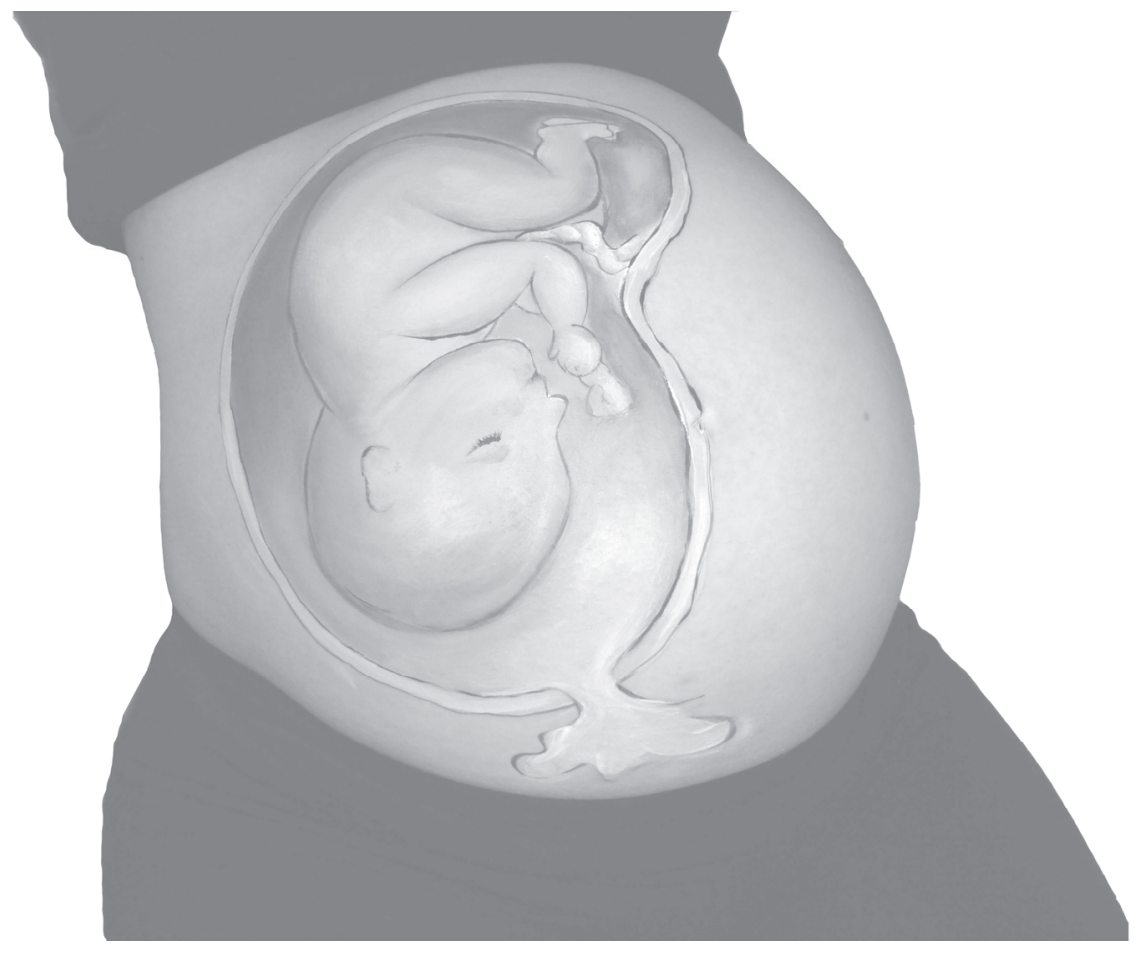




\section{Chapter}

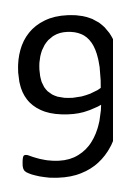

General discussion 
134 Chapter 9 


\section{General discussion}

Preterm prelabor rupture of membranes (PPROM) is a major cause of preterm labor and an important obstetric problem, since it is associated with significant complications, such as perinatal morbidity and mortality, neonatal morbidity (amongst others pulmonary problems, brain or neurological problems and infection or sepsis) and an increased risk of maternal morbidity (in particular maternal sepsis).

The risk of neonatal complications and the preferred management strategy vary with the gestational age at which PPROM occurs. In this thesis several issues on diagnostic procedures, perinatal outcomes and management strategies are outlined.

The risk of neonatal complications is increased due to perinatal infection, placental abruption and umbilical cord compression. ${ }^{1}$ There is a relation between the neonatal inflammatory response and adverse neonatal outcome after PPROM. ${ }^{2}$

Maternal complications might occur as well, in particular maternal infection or sepsis. This thesis however, focuses on perinatal complications rather than maternal complications of (P)PROM.

When performing a literature search, a large amount of literature on this subject was found.

However, results from different studies were often inconsistent and some studies provided insufficient evidence or were performed many years ago. Also because the quality of (neonatal) care has improved significantly over the last years, the results of these studies may not be extrapolated to current clinical practice. Furthermore, studies on extreme preterm (midtrimester) PROM are often performed on small numbers of patients, due to the low incidence of this problem (extreme preterm PROM is a rare condition with an incidence of about 0.5 to $0.7 \%$ ).

In view of the risk of extensive complications and of disabilities later in life, we have recognized the importance of expanding the research done so far on this subject.

Because there are still many unanswered important clinical questions on this topic, we have tried to answer at least some of these questions in this thesis.

The first point of interest concerns the problems and complications that might occur in case of extreme preterm PROM (gestational age $<27$ weeks).

One of the main complications of extreme preterm PROM is pulmonary hypoplasia $(\mathrm{PH})$, often resulting in neonatal death (mortality rate is 70 to $80 \%){ }^{3}$

In this thesis, we assessed the predictive capacity of imaging techniques (ultrasound and MRI parameters) in the evaluation of fetuses with an increased risk of PH. A metaanalysis of 13 studies showed that the sensitivity and specificity of these techniques are very limited.

Searching for methods that are capable to accurately predict the risk of lethal $\mathrm{PH}$ is very important, since it gives parents the well informed choice of termination of pregnancy. Secondly, it is important to have reliable information available while 
counseling when there is a need for decision making about interventions at around viable gestational ages of the fetus. Therefore a meta-analysis was performed on the predictive value of imaging techniques (ultrasound and MRI parameters) for $\mathrm{PH}$ (Chapter 2).

In a previous study by van Teeffelen et al. (2010), the predictive capacity of gestational age at PPROM, latency period (between rupture of membranes and delivery) and amount of amniotic fluid were assessed. Gestational age at PPROM was a better predictor for $\mathrm{PH}$ compared to the other parameters. ${ }^{4}$

Because $\mathrm{PH}$ and perinatal mortality are two of the main problems in case of midtrimester PPROM, there is an ongoing randomized controlled trial in the Netherlands (PPPROMEXIL-3 trial): Expectant management versus amnioninfusion for improving perinatal outcomes in women with very early PPROM. This trial has been started in order to find a treatment to reduce the incidence of such serious complications. This study intends to include 56 singleton pregnancies with PPROM between 16 and 24 weeks' gestation. This study, as well as many other clinical trials, is performed in the collaboration of the Dutch obstetric consortium.

In order to be able to counsel a couple with extreme preterm PROM in the best possible way, we have collected data on the prognosis of the present pregnancy and for the future. The results from previous studies, combined with the studies in this thesis, enables the obstetrician to counsel more objectively about the possible pregnancy outcomes and risks and might help to make decisions for future pregnancies.

Therefore we have performed a retrospective cohort study on 305 pregnancies with PPROM before 27 weeks' gestation, with 99 subsequent pregnancies.

We assessed both the perinatal outcome of these pregnancies (Chapter 3), as well as the risk of recurrence of PPROM or preterm birth in a subsequent pregnancy (Chapter 5). Secondly, we tried to identify parameters with predictive capacity for perinatal mortality.

Previous studies reported rather varying results with regard to perinatal mortality rates (between 25\% and 79-80\%). 5,6,7 Many of these studies are dated (published before 2000). It is important to publish more recent data as well, since the quality of neonatal care has significantly improved over the years, with a significant improvement of neonatal outcome especially at younger gestational ages.

In Chapter $\mathbf{5}$ we described that, compared with a normal population, women with a subsequent pregnancy after a history of early PPROM have an increased risk of PPROM or preterm birth. These findings have been reported by others with a recurrence rate of $6-32 \%$, where a wide interval of gestational age of ROM is assessed in these studies. ${ }^{8,9,10}$ Although risks are increased, still the majority will deliver at term without complications. Nevertheless, in Chapter 5 we found that less than $50 \%$ of the couples decided to conceive again. We would have expected a larger percentage of women with a subsequent pregnancy. Unfortunately we are missing additional information on 
the reasons of these women to refrain from a renewed pregnancy (e.g. completed family), but fear of a renewed complication in a subsequent pregnancy might play an important role for these women.

In Chapter 3 (and Chapter 5), we have developed a prediction model from antepartum variables. Use of antibiotics during admission (amongst others), decreased the risk of perinatal mortality in women with extreme preterm PROM.

Therefore, we would advise to administer prophylactic antibiotics (erythromycin) to all women with early PPROM. Hereby should be noted that this prediction model needs to be externally validated, since it is based on retrospective data.

This opinion however, is in line with the advice that is given from the recently published Practice Bulletin by The American Congress of Obstetricians and Gynecologists (ACOG), which states that prophylactic administration of (broadspectrum) antibiotics prolongs pregnancy, reduces maternal and neonatal infections, and reduces gestational age-dependent morbidity. ${ }^{11}$

In pregnancies with extreme or moderate preterm PROM, outcome might be affected by the latency period (duration between rupture of membranes (ROM) and delivery). However, it remains unclear whether this is a positive or negative effect because previous studies show varying results. ${ }^{12,13,14,15}$

In our study (Chapter 4), both perinatal mortality, as well as composite morbidity and neonatal sepsis improved with longer latency. After a gestational age of 38 weeks at delivery, outcomes did not seems to further improve.

The improvements in perinatal outcome with longer latency, might be explained by reducing the influence of prematurity. However, in this study, only shortterm perinatal outcome was assessed (until 28 days after birth) and long-term morbidity or development was not an outcome.

After elaborating on the problems and pregnancy complications as assessed in Chapters $\mathbf{2}$ to $\mathbf{5}$, it is also important to focus on issues in pregnancies with later PROM (>34 weeks' gestation).

One of these issues is the difficulty in the prediction of clinical chorioamnionitis and neonatal infection, which is an important risk of prolonged rupture of membranes.

Several methods are being used to detect or diagnose intrauterine infection (clinical chorioamnionitis) at an early stage. However, it is even more important to find a diagnostic method to predict the risk of neonatal infection. One of the methods that is being used, is laboratory parameters (C-reactive protein (CRP) and leukocytes).

Following on our study (Chapter 6), we concluded that C-reactive protein and/or leukocytes should not be routinely measured in case of PROM. In addition can be noted that at least at term, measurement of CRP and/or leukocytes is not useful. Moreover, the duration of expectant management at term is generally maximum $48-72$ hours after rupture of the membranes and not longer. 
A meta-analysis by Van de Laar et al. (2009) found no studies reporting on the use of CRP as a predictor of neonatal sepsis. ${ }^{16}$ Thereafter, van der Ham et al. (2013) performed a secondary analysis of the PPROMEXIL trial to develop a prediction model for neonatal sepsis ${ }^{17}$. In this study, CRP was found to be a moderate predictor for neonatal sepsis (odds ratio $1.01(95 \% \mathrm{Cl} 1.00-1.01)$ ). A difference with potential effect on the result of this study and ours was the difference in median gestational age at PPROM. The gestational age at inclusion was lower in Van der Ham's study $\left(35^{+3}\right.$ weeks), whereas it was $37^{+3}$ weeks in our study.

The thesis by D.P. van der Ham (2013) outlined the problems concerning the optimal management strategy in case of (late) PPROM between 34 and 37 weeks' gestation. $^{18}$

The PPROMEXIL trial which is included in this thesis, as well as the PPROMEXIL-2 trial (Chapter 7), concluded that induction of labor (IoL) does not significantly reduce the risk of neonatal sepsis compared to expectant management.

The primary aim of the PPROMEXIL-2 trial was only to extend the magnitude of other existing studies (PPROMEXIL trial and the ongoing PPROMT trial) ${ }^{19,20}$ in order to be able to perform a large individual patient data meta analysis (IPD-MA). Therefore an additional 200 women were recruited within a 12 month period.

In the PPROMEXIL-2 trial there were no differences in other neonatal outcomes (such as respiratory distress syndrome), nor in caesarean section rates.

loL reduced the risk of clinical chorioamnionitis, but a significant difference in histological chorioamnionitis was not found in this study. Chorioamnionitis might affect childhood development, because of an assumed increased risk of cerebral palsy in these infants. ${ }^{21,22,23,24,25,26}$ However, many different criteria and definitions are used in these studies (such as clinical and/or histological chorioamnionitis). There does not seem to be a clear relation between clinical and histological chorioamnionitis. ${ }^{25}$

The incidences of neonatal sepsis in the PPROMEXIL-2 trial (3.0\% versus $4.1 \%$ ) were comparable to the incidences of sepsis in the previous PPROMEXIL trial (2.6\% versus 4.1\%). The incidence of sepsis in case of expectant management (EM) was much lower than expected at the beginning of these studies (7.5\%) .

Performing an IPD-MA after completion of the PPROMT trial, seems important to determine the best treatment strategy in case of PPROM between 34 and 37 weeks' gestation.

In addition, we considered a follow-up study as an essential element of the PPROMEXIL trial (Chapter 8). Performing the trial and obtaining results on the primary and secondary outcomes is part of the trial, but long-term follow-up is important as well, because the 'outcome' of the trial are children.

Because the developmental outcome of the infants is slightly worse in one of the two treatment groups (more often an abnormal score in $\geq 1$ areas of the ASQ in the 
expectant management group), this has somewhat changed the conclusion and advice on the preferred management strategy. For the short-term outcome(s), expectant management seemed preferable, whereas the long-term outcome seems slightly better after induction of labor.

Also other factors that might play a role in the development of the children can be adequately identified from a follow-up trial. When performing a univariate analysis, we found that that $A S Q$ and $C B C L$ outcome are not significantly affected by neonatal morbidity or by gestational age at birth, whereas antenatal administration of corticosteroids and a lower maternal education level are significantly correlated to an abnormal outcome of the CBCL. Even though we expected that chorioamnionitis would be associated with adverse (neuro)developmental outcome, this was not found in the present follow-up study at two years of age.

For the above mentioned reasons, follow-up is an essential part of a trial. Not only for the PPROMEXIL trial, but also for other trials which may benefit from solid follow-up studies.

There are several difficulties which one may encounter when performing a followup study. First of all, informed consent by the participant is necessary. In the original trial, informed consent for follow-up is not always included in the patient information brochure. Furthermore, approval of the medical ethics committee to perform the follow-up study is obligatory if it was not part of the original study.

Then, another issue are the financial difficulties, budgets are overall limited. The grant of the original trial will generally be depleted and obtaining new funding is difficult, even though funding is very important to complete the primary study with solid follow-up. A follow-up study is essential for almost every randomized trial in obstetrics, because theoretically many interventions might affect childhood development. Unfortunately, at this moment many large trials will not perform followup. Often because of lack of money, but another reason might be lack of time to wait for a significant effect to become present. The sponsor of a trial (often the government) should provide funding for follow-up and might even oblige the researchers of a randomized trial in obstetrics to include a solid follow-up study in their trial protocol. If a budget is available for follow-up, the researchers might for example be able to approach the participants annually and it may provide opportunities to perform followup in better ways, for example visits to the clinic with a history taking and physical examination, instead of only postal questionnaires.

Another difficulty in a follow-up study is the accessibility of the participants. When trying to get in contact with participants, we often face the problem that they have moved to another place. This might result in loss-to-follow-up, when contact information can not be obtained in a different way.

Within the Dutch (Obstetric) Consortium, shortly be named Consortium 2.0, researchers are trying to work closely together. The Consortium 2.0 focuses on 
evaluation of the effectiveness and efficiency of medical care, with the aim of improving quality and cost management in medical care.

Performing follow-up studies are part of this strategy.

Since the different follow-up studies are closely linked, the cooperation in the Dutch Consortium is crucial. Hereby, advice and expertise is obtained from two experts in this area (a neonatologist with special interest on this subject and an expert in pedagogic sciences (especially child and adolescent studies)).

Particularly with regard to follow-up, there are obviously very close communication lines between obstetrics and neonatology. Therefore, both parties might benefit from a constructive cooperation.

Three studies have already completed the 2-years follow-up. First, the STAN trial (effectiveness of non-invasive monitoring (cardiotocography + ST-analysis) compared to normal care (cardiotocography + fetal blood sampling) in order to judge whether STanalysis can replace fetal blood sampling). Second, the DIGITAT trial (induction of labor versus expectant monitoring in singleton small for gestational age fetuses (in cephalic position) at $\geq 36^{+0}$ weeks' gestation) and the third study is the HYPITAT trial (induction of labor versus expectant monitoring in women with pregnancy-induced hypertension or pre-eclampsia in a singleton pregnancy and a gestational age $\geq 36^{+0}$ weeks). For our PPROMEXIL follow-up study, we have learned from these three studies and we have been able to improve the quality of our study. Also the close connection and good cooperation with research nurses from different hospitals all across The Netherlands have been essential to improve the response rate.

Although The Netherlands is a country small in size and number of hospitals, the well organized cooperation within the Dutch Consortium allows researchers to perform studies and complete these with not only a sizeable population but also within a foreseeable period of time.

Other studies within the Dutch Obstetric Consortium (both obstetric and fertility studies) are also working on (long-term) follow-up. These are the Hypitat-II, ProTWIN, APOSTEL-II, Triple-P, INES, Lifestyle and MEDIUM studies.

\section{Future perspectives}

$\checkmark$ Determining the capacity of measuring C-reactive protein and leukocytes in women with PPROM before 37 weeks' gestation in predicting neonatal sepsis and/or neonatal infection.

$\checkmark \quad$ Studying whether other advanced ultrasound parameters and other imaging techniques can further improve the prediction of $\mathrm{PH}$.

$\checkmark \quad$ Updating the systematic review on pregnancy outcome after PPROM at a previable gestational age, since at least three studies on this subject are published after the previous systemic review (2001). 
$\checkmark$ Performing an individual patient data meta-analysis (IPD-MA) on management strategy in case of PPROM between 34 and 37 weeks' gestation.

$\checkmark$ Further assessment whether chorioamnionitis is related to adverse long-term outcome in childhood, because of the discrepancy between the finding from our follow-up study and results from previous studies.

$\checkmark$ More research is needed on the effects of neonatal sepsis on long-term developmental outcome (ideally prospective studies assessing childhood development at different ages after experiencing neonatal sepsis after birth).

$\checkmark$ Incorporating long-term follow-up in all (large) randomized trials in obstetrics should be an aim and might even be obliged to retain quality of medical care. In order to achieve this, funding by sponsors (or government) is extremely important. 


\section{References}

1. Mercer BM. Preterm premature rupture of the membranes. Obstet Gynecol 2003;101:178-93.

2. Cornette L. Fetal and neonatal inflammatory response and adverse outcome. Semin Fetal Neonatal Med 2004;9:459-70.

3. Farooqi A, Holmgren PA, Engberg S, Serenius F. Survival and 2-year outcome with expectant management of second-trimester rupture of membranes. Obstet Gynecol 1998;92:895-901.

4. Van Teeffelen AS, Van der Ham DP, Oei SG, Porath MM, Willekes C, Mol BW. The accuracy of clinical parameters in the prediction of perinatal pulmonary hypoplasia secondary to midtrimester prelabour rupture of fetal membranes: a meta-analysis. Eur J Obstet Gynecol Reprod Biol 2010;148:3-12.

5. Klein JM. Neonatal morbidity and mortality secondary to premature rupture of membranes. Obstet Gynecol Clin North Am 1992;19:265-80.

6. Dewan $\mathrm{H}$, Morris JM. A systematic review of pregnancy outcome following preterm premature rupture of membranes at a previable gestational age. Aust N Z J Obstet Gynaecol 2001;41(4): 389-394.

7. Body G, Forveille F, Lemseffer J, Kone M, Pierre F, Lansac J, Soutoul JH, Berger C. Spontaneous rupture of the membranes before 28 weeks of amenorrhea. Obstetrical and perinatal outcome. Apropos of 28 cases. J Gynecol Obstet Biol Reprod (Paris) 1991;20:93-100.

8. Asrat T, Lewis DF, Garite TJ, Major CA, Nageotte MP, Towers CV, Montgomery DM, Dorchester WA. Rate of recurrence of preterm premature rupture of membranes in consecutive pregnancies. Am J Obstet Gynecol 1991;165:1111-5.

9. Lee T, Carpenter MW, Heber WW, Silver HM. Preterm premature rupture of membranes: risks of recurrent complications in the next pregnancy among a population-based sample of gravid women. $\mathrm{Am}$ J Obstet Gynecol 2003;188:209-13.

10. Getahun D, Strickland D, Ananth CV, Fassett MJ, Sacks DA, Kirby RS, Jacobsen SJ. Recurrence of preterm premature rupture of membranes in relation to interval between pregnancies. Am J Obstet Gynecol 2010:202:570.e1-6.

11. ACOG Practice Bulletin No. 139: Premature Rupture of Membranes. Obstet Gynecol 2013;122:918-30.

12. Aziz N, Cheng YW, Caughey AB. Factors and outcomes associated with longer latency in preterm premature rupture of membranes. J Matern Fetal Neonatal Med 2008:21:821-5.

13. Manuck TA, Maclean CC, Silver RM, Varner MW. Preterm premature rupture of membranes: does the duration of latency influence perinatal outcomes? Am J Obstet Gynecol 2009;201:414.e1-6.

14. Melamed N, Ben-Haroush A, Pardo J, Chen R, Hadar E, Hod M, Yogev Y. Expectant management of preterm premature rupture of membranes: is it all about gestational age? Am J Obstet Gynecol 2011;204:48.e1-8.

15. Nayot D, Penaval D, Da Silva O, Richardson BS, de Vrijer B. Neonatal outcomes are associated with latency after preterm premature rupture of membranes. J Perinatol 2012;32:970-7.

16. Van de Laar R, Van der Ham DP, Oei SG, Willekes C, Weiner CP, Mol BW. Accuracy of C-reactive protein determination in predicting chorioamnionitis and neonatal infection in pregnant women with premature rupture of membranes: a systematic review. Eur J Obstet Gynecol Reprod Biol 2009;147: 124-9.

17. Van der Ham DP, Van Kuijk S, Opmeer BC, Willekes C, Van Beek JJ, Mulder ALM, Van Loon A, Groenewout M, Mantel G, Bloemenkamp KWM, Porath M, Kwee A, Akerboom B, Papatsonis DNM, Metz $\mathrm{GCH}$, Nijhuis JG, Mol BWJ. Can neonatal sepsis be predicted in near term prelabour rupture of membranes? Development of a prediction model. 2013; Unpublished.

18. Van der Ham DP. Management of late preterm prelabour rupture of membranes. Thesis, Maastricht University. 2013.

19. Van der Ham DP, Vijgen SM, Nijhuis JG, Van Beek JJ, Opmeer BC, Mulder AL, Moonen R, Groenewout M, Van Pampus MG, Mantel GD, Bloemenkamp KW, Van Wijngaarden WJ, Sikkema M, Haak MC, Pernet PJ, Porath M, Molkenboer JF, Kuppens S, Kwee A, Kars ME, Woiski M, Weinans MJ, Wildschut HI, Akerboom $\mathrm{BM}, \mathrm{Mol} \mathrm{BW}$, Willekes C. Induction of labor versus expectant management in women with preterm prelabor rupture of membranes between 34 and 37 weeks: a randomized controlled trial. PLoS Med 2012;9: e1001208. 
20. Morris JM, Roberts CL, Crowther CA, Buchanan SL, Henderson-Smart DJ, Salkeld G. Protocol for the immediate delivery versus expectant care of women with preterm prelabour rupture of the membranes close to term (PPROMT) Trial [ISRCTN44485060]. BMC Pregnancy Childbirth 2006;6:9.

21. Grether JK, Nelson KB. Maternal infection and cerebral palsy in infants of normal birth weight. JAMA 1997;278:207-11.

22. Alexander JM, McIntire DM, Leveno KJ. Chorioamnionitis and the prognosis for term infants. Obstet Gynecol 1999;94:274-8.

23. Wu YW, Colford JM. Chorioamnionitis as a risk factor for cerebral palsy: a meta-analysis. JAMA 2000; 284:1417-24.

24. Walstab J, Bell R, Reddihough D, Brennecke S, Bessell C, Beischer N. Antenatal and intrapartum antecedents of cerebral palsy: a case-control study. Aust N Z J Obstet Gynaecol 2002;42:138-46.

25. Wu YW, Escobar GJ, Grether JK, Croen LA, Greene JD, Newman TB. Chorioamnionitis and cerebral palsy in term and near-term infants. JAMA 2003;290:2677-84.

26. Leviton A, Allred EN, Kuban KC, Hecht JL, Onderdonk AB, O'shea TM, Paneth N. Microbiologic and histologic characteristics of the extremely preterm infant's placenta predict white matter damage and later cerebral palsy. the ELGAN study. Pediatric Res 2010;67:95-101. 


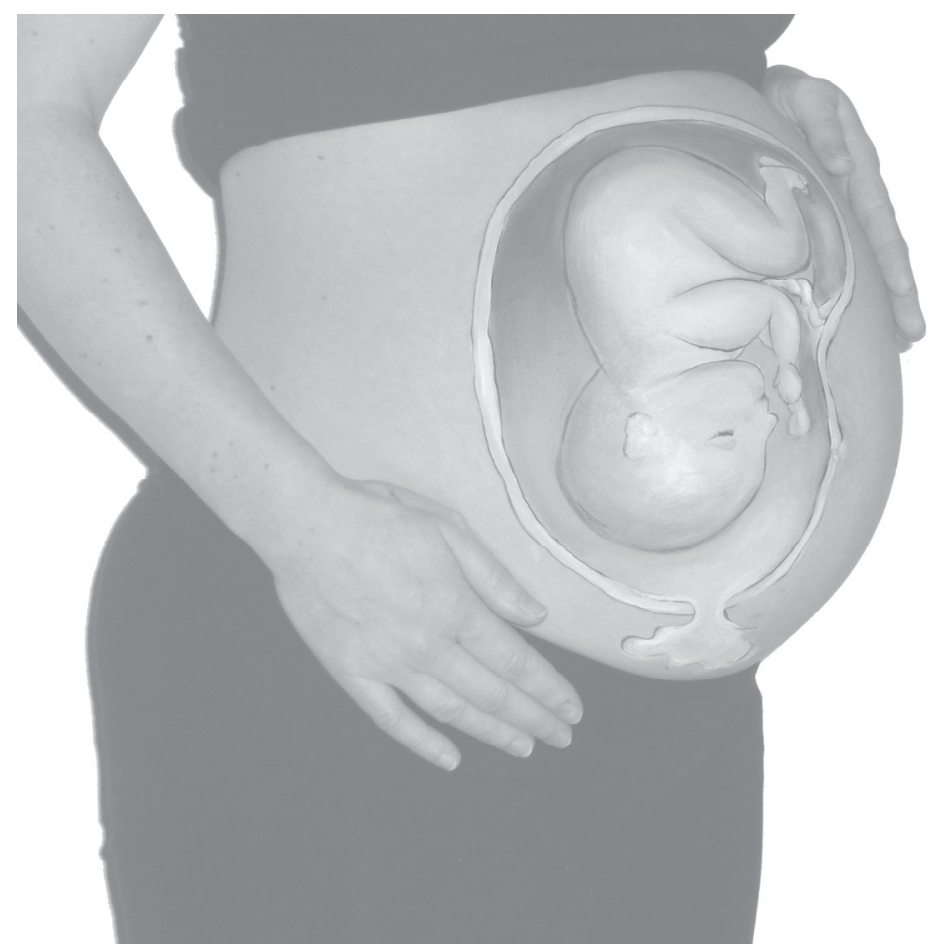


Summary 


\section{Summary and main conclusions}

In this thesis, various issues on preterm prelabor rupture of membranes (PPROM) at different gestational ages are outlined.

In the introduction section (Chapter 1), we have posed several questions that we tried to answer in this thesis:

$\checkmark \quad$ Is an useful diagnostic method available in the prediction of pulmonary hypoplasia in women with extreme preterm PROM? (Chapter 2)

$\checkmark$ How can we best counsel women with (early) PPROM about possible perinatal outcomes? (Chapters 3 and $\mathbf{4}$ )

$\checkmark \quad$ What do we tell women about the risk of recurrence of early PPROM or preterm birth in a subsequent pregnancy after previous early PPROM? (Chapter 5)

$\checkmark$ Can neonatal infection or clinical chorioamnionitis be predicted in women with (preterm) PROM by measuring laboratory parameters? (Chapter 6)

$\checkmark$ Is expectant management preferred over induction of labor in women with PPROM between 34 and 37 weeks' gestation? (Chapter 7)

$\checkmark$ Is there a difference in neurodevelopmental outcome and behavioral development at 2 years of age between induction of labor or expectant management in women with PPROM between 34 and 37 weeks' gestation? (Chapter 8)

(Preterm) PROM carries a certain risks of adverse outcome at any gestational age. Mostly these are perinatal or neonatal risks, but if infection plays a role it might also have consequences for the maternal health. After performing the studies in this thesis, we found that many issues still remain unclear (such as the effect of chorioamnionitis on long-term childhood development and the (neuro)developmental outcome of infants at $>2$ years of age after induction or labor versus expectant management in women with PPROM) and such issues may be interesting for future research. On the other hand, even though there might not be a solution to solve every issue in case of PPROM, and even though not all the necessary information to counsel a couple with such a pregnancy complication will be available, we hope to be able to provide guidance for the counseling of women/couples with (extreme) preterm PROM.

\section{Diagnostic methods}

Chapter 2 describes a meta-analysis on the accuracy of imaging parameters to predict pulmonary hypoplasia in women with midtrimester PPROM. Thirteen cohort studies that report on ultrasound and/or MRI parameters were included in this meta-analysis. Five studies were adequately blinded. Selection bias was present in eight studies, whereas verification bias was not present in any study.

In six of the 13 studies, the diagnosis of lethal pulmonary hypoplasia was not always based on autopsy data, sometimes clinical and radiological data were used. 
The most commonly used ultrasound parameters were chest circumference (seven studies), chest circumference/abdominal circumference ratio (six studies) and chest circumference/femur length ratio (three studies). The MRI parameters used in the only study incorporating MRI were chest circumference and ratio of chest area minus cardiac area divided by cardiac area; volumes were not measured.

Only one study reported an optimal sensitivity for chest circumference, but this was at the expense of low specificity; the other six studies combined a high specificity with a sensitivity varying between $50 \%$ and $80 \%$.

One study demonstrated perfect sensitivity and specificity for chest circumference/abdominal circumference ratio; all other studies had either suboptimal sensitivity or suboptimal specificity.

Another study reported almost perfect accuracy for the chest circumference/femur length ratio, with a sensitivity of $100 \%$ and a specificity of $97 \%$, but the sample size in this study was rather low, as there were only 35 pregnancies in the cohort. Neither the amount nor the timing of measurements performed throughout the latency was uniform.

Therefore, the imaging parameters (measuring ultrasound and MRI parameters) are not useful in the prediction of pulmonary hypoplasia in pregnancies with midtrimester PPROM and routinely measuring these parameters does not contribute to improve adequate counseling of a couple.

Another diagnostic method that was assessed in this thesis, was the predictive value of C-reactive protein (CRP) and leukocytes (white blood cells) for neonatal infection or sepsis in pregnancies with prelabor rupture of membranes (PROM). This study was described in Chapter 6.

Two-hundred ninety nine women with PROM $>24$ hours were included in this retrospective cohort study, using data from 2003 to 2006. The gestational age (GA) at inclusion varied from 26 weeks and 0 days to 41 weeks and 5 days with a median GA of 37 weeks and 3 days. Of the total group, 47 neonates (16\%) developed a clinical infection, of which six children (2\%) had an early onset neonatal sepsis.

The area under the ROC (receiver operating characteristics) curve in the diagnosis of clinical infection was 0.61 for CRP and 0.62 for leukocytes, respectively. The sensitivity of either CRP or leukocytes measurement was maximum $64 \%$, with at the same time a low specificity of maximum $56 \%$.

For maternal temperature (last measurement before delivery), the area under the ROC curve was 0.61 as well.

From these results, we can conclude that there is no evidence that measuring CRP and leukocytes in women with PROM is useful in the prediction of neonatal infection. In particular, these parameters should not be used to decide between induction of labor or expectant management. 
Other factors, such as fetal tachycardia and fetid or colored amniotic fluid might be better indicators of intrauterine infection, but a study on this subject was not included in this thesis.

\section{Perinatal outcome}

In Chapter 3, the pregnancy outcomes of 314 pregnancies with PPROM before 27 weeks were assessed in a retrospective cohort study. There were 6 requests for a termination of pregnancy (1.9\%). Three pregnancies were excluded as their outcome was unknown.

The remaining 305 women were studied and there were 336 neonates eligible for analysis.

For outcome measurements, a subdivision was made for different categories: PPROM between 13 and 20 weeks, 20 to 24 weeks and 24 to 27 weeks.

The GA at PPROM varied from $13^{+0}$ weeks to $26^{+6}$ weeks, with a median GA of $23^{+1}$ weeks.

PPROM following amniocentesis and chorionic villus sampling (iatrogenic PPROM) occurred in $24(7.9 \%)$ and 9 women $(2.9 \%)$, respectively. The mean GA at delivery was $28^{+5}$ weeks (standard deviation (SD) \pm 7.7 ) for iatrogenic PPROM and $25^{+3}$ weeks (SD \pm 3.8 ) for spontaneous PPROM, respectively.

The median interval between PPROM and delivery (latency) was 10 days (mean latency 25 days).

The earlier the GA at PPROM, the longer the interval between PPROM and delivery. In the early gestational age group (PPROM 13-20 weeks), significantly more women were still pregnant 50 days after PPROM, compared to the subcategory PPROM 24-27 weeks (35\% versus 1.4\%; relative risk (RR) 0.31 (95\% confidence interval (CI) 0.23-0.40); $P<0.0001$ ), with an absolute risk reduction (ARR) of $66 \%$.

The overall perinatal mortality rate was $49 \%$ (166/336), of which $28 \%$ were stillbirths.

Of the neonates who were alive seven days after birth, $41 \%$ suffered serious morbidity (respiratory distress syndrome (RDS) grade 3 or 4 , intraventricular hemorrhage (IVH), necrotizing enterocolitis (NEC), chronic lung disease (CLD) or (suspicion of) sepsis).

Overall, 30\% survived without serious morbidity.

From six preselected candidate predictor variables (maternal age, gestational age at PPROM, interval between PPROM and birth, anhydramnios, positive vaginal culture (any bacteria) and positive vaginal culture for GBS (group B streptococcus), three factors were associated with perinatal mortality in multivariable logistic regression analysis: early gestational age at PPROM, long interval between PPROM and birth and positive vaginal culture (any bacteria) were associated with perinatal mortality. Identification of these associative factors is important for objective (individualized) counseling of women with early PPROM. 
Chapter 4 is a retrospective cohort study, including 5723 singleton pregnancies with PPROM between 26 and 34 weeks' gestation (duration of ruptured membranes $>24$ hours) with perinatal mortality, composite morbidity and sepsis as most important outcome measures. Data were obtained from the Netherlands Perinatal Registry (PRN).

Overall perinatal mortality occurred $2.1 \%$ (123 of 5723 cases), of which $1.2 \%$ were stillbirths and $1.0 \%$ of neonates died intrapartum or after birth.

The incidence of composite neonatal morbidity was $21 \%$ and $79 \%$ of neonates survived without severe morbidity. Neonatal sepsis occurred in 914 neonates (16\%).

Advanced gestational age at delivery increased the survival rate up to a gestational age of 38 weeks. Overall, earlier gestational age at PPROM seems to be related to adverse perinatal outcome with an improvement of all perinatal outcomes (mortality, composite morbidity and sepsis) after a longer latency period.

Sixteen percent of all 5723 women with PPROM between 26 and 34 weeks, delivered after 36 weeks.

\section{Risk of recurrence of early PPROM or preterm birth}

In Chapter 5, a retrospective cohort study on the course of subsequent pregnancies after early PPROM (before 27 weeks' gestation) is presented. The study population is equal to the population from the study that is discussed in Chapter 4 , but in this study the outcomes of the first subsequent pregnancy are assessed.

In this study 307 women with a complicated (index) pregnancy were included, of which 118 women (38\%) had at least one subsequent pregnancy and 163 women (53\%) did not conceive again. Of 19 women, data on the subsequent pregnancies were unknown, leaving 99 pregnancies eligible for analysis.

The recurrence risk of PPROM before 27 weeks was 9\% and PPROM occurred between 27 and 34 weeks' gestation in another $6 \%$ of women.

The mean gestational age at delivery in the subsequent pregnancy was 35 weeks and 6 days (SD \pm 6.0 days). Overall 9 women (9\%) delivered before 27 weeks, 13 (13\%) between 27 and 34 weeks, 13 (13\%) between 34 and 37 weeks, and 58 women (59\%) delivered at term.

In the subsequent pregnancy, $50 \%$ of women had delivered before a gestational age of 37.9 weeks (demonstrated by Kaplan-Meier analysis) .

Seventy-one subsequent pregnancies ended in a delivery after 34 weeks' gestation without major complications during pregnancy $(72 \%)$.

In multivariable analysis, potential associative factors for preterm delivery in a subsequent pregnancy were assessed.

These factors were positive vaginal culture for GBS (reduced the risk of preterm delivery (odds ratio (OR) $0.19,95 \% \mathrm{Cl}: 0.04-0.91$ )) and increased maternal age (increased risk of preterm delivery (OR 1.12, 95\% Cl: 1.0-1.26)). Moreover, (early) gestational age at PPROM in the index pregnancy, but not gestational age at delivery was also slightly associative for renewed preterm birth (OR $0.97,95 \% \mathrm{Cl}$ : 0.94-1.0). 
The factor positive vaginal culture for GBS was an unexpected finding and the opposite of what we expected. A possible explanation might be that women who are known to be GBS positive in the index pregnancy, are extra checked in the subsequent pregnancy and/or they might get prophylactic antibiotics.

\section{Preferred policy in case of PPROM between 34 and 37 weeks' gestation}

In the PPROMEXIL-2 trial (Chapter 7), 195 women with PPROM between 34 and 37 weeks were randomized between induction of labor ( $\mathrm{loL})(\mathrm{n}=100)$ and expectant management (EM) ( $n=95)$.

The median gestational age at randomization was 251 days. Women in the loL group delivered on average 3.5 days earlier $(95 \% \mathrm{Cl}, 1.8-5.2$ days) than women in the EM group.

Antibiotics during admission and during labor were administered equally.

Neonatal sepsis was seen in three neonates (3.0\%) in the loL group versus four neonates (4.1\%) in the EM group (RR, 0.74; 95\% Cl 0.17-3.2).

Neonates born in the IoL group were equally admitted to the NICU (7 [7.0\%] cases versus 8 [8.2\%] in the EM group; RR, 0.86; $95 \% \mathrm{Cl} 0.32-2.3)$. In the loL group, neonates stayed 7.4 days in the hospital compared with 6.9 days (mean difference (MD), 0.52; $95 \% \mathrm{Cl}-0.5$ to 2.3 days) after EM.

Respiratory distress syndrome was seen in 6 newborns in the loL group (6.0\%) versus 5 in the EM group (5.1\%) (RR, 1.2; 95\% Cl 0.37-3.7).

There were no significant differences between both groups for RDS, hypoglycemia, hyperbilirubinemia and other neonatal outcomes.

Clinical chorioamnionitis was not seen in the loL group and in 4 women in the EM group (4.3\%) $(P=0.038)$. The incidence of histological chorioamnionitis was $12(18 \%)$ versus 18 (31\%), respectively (RR 0.64; 95\% Cl 0.33-1.2).

In an updated meta-analysis, in total 9 studies with 1428 neonates could be analyzed.

The risk ratios for neonatal infection/sepsis, culture-proven sepsis, respiratory distress syndrome and cesarean section rate were not statistically different.

\section{Developmental outcome of children at 2 years of age}

Chapter 8 describes the two-years follow-up study of the original PPROMEXIL trial. In this follow-up study, 552 women (both randomized as non-randomized participants) were approached to fill out three questionnaires (general questionnaire, ages and stages questionnaire (ASQ) and the child behavioral checklist (CBCL)) with a response rate of $58 \%$.

From the total group of responders, there were 56 infants (17\%) with an abnormal score in $\geq 1$ areas of the ASQ and 45 infants (14\%) with one or more abnormal scores on the $\mathrm{CBCL}$. 
In the induction of labor (IoL) group, $14 \%(n=16)$ had an abnormal score in $\geq 1$ areas of the ASQ, whereas $26 \%(n=27)$ of the children in the expectant management (EM) group had an abnormal score in $\geq 1$ areas $(P=0.033)$. For the $C B C L$ we found no difference between the IoL and the EM groups ( $13 \%$ and $15 \%$, respectively; $P=0.645$ ).

Univariate regression analysis was performed to identify factors with a correlation with an abnormal ASQ or CBCL result. The only two factors that were found to have a significant correlation with an abnormal outcome of the $\mathrm{CBCL}$, were antenatal administration of corticosteroids and a lower maternal education level. Only management strategy (expectant management) was associated with an abnormal ASQ outcome in the randomized group. None of the other variables were correlated with an abnormal outcome of the ASQ.

Therefore, we would advise to be reluctant to the use of antenatal corticosteroids. However, the usefulness of administration of corticosteroids in case of threatened preterm birth before 32 weeks' gestation is widely known and generally accepted, which means that the use of this medication should not be completely abolished. Obviously, maternal education level cannot be influenced at all.

All issues that were discussed in the thesis, were analyzed in-depth in the general discussion

(Chapter 9). In Chapter 9, issues derived from all different Chapters in this thesis are discussed.

For instance, that it would be helpful to find parameters or techniques that are useful in the prediction of pulmonary hypoplasia, because this is an important perinatal problem in case of extreme preterm PROM. Following on Chapter $\mathbf{3}$ we concluded that an updated meta-analysis on the outcome of pregnancies with extreme preterm PROM can be contributing, because the latest meta-analysis dates from 2001.

Furthermore studying the predictive capacity of laboratory parameters (C-reactive protein and leukocytes) for neonatal infection, would be useful in pregnancies with PPROM before 37 weeks' gestation, because in our study the majority of the study population had a gestational age above 37 weeks (Chapter 6).

Also on the subject of the preferable management strategy in case of late preterm PROM, a meta-analysis would be useful. After the PPROMEXIL trial, the PPROMEXIL-2 trial and the ongoing PPROMT trial, many data on perinatal and neonatal outcomes after induction of labor versus expectant management in women with PPROM between 34 and 37 weeks' gestation will be available for an individual patient data meta-analysis (IPD-MA).

In Chapter 8 the long-term childhood development of infants at two years of age after induction of labor versus expectant management for late preterm PROM was assessed. In the expectant management group, an abnormal score on $\geq 1$ areas of the ASQ was more often found compared with the induction of labor group. However, we only assessed the (neuro)developmental outcome at two years of age. It would be 
meaningful to perform a follow-up study at later ages (e.g. 5 and 8 years of age) as well. Also the effect of chorioamnionitis on long-term outcome would be interesting to study further, because in previous studies there seems to be an increased risk of adverse long-term outcome due to chorioamnionitis, whereas this was not confirmed in our present follow-up study.

The same applies to neonatal sepsis, there possibly is an increased risk of adverse long-term developmental outcome, even though this was not found in our present follow-up study.

In addition, in Chapter $\mathbf{9}$ we have made an important remark on the need for solid follow-up in all (large) randomized obstetric trials and the importance of funding by sponsors (or government).

\section{Main conclusions}

$\checkmark$ Biometric parameters (by ultrasound or MRI) show limited accuracy in the prediction of pulmonary hypoplasia in case of midtrimester PPROM.

* Therefore, there is no indication to perform such diagnostic imaging tests in a clinical setting in women with midtrimester PPROM.

$\checkmark \quad$ In the counseling of women with PPROM before 27 weeks', the prognosis and risks should be addressed: mortality rate of almost $50 \%$ and a $30 \%$ chance of survival without severe neonatal morbidity. Several antepartum variables seem to be useful in the prediction of the individualized risk of perinatal mortality, and prophylactic administration of antibiotics is advised in case of PPROM before 27 weeks.

$\checkmark$ The perinatal mortality rate of pregnancies with PPROM between 26 and 34 weeks' gestation (with a duration of ROM $>24$ hours) is $2.1 \%$. The incidence of adverse neonatal outcome decreases with increasing gestational age at PPROM and at delivery. A longer latency period is associated with better perinatal outcomes.

$\checkmark$ The risk of recurrence of early PPROM is increased for women who have previously suffered from PPROM before 27 weeks' gestation. Furthermore, the risk of a premature delivery in future pregnancies is $35 \%$, which is approximately 3 to 4 times higher compared with the general population risk.

$\checkmark \quad$ CRP and leukocytes in maternal serum are poor predictors of neonatal infection in case of PROM. Therefore, these parameters should not be routinely measured in women with PROM.

$\checkmark$ The incidence of neonatal sepsis is not reduced by induction of labor. The incidence of neonatal sepsis is low. Induction of labor does not seem to increase the risk of any adverse neonatal or maternal outcome.

$\checkmark$ The neurodevelopmental outcome of infants at two years of age seems slightly better after induction of labor compared with expectant management in pregnancies with near-term PPROM (gestational age 34 to 37 weeks). 
$\checkmark$ For short-term outcomes, expectant management is preferred over induction of labor in women with near-term PPROM, whereas the long-term outcome (of infants at two years of age) might be slightly better after induction of labor. 


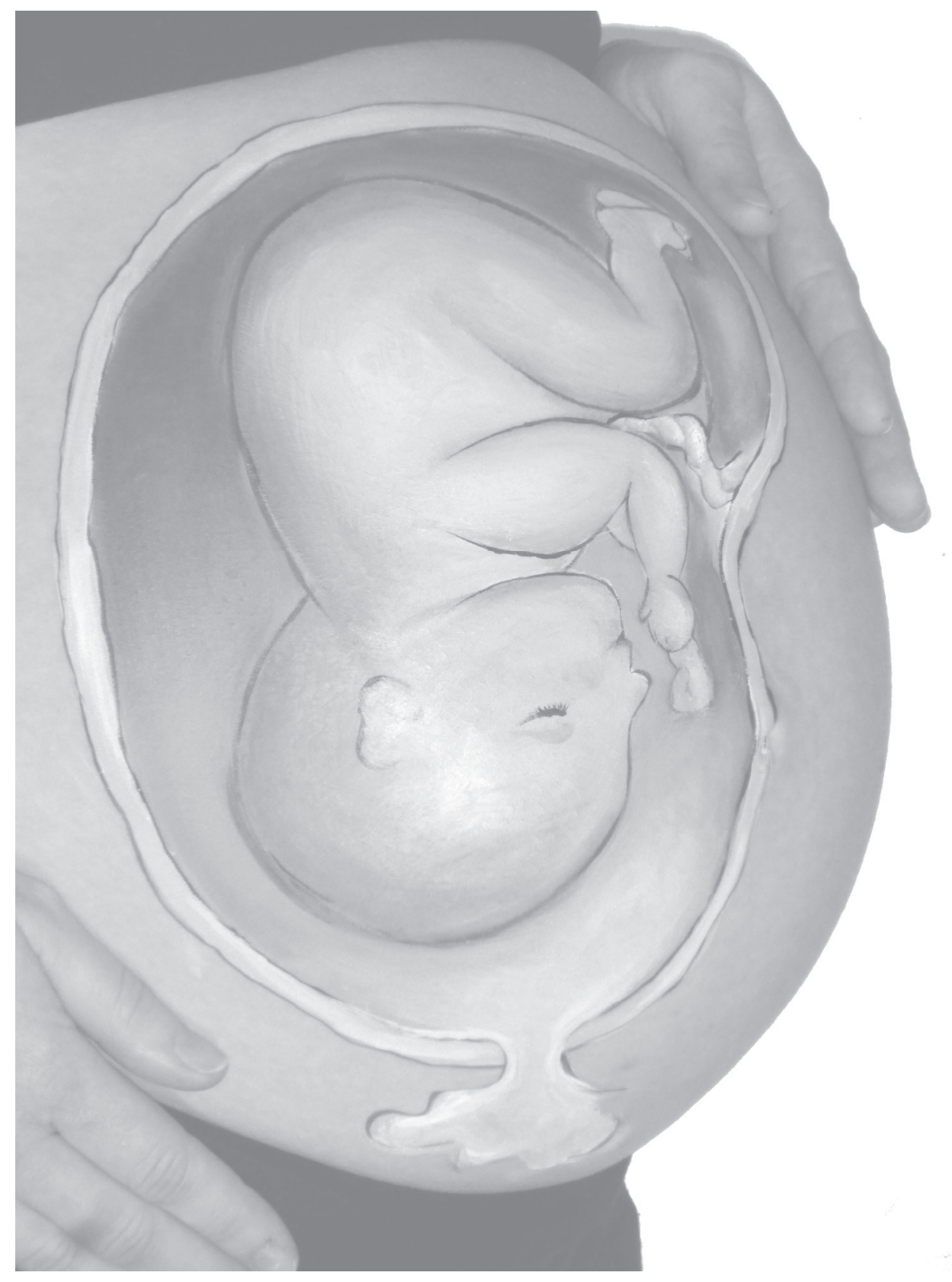


Nederlandse samenvatting en conclusies 
158 


\section{Nederlandse samenvatting en conclusies}

Dit proefschrift geeft een uiteenzetting van verschillende problemen rondom het vroegtijdig breken van de vliezen (Preterm Prelabor Rupture Of Membranes; PPROM) bij verschillende zwangerschapstermijnen.

In de introductie (Hoofdstuk 1) stelden we enkele vragen, welke we in dit proefschrift getracht hebben te beantwoorden:

$\checkmark$ Is er een zinvolle diagnostische methode beschikbaar om adequaat longhypoplasie bij vrouwen met extreem vroegtijdige PROM te voorspellen? (Hoofdstuk 2)

$\checkmark$ Hoe kunnen we vrouwen met (zeer vroegtijdige) PROM optimaal counselen (informatie verstrekken en advies geven) over eventuele zwangerschapsuitkomsten? (Hoofdstukken 3 en 4)

$\checkmark$ Wat kunnen we vrouwen vertellen over de herhalingskans van zeer vroegtijdige PROM of vroeggeboorte in een volgende zwangerschap nadat ze een eerdere zwangerschap met zeer vroegtijdige PROM hebben doorgemaakt? (Hoofdstuk 5)

$\checkmark$ Is het mogelijk om klinische chorioamnionitis of neonatale infectie te voorspellen bij vrouwen met (vroegtijdige) PROM middels het meten van bepaalde laboratorium parameters? (Hoofdstuk 6)

$\checkmark \quad$ Heeft afwachtend beleid de voorkeur ten opzichte van inleiding van de baring bij vrouwen met PPROM tussen 34 en 37 weken zwangerschapsduur? (Hoofdstuk 7)

$\checkmark$ Is er een verschil in neurologische- en gedragsontwikkeling van de kinderen op 2-jarige leeftijd in geval van PPROM tussen 34 en 37 weken zwangerschapsduur, waarbij de behandelstrategie inleiding van de baring of afwachtend beleid was? (Hoofdstuk 8)

(Vroegtijdige) PROM draagt meerdere risico's op een slechtere uitkomst met zich mee, ongeacht de zwangerschapsduur. Dit zijn meestal risico's voor het kind rondom de geboorte of in de periode net erna, maar als infectie een rol speelt kan het ook gevolgen hebben voor de gezondheid van de moeder. Na het voltooien van de verschillende studies uit dit proefschrift, moeten we concluderen dat er niet altijd een oplossing is voor deze zwangerschapscomplicaties en dat vele kwesties nog onopgelost zijn, zoals het effect van chorioamnionitis op de lange termijn ontwikkeling van het kind en de (neurologische) ontwikkeling van kinderen op >2-jarige leeftijd na inleiding van de baring versus afwachtend beleid bij vrouwen met PPROM. Zulke onderwerpen kunnen interessant zijn voor aanvullend toekomstig onderzoek. Aan de andere kant, ook al is er niet altijd een oplossing voor de problemen door PPROM, en ook al is niet alle noodzakelijke informatie beschikbaar voor het counselen van een vrouw en haar partner met een dergelijke zwangerschapscomplicatie, hopen we dat we met onze studies wel handvaten kunnen geven bij het counselen van een vrouw en haar partner in geval van (extreem) vroegtijdige PROM. 


\section{Diagnostische methoden}

Hoofdstuk 2 beschrijft een meta-analyse over of beeldvormende technieken longhypoplasie kunnen voorspellen in geval van zeer vroege PPROM (in het $2^{\mathrm{e}}$ trimester). Dertien cohort studies die rapporteren over echoscopische en/of MRI parameters werden geïncludeerd in deze meta-analyse. Bij vijf studies werd er adequaat geblindeerd. Selectie bias was aanwezig in acht studies, terwijl verificatie bias in geen van de studies aanwezig was.

De diagnose 'letale longhypoplasie' werd in lang niet alle studies gesteld op basis van autopsie gegevens, soms werden alleen klinische en radiologische gegevens gebruikt.

De meest gebruikte echoscopische parameters waren thoraxomtrek (zeven studies), thoraxomtrek/abdominale omtrek ratio (zes studies) en thoraxomtrek/femur lengte ratio (drie studies).

Slechts één studie rapporteerde een optimale sensitiviteit voor thoraxomtrek, maar dit ging ten koste van een lage specificiteit; de andere zes studies combineerden een hoge specificiteit met een sensitiviteit variërend tussen $50 \%$ en $80 \%$.

Eén studie liet een perfecte sensitiviteit en specificiteit zien voor thoraxomtrek/abdominale omtrek ratio; alle overige studies hadden ofwel een suboptimale sensitiviteit, ofwel een suboptimale specificiteit.

Een andere studie rapporteerde een bijna perfecte nauwkeurigheid voor de thoraxomtrek/femur lengte ratio, met een sensitiviteit van $100 \%$ en een specificiteit van $97 \%$, maar de sample size (grootte) van deze studie was nogal klein, slechts 35 zwangerschappen. Noch het aantal, noch de timing van de metingen was uniform.

Aan de hand van deze meta-analyse kan gesteld worden dat de beschreven beeldvormende technieken (het meten van echoscopische en MRI parameters), niet adequaat longhypoplasie in zwangerschappen met midtrimester PPROM kunnen voorspellen en dat het routinematig meten van deze parameters niet bijdraagt aan betere counseling van de zwangere en haar partner.

In Hoofdstuk 6 hebben we de voorspellende waarde van C-reactive protein (CRP) en leukocyten (witte bloedcellen) voor het ontstaan van neonatale infectie of sepsis onderzocht bij zwangerschappen met langdurig gebroken vliezen (PROM).

Tweehonderd negenennegentig vrouwen met PROM gedurende tenminste 24 uur werden geïncludeerd in deze retrospectieve cohort studie (periode 2003-2006). De zwangerschapsduur (amenorroeduur; AD) ten tijde van inclusie varieerde van 26 weken en 0 dagen tot 41 weken en 5 dagen met een mediane AD van 37 weken en 3 dagen. In totaal was er bij 47 neonaten (16\%) sprake van een klinische infectie, waarvan 6 kinderen (2\%) een early onset neonatale sepsis hadden (sepsis ontstaan binnen 72 uur na de geboorte).

De area under the ROC (receiver operating characteristics) curve voor de diagnose klinische infectie was respectievelijk 0.61 voor CRP en 0.62 voor leukocyten. De 
sensitiviteit van CRP en leukocyten bepaling was maximaal $64 \%$, met tegelijkertijd een lage specificiteit van maximaal $56 \%$.

Voor maternale temperatuur (laatste meting voor de bevalling), was de area under the ROC curve ook 0.61 .

Met deze resultaten kunnen we concluderen dat er geen bewijs is dat bepaling van CRP en leukocyten zinvol is bij vrouwen met PROM om de kans op neonatale infectie te voorspellen.

Deze parameters dienen met name niet gebruikt te worden om een beslissing te nemen of de baring ingeleid dient te worden of dat een afwachtend beleid gehandhaafd blijft.

Andere factoren, zoals tachycardie van de foetus en stinkend of gekleurd vruchtwater zijn mogelijk betere indicatoren voor een intra-uteriene infectie.

\section{Perinatale uitkomsten}

In Hoofdstuk 3 werden de zwangerschapsuitkomsten van 305 zwangerschappen met PPROM voor 27 weken zwangerschapsduur bestudeerd in een retrospectieve cohort studie, met in totaal 336 neonaten.

Voor de uitkomstmaten werd een onderverdeling gemaakt in verschillende categorieën: PPROM tussen 13 en 20 weken, 20 tot 24 weken en 24 tot 27 weken.

De AD bij PPROM varieerde van $13^{+0}$ weken tot $26^{+6}$ weken, met een mediane AD van $23^{+1}$ weken.

latrogene PPROM (breken van de vliezen na een amniocentese (vruchtwaterpunctie) of een vlokkentest) trad op bij respectievelijk 24 (7.9\%) en 9 vrouwen (2.9\%). De gemiddelde AD bij bevalling was $28^{+5}$ weken (standaard deviatie (SD) \pm 7.7 ) voor iatrogene PPROM en $25^{+3}$ weken (SD \pm 3.8 ) voor spontane PPROM.

Het mediane interval tussen PPROM en bevalling (latentietijd) was 10 dagen (gemiddelde latentietijd was 25 dagen).

Hoe vroeger de zwangerschapsduur ten tijde van PPROM, hoe langer het interval tussen PPROM en bevalling. In de vroege groep qua zwangerschapsduur (PPROM 13-20 weeks), waren 50 dagen na het breken van de vliezen significant meer vrouwen nog zwanger, vergeleken met de subgroep PPROM $24-27$ weken (35\% versus $1.4 \%$; relatief risico (RR) 0.31 (95\% betrouwbaarheidsinterval (BI) 0.23-0.40); $p<0.0001$ ), met een absolute risico reductie (ARR) van $66 \%$.

De totale perinatale mortaliteit was $49 \%$ (166/336), waarvan $28 \%$ foetale (intrauteriene) sterfte bedroeg.

Van de neonaten die 7 dagen na geboorte in leven waren, leed $41 \%$ aan ernstige morbiditeit (respiratory distress syndrome (RDS) graad 3 of 4 , intraventricular hemorrhage (IVH), necrotiserende enterocolitis (NEC), chronic lung disease (CLD) of (verdenking op) sepsis). In totaal overleefde 30\% zonder ernstige morbiditeit.

Van zes vooraf geselecteerde voorspellende variabelen (maternale leeftijd, zwangerschapsduur bij PPROM, interval tussen PPROM en bevalling, anhydramnion, 
positieve vaginakweek (elke bacterie) en positieve vaginakweek voor GBS (groep B streptokokken), waren in een multivariabele logistische regressie analyse drie factoren geassocieerd met perinatale mortaliteit: Vroege zwangerschapsduur bij PPROM, langer interval tussen PPROM en bevalling en een positieve vaginakweek (elke bacterie). Het identificeren van deze associatieve factoren is belangrijk voor objectieve (geïndividualiseerde) counseling van vrouwen met vroege PPROM.

Hoofdstuk 4 beschrijft een onderzoek waarin 5723 eenlingzwangerschappen met PPROM tussen 26 en 34 weken zwangerschapsduur (duur van de gebroken vliezen >24 uur) retrospectief zijn bestudeerd. De benodigde gegevens werden verkregen uit de Perinatale Registratie Nederland (PRN).

In dit onderzoek was de totale perinatale mortaliteit bij PPROM tussen 26 en 34 weken $2.1 \%$ (123 van 5723 gevallen), waarvan $1.2 \%$ foetale (intra-uteriene) sterfte was en $1.0 \%$ van de pasgeborenen overleed gedurende of na de geboorte.

De incidentie van samengestelde neonatale morbiditeit (RDS, IVH, bronchopulmonaire dysplasie (BPD), NEC, neonatale sepsis en Apgar score $<7$ na 5 minuten) was $21 \%$ (en $79 \%$ van de neonaten overleefde zonder ernstige morbiditeit. Neonatale sepsis trad op bij 914 pasgeborenen (16\%).

Toegenomen zwangerschapsduur bij de bevalling gaf een toename van de kans op overleving tot een zwangerschapsduur van 38 weken.

Over het algemeen lijkt vroegere zwangerschapsduur bij PPROM gerelateerd te zijn aan een slechtere perinatale uitkomst en alle perinatale uitkomsten (mortaliteit, samengestelde morbiditeit en sepsis) verbeterden met een langere latentietijd.

Zestien procent van alle 5723 vrouwen met PPROM tussen 26 en 34 weken, beviel na 36 weken.

\section{Herhalingskans van vroegtijdige PPROM of vroeggeboorte}

In Hoofdstuk $\mathbf{5}$ wordt een retrospectieve cohort studie beschreven over het beloop van volgende zwangerschappen na vroege PPROM (voor 27 weken zwangerschapsduur). De studiepopulatie is gelijk aan de populatie van de studie die is beschreven in Hoofdstuk 4, maar in dit onderzoek worden de uitkomsten van de eerstvolgende zwangerschap bestudeerd.

In deze studie werden 307 vrouwen met een gecompliceerde zwangerschap (zwangerschap met PPROM voor 27 weken; index zwangerschap) geïncludeerd, waarvan 118 vrouwen (38\%) tenminste één volgende zwangerschap hadden en 163 vrouwen (53\%) niet opnieuw zwanger werden. Van de volgende zwangerschappen, konden er 99 geanalyseerd worden.

Het herhalingsrisico van PPROM voor 27 weken was $9 \%$ en bij nog $6 \%$ trad PPROM op tussen 27 en 34 weken zwangerschapsduur.

De gemiddelde zwangerschapsduur bij bevalling in de volgende zwangerschap was 35 weken en 6 dagen (SD \pm 6.0 dagen). In totaal bevielen 9 vrouwen (9\%) voor 27 weken, 
13 vrouwen (13\%) tussen 27 en 34 weken, 13 (13\%) tussen 34 en 37 weken en 58 vrouwen ( $59 \%$ ) bevielen à terme ( $\geq 37$ weken).

In de volgende zwangerschap, was $50 \%$ van de vrouwen bevallen vóór een zwangerschapsduur van 37.9 weken (aangetoond middels een Kaplan-Meier analyse) en eindigden 71 zwangerschappen (72\%) in een bevalling na 34 weken zonder grote complicaties tijdens de zwangerschap.

Met behulp van een multivariabele analyse werd gezocht naar factoren die een potentiële associatie hebben met vroeggeboorte in een volgende zwangerschap.

Deze factoren waren positieve vaginakweek voor GBS (gaf een afname van risico op vroeggeboorte (odds ratio (OR) $0.19,95 \% \mathrm{BI}$ : 0.04-0.91)) en toegenomen maternale leeftijd (gaf een toename van risico op vroeggeboorte (OR 1.12, 95\% BI: 1.0-1.26)). Verder was er een lichte associatie tussen (vroege) zwangerschapsduur bij PPROM in de index zwangerschap (maar niet zwangerschapsduur bij de bevalling) en hernieuwde vroeggeboorte (OR 0.97, 95\% BI: 0.94-1.0).

De factor positieve vaginakweek voor GBS was een onverwachte bevinding. Het tegenovergestelde hadden we verwacht. Een mogelijke verklaring zou kunnen zijn, dat vrouwen waarbij een GBS is aangetoond in de index zwangerschap, extra worden gecontroleerd tijdens de volgende zwangerschap en/of profylactisch antibiotica krijgen toegediend.

\section{Voorkeursbeleid in geval van PPROM tussen 34 en 37 weken zwanger- schapsduur}

In de PPROMEXIL-2 studie (Hoofdstuk 7), werden 195 vrouwen met PPROM tussen 34 en 37 weken gerandomiseerd tussen inleiding van de baring (induction of labor; loL) ( $N=100$ vrouwen) en afwachtend beleid (expectant management; $E M)$ ( $N=95$ vrouwen).

De mediane zwangerschapsduur bij randomisatie was 251 dagen. Vrouwen in de loL groep bevielen gemiddeld 3.5 dagen vroeger (95\% BI 1.8-5.2 dagen) dan vrouwen in de EM groep.

Antibiotica tijdens opname en tijdens de bevalling werden even vaak toegediend in beide groepen.

Neonatale sepsis werd gezien bij drie pasgeborenen (3.0\%) in de loL groep versus vier pasgeborenen (4.1\%) in de EM groep (RR 0.74; 95\% BI 0.17-3.2).

Neonaten die geboren werden in de loL groep werden even vaak opgenomen op de neonatale intensive care unit (NICU) als neonaten in de EM groep (7 [7.0\%] gevallen versus 8 [8.2\%]; RR, 0.86; 95\% BI 0.32-2.3). In de loL groep, bleven de neonaten gedurende 7.4 dagen in het ziekenhuis vergeleken met 6.9 dagen na EM (mean difference (MD) 0.52; 95\% BI -0.5 tot 2.3 dagen).

Er waren geen significante verschillen tussen beide groepen in het vóórkomen van RDS, hyperbilirubinemie, hypoglycemie en andere neonatale uitkomstmaten. 
Klinische chorioamnionitis werd niet gezien in de loL groep en bij 4 vrouwen in de EM groep (4.3\%) ( $p=.038)$. De incidentie van histologische chorioamnionitis was respectievelijk 12 (18\%) versus 18 (31\%) (RR 0.64; 95\% Cl 0.33-1.2).

In een bijgewerkte meta-analyse, werden in totaal 9 studies met 1428 neonaten geanalyseerd.

Er waren geen statistische verschillen in de risk ratio's voor neonatale infectie, sepsis (bewezen m.b.v. een kweek), RDS en aantal keizersnedes.

\section{Ontwikkelingsuitkomsten van kinderen op 2-jarige leeftijd}

Hoofdstuk 8 beschrijft de 2-jaars follow-up studie van de originele PPROMEXIL studie. In deze follow-up studie werden 552 vrouwen (zowel gerandomiseerde als nietgerandomiseerde deelneemsters) benaderd met het verzoek om drie vragenlijsten in te vullen (algemene vragenlijst, een ontwikkelingsvragenlijst (Ages and Stages Questionnaire (ASQ)) en een gedragsvragenlijst (Child Behavioral Checklist (CBCL))), waarbij het responspercentage $58 \%$ was.

Van de totale groep responders $(n=320)$, waren er 56 kinderen $(18 \%)$ met een abnormale score in $\geq 1$ domeinen van de ASQ en 45 kinderen (14\%) met een of meer abnormale scores op de CBCL.

In de groep waarbij de baring was ingeleid had $14 \%$ een abnormale score in $\geq 1$ domeinen van de ASQ, terwijl $26 \%$ van de kinderen in de groep waarbij een afwachtend beleid was gevoerd een abnormale score had in $\geq 1$ domeinen $(p=0.033)$. Voor de CBCL vonden we geen verschillen tussen de groep die was ingeleid en de groep waarbij was afgewacht (respectievelijk $13 \%$ versus $15 \%$; $P=0.645$ ).

Een univariate regressie analyse werd verricht om factoren te identificeren die geassocieerd zijn met een abnormaal resultaat van de ASQ of CBCL. De enige twee factoren die een significante correlatie bleken te hebben met een abnormale uitkomst van de $\mathrm{CBCL}$, waren antenatale toediening van corticosteroïden en een lager maternaal opleidingsniveau. Geen van de variabelen was geassocieerd met een abnormale ASQ uitkomst.

Vanzelfsprekend kunnen en moeten deze twee factoren niet veranderd worden, aangezien de toediening van corticosteroïden bij dreigende vroeggeboorte vóór 32 weken zwangerschapsduur zijn nut heeft bewezen en algemeen geaccepteerd is. Maternaal opleidingsniveau kan uiteraard ook niet beïnvloed worden.

Alle onderwerpen die in dit proefschrift aan bod kwamen, werden in de discussie (Hoofdstuk 9) uitgebreid geanalyseerd. In Hoofdstuk 9 werden alle onderwerpen uit de verschillende hoofdstukken besproken.

Bijvoorbeeld, dat het nuttig zou zijn om parameters of technieken te vinden die kunnen helpen in het voorspellen van longhypoplasie, aangezien dit een belangrijk probleem is bij extreem vroegtijdige PROM. Naar aanleiding van Hoofdstuk 3 hebben we geconcludeerd dat het updaten van een meta-analyse over de uitkomsten van 
zwangerschappen met extreem vroegtijdige PPROM zinvol zou kunnen zijn, aangezien de meest recente meta-analyse dateert van 2001.

Verder zou het nuttig kunnen zijn om de voorspellende waarde van laboratorium parameters (C-reactive protein en leukocyten) voor neonatale infectie te bestuderen bij zwangerschappen met PPROM voor 37 weken, omdat in onze studie het grootste deel van de studiepopulatie een zwangerschapsduur boven 37 weken had (Hoofdstuk 6).

Ook over de voorkeursbehandeling bij PPROM tussen 34 en 37 weken zou het zinvol zijn om een meta-analyse te verrichten. Na het voltooien van de PPROMEXIL studie, de PPROMEXIL-2 studie en de nog lopende PPROMT studie, zijn er zeer veel data beschikbaar voor een 'individual patient data meta-analysis (IPD-MA)' over de perinatale en neonatale uitkomsten na inleiding van de baring versus afwachtend beleid bij vrouwen met PPROM tussen 34 en 37 weken.

In Hoofdstuk 8 werd de lange termijn ontwikkeling onderzocht van kinderen op 2jarige leeftijd die geboren waren na inleiding van de baring versus afwachtend beleid vanwege PPROM tussen 34 en 37 weken. In de groep met afwachtend beleid, kwam een abnormale score op $\geq 1$ domeinen van de ASQ vaker voor vergeleken met de groep waarbij de baring werd ingeleid. We hebben echter alleen de (neurologische) ontwikkeling op 2-jarige leeftijd bestudeerd. Het zou belangrijk kunnen zijn om ook een follow-up studie op latere leeftijd te verrichten (bijvoorbeeld op 5- en 8-jarige leeftijd).

Daarnaast zou het interessant zijn om het effect van chorioamnionitis op lange termijn uitkomsten verder te bestuderen, omdat er in eerdere studies een verhoogd risico lijkt te zijn op nadelige lange termijn uitkomsten bij chorioamnionitis, terwijl dit niet bevestigd kon worden in onze huidige follow-up studie.

Hetzelfde geldt voor neonatale sepsis. Er is mogelijk een verhoogd risico op een nadelige lange termijn uitkomst, hoewel dit niet gevonden werd in onze huidige followup studie.

Daarnaast hebben we in Hoofdstuk 9 een belangrijke opmerking gemaakt over de noodzaak van gedegen follow-up in alle (grote) gerandomiseerde obstetrische studies en het belang van financiering door sponsoren (of de overheid).

\section{Belangrijkste conclusies}

Biometrische parameters (gemeten met behulp van echoscopisch onderzoek en/of MRI) hebben beperkte waarde bij het voorspellen van longhypoplasie bij vrouwen met vroege (midtrimester) PPROM.

* In de huidige klinische setting zijn dit soort diagnostische beeldvormende onderzoeken niet geïndiceerd bij vrouwen met midtrimester PPROM.

$\checkmark \quad$ Bij het counselen van vrouwen met PPROM voor 27 weken, dienen de prognose en mogelijke risico's besproken te worden: de kans op perinatale sterfte is bijna $50 \%$ en er is een kans van $30 \%$ op overleving zonder ernstige complicaties. Verschillende antepartum variabelen lijken zinvol te zijn bij de voorspelling van een 
geïndividualiseerd risico op perinatale sterfte en profylactische toediening van antibiotica wordt geadviseerd bij PPROM voor 27 weken.

$\checkmark \quad$ De incidentie van perinatale sterfte bij zwangerschappen met PPROM tussen 26 en 34 weken (duur van gebroken vliezen $>24$ uur) is $2.1 \%$. De incidentie van slechte neonatale uitkomst nam af bij een toenemende zwangerschapsduur bij PPROM en bij bevalling. Langere latentietijd lijkt te leiden tot betere perinatale uitkomsten.

$\checkmark$ Het herhalingsrisico van vroege PPROM is toegenomen bij vrouwen die een eerdere zwangerschap met PPROM voor 27 weken hebben doorgemaakt. Daarnaast is het risico op vroeggeboorte in een toekomstige zwangerschap 35\%, wat circa 3 tot 4 keer hoger is vergeleken met het risico in de algemene populatie.

$\checkmark$ CRP en leukocyten in maternaal bloed (serum) zijn slechte voorspellers voor neonatale infectie in geval van langdurig gebroken vliezen. Deze parameters dienen daarom niet routinematig bepaald te worden bij vrouwen met langdurig gebroken vliezen.

$\checkmark$ Het ontstaan van neonatale sepsis wordt niet gereduceerd door inleiding van de baring. De incidentie van neonatale sepsis is laag. Inleiding van de baring lijkt niet te leiden tot toename van het risico op een nadelige uitkomst voor moeder of kind.

$\checkmark$ De neurologische ontwikkeling van kinderen op 2-jarige leeftijd is iets beter na inleiding van de baring vergeleken met afwachtend beleid in zwangerschappen met PPROM tussen 34 en 37 weken zwangerschapsduur.

$\checkmark$ Voor de korte termijn uitkomsten heeft afwachtend beleid de voorkeur boven inleiding van de baring bij vrouwen met late PPROM (zwangerschapsduur 34 tot 37 weken), terwijl de uitkomst op langere termijn (van kinderen op 2-jarige leeftijd) wat beter lijkt te zijn na inleiding van de baring. 
List of co-authors 


\section{List of co-authors}

Bettina MC Akerboom, MD, Department of Obstetics and Gynecology, Albert Schweitzer Hospital, Dordrecht, the Netherlands

Robert Aardenburg, MD PhD, Department of Obstetrics and Gynecology, Orbis Medical Center, Sittard, the Netherlands

Anneloes L van Baar, PhD, Department of Child and Adolescent Studies (CAS), Faculty of Social and Behavioural Sciences, Utrecht University, Utrecht, the Netherlands.

Caroline J Bax, MD PhD, Department of Obstetrics and Gynecology, VU Medical Center, Amsterdam, the Netherlands

J (Hans) J van Beek, MD PhD, Department of Obstetrics and Gynecology, VieCuri Medical Center, Venlo, the Netherlands

Kitty WM Bloemenkamp, MD PhD, Department of Obstetrics and Gynecology, Leids University Medical Center, Leiden, the Netherlands

J (Anne) CG Coolen, MD, Department of Obstetrics and Gynecology, Elkerliek Hospital, Helmond, the Netherlands

J (Hans) J Duvekot, MD PhD, Department of Obstetrics and Gynecology, Erasmus Medical Center, Rotterdam, the Netherlands

Maureen TM Franssen, MD PhD, Department of Obstetrics and Gynecology, University Medical Center Groningen, Groningen, the Netherlands

Mariette Groenewout, MD PhD, Department of Obstetrics and Gynecology, University Medical Center Groningen, Groningen, the Netherlands

Christianne JM de Groot, MD PhD, Department of Obstetrics and Gynecology, VU Medical Center, Amsterdam, the Netherlands

Feico J Halbertsma, MD PhD, Department of Pediatrics/Neonatology, Máxima Medical Center, Veldhoven, the Netherlands

David P van der Ham, MD PhD, Department of Obstetrics and Gynecology, Martini Hospital, Groningen, the Netherlands

Janneke van 't Hooft, MD, Department of Obstetrics and Gynecology, Academic Medical Center, Amsterdam, the Netherlands

Timothy Janssen, Bachelor student Hospitality management, Washtenaw Community College, Ann Arbor, Michigan, USA

Anneke Kwee, MD PhD, Department of Obstetrics and Gynecology, University Medical Center Utrecht, Utrecht, the Netherlands 
Sander van Kuijk, MSc PhD, Department of Epidemiology, GGD Zuid-Limburg

Jan W de Leeuw, MD PhD, Department of Obstetrics and Gynecology, Ikazia Hospital, Rotterdam, the Netherlands

Aren J van Loon, MD PhD, Department of Obstetrics and Gynecology, Martini Hospital, Groningen, the Netherlands

Helena JMM Mertens, MD PhD, Department of Obstetrics and Gynecology, Orbis Medical Center, Sittard, the Netherlands

Ben Willem J Mol, MD PhD, Department of Obstetrics and Gynecology, Academic Medical Center, Amsterdam, the Netherlands

Rob Moonen, MD PhD, Department of Pediatrics, Atrium Medical Center, Heerlen, the Netherlands

Antonius LM Mulder, MD PhD, Department of Pediatrics/Neonatology, Maastricht University Medical Center, GROW - School for Oncology and Developmental Biology, Maastricht, The Netherlands

S (Bas) WA Nij Bijvank, MD, Department of Obstetrics and Gynecology, Isala klinieken, Zwolle, the Netherlands

Jan G Nijhuis, MD PhD, Department of Obstetrics and Gynecology, Maastricht University Medical Center, GROW - School for Oncology and Developmental Biology, Maastricht, The Netherlands

Kim JB Notten, MD, Department of Obstetrics and Gynecology, Atrium Medical Center, Heerlen, the Netherlands

S (Guid) G Oei, MD PhD, Department of Obstetrics and Gynecology, Máxima Medical Center, Veldhoven, the Netherlands

Brent C Opmeer, MSc PhD, Department of Clinical Epidemiology, Biostatistics and Bioinformatics, Academic Medical Center, Amsterdam, the Netherlands

Martijn A Oudijk, MD PhD, Department of Obstetrics and Gynecology, University Medical Center Utrecht, Utrecht, the Netherlands.

Eva Pajkrt, MD PhD, Department of Obstetrics and Gynecology, Academic Medical Center, Amsterdam, the Netherlands

Martina M Porath, MD PhD, Department of Obstetrics and Gynecology, Máxima Medical Center, Veldhoven, the Netherlands

Joris A van der Post, MD PhD, Department of Obstetrics and Gynecology, Academic Medical Center, Amsterdam, the Netherlands 
Anita CJ Ravelli, MSc PhD, Department of Medical Informatics, Academic Medical Center, Amsterdam, the Netherlands

Jelle M Schaaf, MD PhD, Department of Obstetrics and Gynecology, Flevo Hospital, Almere, the Netherlands

J (Marko) M Sikkema, MD PhD, Department of Obstetrics and Gynecology, Hospital Group Twente, Almelo, the Netherlands

A (Stijn) SP van Teeffelen, MD, Department of Obstetrics and Gynecology, Maastricht University Medical Center, GROW - School for Oncology and Developmental Biology, Maastricht, The Netherlands

Aleid G van Wassenaer, MD PhD, Department of Pediatrics/Neonatology, Academic Medical Center, Amsterdam, the Netherlands

Christine Willekes, MD PhD, Department of Obstetrics and Gynecology, Maastricht University Medical Center, GROW - School for Oncology and Developmental Biology, Maastricht, The Netherlands

Mallory D Woiski, MD, Department of Obstetrics and Gynecology, St. Radboud University Medical Center, Nijmegen, the Netherlands 
172 
List of publications 


\section{Publications}

van der Heyden JL, van Teeffelen SS, Coolen AC, Halbertsma FJ, Aardenburg $\mathrm{R}$, Mertens HJ, Mol BW. Is it useful to measure C-reactive protein and leukocytes in patients with prelabor rupture of membranes? Am J Perinatol. 2010;27:543-547.

van Teeffelen AS, Van Der Heijden J, Oei SG, Porath MM, Willekes C, Opmeer B, Mol BW. Accuracy of imaging parameters in the prediction of lethal pulmonary hypoplasia secondary to midtrimester prelabour rupture of fetal membranes: a systematic review and meta-analysis. Ultrasound Obstet Gynecol. 2012;39: 495-499

Van der Heyden JL, van der Ham DP, van Kuijk S, Notten K, Janssen T, Nijhuis JG, Willekes C, Porath MM, van der Post J, Halbertsma F, Mol BWJ, Pajkrt E. Outcome of pregnancies with preterm prelabour rupture of membranes before 27 weeks' gestation: a retrospective cohort study. Eur J Obstet Gynecol Reprod Biol. 2013;170:125-130

Van der Heyden JL, van Kuijk S, van der Ham DP, Notten K, Janssen T, Nijhuis JG, Willekes C, Porath MM, van der Post J, Halbertsma F, Pajkrt E, Mol BWJ. Subsequent pregnancy after preterm prelabor rupture of membranes before 27 weeks. AJP Rep. 2013;3:113-118.

van der Ham DP, van der Heyden JL, Opmeer BC, Mulder ALM, Moonen RMJ, van Beek JJ, Franssen MTM, Bloemenkamp KWM, Sikkema JM, de Groot CJM, Porath M, Kwee A, Woiski MD, Duvekot JJ, Akerboom BMC, van Loon AJ, de Leeuw JW, Willekes C, Mol BWJ, Nijhuis JW: Management of late-preterm premature rupture of membranes: the_PPROMEXIL-2 trial. Am J Obstet Gynecol. 2012;207:276.

van der Heyden JL, Willekes $C$, van Baar AL, van Wassenaer-Leemhuis $A G$, Pajkrt E, Oudijk MA, Porath MM, Duvekot JJ, Bloemenkamp KWM, Groenewout M, Woiski M, Nij Bijvank B, Bax CJ, van 't Hooft J, Sikkema JM, Mulder ALM, Nijhuis JG, Mol BWJ, van der Ham DP. Behavioral and developmental outcome of neonates at 2 years of age after preterm prelabor rupture of membranes: Follow up of the PPROMEXIL trial. Submitted

van der Heyden JL, Ravelli ACJ, van Teeffelen ASP, van der Ham DP, Schaaf JM, Willekes C, Pajkrt E, Mol BWJ, Nijhuis JG. The relation between duration of rupture of membranes and perinatal outcome in patients with preterm prelabor rupture of membranes. Submitted 
Other publications

van der Heyden JL, Oei SG, van Lijnschoten G. Terminale villusdeficiëntie: Case report en review van de literatuur. Medisch Journaal. 2008; 37:13-15

van der Heyden JL, Rutten A, van Teeffelen ASP, Coolen ACG, Halbertsma FJ, Aardenburg R, Mertens HJMM, Mol BWJ. Heeft het zin om C-reactief proteïne en het leukocytenaantal te bepalen bij patiënten met vroegtijdig breken van de vliezen? Medisch Journaal. 2012; 41:9-13

van Teeffelen ASP, van der Heijden JL, van der Ham DP, Schaaf JM, Ravelli ACJ, Pajkrt E, Willekes C, Nijhuis JG, Mol BWJ. The relation between duration of ruptured membranes and perinatal outcome in patients with midtrimester preterm prelabor rupture of membranes. Submitted

Bakhuizen SE, Teune MJ, van Wassenaer AG, de Haan T, van der Heyden JL, van der Ham DP, Mol BWJ. Does neonatal sepsis result in severe morbidity in later life: a systematic review. Submitted

Oral presentations

van der Heyden J, van Teeffelen Stijn, Oei G, Mol BW. Preterm prelabour rupture of membranes: Risk of recurrence. $35^{\text {th }}$ Annual Meeting of the Fetal and Neonatal Physiological Society - Maastricht, June 22-25, 2008

van der Heyden JL, Willekes $C$, van Baar AL, van Wassenaer-Leemhuis AG, Pajkrt E, Oudijk MA, Porath MM, Duvekot JJ, Bloemenkamp KWM, Groenewout M, Woiski M, Nij Bijvank B, Bax CJ, van 't Hooft J, Sikkema JM, Mulder ALM, Nijhuis JG, Mol BWJ, van der Ham DP. Behavioral and developmental outcome of neonates at 2 years of age after preterm prelabor rupture of membranes: Follow up of the PPROMEXIL trial. Gynaecongres - Leeuwarden, May 23, 2014

\section{Poster presentations}

van der Ham DP, van der Heijden J, Ravelli ACJ, Nijhuis JG, Mulder A, van Beek $\mathrm{JJ}$, Mol BWJ, Willekes C. Neonatal outcome of pregnancies complicated by PPROM between 34 and 37 weeks of gestation. $30^{\text {th }}$ Annual Meeting of the Society for Maternal Fetal medicine - Chicago, USA. Februari 1-6, 2010.

van der Heyden JL, Janssen T, Notten K, van der Ham DP, Willekes C, Porath M, van der Post JA, Mol BW, Pajkrt E. Outcome of preterm premature rupture of membranes before 27 weeks' gestation. $31^{\text {st }}$ Annual Meeting of the Society for Maternal-Fetal Medicine - San Francisco, USA. February 11, 2011. 
van der Heyden JL, Janssen T, Notten K, van der Ham DP, Willekes C, Porath M, van der Post JA, Pajkrt E, Mol BWJ. Risk of recurrence of PPROM after PPROM before 27 weeks' gestation. $31^{\text {st }}$ Annual Meeting of the Society for MaternalFetal Medicine - San Francisco, USA. February 11, 2011.

van der Heyden JL, van Teeffelen S, van der Ham D, Schaaf J, Ravelli A, Willekes $\mathrm{C}$, Nijhuis J, Mol B. The relation between duration of rupture of membranes and perinatal outcome in patients with preterm prelabor rupture of membranes. $32^{\text {nd }}$ Annual meeting of the Society for Maternal-Fetal Medicine - Dallas, USA, February $6-11,2012$

van der Heyden JL, Willekes $C$, van Baar $A L$, van Wassenaer-Leemhuis $A G$, Oudijk MA, Porath MM, Duvekot JJ, Bloemenkamp KWM, Groenewout M, Woiski M, Nij Bijvank B, Bax CJ, Sikkema JM, Mulder ALM, Nijhuis JG, Mol BWJ, van der Ham DP. Behavioral and developmental outcome of neonates at 2 years of age after preterm prelabor rupture of membranes: Follow up of the PPROMEXIL trial. $34^{\text {th }}$ Annual meeting of the Society for Maternal-Fetal Medicine - New Orleans, USA, February 8, 2014 
Dankwoord 


\section{Dankwoord}

Allereerst wil ik alle patiënten bedanken die hebben deelgenomen aan de PPROMEXILstudies en de follow-up studie. Zonder zo'n grote groep bereidwillige patiënten hadden we nooit een mooie studie kunnen afronden. Ik ben me ervan bewust dat het invullen van een pakket vragenlijsten echt wel tijd en moeite kost en ben erg dankbaar dat meer dan 300 patiënten dit hebben willen doen.

Prof. Dr. Nijhuis, u hebt uw rol als promotor wel bewezen. $U$ was altijd bereikbaar voor advies en vragen. Wat erg fijn is dat $u$ altijd vriendelijk bent en met motiverende woorden weet te komen. Zo beginnen uw emails altijd met een positief punt of compliment, dit waardeer ik erg. Dank voor uw betrokkenheid en geweldige hulp bij het tot stand komen van dit proefschrift.

Prof. Dr. Mol, beste Ben Willem. Vanaf het allereerste begin ben je bij dit onderzoek betrokken geweest. Tijdens de WESP-stage in Veldhoven heb je al geprobeerd om me enthousiast te maken voor het onderzoek en het is je nog gelukt ook! Vervolgens heb je meerdere onderwerpen bedacht waar ik me op kon storten toen ik kwam vragen naar mogelijkheden om verder onderzoek te doen. Sindsdien ben je altijd buitengewoon betrokken geweest, regelmatig heb je me gemotiveerd om door te gaan of door te werken. Want dit was nogal eens nodig..... Zonder deze druk was dit proefschrift nooit geworden zoals het nu is en daar ben ik je dankbaar voor. Eerste versies van mijn eerste artikelen werden nooit afgekraakt, maar op een positieve manier gecorrigeerd zodat ik ervan leerde hoe ik een artikel moet opbouwen. En vanaf nu ga ik proberen om dat zonder je hulp te doen! Wat ben ik blij dat je er op 27 maart bij kan zijn ondanks dat je recent naar Australië bent geëmigreerd. Zelf had ik nooit gedacht dat ik deze datum zou gaan halen, maar dankzij jouw 'je moet in oplossingen denk en niet in problemen' is het met een eindsprint alsnog gelukt.

Dr. Willekes, beste Christine. Dank voor je kritische blik op artikelen en op de rest van de tekst in dit proefschrift. Maar ook voor het feit dat je oog hebt voor de persoon achter de promovendus. Het was fijn dat je bereikbaar was voor een goed gesprek en opbeurende woorden op momenten dat ik het nogal druk had.

Dr. van der Ham, beste David. Toen ik voor de follow-up betrokken raakte bij het PPROMEXIL onderzoek werd je mijn 'buddy-onderzoeker'. Gelukkig maar, want daar heb ik veel aan gehad! Ondanks dat je druk was met je eigen promotie-onderzoek, was je altijd bereid om mee te denken en advies te geven over mijn deel van het onderzoek. Je bent kritisch en wil alles (tot in detail) goed hebben. Een fijne eigenschap bij het schrijven van artikelen. Wat vind ik het knap dat je vlak na je eigen promotie, mijn copromotor bent geworden. Als laatste auteur van het follow-up artikel ben je hier bijzonder betrokken bij geweest. Alle tabellen werden mooier en beter nadat je erover 
had meegedacht! En ondanks je drukke gezin met 4 lieve meiden heb je altijd tijd gemaakt om mij te helpen. De avonden dat ik in Venlo langs mocht komen en dat we aan de laptop zaten waren erg waardevol. Dit motiveerde telkens weer om door te gaan.

Verder veel dank aan de beoordelingscommissie. Prof. dr. Bruggeman, prof. dr. Kramer, prof. dr. Oei en dr. Smits. Uw hebt allen uw uiterste best gedaan om dit proefschrift op korte termijn te beoordelen en hier ongetwijfeld heel wat werk en aandacht aan besteed. Behalve dat ik natuurlijk erg blij ben dat het proefschrift door $u$ is goedgekeurd om voor verdediging in aanmerking te komen, ben ik u dankbaar voor het werk dat u hieraan gehad hebt.

Ook de leden die deelnemen aan de corona op 27 maart wil ik bedanken voor de tijd en moeite die dit kost. Want zonder een goede corona is de verdediging niet wat het hoort te zijn.

Alle mede-auteurs van de artikelen. Wat is het fijn om hulp te krijgen op verschillende gebieden. Het is erg waardevol om input te krijgen van onder andere kinderartsen, epidemiologen en gynaecologen/perinatologen. leder is expert op zijn/haar eigen gebied en heeft een steentje bijgedragen aan de artikelen. Hopelijk hebben we met $z^{\prime} n$ allen een paar leuke artikelen afgeleverd. Wie weet heb ik jullie in de toekomst nog nodig voor het meeschrijven aan eventuele nieuwe stukken...! Sander, bedankt voor de tijd die je hebt gestoken in het uitleggen van de analyses in SPSS en het geduld dat je hiervoor had, omdat ik nooit eerder had gewerkt met dit programma.

Seniorstaf van het MUMC. Inmiddels werk ik twee jaar met plezier bij jullie. Dankzij de mogelijkheid die ik kreeg om een schrijfstage van 2 maanden te doen kwam het proefschrift in een stroomversnelling. Jullie zijn goed in opleiden en hadden vaak ook interesse in het onderzoek waar ik mee bezig was. Dank daarvoor.

Juniorstaf van het MUMC, lieve collega's. Wat werken we met een fijne groep mensen. Over het algemeen is iedereen bereid om taken van elkaar over te nemen als dat nodig is. Gezellig dat er bijna altijd wel iemand in de assistentenkamer zit, want wat hebben we daar vaak een hoop lol!

Maatschap gynaecologen van het VieCuri MC. De eerste twee jaar van mijn opleiding heb ik bij jullie in Venlo/Venray gewerkt. Wat een fijne tijd was dat, het is een genot om met jullie te werken. Jullie hebben een zeer prettige maatschap en ik denk dat ik bij jullie een hoop heb geleerd. Als ik komend jaar terug kom hoop ik dat voort te zetten. Het voelt in elk geval fijn om weer bij jullie te komen werken. 
Arts-assistenten van het VieCuri MC, lieve collega's. Bedankt voor de hele fijne en gezellige samenwerking. Ik heb erg goede herinneringen aan de tijd dat we met 6 of 7 assistenten in Venlo zaten en echt goed contact met elkaar kregen. Ook al zagen we elkaar overdag niet vaak omdat we vaak druk bezig waren, buiten werktijd hadden we het ontzettend gezellig en kon ik met jullie altijd goed praten, zowel werkgerelateerd als ook over privé-aangelegenheden! Esther, Marjo en Odette, wat was het fijn om jullie in Maastricht weer te treffen en daar weer collega's te worden. Wat leuk dat jullie op mijn vrijgezellenfeest wilden komen. Het is jammer dat we straks niet meer allemaal in dezelfde kliniek terechtkomen, maar laten we elkaar vooral niet uit het oog verliezen!

Maatschap gynaecologen in het Rijnstate ziekenhuis Arnhem en Máxima MC Veldhoven/Eindhoven. Na een leuke stage als semi-arts in het MMC Veldhoven werd ik door het geweldige werk bij de gynaecologen en arts-assistenten in Arnhem echt enthousiast over het vak. Op het moment dat ik ANIOS werd, wist ik nog niet $100 \%$ zeker of het vak bij me zou passen en of het niet te zwaar zou zijn. Maar de manier waarop in Arnhem werd gewerkt, de leuke spreekuren en fijne verloskamerdiensten wist ik het zeker: ik wil in opleiding komen. Aangezien het starten met wetenschappelijk onderzoek de kansen op een opleidingsplek zouden vergroten, besloot ik (na overleg met Ben Willem) met de follow-up studie van de PPROMEXIL te starten. Gelukkig kreeg ik de kans om in Veldhoven te gaan werken omdat dit beter te combineren was met het onderzoek. Ondanks het feit dat ik het in Arnhem erg naar mijn zin had, heb ik nooit spijt gehad van de overstap naar Veldhoven. Ook hier was de sfeer super, het opleidingsklimaat erg goed en werd ik in korte tijd klaargestoomd om te beginnen aan de opleiding. Hoewel ik na een half jaar werken in Veldhoven zelf nog twijfelde of ik er wel klaar voor was om te solliciteren voor de opleiding, werd ik gelukkig goed geadviseerd door mentor Peggy Geomini en ben ik nu erg blij dat ik dit destijds heb gedaan!

Mijn carpoolmaatjes: Femke, Josien, Esther, Marjo en Linda. Wat maakt het carpoolen de reis naar Maastricht een stuk aangenamer! De dagen dat ik alleen moet rijden, is $100 \mathrm{~km}$ wel erg ver en vermoeiend. De dagen dat we samen rijden zijn gezellig en op die moment stelt de afstand een stuk minder voor. Die gezellige ritjes en het napraten over de werkdag ga ik wel missen als ik straks weer alleen richting Venlo moet rijden!

Research medewerkers van het Consortium. Ook zonder jullie was het nooit gelukt om dit alles voor elkaar te krijgen. Ondanks jullie drukke werkzaamheden, waarbij er eigenlijk al te weinig tijd is om alle taken gedaan te krijgen, hebben jullie veel moeite gedaan voor het versturen van de vragenlijsten, bellen van de deelneemsters en achterhalen van contactgegevens. Het was een flinke klus om $75 \%$ van de vragenlijsten verstuurd te krijgen, zeker omdat de PPROMEXIL-studie in veel verschillende centra 
liep, ook kleinere centra waar jullie niet dagelijks of wekelijks komen. Uiteindelijk mogen we blij zijn met het responspercentage dat we bereikt hebben! Veel dank voor al jullie inzet!

Malouk, dankjewel voor je hulp bij het invoeren van de ASQ lijsten! Ik weet dat dit hartstikke veel werk was, maar je hebt dit in een razend tempo gedaan! Ik vind het knap dat je in no time doorhad hoe de database in elkaar zat en dat je altijd tijd maakte op de momenten dat het belangrijk was dat de lijsten ingevoerd moesten zijn! Ik hoop dat we in de toekomst nog leuk vervolgonderzoek kunnen gaan doen.

De follow-up club van het Consortium. Wat was het een goed initiatief om dit op te starten. De expertise van de experts en van de onderzoekers die follow-up studies doen of gedaan hebben is erg waardevol bij het opstarten van nieuwe studies en bij de uitvoer ervan. Wat zou het mooi zijn als alle gerandomiseerde studies binnen de obstetrie een gedegen follow-up studie erbij zouden doen! Laten we dat met $z$ 'n allen nastreven.

Lieve Christel en Marjo, dankjewel voor jullie werk en hulp als paranimfen richting de promotie. Ik wist en weet zeker dat ik aan jullie twee goeie heb!

Christel, we kennen elkaar vanaf 2002 en zijn de loop van de jaren echt goede vriendinnen geworden. Ik vind het super dat jullie vlakbij wonen en we elkaar daarom best regelmatig kunnen zien! Het is altijd een feestje om die 3 lieve kindjes van jullie te zien, om met ze te lachen en ze lekker te knuffelen. Wat is het toch gaaf dat je nu als research nurse bij de fertiliteit in het Radboud ziekenhuis werkt!

Marjo, jij bent een van die bijzondere collega's waarvan ik weet dat ik je altijd mag lastigvallen als dat nodig is. Fijn dat we over een paar maanden weer samenwerken in Venlo!

En dan zijn er nog wat vrienden om te bedanken.

Lieve Joyce en Alex, dank voor jullie bijzondere vriendschap. Joyce, wat ben ik blij dat je jouw mooie zwangere buik beschikbaar wilde stellen voor de bellypaint die nu op de kaft van dit proefschrift staat. Hoe bijzonder is het dat mijn beste vriendin en lieve petekindje onderdeel uitmaken van dit proefschrift. Inmiddels is jullie prachtige zoon Pepijn geboren en daar ben ik heel blij mee. Hij zal als petekindje altijd een belangrijke rol in mijn leven spelen, en daar ben ik ontzettend dankbaar voor.

Verder ook mijn vriendinnen Liesbeth, Wanita, Stephanie en Pauline. Een aantal van jullie wonen een beetje op afstand, maar dat weerhoudt ons er niet van om af en toe eens af te spreken! Tussen al onze drukke bezigheden door, is het echt fijn om de afleiding te hebben van een gezellig avondje eten (en drinken!) met elkaar. 
Mijn lieve neven en nichten, in het bijzonder: Jop \& Marianne, Jorrit \& Willeke, Sjoerd \& Floor, Timo \& Eveline. Wat ben ik blij met zo'n familie! Jullie zijn stuk voor stuk niet alleen familieleden (of aanhang) maar zeker ook vrienden. Wat kunnen we lol hebben met elkaar en het is altijd gezellig om met $z$ 'n allen te dansen, op stap te gaan, spelletjes avonden te hebben en weekendjes weg.

Maarten en Gerdien, inmiddels zijn jullie al ruim 12 jaar mijn schoonouders en wat ben ik daar blij mee. Het is heel fijn dat jullie me het gevoel geven dat ik 'een van de kinderen' ben. In jullie warme gezin voel ik me dan ook heel erg thuis. Dank voor jullie betrokkenheid bij mijn werk en promotieonderzoek. Nooit hebben jullie er een probleem van gemaakt als ik tijdens een bezoek aan jullie nog een uurtje mijn laptop pakte om even te gaan zitten werken als er nog iets af moest (of in elk geval heb ik nooit gemerkt als jullie hebben gedacht: 'moet dat nou'!). Ik hoop jullie dan ook nog lang als schoonouders te mogen hebben.

Esther en Dennis met aanhang, mijn schoonzus en - broertje; we zien elkaar niet heel erg vaak, maar gelukkig vaak genoeg om zo nu en toe gezellig bij te kletsen. Gezellig met een wijntje bij de barbecue of op de bank met een kop thee, maar ook met $z^{\prime} n$ allen bij Maarten en Gerdien aan tafel.

Tess, Mads en Jaison; wat brengen jullie een hoop plezier en vreugde! Jullie zijn alledrie schatten van kinderen en het is altijd zo leuk om jullie te zien, lekker met jullie te spelen en zo nu en dan even te knuffelen. Dit brengt altijd hele fijne afleiding in het drukke werkende leven!

Lisette, je bent mijn enige zusje. Wat ben ik blij met een zus waarmee ik zo'n sterke band heb als met jou! Ik zou je voor geen goud kunnen missen. Wat ben ik trots op wat jij allemaal bereikt hebt en op de persoon die je bent. Graag had ik nog wat van jouw karaktereigenschappen willen hebben. In elk geval ben je de allerliefste!

Lieve papa en mama, er valt zoveel te zeggen over en tegen jullie.... Laat ik beginnen te vertellen hoe belangrijk en waardevol jullie zijn. De opvoeding en liefde die wij altijd van jullie hebben gekregen gun ik alle kinderen ter wereld. Dat het met ons goed zou gaan in het leven heeft voor jullie altijd op de eerste plek gestaan. Ik ben dan ook erg blij dat we een huis hebben gekocht vlak bij jullie in de buurt. Dat maakt het leven in Nuenen erg gezellig! Jullie steun waardeer ik heel erg, zowel fysiek als emotioneel als financieel word ik waar mogelijk geholpen! De laptop die ik van jullie kreeg om onderweg te kunnen werken, papa die heeft geholpen aan het tot stand komen van dit proefschrift door ruim 300 vragenlijsten in te voeren in een computerprogramma en mama die om de haverklap op de stoep staat om te helpen met het huishouden zodat wij tijd hebben voor andere dingen. Ik weet niet veel meer te zeggen dan: "Dankjewel" en laten we hopen dat we nog vele jaren met elkaar kunnen genieten van gezellige momenten! 
Peter, lieve schat. Last but not least nog een woordje voor jou. We zijn niet voor niets al ruim 12 jaar samen. Gelukkig zijn we vorig jaar getrouwd, dat werd wel tijd...! lk heb in de voorbereidingen voor de bruiloft al mogen zeggen waarom je zo bijzonder voor me bent en waarom ik met jou oud wil worden. Die redenen zijn sindsdien niet veranderd. Je bent een schat en we delen gelukkig een heleboel dezelfde interesses (alleen niet werkgerelateerd, dat is duidelijk!) Sorry dat ik af en toe lekker op je mopper. Ik weet dat het niet altijd leuk voor je is, maar ik heb het soms een beetje nodig. Dank voor je begrip dat mijn werk belangrijk voor me is en dat het geen kantoorbaan is. Ik heb altijd geprobeerd om zoveel mogelijk aan dit promotieonderzoek te werken op momenten dat je niet thuis was en de spaarzame momenten dat we samen thuis waren te gebruiken om dingen samen te doen. Toch is het onvermijdelijk dat er ook af en toe gewerkt moe(s)t worden op momenten die we samen vrij waren. Dankjewel dat je hier zelden over hebt gemopperd.

Wat ben ik blij en trots dat we een kleine Snoek verwachten! Dit is iets waar we allebei heel erg naar uitkijken. Ik hoop echt dat we net zo succesvol worden in het opvoeden als onze ouders. En anders willen ze ons hier hopelijk een beetje bij helpen! Ik hoop dat de zwangerschap goed zal verlopen. En mochten de vliezen vroegtijdig breken, zullen we dan naar Australië gaan voor inclusie in de PPROMT trial...?! Nou ja, dat zien we dan wel weer...! 
Curriculum vitae 


\section{Curriculum vitae}

Jantien Leonie van der Heyden werd op 28 juni 1984 geboren in Woerden. Na enkele jaren verhuisde ze van Woerden naar Nuenen (Noord-Brabant). In 2002 behaalde zij haar VWO-diploma aan het Augustinianum te Eindhoven. Datzelfde jaar startte zij met de opleiding Geneeskunde aan de Universiteit Maastricht en in 2006 werd het doctoraal examen behaald. Er werd een keuze co-schap gynaecologie/obstetrie gevolgd in het Máxima Medisch Centrum Veldhoven en het co-schap Psychiatrie werd gevolgd aan SUNY Upstate Medical University, Syracuse, USA. Tijdens de semi-arts stage werd het klinische deel van de stage gecombineerd met een wetenschapsstage gedurende 36 weken in het Máxima Medisch Centrum Veldhoven en werd de basis gelegd voor het promotieonderzoek.

In 2008 werd de opleiding Geneeskunde afgerond en ging zij als ANIOS gynaecologie/obstetrie aan het werk in het Rijnstate ziekenhuis te Arnhem (opleider dr. A. Huisman, later overgenomen door dr. F.H.P.L. Dijkhuizen). Een jaar later werd het werk als ANIOS voortgezet in het het Máxima Medisch Centrum Veldhoven (opleider prof. dr. S.G. Oei, later overgenomen door dr. M.Y. Bongers) en startte zij in 2009 als promovendus met de follow-up van de PPROMEXIL studie, later uitgebreid met ander onderzoek. In 2010 werd de opleiding tot gynaecoloog gestart in het Viecuri Medisch Centrum te Venlo (opleider dr. J.J. van Beek en vice-opleider dr. I. van Gestel) en in 2012 voortgezet in het Maastricht Universitair Medisch Centrum te Maastricht (opleiders prof. dr. R.F.P.M. Kruitwagen en dr. G.A.J. Dunselman).

Jantien is in 2013 getrouwd met Peter Snoek en zij verwachten medio 2014 hun eerste kind. 
